\title{
ESTUDO DO DESEMPENHO NA FRENAGEM DE UM BI-TREM COM SUSPENSÃO EM "TANDEM" E COM ABS.
}

Dissertação apresentada à Escola de Engenharia de São Carlos da Universidade de São Paulo como parte dos requisitos para obtenção do Título de Mestre em Engenharia Mecânica

Orientador: Prof. Dr. Antônio Carlos Canale

São Carlos 

Dedico este trabalho aos meus pais e aos meus irmãos, pois este trabalho só foi possível graças à sua ajuda, compreensão e incentivo. 


\section{AGRADECIMENTOS}

Agradeço ao Prof. Dr. Antônio Carlos Canale pela orientação, pelo apoio e pela amizade. A todos os colegas do LCV (Laboratório Computacional Veicular) e do Departamento de Engenharia de Materiais, Aeronáutica e Automobilística pelo incentivo e pela amizade.

Gostaria de agradecer à Haldex do Brasil e a FIPAI pelo apoio financeiro a esta pesquisa

Agradeço também à Universidade de São Paulo pela estrutura fornecida e aos seus funcionários por toda a ajuda fornecida 


\section{RESUMO}

Polito, R.F. (2005). Estudo do Desempenho na Frenagem de um Bi-trem com Suspensão em "tandem" e com ABS. Dissertação (Mestrado) - Escola de Engenharia de São Carlos, Universidade de São Paulo, São Carlos, 2005.

O bi-trem é um veículo cada vez mais comum no trânsito brasileiro. Por ser um veículo de grande porte, é capaz de se envolver em acidentes catastróficos caso o sistema de freio não esteja projetado de maneira adequada. Neste contexto é necessário um estudo que permita prever e otimizar o desempenho do sistema de freios para qualquer condição operacional. Para isso foi desenvolvida uma planilha de cálculos para estudar o desempenho da frenagem de um bi-trem. A planilha calcula a aderência que cada eixo utiliza, a desaceleração máxima desenvolvida pelo veículo, o espaço e o tempo de parada, a força de frenagem (e sua porcentagem) em cada eixo, a temperatura final do tambor, a eficiência do sistema de freios, as forças normais ao pavimento, a distribuição real e ideal das forças de frenagem e verifica se o cavalo mecânico e os semi-reboques se enquadram, respectivamente, nos diagramas 3 e 4 do anexo 10 da ECE-R13. Tais cálculos podem ser feitos com o veículo utilizando ou não ABS e com válvula sensível a carga nos semi-reboques e no "tandem" do cavalo mecânico. A planilha de cálculo foi aplicada em um veículo exemplo e os resultados são apresentados nesta dissertação. O sistema de freios desse veículo foi otimizado com a utilização da planilha, mostrando como ela pode ser de grande auxilio ao projetista.

Palavras-chave: Bi-trem; Desempenho na Frenagem; Dinâmica da Frenagem; ABS; Suspensão em Tandem; Combinações Veiculares de Carga (CVC); Veiculos Articulados. 


\section{ABSTRACT}

Polito, R.F. (2005). Braking Performance of a Bi-trem With Tandem Axle and ABS. São Carlos, 2005. M.Sc Dissertation (Mestrado) - Escola de Engenharia de São Carlos, Universidade de São Paulo, São Carlos, 2005.

The bi-trem (a vehicle similar to a twin trailler truck)is more and more common in the Brazilians highways. Because it's a Large and heavy vehicle it can cause catastrophics accidents if the brakes are not well developed. In this context it is necessary a study that allows to foresee and to optimize the performance of the brakes system for any operational condition. In this work an electronic spread sheet was developed in order to study the braking performance of a bi-trem. The spread sheet calcs the adhesion in each axle, the maximum deceleration, the braking space and the braking time, the braking force (and its percentage) in each axle, the final temperature of the drum, the brake system's efficiency, the normal forces, the actual and ideal brake force distribution, and verifies if the tractor and the semi trailers are fitted in the annex 10 of ECE-R13. The reckoning can be made for a vehicle equipped or not with $A B S$ and with the load sensing valve in the semi trailers and in the tandem axle of the tractor. The spread sheet was applied in a example vehicle and the results are presented in this dissertation. The brakes system of this vehicle was optimized with the use of the spread sheet, showing as it can be of great assists the designer.

Keywords: Bi-trem; Braking Performance; ABS; Tandem Axle; Braking Dynamics; Longer Combination Vehicles (LCV) 


\section{LISTA DE FIGURAS}

FIGURA 1.1 - Esquema de um bi-trem.

FIGURA 1.2 - Veículos combinados mais utilizados nos EUA Fonte -

FORKENBROCK E HANLEY (2002).

FIGURA 2.1 - Posicionamento do CG na direção longitudinal; CANALE (1989) 9 FIGURA 2.2 - Posicionamento do CG na direção vertical; CANALE (1989) .....10 FIGURA 2.3 - Posicionamento do CG na direção vertical; CANALE (1989).....11 FIGURA 2.4 - Posicionamento do CG na direção vertical; DIXON (1996)........12 FIGURA 2.5 - Área de contato de uma roda elástica; CANALE (1989) ............13 FIGURA 2.6 - Coeficiente de adesão para a tração (a) e frenagem (b); MILLIKEN(1995)

FIGURA 2.7 - Relação real e ideal das forças de frenagem - veículo de dois eixos; CANALE (1998).

FIGURA 2.8 - Relação real e ideal das forças de frenagem - veículo de dois eixos com válvula; CANALE (1998).

FIGURA 2.9 - Funcionamento da válvula sensível a carga; Cortesia Haldex do Brasil. 19

FIGURA 2.10 - Diagrama da válvula sensível a carga; Cortesia Haldex do Brasil.

FIGURA 2.11 - Exemplos de discos de freio sólido (A)e ventilado (B); BROSSi (2002) .22

FIGURA 2.12 - Pinça fixa(a) e pinça flutuante (b); BROSSI (2002)... .22 FIGURA 2.13 - Freio a tambor; Sapata primária e secundária; BROSSI (2002)

FIGURA 2.14 - Arranjos das sapatas no freio a tambor; LIMPERT (1992)......24

FIGURA 2.15 - Componentes do Freio a tambor (sem o tambor); Cortesia de Haldex do Brasil.

FIGURA 2.16 - Forças atuando nas sapatas em um freio a tambor padrão;

GILLESPIE (1992). .26

FIGURA 2.17 - Comparação do fator de freio para vários tipos de freios;

LIMPERT (1992). .29

FIGURA 2.18 - Perda de estabilidade de um cavalo/semi-reboque;Fitch (1994) 
FIGURA 2.19 - Funcionamento do ABS; GILLESPIE (1992).

FIGURA 2.20 - ABS mantém o veículo próximo ao pico de aderência;

GILLESPIE (1992).

FIGURA 2.21-Momento de yaw devido a coeficientes de adesão diferentes;

Limpert (1992) . 32

FIGURA 2.22 - Comparação da desaceleração com algumas estratégias de controle do ABS, Canale (1991).

FIGURA 2.23 - Comparação da desaceleração com o tipo de pavimento,

Oppenheimer (1988)

FIGURA 2.24 - Comparação da eficiência da frenagem com a probabilidade de travamento, Gillespie (1992)...........................................35

FIGURA 2.25 - Temperatura x Fator de Freio; Canale (1999)........................37

FIGURA 2.26 - Forças de resistência ao rolamento; Canale (1989).................39

FIGURA 2.27 - Arrasto aerodinâmico; Gillespie (1992) .................................41

FIGURA 2.28 - Análise da distância de parada; Limpert(1992)......................43

FIGURA 2.29 - Aumento da pressão em freios pneumáticos; Limpert (1992). .47

FIGURA 2.30 - Distribuição da pressão no solo para veículos com 6 e 4 rodas;

Fitch (1994). .48

FIGURA 2.31 - Forças agindo numa suspensão em "tandem”; Limpert (1992).

FIGURA 2.32 - Carga dinâmica de eixo "tandem" em função da desaceleração; Limpert(1992)

FIGURA 3.1 - Variação do coeficiente de adesão com a carga normal; Gillespie (1992). .54

FIGURA 3.2 - Esquema da geração das forças de frenagem; Brossi (2002). ..55

FIGURA 3.3 - Esquema simplificado das forças atuando no bi-trem.... .58

FIGURA 3.4 - Esquema das forças atuando no segundo semi-reboque ..........59

FIGURA 3.5 - Esquema das forças atuando no primeiro semi-reboque ...........60

FIGURA 3.6 - Esquema das forças atuando no cavalo mecânico ...................61

FIGURA 3.7 - Fluxograma do programa computacional ..............................64

FIGURA 4.1 - Pressão x Aderência utilizada; veículo carregado; sem ABS .....70

FIGURA 4.2 - Pressão x Aderência utilizada; veículo carregado; com ABS.....71

FIGURA 4.3 - Pressão x forças normais ao solo; veículo carregado sem ABS 72 FIGURA 4.4 - Pressão x forças normais ao solo; veículo carregado com ABS 73 
FIGURA 4.5 - Pressão x desaceleração máxima; veículo carregado sem ABS

FIGURA 4.6 - Pressão x desaceleração máxima; veículo carregado com ABS

FIGURA 4.7 - Pressão x eficiência do sistema de freios; veículo carregado sem ABS.

FIGURA 4.8 - Pressão x eficiência do sistema de freios; veículo carregado com ABS. .76

FIGURA 4.9 - Pressão x espaço de parada; veículo carregado sem ABS. ......77 FIGURA 4.10 - Pressão x espaço de parada; veículo carregado com ABS. ...77 FIGURA 4.11 - Pressão x tempo de parada; veículo carregado sem ABS......78 FIGURA 4.12 - Pressão x tempo de parada; veículo carregado com ABS. ......78 FIGURA 4.13 - Pressão x temperatura final do tambor; veículo carregado sem ABS. .79

FIGURA 4.14 - Pressão x temperatura final do tambor; veículo carregado com ABS.

FIGURA 4.15 - Pressão $x$ \% força de frenagem; veículo carregado sem ABS. 81 FIGURA 4.16 - Pressão $x$ \% força de frenagem; veículo carregado com ABS.81 FIGURA 4.17 - Pressão $x$ força de frenagem; veículo carregado sem ABS.....82 FIGURA 4.18 - Pressão x força de frenagem; veículo carregado com ABS....82 FIGURA 4.19 - Pressão de Entrada x Pressão de Saída; curva da válvula......83 FIGURA 4.20 - Pressão x Aderência utilizada; veículo descarregado; sem ABS

FIGURA 4.21 - Pressão x Aderência utilizada; veículo descarregado; com ABS

FIGURA 4.22 - Pressão x eficiência do sistema de freios; veículo descarregado sem ABS. .85

FIGURA 4.23 - Pressão x eficiência do sistema de freios; veículo descarregado com ABS. .86

FIGURA 4.24 - Pressão x desaceleração máxima; veículo descarregado sem ABS

FIGURA 4.25 - Pressão x desaceleração máxima; veículo descarregado com ABS 
FIGURA 4.26 - Pressão x eficiência do sistema de freios; veículo descarregado sem $A B S$ e sem válvula reguladora.

FIGURA 4.27 - Pressão x eficiência do sistema de freios; veículo descarregado com ABS e sem válvula reguladora. .88

FIGURA 4.28 - Pressão x Aderência utilizada; veículo carregado; sem ABS ...89 FIGURA 4.29 - Pressão x Aderência utilizada; veículo carregado; com ABS ...90 FIGURA 4.30 - Pressão x forças normais ao solo; veículo carregado sem ABS

FIGURA 4.31 - Pressão x forças normais ao solo; veículo carregado com ABS

FIGURA 4.32 - Pressão x desaceleração máxima; veículo carregado sem ABS

FIGURA 4.33 - Pressão x desaceleração máxima; veículo carregado e com ABS .92

FIGURA 4.34 - Pressão x eficiência; veículo carregado sem ABS .93

FIGURA 4.35 - Pressão x eficiência; veículo carregado com ABS .93

FIGURA 4.36 - Pressão x espaço de parada; veículo carregado sem ABS .....94

FIGURA 4.37 - Pressão x espaço de parada; veículo carregado com ABS .....94

FIGURA 4.38 - Pressão x tempo de parada; veículo carregado sem ABS.......95

FIGURA 4.39 - Pressão x tempo de parada; veículo carregado com ABS.......95

FIGURA 4.40 - Pressão x temperatura final do tambor; veículo carregado sem

ABS. .96

FIGURA 4.41 - Pressão x temperatura final do tambor; veículo carregado com ABS.

FIGURA 4.42 - Pressão x \% força de frenagem; veículo carregado sem ABS.97 FIGURA 4.43 - Pressão x \% força de frenagem; veículo carregado com ABS.98 FIGURA 4.44 - Pressão x força de frenagem; veículo carregado sem ABS....99 FIGURA 4.45 - Pressão x força de frenagem; veículo carregado com ABS.....99 FIGURA 4.46 - distribuição ideal das forças de frenagem. 100

FIGURA 4.47 - Diagrama 3 (para cavalo mecânico) do anexo 10 da ECE R13 Veículo carregado e sem ABS.

FIGURA 4.48 - Diagrama 3 (para cavalo mecânico) do anexo 10 da ECE R13 Veículo carregado e com ABS. 101 
FIGURA 4.49 - Diagrama 4 do anexo 10 da ECE R13; 1ํ Semi-reboque -

Veículo carregado e sem ABS.

FIGURA 4.50 - Diagrama 4 do anexo 10 da ECE R13; 1ํ Semi-reboque -

Veículo carregado e com ABS.

FIGURA 4.51 - Diagrama 4 do anexo 10 da ECE R13; 2ํㅗㄴ Semi-reboque -

Veículo carregado e sem ABS...............................................102

FIGURA 4.52 - Diagrama 4 do anexo 10 da ECE R13; 2ํㅗㄴ-reboque -

Veículo carregado e com ABS...............................................103

FIGURA 4.53 - Pressão x Aderência utilizada; veículo carregado; sem ABS ;

sistema de freios alterado.

FIGURA 4.54 - Pressão x desaceleração máxima; veículo carregado sem ABS;

sistema de freios alterado.

FIGURA 4.55 - Diagrama 3 (para cavalo mecânico) do anexo 10 da ECE R13

- Veículo carregado e sem ABS ; sistema de freios alterado..107

FIGURA 4.56 - Diagrama 4 do anexo 10 da ECE R13; 1ํ Semi-reboque -

Veículo carregado e sem ABS; sistema de freios alterado......108

FIGURA 4.57 - Diagrama 4 do anexo 10 da ECE R13; $2^{\circ}$ Semi-reboque -

Veículo carregado e sem ABS; sistema de freios alterado......108

FIGURA 5.1 - Transferência de peso num cavalo mecânico + semi-reboque; a força de compressão no eixo traseiro do cavalo mecânico aumenta enquanto diminui no semi-reboque.

FIGURA 5.2 - Transferência de peso num bi-trem 


\section{LISTA DE TABELAS}

Tabela 1.1 - Uso do ABS e alavanca ajustadora em alguns países e regiões do

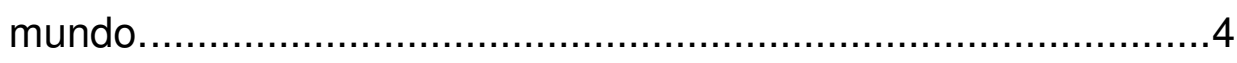

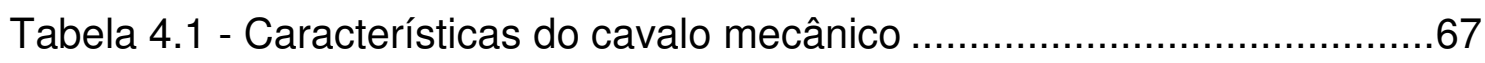

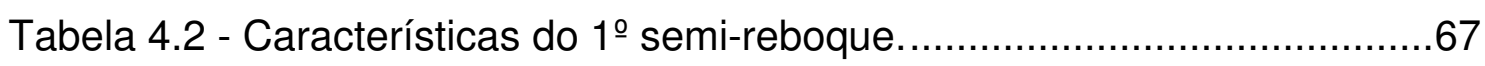

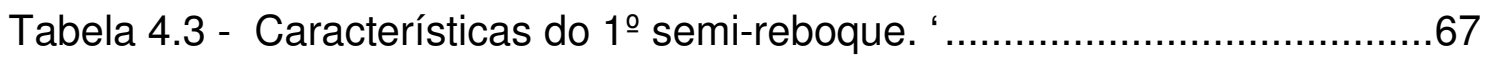

Tabela 4.4 - Características do sistema de freio de cada eixo .........................68

Tabela 4.5 - Características da suspensão em "tandem". ................................68

Tabela 4.6 - Condições em que a frenagem ocorre .........................................69

Tabela 4.7 - Alterações sugeridas no sistema de freios do cavalo mecânico.104

Tabela 4.8 - Alterações sugeridas no sistema de freios do $1^{\circ}$ semi-reboque .105

Tabela 4.9 - Alterações sugeridas no sistema de freios do $1^{\circ}$ semi-reboque .105 


\section{LISTA DE SÍMBOLOS}

A - Área frontal do veículo

$\left[\mathrm{m}^{2}\right]$

A - Área do cilindro de freio $\left[\mathrm{m}^{2}, \mathrm{~mm}^{2}\right.$, ou in $\left.{ }^{2}\right]$

a - (Des)aceleração do veículo $\left[\mathrm{m} / \mathrm{s}^{2}\right]$

$a_{\max } \quad$ (Des)aceleração máxima desenvolvida $\left[\mathrm{m} / \mathrm{s}^{2}\right]$

$a_{x}$ - Aceleração do veículo na direção $x$ $\left[\mathrm{m} / \mathrm{s}^{2}\right]$

$B$ - Força de frenagem total

b - Desaceleração da combinação $\left[\mathrm{m} / \mathrm{s}^{2}\right]$

b - Dimensão da suspensão

$B_{1}$ - Força de frenagem no eixo dianteiro do cavalo

$B_{21}$ - Força de frenagem no eixo dianteiro do "tandem" do cavalo

$B_{22}$ - Força de frenagem no eixo traseiro do "tandem" do cavalo

$B_{31}$ - Força de frenagem no eixo dianteiro do "tandem" do primeiro semireboque

$B_{32}$ - Força de frenagem no eixo traseiro do "tandem" do primeiro semireboque

$B_{41}$ - Força de frenagem no eixo dianteiro do "tandem" do segundo semireboque

$\mathrm{B}_{42}$ - Força de frenagem no eixo traseiro do "tandem" do segundo semireboque

$\mathrm{B}_{\text {real }}$ - Soma de todas as forças de frenagem aplicadas no veículo

c - Dimensão da suspensão

$\bar{c}$ - Calor específico médio do tambor

$C_{D}-$ Coeficiente de arrasto aerodinâmico

D - Diâmetro do tambor

d - Dimensão da suspensão

$D_{A}-$ Força de arrasto aerodinâmico

E - Raio do came "s"

e - Distância do ponto de pivotamento à massa adicionada

e - Braço da força aplicada na lona para pressiona-la contra o tambor, em relação ao pivô 
$f-\quad$ Coeficiente de resistência ao rolamento

$\mathrm{F}_{\mathrm{c}}$ - Força aplicada na alavanca ajustadora $\quad[\mathrm{N}]$

$\mathrm{FF}_{\text {primária }}$ - Fator de freio de uma lona primária [-]

$\mathrm{FF}_{\text {secundária }}$ - Fator de freio de uma lona secundária [-]

$\mathrm{F}_{\mathrm{t} 1}$ - Força que a lona primária faz no tambor $\quad[\mathrm{N}]$

$\mathrm{F}_{\mathrm{t} 2}$ - Força que a lona secundária faz no tambor $\quad[\mathrm{N}]$

$\mathrm{F}_{\mathrm{xf}}$ - Força aplicada no eixo frontal na direção $\mathrm{x} \quad[\mathrm{N}]$

$\mathrm{F}_{\mathrm{xr}}$ - Força aplicada no eixo traseiro na direção $\mathrm{x} \quad[\mathrm{N}]$

F x2RF - Força aplicada na direção x no contato do pneu do eixo dianteiro do" tandem" com o solo

$F_{\text {z2RF }}$ - Força aplicada na direção z no contato do pneu do eixo dianteiro do" tandem" com o solo

$\mathrm{H}$ - $\quad$ Altura do centro de gravidade

$\mathrm{K}$ - Fator de freio

$L$ - Entre eixos do veículo

$\mathrm{L}_{f}$ - Posição do centro de gravidade, na horizontal, em relação ao eixo dianteiro

$\mathrm{L}_{\mathrm{a}}$ - Comprimento da alavanca ajustadora [m, mm ou in]

M - Massa do veículo

$\mathrm{m}$ - Massa de troca de calor

m - Massa do veículo

$m$ - Braço da força normal, em relação ao pivô, entre o tambor e a lona [m]

$\mathrm{m}_{\mathrm{e}}-$ Massa adicionada ao veículo

$\mathrm{N}$ - Altura na qual o eixo foi levantado descontando-se o raio da roda [m]

$\mathrm{n}$ - Braço da força de atrito, em relação ao pivô, entre o tambor e a lona [m]

$P$ - Pressão que chega ao cilindro de freio

$\left[\mathrm{N} / \mathrm{m}^{2}\right.$ ou bar]

$Q$ - Calor gerado na frenagem

$r$ - Raio dinâmico do pneumático

$r_{d}-\quad$ Raio dinâmico do pneumático

$\mathrm{R}_{\text {din }}$ - Raio dinâmico do pneu

$\mathrm{R}_{g}$ - Força de resistência ao movimento devido à inclinação da pista 
$S_{1}$ - Posição do centro de gravidade, na transversal, em relação à roda direita

$S_{1}$ - Distância percorrida durante momento o tempo de reação do motorista e do sistema de freios

$\mathrm{S}_{2}-$ Distância percorrida durante o aumento da desaceleração

$\mathrm{S}_{3}$ - Distancia percorrida durante a desaceleração máxima

$\mathrm{S}_{T}$ - Distância total percorrida durante a frenagem

$\mathrm{T}_{1}$ - Torque aplicado no came "s"

$T$ - Torque de frenagem gerado pelo tambor

$t_{\text {total }}$ - Tempo de aplicação do sistema de freios

$\mathrm{t}_{1}$ - Tempo para um sinal de pressão "viajar" da válvula de aplicação até o cilindro de freio

$t_{2}-\quad$ Tempo para se vencer as folgas entre a lona e o tambor

$t_{3}$ - Tempo para que a pressão na linha do sistema de freios atinja o valor máximo especificado

$t_{r}-$ Tempo de reação do motorista

$t_{a}-$ Tempo de reação do sistema de freios

$t_{b}$ - Tempo para a pressão no circuito de freio atingir $90 \%$ da pressão máxima

$\mathrm{T}_{\mathrm{amb}}$ - Temperatura ambiente

$T_{F}$ - Temperatura do tambor após a frenagem

u - Dimensão da suspensão

V - Velocidade relativa entre o veículo e o fluido

$v$ - Dimensão da suspensão

$V_{1}$ - Velocidade do veículo durante o espaço $S_{1}$

$\mathrm{X}_{1}$ - Força na direção $\mathrm{x}$ aplicada no ponto "1" da suspensão em "tandem" [N]

$\mathrm{X}_{3}$ - Força na direção $x$ aplicada no ponto "3" da suspensão em "tandem" [N]

W - Peso do veículo

$\mathrm{W}_{1}$ - Peso do cavalo mecânico

$W_{2}$ - Peso do primeiro semi-reboque

$W_{3}$ - Peso do segundo semi-reboque

$W_{b f}$ - Peso dinâmico no eixo dianteiro de um veículo de dois eixos

$\mathrm{W}_{\mathrm{br}}$ - Peso dinâmico no eixo traseiro de um veículo de dois eixos

$W_{f}-$ Peso estático no eixo dianteiro de um veículo de dois eixos 
$W_{f}^{\prime}-$ Peso no eixo dianteiro com o veículo inclinado

$\mathrm{W}_{\mathrm{F}}$ - Peso da massa não suspensa do eixo dianteiro do "tandem"

$W_{R}$ - Peso da massa não suspensa do eixo traseiro do "tandem"

$\mathrm{W}_{\mathrm{r}}$ - Peso estático no eixo traseiro de um veículo de dois eixos

$\mathrm{Y}_{1}$ - Força na direção y aplicada no ponto "1" da suspensão em "tandem" [N]

$\mathrm{Y}_{2}$ - Força na direção y aplicada no ponto "2" da suspensão em "tandem" [N]

$\mathrm{Y}_{3}$ - Força na direção y aplicada no ponto "3" da suspensão em "tandem" [N]

z - Distância do ponto de pivotamento ao centro de gravidade

$\beta$ - Ângulo em que o veículo é inclinado

$\gamma_{b}$ - Fator que considera a inércia dos elementos em rotação do veículo ligados à roda

$\theta$ - Inclinação da pista

$\mu_{0}-$ Coeficiente de aderência máximo

$\mu-\quad$ Coeficiente de atrito entre a lona e o tambor

$\eta$ - Eficiência do sistema de freios

$\eta_{b}$ - Eficiência do sistema de freios

$\rho$ - $\quad$ Densidade do fluido

$\xi$ - Relação de transmissão 


\section{SUMÁRIO}

RESUMO ............................................................................................. VI

ABSTRACT .................................................................................. VII

1. INTRODUÇÃO..............................................................................

2. REVISÃO BIBLIOGRÁFICA ..................................................... 7

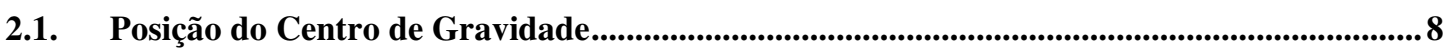

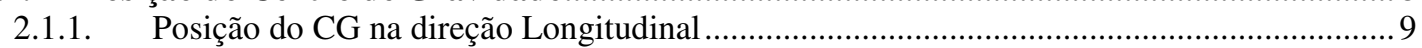



2.1.3. Posição do CG na vertical - segundo método ..................................................................... 11

2.1.4. Posição do CG na vertical - alternativa de Dixon (1996) .................................................... 12

2.2. Interação Pneumático $x$ Pavimento ....................................................................................13

2.3. O sistema de freios .............................................................................................................................. 15

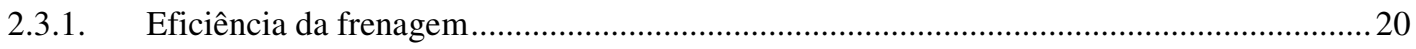





2.3.4. Fator de freio (calculo e valores comuns para diferentes tipos de freios) ...........................2 26

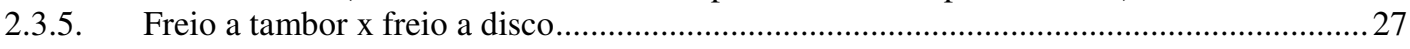

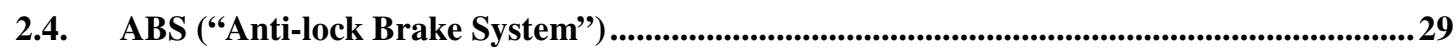

2.5. Efeitos da temperatura na frenagem .......................................................................................36

2.6. Forças de resistência ao movimento ………………..........................................................................38

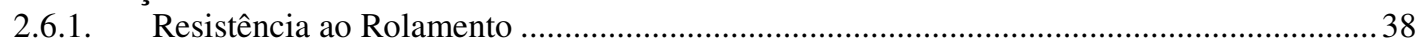

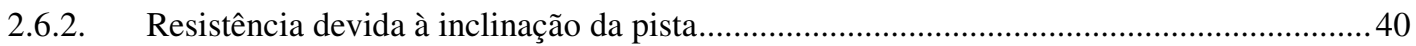

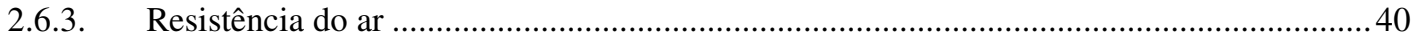

2.6.4. Resistência das forças de inércia .................................................................................. 41

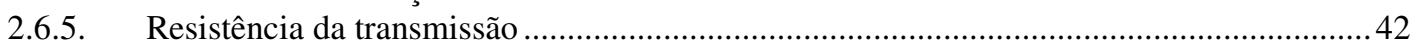

2.7. Dinâmica da frenagem .....................................................................................................................42



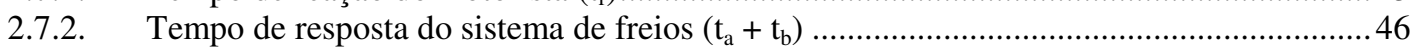

2.8. A suspensão em "tandem" "...................................................................................................................48



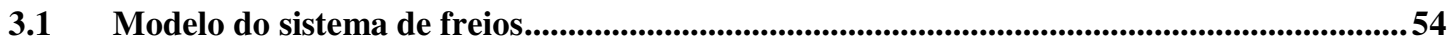

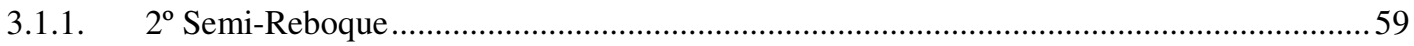

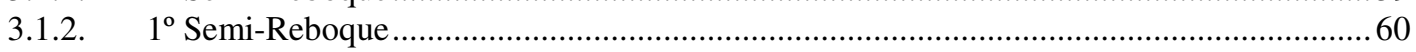

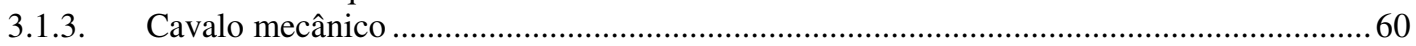

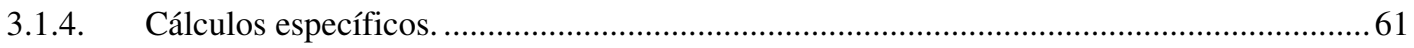

$3.2 \quad$ Programa computacional ..................................................................................................................63

4. RESULTADOS OBTIDOS.............................................................66

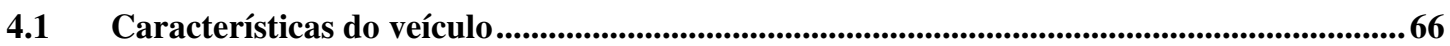

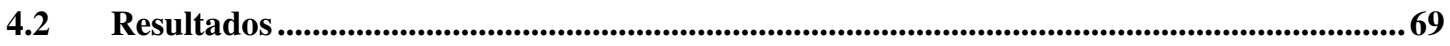

4.2.1 Veículo carregado e coeficiente de adesão baixo .......................................................... 70

4.2.2 Veículo vazio e coeficiente de adesão baixo ..............................................................8 83

4.2.3. Veículo carregado e coeficiente de adesão alto.............................................................8 89

4.2.4 Distribuição ideal e análise do anexo 10 da ECE R13 ................................................99 
5. CONCLUSÃO

6. REFERÊNCIAS BIBLIOGRÁFICAS .................................................114 


\section{INTRODUÇÃO}

O transporte de cargas no Brasil, diferentemente de outros países de tamanho continental, é realizado na sua maioria por meio rodoviário, ou seja, com o uso de caminhões simples e combinados. Com o objetivo de reduzir custos, utilizam-se cada vez mais veículos combinados e dentre eles o bi-trem vem se destacando. $\mathrm{O}$ uso do bi-trem vem se difundindo devido à sua relativa simplicidade e grande volume de carga. De acordo com Reis (1996) a densidade média das cargas transportadas diminui com o desenvolvimento tecnológico de um país. Isso implica na necessidade de veículos com maior capacidade volumétrica como o bi-trem. As empresas de transporte de carga, que utilizam o bi-trem, visam ainda à redução de custos, uma vez que esse veículo reduz a quantidade de motoristas, a quantidade de cavalos mecânicos e a sua ociosidade. Há também economia na manutenção - já que um bi-trem substitui dois cavalo/semi-reboque simples - além de o impacto ambiental ser menor com o menor consumo de combustível.

Por ser um veículo que entrou recentemente no mercado, há poucos estudos e publicações a seu respeito, ou seja, pouco se conhece sobre o desempenho da frenagem desse veículo e como ele se enquadra na legislação e normas vigentes. $\mathrm{O}$ bi-trem é uma composição tipicamente brasileira, apesar de existirem configurações parecidas em outros países como mostrado na Figura 1.2. Isso faz com que as publicações sobre frenagem e segurança disponíveis, mesmo no exterior, sejam ainda mais escassas.

O bi-trem pode ser considerado membro da família dos Veículos Combinados Longos ( Longer Combination Vehicles - LCVs - em inglês) e consiste de um veículo trator e dois semi-reboques, como mostra o esquema da Figura 1.1. 


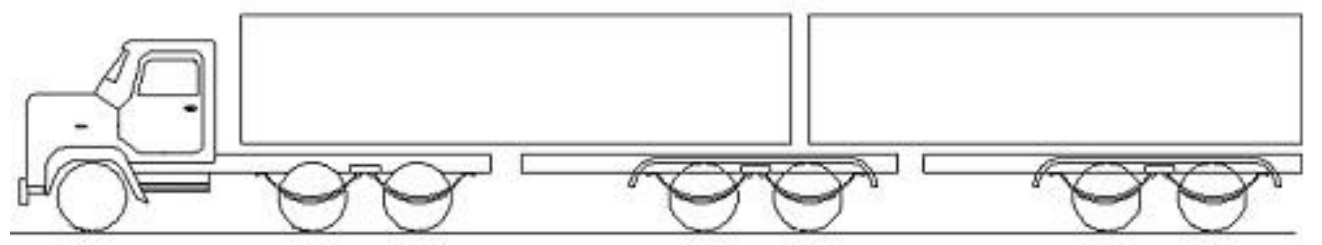

FIGURA 1.1 - Esquema de um bi-trem

O tipo de suspensão mais usado no Brasil, seja em bi-trens ou em semireboques simples, é a suspensão em "tandem" metálica de feixe de molas. Esse foi o tipo de suspensão considerada neste estudo. Este tipo de suspensão apresenta custos de fabricação e manutenção menores comparados com os da suspensão a ar, mas apresenta um menor desempenho na estabilidade direcional e na proteção da carga por vibrações oriundas do pavimento. Por distribuir igualmente a força normal entre os eixos, em movimento não acelerado longitudinalmente, esse tipo de suspensão também é menos nociva ao pavimento como é mostrado na seção 2.8 .

Os freios normalmente usados nos bi-trens são os freios a tambor acionados por came "s". É o tipo de freio mais comum no Brasil em veículos comerciais devido ao seu baixo custo de instalação e manutenção.

O sistema de freio é o principal sistema de segurança ativa de um veículo. Apesar de não haver muitas publicações a respeito de segurança de bi-trens, Forkenbrock e Hanley (2002) mostram as condições nas quais veículos LCV's usados nos Estados Unidos, mostrados na Figura 1.2, têm maior chance de se envolver em acidentes que os veículos tradicionais. Esse estudo conclui que os veículos combinados têm uma maior probabilidade de se envolver em acidentes fatais. Embora o bi-trem não faça parte dos veículos estudados, pode-se estender essa conclusão a ele, uma vez que ele apresenta características similares com os demais veículos estudados. No entanto, algumas das condições em que isso ocorre são extremamente raras no Brasil (como neve e gelo, por exemplo). Isso torna necessária a realização de um estudo do mesmo tipo, com dados da realidade brasileira. Ainda, Forkenbrock e Hanley (2002) lançam a seguinte questão: O uso de veículos combinados aumenta a capacidade de carga e, por conseqüência, diminui a quantidade de 
veículos nas estradas. Isso não diminuiria o número total de colisões fatais? Essa pergunta permanece sem resposta com respaldo científico.

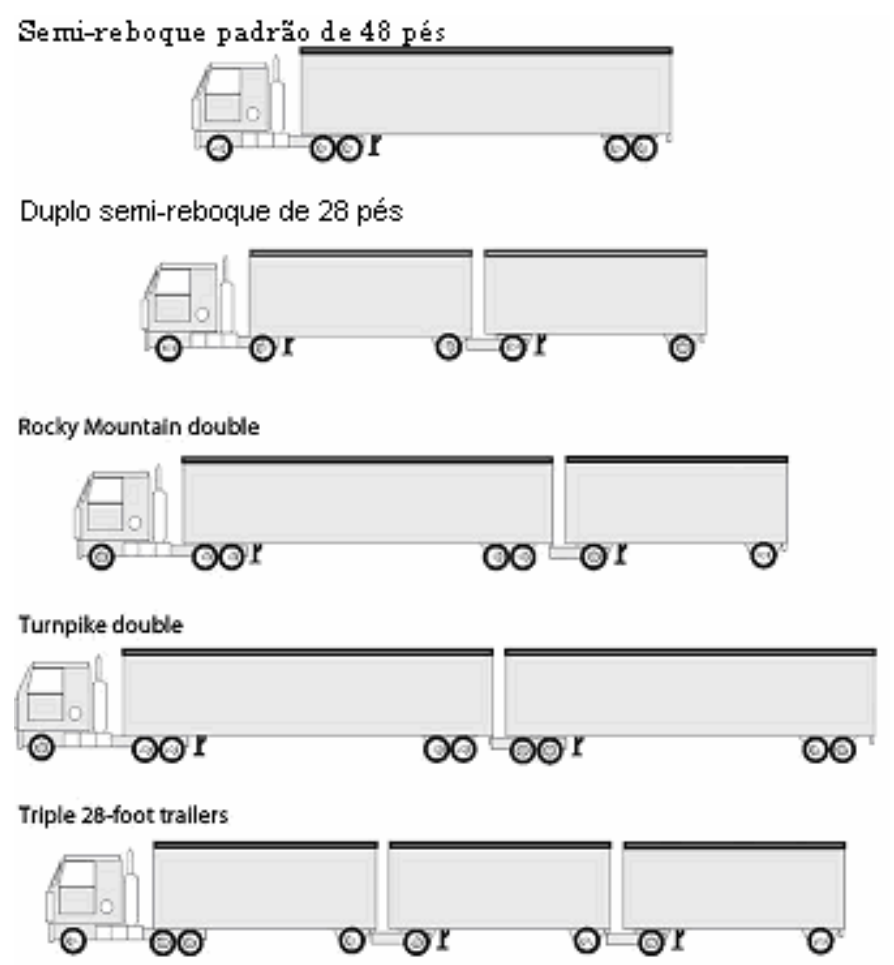

FIGURA 1.2 - Veículos combinados mais utilizados nos EUA Fonte FORKENBROCK E HANLEY (2002)

O sistema de freios deve agir de forma a atender aos requisitos de projeto, normas e leis, em diversas condições operacionais, tais como: pista seca ou molhada (com vários níveis de aderência), com o veículo totalmente carregado ou vazio, dentre outras. Essa grande variedade de condições torna o projeto de um sistema de freios complexo. Dessa forma uma ferramenta de auxilio ao projetista seria de grande utilidade para profissionais dessa área.

Um dos dispositivos de segurança mais comuns atualmente é o sistema de anti-bloqueio dos freios (ABS). O ABS aumenta a segurança do veículo, pois mantém a sua estabilidade mesmo em situações perigosas (pistas com baixa aderência). Devido ao seu alto custo, o seu uso é pouco difundido no Brasil. Isso obriga que as forças de frenagem sejam bem distribuídas entre os eixos para se garantir segurança. Um estudo realizado por Canale et.al (2005) mostra o uso obrigatório do ABS e da alavanca ajustadora automática de folga entre as lonas e o tambor em alguns países. A Tabela 1.1 mostra a 
obrigatoriedade ou não desses dois equipamentos de segurança em alguns países.

Tabela 1.1 - Uso do ABS e alavanca ajustadora em alguns países e regiões do mundo.

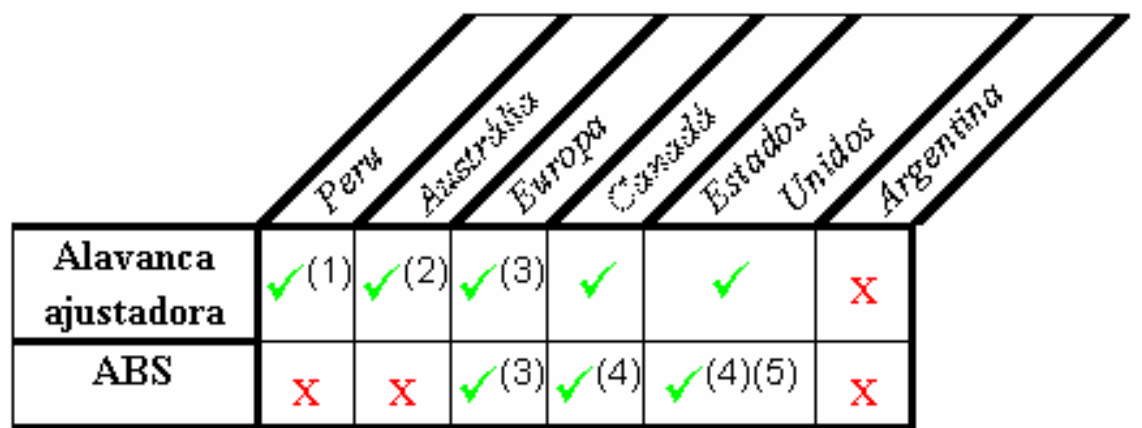

$\checkmark$ uso obrigatório

$X$ uso não obrigatório

(1) Apenas para algumas combinações a partir de 1/1/2010

(2) Apenas para algumas combinações

(3) Opcional para alguns veículos fora de estrada

(4) Veículos de com freio pneumático

(5) Veículos de freio hidráulico de peso total superior a 10.000 lbs

O ABS atualmente não é um equipamento de uso obrigatório no Brasil ,mas já esta normalizado pela ABNT 14353. A sua eficácia é cada vez mais comprovada e, seguindo a tendência de outros países, a sua utilização deverá ser exigida por lei no futuro. Por essa razão, o uso do ABS no bi-trem é previsto e considerado neste estudo.

Devido à geometria da malha rodoviária brasileira, a legislação estipula limites de comprimento e peso de veículos comerciais para garantir segurança de operação e evitar o deterioramento prematuro do pavimento. A resolução 68198 do CONTRAN limita o comprimento máximo de qualquer combinação de veículos de carga - CVC com mais de duas unidades - em 30,00 m. O PBTC máximo pode chegar a 74 toneladas, de acordo com a resolução $12 \backslash 98$ do CONTRAN, quando se utiliza semi-reboques de três eixos. A resolução 12198 limita os pesos por eixo da seguinte maneira:

- Peso nos eixos isolados, dotados de dois pneumáticos, $6 \mathrm{t}$

- Peso bruto por eixo isolado: $10 \mathrm{t}$.

- Peso bruto por conjunto de dois eixos em tandem, quando a distância entre os dois planos verticais, que 
contenham os centros das rodas, for superior a $1,20 \mathrm{~m}$ e inferior ou igual a 2,40 m: 17t;

- Peso bruto por conjunto de dois eixos não em tandem, quando a distância entre os dois planos verticais, que contenham os centros das rodas, for superior a 1,20m e inferior ou igual a 2,40m: 15t;

- Peso bruto por conjunto de três eixos em tandem, aplicável somente a semi-reboque, quando a distância entre os três planos verticais, que contenham os centros das rodas, for superior a 1,20 $\mathrm{m}$ e inferior ou igual a 2,40 $m: 25,5 t$;

Dessa forma, o bi-trem pode ter PBTC de 57t. Esse tipo de veículo é cada vez mais comum nas estradas brasileiras e seu uso deve se difundir ainda mais, pois a partir do dia 15 de setembro de 2004 os CVCs de até 19,80m e PBTC de 57t não necessitam mais de Autorização Especial de Trânsito (AET) para rodar no território nacional de acordo com a resolução 164/04 do CONTRAN.

O objetivo de um sistema de freios, de acordo com Limpert (1992) é:

- Desacelerar um veículo mantendo a estabilidade e a dirigibilidade com alta eficiência (até a parada total se necessário).

- Manter a velocidade do veículo em descidas de serra e controlar a velocidade no trânsito.

- Manter o veículo parado em desníveis.

O bi-trem é uma composição de sete eixos dos quais seis possuem quatro pneumáticos e um (o eixo direcional) possui dois, totalizando 26 pneus. Como toda a força de frenagem, aceleração ou lateral é produzida na pequena área de contato do pneu com o pavimento fica claro que o conhecimento da interação do pneu com o pavimento é muito importante para o desenvolvimento de um bom sistema de freios. Apenas forças iguais ou menores que o produto da força normal e o coeficiente de adesão máximo podem ser transmitidas pela 
banda de rodagem do pneu. Mesmo os freios ideais não são capazes de utilizar mais tração do que os pneus e o pavimento provêm. (LIMPERT, 1992 p.1)

Este estudo tem como objetivo desenvolver um modelo matemático da dinâmica da frenagem e dos sistemas de freio e um programa computacional decorrente para o estudo do desempenho de um bi-trem freando em regime permanente. O modelo matemático e o programa computacional decorrente serão desenvolvidos para que possa ser utilizado nas fases de projeto, otimização e certificação do sistema de freios e da suspensão. No modelo matemático desenvolvido a dinâmica das suspensões em "tandem" do eixo traseiro do cavalo mecânico e dos semi-reboques são consideradas. Com esse programa podem-se obter as forças de frenagem e a sua distribuição, as forças normais ao pavimento nas rodas, a aderência utilizada em cada eixo, a desaceleração máxima, a eficiência de frenagem, espaço e tempo de parada. Todos estes fatores podem ser obtidos levando-se em consideração a utilização ou não de ABS nos freios e o tempo de reação do motorista. Também é possível simular frenagens com várias condições de aderência e carregamento e comparar o desempenho do sistema de freios com os requisitos do Anexo 10 da ECE-R13 e da norma ABNT 14354.

No capítulo 2 deste estudo é apresentada uma breve revisão da bibliografia referente à dinâmica veicular e, em especial, a dinâmica da frenagem.

O capítulo 3 descreve o modelo matemático desenvolvido que foi utilizado para a elaboração da planilha de cálculo. Mostra também toda a metodologia utilizada e o desenvolvimento do programa de simulação.

No capítulo 4 os resultados das simulações realizadas em várias condições operacionais são mostrados e comentados.

No capítulo 5 encontram-se as conclusões tiradas a partir dos resultados obtidos no capítulo anterior. 


\section{REVISÃO BIBLIOGRÁFICA}

A função do sistema de freios é transformar a energia cinética do veículo em energia térmica, proporcionando uma desaceleração ao mesmo. Ele deve ser projetado de modo a garantir uma desaceleração segura, mantendo a dirigibilidade e a estabilidade do veículo, obedecendo à legislação vigente.

Canale (1998) define estabilidade como a tendência decrescente das amplitudes do movimento de um veículo após o término da perturbação e dirigibilidade (ou manobrabilidade) como a capacidade e habilidade do veículo/piloto em sair de uma dada condição de regime permanente para uma outra condição.

Brossi (2002) realizou um estudo sobre o desempenho da frenagem de um ônibus bi-articulado. Esse veículo é muito semelhante ao bi-trem ao ser estudado na frenagem, pois possui uma unidade tratora e duas rebocadas. A diferença é a suspensão em "tandem" a qual o ônibus bi-articulado não possui, a válvula sensível a carga e o ABS. A metodologia a ser utilizada nos cálculos das forças e desempenho de frenagem do bi-trem é semelhante à usada por Brossi em seu estudo.

Limpert (1992) cita que o projetista do sistema de freios deve saber as seguintes características do veículo:

- Peso do veículo vazio e carregado

- Peso estático em cada eixo (vazio e carregado)

- Distância entre-eixos

- Posição do centro de gravidade (vazio e carregado)

- Finalidade do veículo

- Tipo do pneu

- Velocidade máxima

- Exigências do sistema de freios 
Todos esses dados são importantes para o projeto do sistema de freios do veículo e alguns serão discutidos a seguir.

\subsection{Posição do Centro de Gravidade}

Fernandes et al. (1998) utilizam a técnica de mapas de desempenho para mostrar como o carregamento pode influenciar o desempenho de veículos combinados na frenagem. O mesmo autor ressalta que apesar da legislação exigir testes de desempenho apenas com o veículo vazio ou totalmente carregado, a pior condição de frenagem pode estar em um ponto intermediário. Isso se dá devido à distribuição de carga no veículo. Sendo assim, a localização do centro de gravidade é muito importante para o desenvolvimento do sistema de freios.

Canale (1989) demonstra que a força de reação normal ao solo, para um veículo de dois eixos, considerando o peso dinâmico (transferência de peso entre os eixos de um veículo pela ação de uma força) é dada por:

$$
W_{b r}=\frac{1}{L} \cdot\left[L_{f} \cdot W-H \cdot(B+f \cdot W)\right]
$$

$$
\text { sendo: } \begin{array}{ll}
L=\text { distância entre eixos do veículo } & {[\mathrm{m}]} \\
L_{f}=\text { distância do CG em relação ao eixo dianteiro } & {[\mathrm{m}]} \\
W=\text { peso do veículo } & {[\mathrm{N}]} \\
\mathrm{H}=\text { altura do centro de gravidade } & {[\mathrm{m}]} \\
\mathrm{B}=\text { força de frenagem }, & {[\mathrm{N}]} \\
\mathrm{f}=\text { coeficiente de resistência ao rolamento } & {[-]}
\end{array}
$$

Em veículos comerciais a transferência de força normal entre os eixos é mais complexa devido, principalmente, à dinâmica da suspensão em "tandem" e ao maior número de eixos.

Como o conhecimento da força de reação normal ao solo é muito importante, como será discutido ao longo do trabalho, a correta determinação do CG também o é, pois estão inter-relacionadas. 
Canale (1989) também fornece meios para determinar o CG, reproduzido a seguir:

\subsubsection{Posição do CG na direção Longitudinal}

A posição do centro de gravidade de um veículo na direção longitudinal pode ser obtida, conforme a Figura 2.1, pesando-se os eixos do veículo e depois fazendo os cálculos a seguir.



FIGURA 2.1 - Posicionamento do CG na direção longitudinal; CANALE (1989)

Como W (o peso do veículo) e $L$ são conhecidos é possível medir $W_{f}$ ou $W_{r}$, e calcular $L_{f}$ e $L_{r}$ pelo somatório de momentos em torno dos pontos $A$ e $B$ respectivamente:

$$
L_{f}=\frac{W_{r} \cdot L}{W}
$$

sendo:

$$
L=\text { distância entre eixos do veículo }
$$

$\mathrm{L}_{f}=$ distância do $C G$ em relação ao eixo dianteiro

$\mathrm{W}=$ peso do veículo

$\mathrm{W}_{\mathrm{r}}=$ peso no eixo traseiro do veículo

$$
L_{r}=\frac{W_{f} \cdot L}{W}
$$

sendo:

$$
\begin{aligned}
& L=\text { distância entre eixos do veículo } \\
& L_{f}=\text { distância do CG em relação ao eixo dianteiro } \\
& W=\text { peso do veículo } \\
& W_{f}=\text { peso no eixo dianteiro do veículo }
\end{aligned}
$$


Procedimento parecido é adotado para se determinar a posição longitudinal do centro de gravidade de veículos combinados. O mesmo procedimento pode ser utilizado para se obter o posicionamento do c.g. do cavalo mecânico e dos semi-reboques separadamente.

\subsubsection{Posição do CG na vertical}

A determinação do CG na vertical é mais difícil e por vezes mais perigoso, pois envolve o levantamento de pelo menos parte do veículo, como visto na Figura 2.2. Uma das maneiras apontadas por Canale (1989) é ilustrada a seguir.

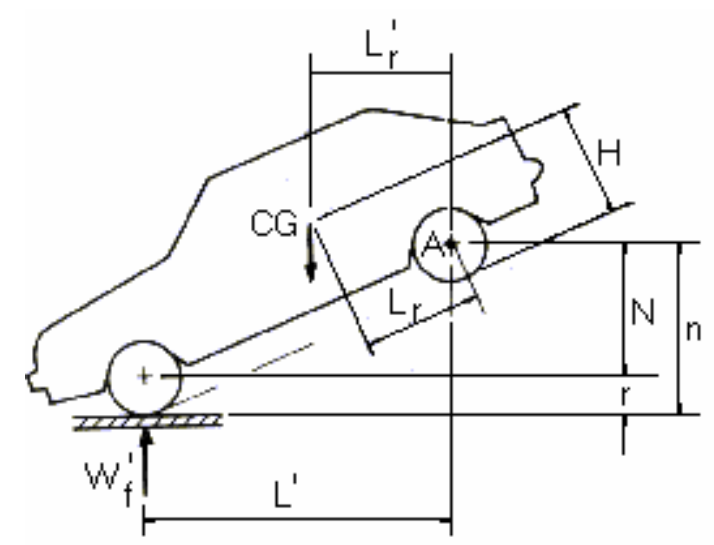

FIGURA 2.2 - Posicionamento do CG na direção vertical; CANALE (1989)

Para o cálculo, primeiro levanta-se um dos eixos do veículo a uma altura "n" e então mede-se $W_{f}^{\prime}$ e L'. Feitas essas medidas o cálculo da altura do CG, para veículos com rodas dianteiras e traseiras de mesmo diâmetro, é dado por:

$$
H=r+\frac{\left(W_{f}^{\prime}-W_{f}\right) \cdot L \cdot \sqrt{L^{2}-N^{2}}}{W \cdot N}
$$


sendo:

$\mathrm{H}=$ altura do $\mathrm{CG}$

$r=$ raio do pneumático

$W_{f}^{\prime}=$ peso eixo dianteiro com o veículo inclinado

$\mathrm{W}_{\mathrm{f}}=$ peso estático no eixo dianteiro

$\mathrm{W}=$ peso total do veículo

$\mathrm{L}=$ distância entre eixos do veículo

$\mathrm{N}=$ Altura na qual o eixo foi levantado, descontando-se o raio da roda

Para determinar a altura do centro de gravidade do cavalo mecânico de uma combinação veicular, utiliza-se o mesmo princípio, elevando-se o eixo traseiro ou o dianteiro. Quando o cavalo mecânico for $6 \times 4$, as rodas de um dos eixos do "tadem" devem ser retiradas, a suspensão travada e as rodas remanescentes colocadas sobre a balança, elevando-se então o eixo dianteiro. Após a obtenção da posição do CG com (2.4), o mesmo deve ser corrigido matematicamente com a inclusão das rodas que foram retiradas. Para os semireboques, adota-se o mesmo procedimento para o cavalo $6 \times 4$, elevando-se a quinta roda.

\subsubsection{Posição do CG na vertical - segundo método}

O segundo método proposto por Canale (1989) consiste em elevar o veículo conforme a Figura 2.3. O autor define as condições nas quais as medições devem ser feitas bem como as limitações do método. O cálculo é apresentado a seguir.

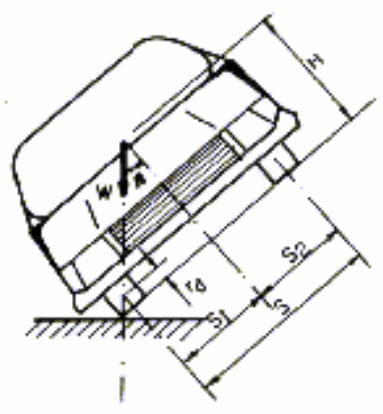

FIGURA 2.3 - Posicionamento do CG na direção vertical; CANALE (1989) 


$$
H=\frac{S_{1}}{\tan (\beta)}+r_{d}
$$

sendo:

$$
\begin{aligned}
& H=\text { altura do } C G \\
& S_{1}=\text { distância do CG à roda não levantada } \\
& r_{d}=\text { raio dinâmico do pneumático } \\
& \beta=\text { ângulo de inclinação do veículo }
\end{aligned}
$$

2.1.4. Posição do CG na vertical - alternativa de Dixon (1996)

Este método é mais indicado para veículos grandes, uma vez que os anteriores são muito difíceis de se fazer para veículos dessa dimensão. $O$ método consiste em elevar o veículo num ponto diretamente acima do CG, como na Figura 2.4. Adiciona-se então uma massa conhecida, $m_{e}$, em uma das extremidades causando uma inclinação de um ângulo $\theta$. Assim a distância do CG ao ponto de pivotamento é encontrado com a equação (2.6).
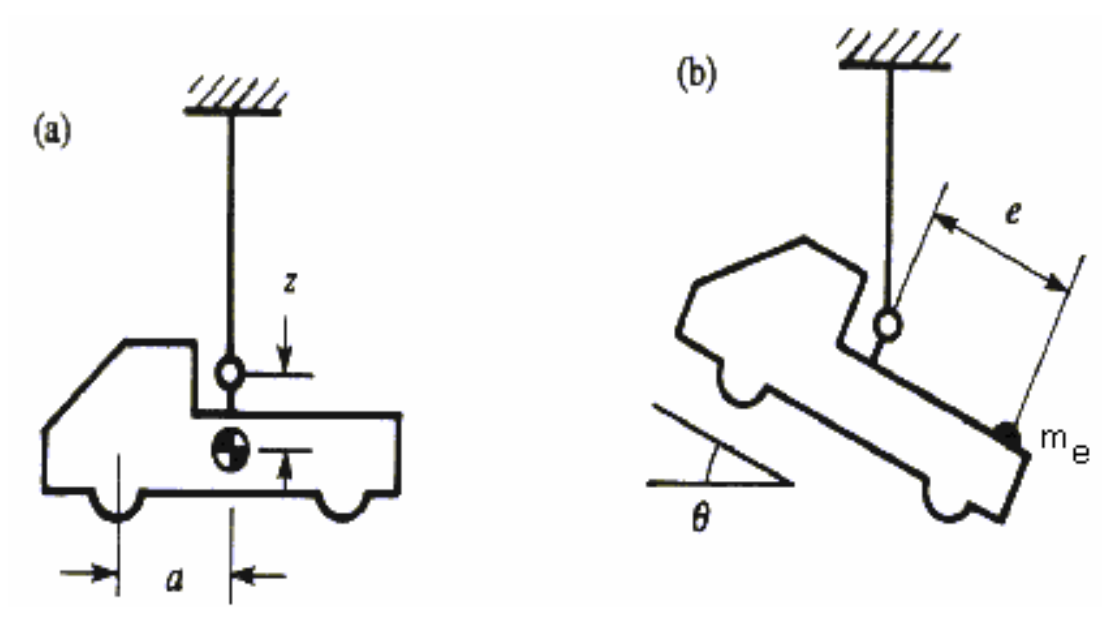

FIGURA 2.4 - Posicionamento do CG na direção vertical; DIXON (1996)

$$
z=\frac{m_{e} \cdot e}{m \cdot \tan (\theta)}
$$

sendo: 


$$
\begin{aligned}
& z=\text { distância do CG ao ponto de fixação } \\
& m_{e}=\text { massa adicionada } \\
& m=\text { massa do veículo } \\
& e=\text { distância da massa adicionada ao CG } \\
& \theta=\text { ângulo de inclinação do veículo }
\end{aligned}
$$

Esses dois últimos modos não são os usuais para a obtenção do CG por serem relativamente complicados (principalmente para veículos de carga)

\subsection{Interação Pneumático x Pavimento}

A maioria das forças que atuam em um autoveículo, incluindo as forças de controle como as laterais e de tração/frenagem, ocorrem na pequena área de contato entre o pneumático e o pavimento. Dessa forma, é muito importante o conhecimento da interação entre eles para o completo entendimento da dinâmica de um veículo combinado.

A primeira característica que se deve prestar atenção é que o pneu é elástico e assim sendo não existe um ponto de contato e sim uma área, como mostrado na Figura 2.5.

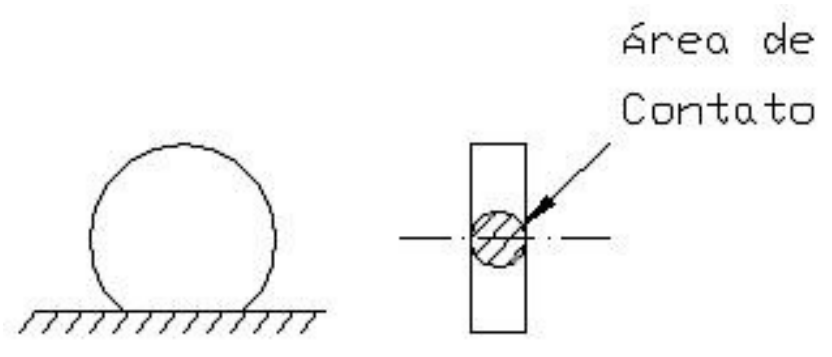

FIGURA 2.5 - Área de contato de uma roda elástica; CANALE (1989)

De acordo com Gillespie (1992) os dois principais mecanismos "geradores" de atrito entre as superfícies do pneumático e do pavimento são a adesão superficial e o efeito de histerese, responsável por uma perda de energia na borracha. Ainda, segundo Gillespie (1992), existe um escorregamento parcial durante o rolamento da roda, devido à deformação, principalmente, do pneumático. 
O conceito de Coeficiente de Adesão é definido como a relação da força gerada pelo pneumático - longitudinal no caso da frenagem - e a força normal ao solo. Pode ser interpretado como a quantidade de atrito "usado" pelo pneu durante uma frenagem. O coeficiente de adesão é função do escorregamento parcial do pneumático como é mostrado na Figura 2.6 (na tração e na frenagem).
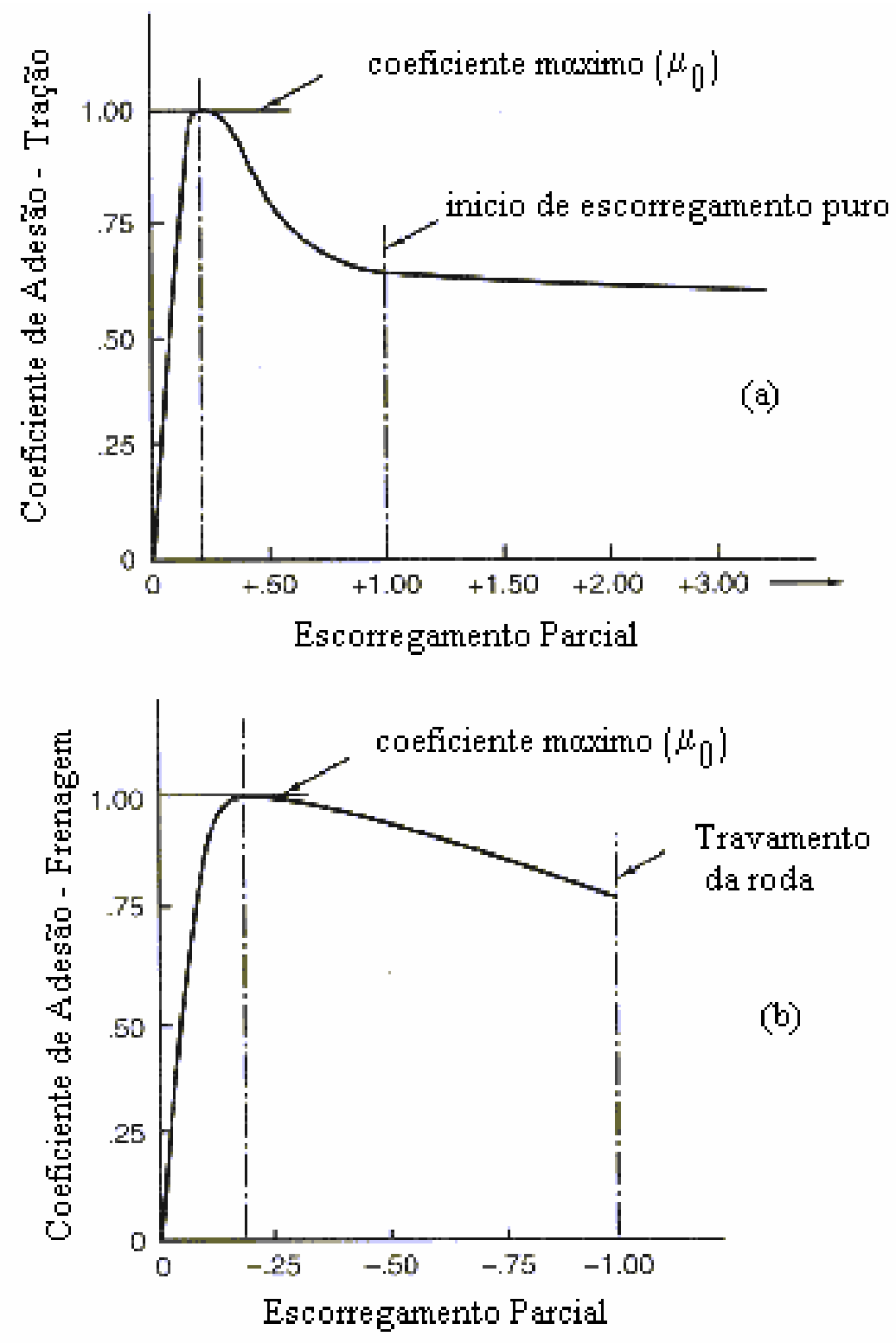

FIGURA 2.6 - Coeficiente de adesão para a tração (a) e frenagem (b); MILLIKEN(1995)

A Figura 2.6(b) mostra que com o aumento da força de frenagem aumenta-se o coeficiente de adesão utilizado até o valor máximo, $\mu_{0}$, com 
aproximadamente $20 \%$ de escorregamento parcial. A partir desse ponto 0 coeficiente de adesão decaí e junto com ele a força que o pneu pode gerar atingindo o coeficiente de escorregamento $\left(\mu_{\mathrm{s}}\right)$ aos $100 \%$ de escorregamento. Essa é uma condição perigosa, pois com $100 \%$ de escorregamento relativo os pneus perdem a capacidade de gerar forças laterais, deixando o veículo instável. Processo semelhante ocorre com o pneu durante a tração (Figura 2.6 a).

Gillespie (1992) aponta como os principais fatores que influenciam os valores de $\mu_{0}$ e $\mu_{\mathrm{s}}$ a velocidade (quanto maior a velocidade, menor esses valores), a pressão dos pneumáticos (apenas em pistas molhadas $\mu_{0}$ e $\mu_{s}$ aumentam com o aumento da pressão) e a carga vertical no pneumático (em geral $\mu_{0}$ e $\mu_{\mathrm{s}}$ decaem de 0,01 para um aumento da carga de $\left.10 \%\right)$.

\subsection{O sistema de freios}

O sistema de freios é o conjunto de mecanismos encarregados de gerar as forças necessárias para impor uma desaceleração ao veículo. Essas forças são geradas por friç̧ão. Scharf (1989) define fricção (ou atrito) como a resistência ao movimento de dois corpos em contato. Sua intensidade depende do tipo de material em contato, a rugosidade da superfície e da força que mantém os corpos unidos. A maioria dos veículos gera as forças de frenagem atritando sapatas contra tambores (em freios a tambor) ou pastilhas contra discos (em freios a disco). Esses mecanismos de geração de forças serão apresentados ao longo dessa dissertação.

O sistema de freios deve ser projetado de tal forma que o mesmo garanta uma frenagem segura em quaisquer condições tais como: pista seca ou molhada, em aclive ou declive, em trajetória retilínea ou em curva.

Um fator muito importante a ser considerado na frenagem é a transferência de peso entre os eixos na frenagem. Durante uma frenagem a transferência de peso ocorre devido à inércia do veículo. Quando uma força de frenagem é aplicada nas rodas toda a massa suspensa tende a girar em torno 
do centro de arfagem do veículo ("pitch center"), carregando as rodas dianteiras e descarregando as traseiras.

Devido às suas dimensões, às várias possibilidades de carregamento e pela suspensão em "tandem" a transferência de peso entre os eixos é ainda mais complexa no bi-trem.

É importante conhecer a distribuição dos pesos nos eixos pois a maior força de frenagem possível só será atingida quando todas as rodas do veículo atingirem o coeficiente de adesão máximo $\left(\mu_{0}\right)$, ou seja é necessário conhecer as forças normais ao solo para que se possa determinar a melhor força de frenagem a ser obtida. Resumindo a força de frenagem máxima para cada roda é, segundo Canale(1989):

$$
B=W_{b} \cdot \mu_{0} \quad\left(\text { veja } \mu_{0} \text { na Figura } 2.6\right. \text { b) }
$$

Sendo:

$$
\begin{aligned}
& B=\text { força de frenagem } \\
& W_{b}-\text { peso sobre a roda } \\
& \mu_{0}-\text { coeficiente de aderência máximo }
\end{aligned}
$$

A equação anterior mostra como é importante o conhecimento do peso dinâmico em cada eixo, pois é o que vai definir a distribuição ideal da força de frenagem. Fernandes et al. (1997) ressalta a perda de estabilidade de veículos cavalo/semi-reboque em curvas quando há o escorregamento das rodas de um ou vários eixos. Isso ocorre assim que a força de frenagem aplicada excede a força ideal $\left(\mathrm{W}_{\mathrm{b}} \cdot \mu_{0}\right)$.

Como foi mostrado anteriormente, há transferência de peso do eixo traseiro para o dianteiro durante uma frenagem. Dessa forma é possível encontrar a distribuição ideal das forças de frenagem entre os eixos e confrontá-la com a distribuição real, da mesma maneira feita por Canale (1998) e apresentado na Figura 2.7. 


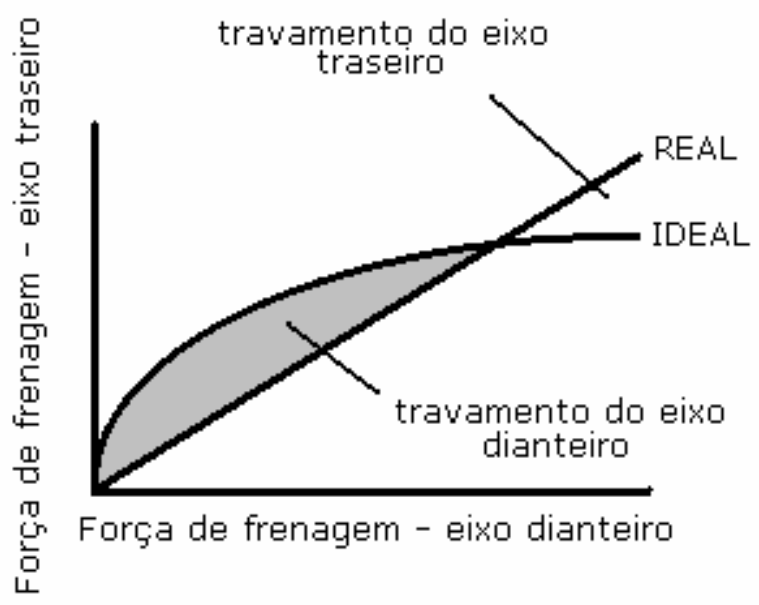

FIGURA 2.7 - Relação real e ideal das forças de frenagem - veículo de dois eixos; CANALE (1998)

A curva da distribuição ideal tem geralmente um formato parabólico. Isso ocorre devido à transferência de peso entre os eixos, o que faz com que a força ideal do eixo traseiro diminua enquanto a do eixo dianteiro aumenta. $A$ área escura no gráfico mostra as condições onde as rodas do eixo dianteiro travam antes que as do eixo traseiro, pois é a região em que a força de frenagem dianteira é maior que a ideal. Nessa condição o motorista perderá o controle do veículo, pois os pneumáticos não terão mais a capacidade de gerar forças laterais. Após o encontro das duas curvas (a ideal e a real), essa seqüência se altera e os eixos traseiros é que tem a possibilidade de travar primeiro. $\mathrm{O}$ travamento do eixo traseiro deve ser evitado, pois torna a frenagem instável. Em veículos de dois eixos, o travamento do eixo traseiro pode fazer com que o mesmo rode na pista. Em veículos combinados isso é ainda mais perigoso. De acordo com Canale (1998), o travamento dos eixos traseiros do cavalo mecânico gera um movimento rápido e instável. O cavalo gira, levando consigo o semi-reboque num movimento conhecido como "jackknife". Quando os eixos traseiros do semi-reboque travam, o mesmo gira em torno do cavalo num movimento relativamente lento que é possível ser controlado por um motorista experiente. Esse movimento é conhecido como "jackknife" do semireboque.

Por ter, o bi-trem, dois semi-reboques esses movimentos instáveis podem ser ainda mais perigosos, já que além do movimento relativo entre os 
semi-reboques e o cavalo mecânico, é possível que ocorra movimentos relativos entre cada um dos semi-reboques.

Como o travamento dos eixos traseiros é muito perigoso, a adoção de válvulas que alteram a distribuição das forças de frenagem, como mostrado na Figura 2.8, altera a distribuição das forças de frenagem real, fazendo com que o eixo traseiro nunca seja o primeiro a travar.

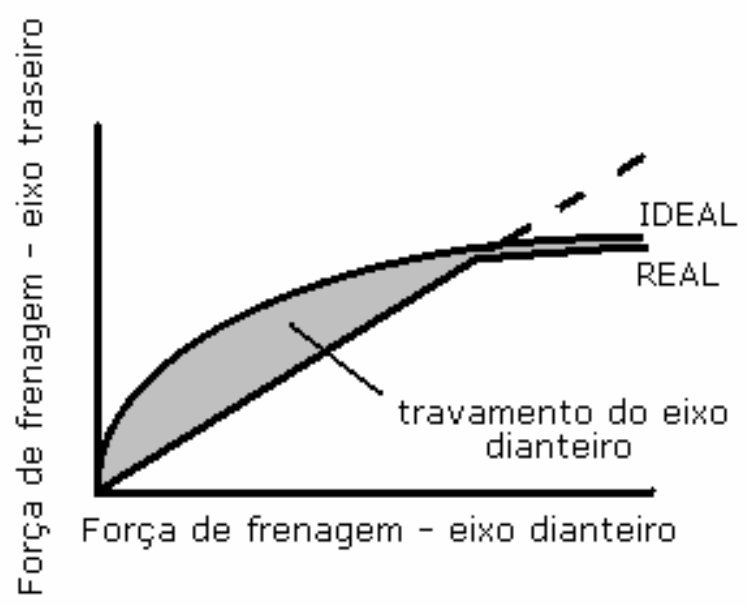

FIGURA 2.8 - Relação real e ideal das forças de frenagem - veículo de dois eixos com válvula; CANALE (1998).

Como o peso de um veículo comercial pode variar muito ao longo de sua utilização, válvulas sensíveis a carga são instaladas nos mesmos. Essa válvula é instalada em veículos (cavalos mecânicos, semi-reboques e reboques) com sistema de freios pneumático e suspensão pneumática ou mecânica. A válvula controla a pressão no circuito pneumático de acordo com a carga estática do veículo, controlando, assim, a força de frenagem. Seu funcionamento é mostrado na Figura 2.9 


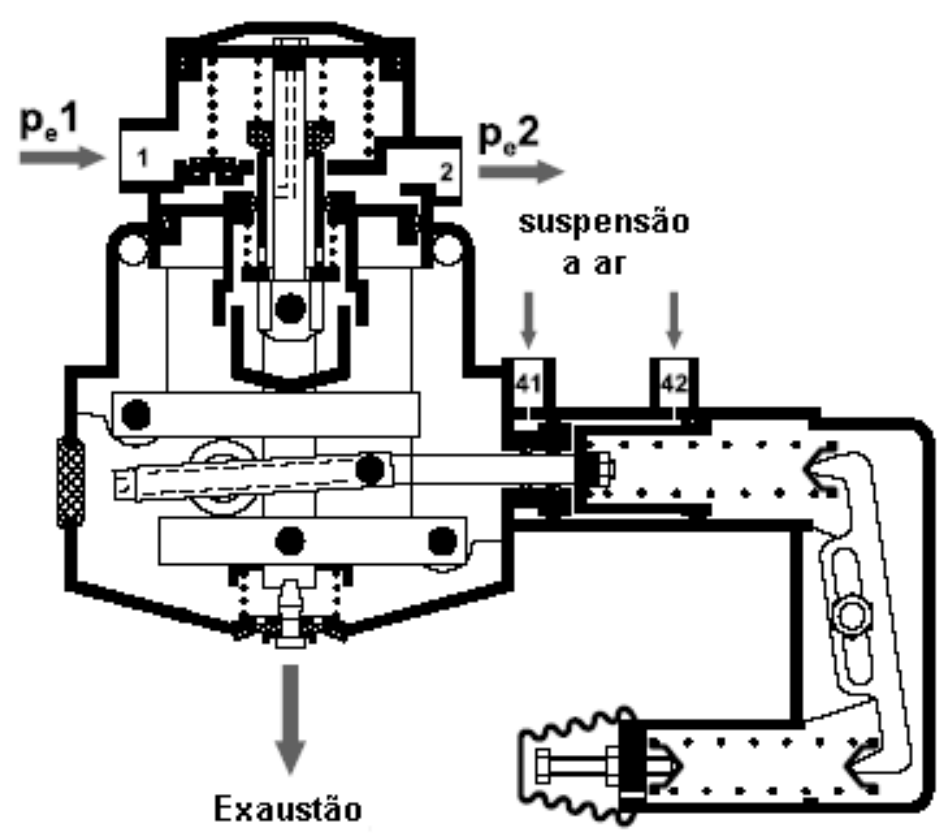

FIGURA 2.9 - Funcionamento da válvula sensível a carga; Cortesia Haldex do Brasil

Quando a carga estática muda no cavalo mecânico e/ou nos semireboques (alterando-se o carregamento do veículo), a pressão na suspensão também varia. Essa pressão é usada para controlar as conexões 41 e 42 . Dessa forma, a relação $\mathrm{p}_{\mathrm{e}} 1$ (pressão de entrada na válvula) com $\mathrm{p}_{\mathrm{e}} 2$ (pressão de saída) é ajustada. A área de atuação da válvula é mostrada na Figura 2.10. A válvula é regulada de maneira a ter uma característica proporcional com a carga estática. Ela começa a atuar apenas a partir de uma pressão de controle (pD). A influência dos movimentos oscilatórios da suspensão na válvula sensível a carga durante a frenagem é pequena, desse modo não há alteração considerável do efeito da válvula durante o processo de frenagem. 


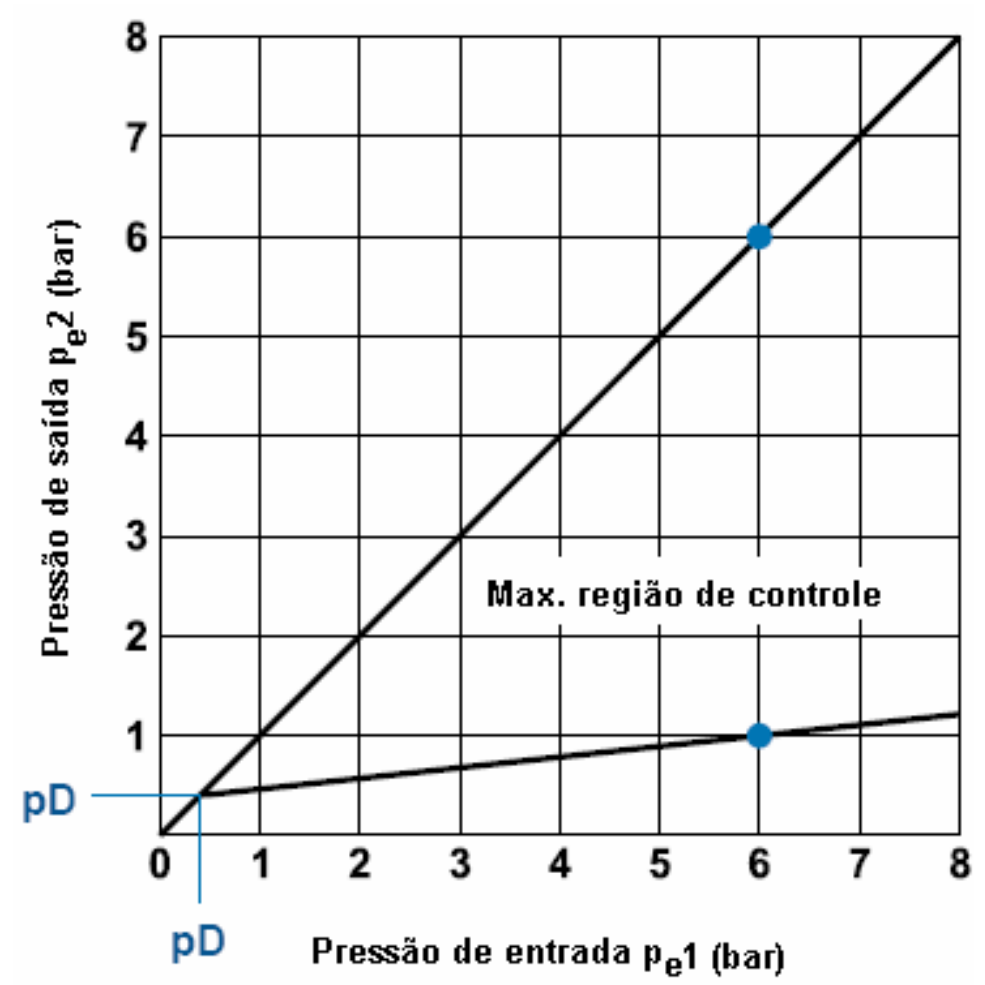

FIGURA 2.10 - Diagrama da válvula sensível a carga; Cortesia Haldex do Brasil

\subsubsection{Eficiência da frenagem}

Tendo em vista que o desempenho da frenagem depende da aderência do pavimento, Gillespie (1992) definiu a eficiência da frenagem como a relação da força de frenagem real e a força máxima admissível no pavimento. Esta relação é mostrada na equação 2.8 na qual a força de frenagem é calculada em unidades de g's (aceleração da gravidade).

$$
\eta_{b}=\frac{B_{r e a l}}{\mu_{0}}
$$

Sendo: trem.

$\mathrm{B}_{\text {real }}=$ soma de todas as forças de frenagem de todos os eixos do bi-

$\mu_{0}=$ coeficiente de aderência máximo

A eficiência de frenagem é um método muito útil para avaliar o desempenho do sistema de freios, principalmente em veículos pesados. $O$ método consiste em determinar a força de frenagem, desaceleração e a 
aderência utilizada em cada eixo, em função da pressão aplicada. A eficiência do sistema de freios é a relação da desaceleração pelo pico da curva de aderência ( $\mu_{0}$, Figura 2.6 b).

Gillespie (1992) recomenda avaliar a contribuição de cada eixo na frenagem, através do gráfico de aderência utilizada em cada eixo contra a pressão aplicada e diz que, idealmente, as curvas de todos os eixos devem ser iguais. Isso não ocorre na prática devido ás várias condições de carregamento possíveis no veículo, da transferência de peso dinâmico entre os eixos na frenagem e por limitações técnicas do sistema de freios. Ainda, segundo Oppenheimer (1996), por vários conjuntos de rodas serem controladas por um único pedal, raramente o pico de adesão é atingindo simultaneamente em cada roda. Assim a eficiência de frenagem geralmente fica abaixo de $100 \%$.

\subsubsection{Freio a disco}

Basicamente o freio a disco (ou axial) é composto de um disco (também chamado de rotor) que gira solidário ao eixo do veículo. A força de frenagem é gerada quando as pastilhas são pressionadas, na direção axial, contra o disco.

Os discos podem ser classificados como sólidos ou ventilados. Os discos ventilados são aqueles que possuem dutos de ar radiais por onde ocorre a circulação de ar, melhorando a dissipação da energia térmica gerada durante a frenagem. Já os discos sólidos são maciços. Ambos podem ser vistos na Figura 2.11.

As pinças, que são os alojamentos das pastilhas nos freios a disco, podem ser classificadas como fixas ou flutuantes (como mostrado na Figura 2.12). Nos freios de pinças fixas, as pastilhas de ambos os lados do disco são pressionadas contra esse através de pistões. Nos freios de pinça flutuante apenas uma das pastilhas é pressionada por meio de um pistão. A segunda pastilha é fixada diretamente na pinça e levada ao contato com o disco pelo movimento da pinça. 


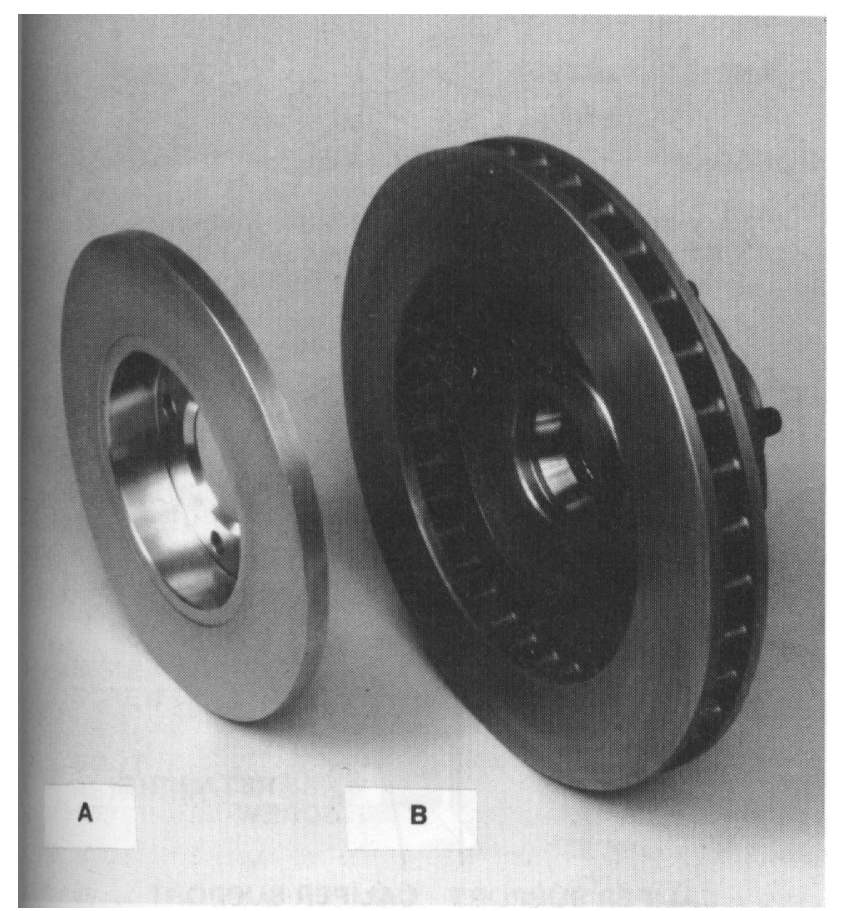

FIGURA 2.11 - Exemplos de discos de freio sólido (A)e ventilado (B); BROSSi (2002)

A Figura 2.12 mostra esquematicamente a pinça fixa e a flutuante

a) pinça fixa, b) pinça flutuante, 1. pastilha de freio,

2. pistão 3. disco de freio, 4. pinça, 5. suporte.

a

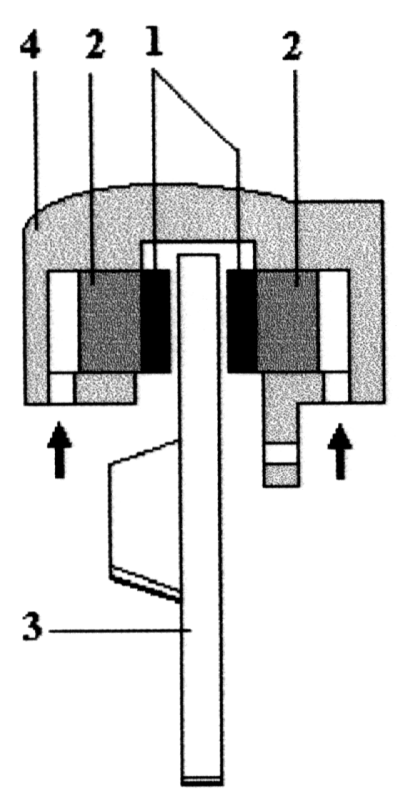

b

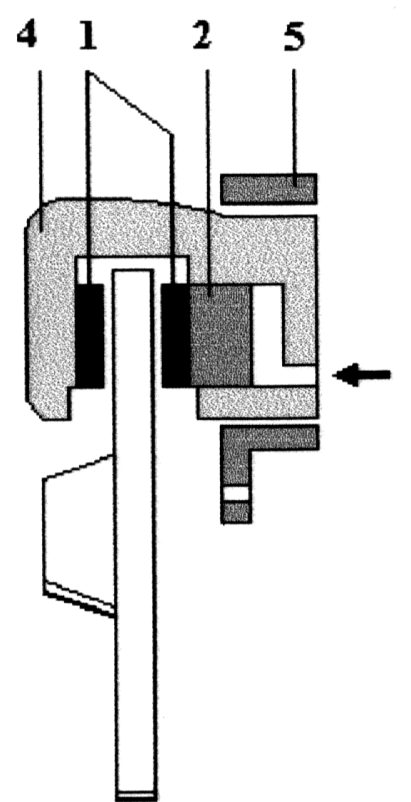

FIGURA 2.12 - Pinça fixa(a) e pinça flutuante (b); BROSSI (2002) 
Os freios a disco .são incomuns atualmente no Brasil nos semi-reboques e usados apenas em pequena escala nos cavalos mecânicos. Existe uma tendência mundial da substituição de freios a tambor por freios a disco por estes dissiparem melhor o calor gerado na frenagem.

\subsubsection{Freio a tambor}

Usado desde os primórdios da industria automobilística, segundo Scharff (1989), o freio a tambor consiste de um tambor girando solidário à roda e sapatas presas ao chassi nas quais as lonas se alojam. A força de frenagem é gerada pela compressão das lonas na superfície (geralmente a interna) do tambor.

Esse é o tipo de freio mais comum no mercado brasileiro de veículos comerciais e no bi-trem atualmente

De acordo com Brossi (2002) o uso de duas sapatas equilibra os esforços nos apoios, o que permite o uso de mancais menores e também melhoram o aproveitamento da superfície interna do tambor. Sendo assim, os freios a tambor com duas sapatas, com variados tipos de arranjos são largamente utilizados pela industria automobilística.

As sapatas podem ser classificadas como primárias ou secundárias. As sapatas primárias são aquelas em que o sentido da aplicação da força coincide com a rotação do tambor fazendo com que este "puxe" a sapata ao seu encontro, aumentando a força de contato. Já nas sapatas secundárias o sentido de aplicação da força é oposto à rotação do tambor. Desse modo o tambor acaba por "repelir" a sapata, diminuindo a força de contato. Esses fenômenos são ilustrados na Figura 2.13. 


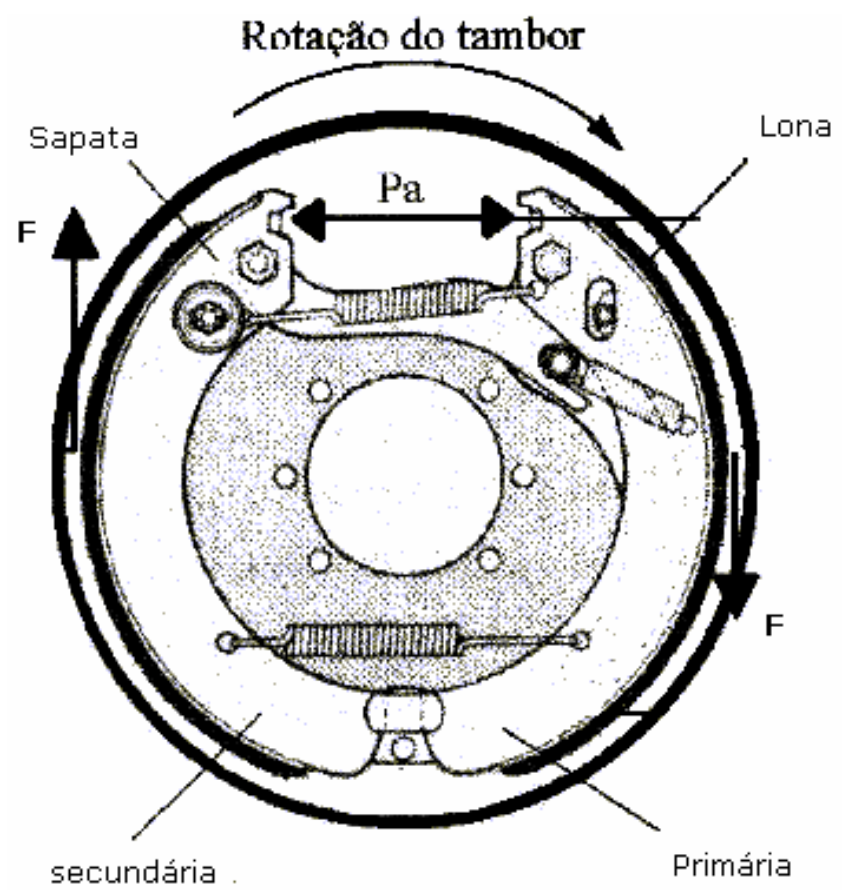

FIGURA 2.13 - Freio a tambor; Sapata primária e secundária; BROSSI (2002)

De acordo com o arranjo das sapatas, Limpert (1992) classifica os freios a tambor como mostrado na Figura 2.14.

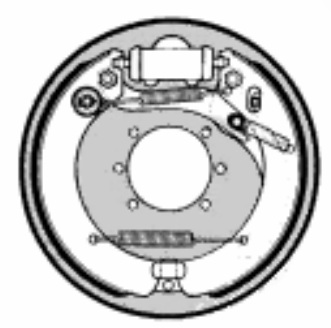

a) Primária-secundária

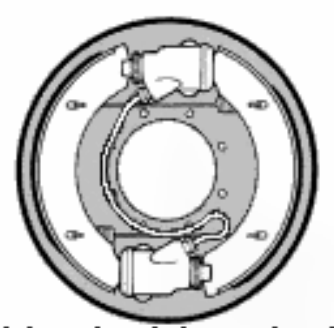

b) Primária-primária/

Secundária-secundária

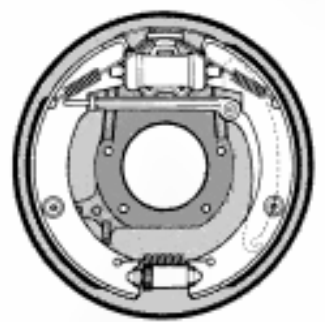

c) Duo servo

FIGURA 2.14 - Arranjos das sapatas no freio a tambor; LIMPERT (1992). 
Nos freios do tipo primária-secundária e primária-primária (ou secundária-secundária) cada sapata tem o seu próprio apoio, enquanto nos freios duo servo apenas a sapata secundária é apoiada (geralmente por um pivô). Segundo Limpert (1992) essa característica faz com que os freios duo servo tenham uma eficiência maior na geração de torque de frenagem devido ao fato da sapata primária pressionar a parte inferior da secundária. Ou seja, é o que possui o maior fator de freio (ganho mecânico do freio). O fator de freio é a relação entra a força de frenagem que sai do freio pela força aplicada nas lonas.

Vale lembrar que a classificação das sapatas depende do sentido de rotação do tambor. Assim uma sapata que é primária em marcha a frente passa a ser secundária em marcha a ré e vice-versa.

A maioria dos veículos médios e pesados utiliza freios a tambor, acionados por um came em forma de "S" (um freio a tambor acionado por came "s" é mostrado na Figura 2.15). De acordo com Brossi (2002), isso ocorre pelo fato do came "s" ser simples, de fácil manutenção, confiável, menos sensível a temperatura, possuir um ajuste preciso devido à alavanca ajustadora e apresentar baixo desgaste das lonas.

O freio por came "s" utiliza o arranjo primário-secundário sendo que as lonas são pressionadas contra o tambor por meio da rotação de um came em forma de "S" que empurra as sapatas contra o tambor. O came é rotacionado pela alavanca ajustadora que por sua vez esta conectada a um atuador.

A alavanca ajustadora garante a perfeita folga entre a lona e o tambor durante a vida útil deste par. De acordo com Limpert (1992), cerca de 50 ajustes devem ser feitos para manter a folga ideal durante a vida útil das guarnições quando o sistema de freios não possui uma alavanca ajustadora automática. As alavancas ajustadoras são dotadas de catracas que corrigem a folga automaticamente e são elementos importantes para se garantir a desempenho do sistema de freios durante toda a vida do par lona - tambor. 


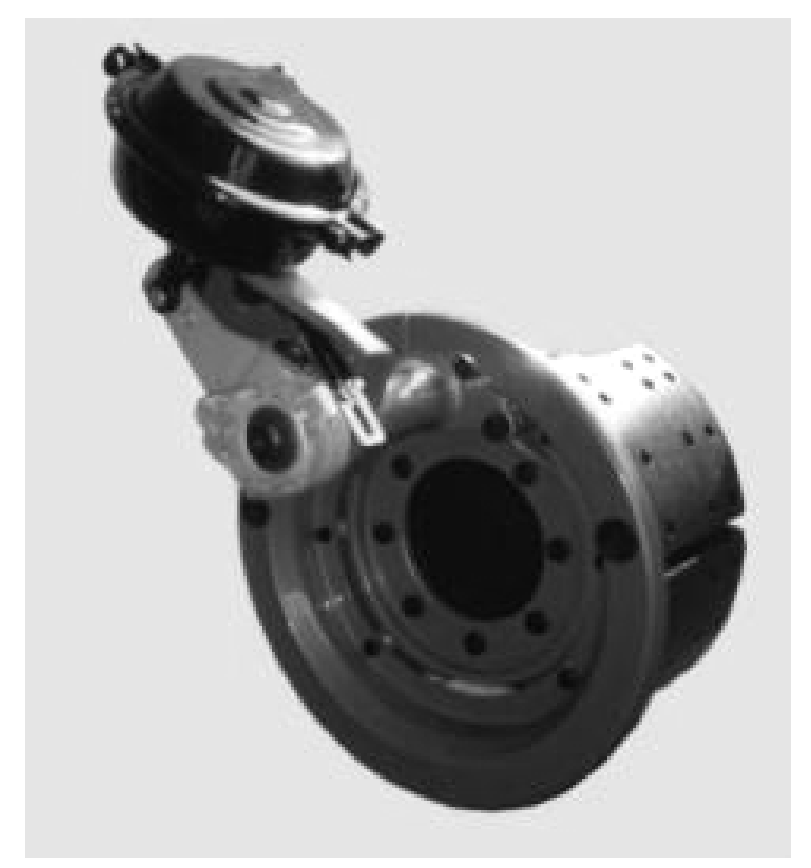

FIGURA 2.15 - Componentes do Freio a tambor (sem o tambor); Cortesia de Haldex do Brasil.

2.3.4. Fator de freio (calculo e valores comuns para diferentes tipos de freios)

O fator de freio é a relação da força gerada no contato entre a lona e o tambor ou entre a pastilha e o disco com a força aplicada para comprimi-los. È um indicador da capacidade do freio de gerar torque de frenagem para diferentes coeficientes de fricção (ver Figura 2.17) A Figura 2.16 ilustra esquematicamente as forças atuando no tambor para o cálculo do fator de freio



FIGURA 2.16 - Forças atuando nas sapatas em um freio a tambor padrão; GILLESPIE (1992). 
Gillespie (1992) faz a seguinte alteração de variável $F_{A}=\mu N_{A} \quad e \quad F_{B}=\mu N_{B}$ e chega às seguintes equações para o fator de freio:

$$
F F_{\text {PRIMARIA }}=\frac{\mu e}{(m-\mu n)} \text { e } F F_{\text {SECUNDARIA }}=\frac{\mu e}{m+\mu n}
$$

Sendo: $\quad \mu=$ coeficiente de atrito entre tambor e lona $\mathrm{e}=$ distância do pivotamento da lona à força $\mathrm{P}_{\mathrm{a}} \quad[\mathrm{m}]$ $\mathrm{m}=$ braço da força $\mathrm{Na}_{\mathrm{a}} \quad$ [m] $\mathrm{n}=$ braço da forca $\mu \mathrm{N}_{\mathrm{a}}$ $[\mathrm{m}]$

Como já dito anteriormente, as sapatas primárias desenvolvem mais torque de frenagem por serem "puxadas" contra o tambor enquanto as secundárias são "repelidas". A equação 2.9 deixa isso bem evidente. $O$ fator de freio de uma sapata primária aumenta de acordo com o atrito não apenas pelo numerador ser proporcional ao fator $\mu$, mas também pelo denominador diminuir com o aumento de $\mu$. Isso apresenta um problema quando $\mu$ cresce e o termo " $\mu n$ " aproxima-se do termo "m",fazendo o denominador tender a zero e, por conseqüência, o fator de freio tender a infinito. Dessa forma ocorrerá o travamento das rodas. De forma análoga, demonstra-se porque o fator de freio de uma sapata secundária é menor que o de uma primária. $\mathrm{O}$ denominador de uma sapata secundária, aumenta com o aumento de $\mu$. Limpert (1992) demonstra como calcular o fator de freio para diversos tipos de arranjo de sapatas e freios.

\subsubsection{Freio a tambor $x$ freio a disco}

A maior vantagem dos discos de freios é a capacidade de operar em altas temperaturas (até $1173 \mathrm{~K}$, segundo Limpert (1992)). Os freios a disco também ficam constantemente em contato com 0 ar e ainda podem ser ventilados. Dessa forma a troca de calor com o meio é bem maior que em um 
freio a tambor o que permite a ele manter a temperatura mais estável. A influência da temperatura na frenagem será discutida nos próximos tópicos.

Já os freios a tambor são bem mais sensíveis em relação à temperatura. A temperatura máxima não deve exceder $700 \mathrm{~K}$, pois o coeficiente de fricção é muito afetado pela temperatura. Além disso, o diâmetro do tambor aumenta com o aumento da temperatura (em um veiculo de passeio pode chegar a $1,5 \mathrm{~mm})$. Isso faz com que seja necessário um deslocamento maior do pedal de freio. Para completar, o aumento do diâmetro causa contato inapropriado entre a lona e o tambor que resulta num pico de pressão e um aumento local da temperatura e uma variação do torque de frenagem.

Um outro ponto que o freio a disco se diferencia do freio a tambor é a relação linear entre o torque produzido e o coeficiente de fricção entre a pastilha e o rotor (ver Figura 2.17). Dessa forma um aumento de $10 \%$ no coeficiente de fricção aumenta o torque de frenagem em $10 \%$ em um freio a disco enquanto no freio a tambor o aumento do torque de frenagem é de 30 a $35 \%$. Os freios a tambor, por sua vez, são os que apresentam maior fator de freio.

A Figura 2.17 mostra a relação do fator de freio e o coeficiente de fricção. Os freios do tipo duo servo são os que apresentam maior fator de freio para um dado coeficiente de atrito. Apesar de ser uma característica desejável para freios de estacionamento, esses freios, segundo Limpert (1992) são inseguros se usados nos eixos traseiros e também não devem ser usados nos eixos frontais devido ao potencial desbalanceamento das forças de frenagem entre o lado direito e o esquerdo. Já os freios tipo primária-primária provêm força de frenagem estável o suficiente para serem usados nos eixos traseiros e um alto fator de freio para freios de estacionamento. 


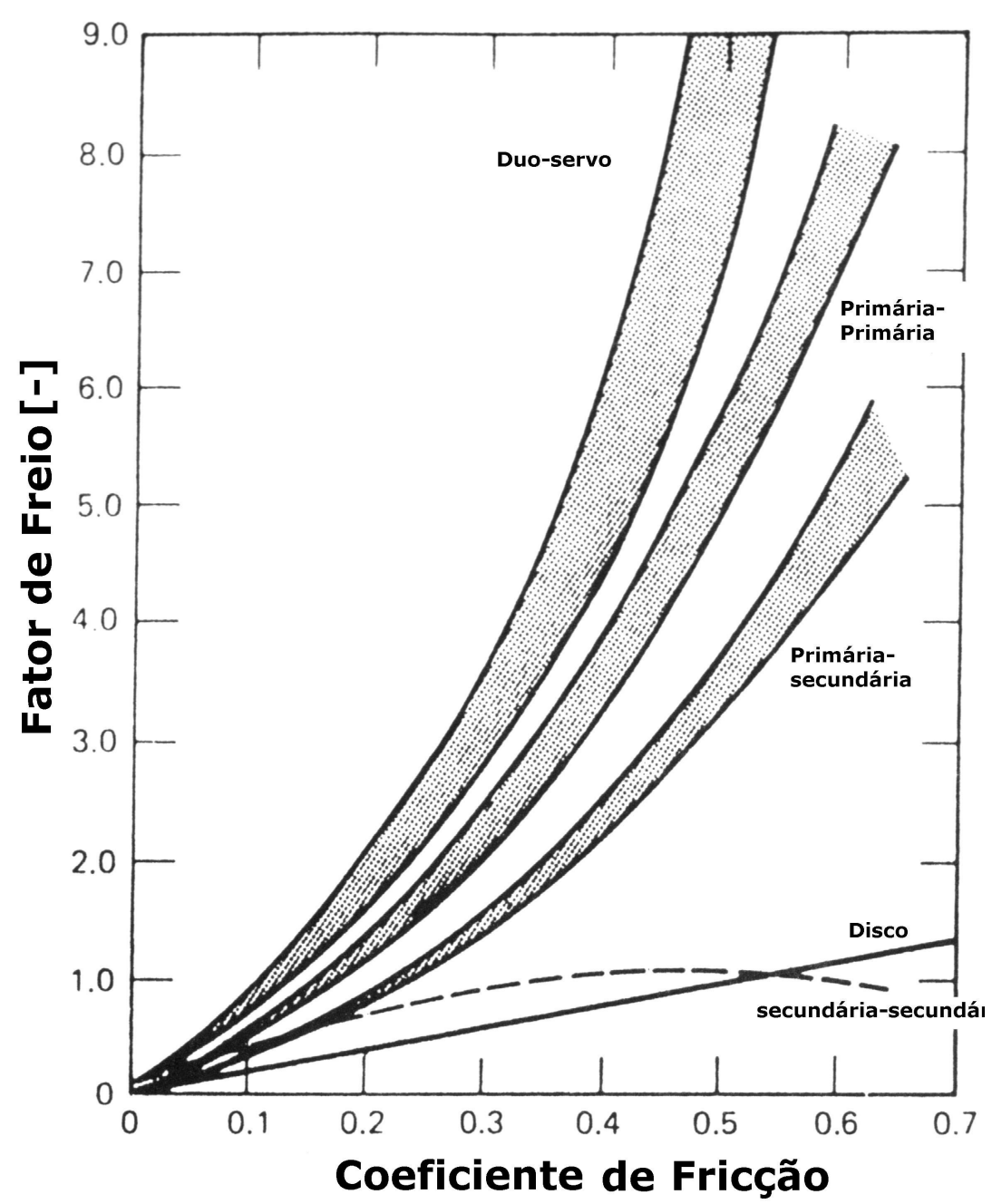

FIGURA 2.17 - Comparação do fator de freio para vários tipos de freios; LIMPERT (1992).

\subsection{ABS (“Anti-lock Brake System”)}

O travamento de rodas reduz a força de frenagem e leva a perda de dirigibilidade e estabilidade do veículo. Enquanto o travamento do eixo dianteiro leva a perda da capacidade de fazer curvas (o veículo permanece em linha reta apesar de qualquer entrada no volante), o travamento das rodas traseiras faz com que o veículo comece um movimento de rotação caso haja algum distúrbio de "yaw" (que estão sempre presentes, segundo Gillespie (1992)). A Figura 2.18 mostra os possíveis movimentos instáveis de uma combinação cavalo/semi-reboque 

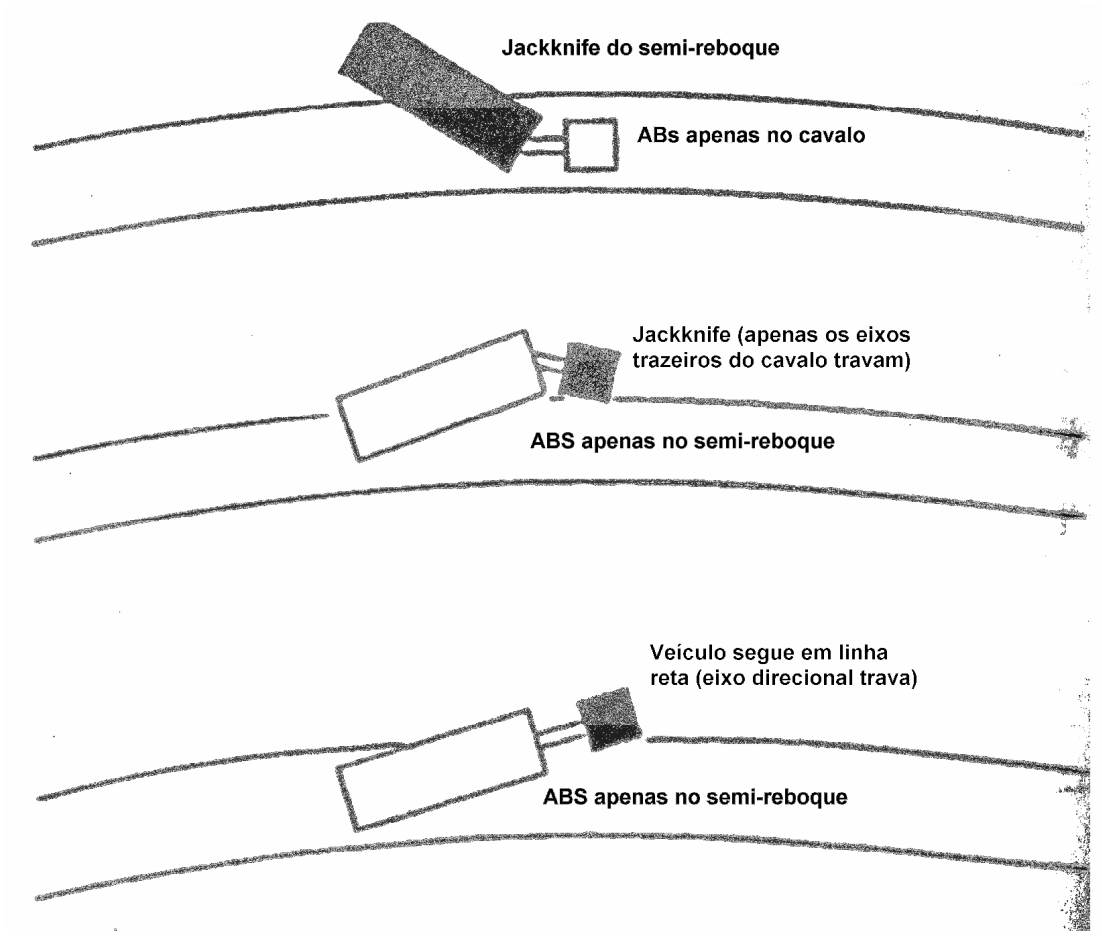

FIGURA 2.18 - Perda de estabilidade de um cavalo/semi-reboque;Fitch (1994)

O bi-trem apresenta também o "jacknife" do segundo semi-reboque por possuir um semi-reboque a mais.

Com o intuito de evitar a instabilidade de um veículo durante uma frenagem, sistemas de antitravamento das rodas (ABS) foram desenvolvidos. Esses sistemas são capazes de "sentir" quando ocorre o travamento da roda e momentaneamente liberam o freio na mesma. Assim que a roda volta a girar os freios são aplicados novamente em um ciclo que pode ocorrer algumas vezes por segundo.

As Figuras 2.19 e 2.20 mostram o funcionamento básico do ABS, de acordo com Gillespie (1992). Quando os freios são aplicados, a velocidade das rodas diminui como mostrado na região 1 . Se os freios são aplicados muito intensamente ou o pavimento esta escorregadio, o velocidade de uma ou mais rodas diminui rapidamente (ponto 2), indicando que o pneu passou do pico da curva de aderência e esta prestes a travar. Nesse ponto o ABS intervém e libera os freios nessas rodas antes que o travamento ocorra (ponto 3 ). Os freios são reaplicados assim que a velocidade das rodas aumenta. O ABS se utiliza desse mecanismo para manter cada pneu próximo do pico da curva de aderência (Figura 2.20). 


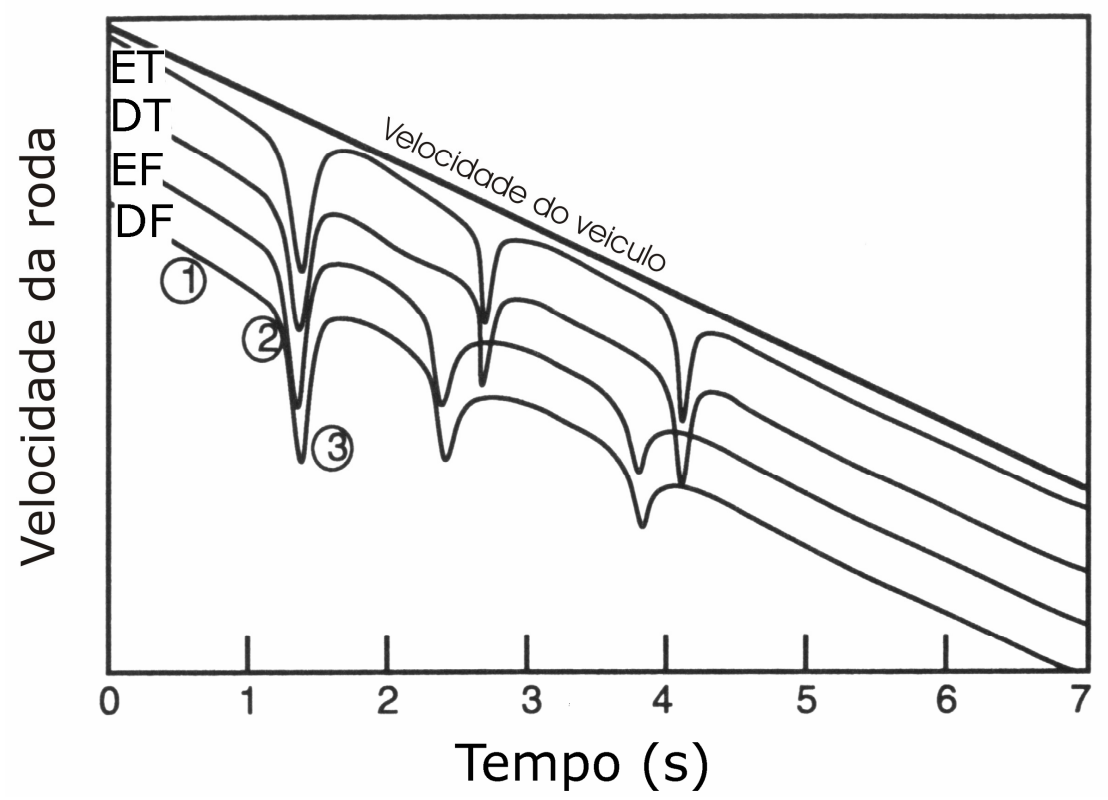

FIGURA 2.19 - Funcionamento do ABS; GILLESPIE (1992)

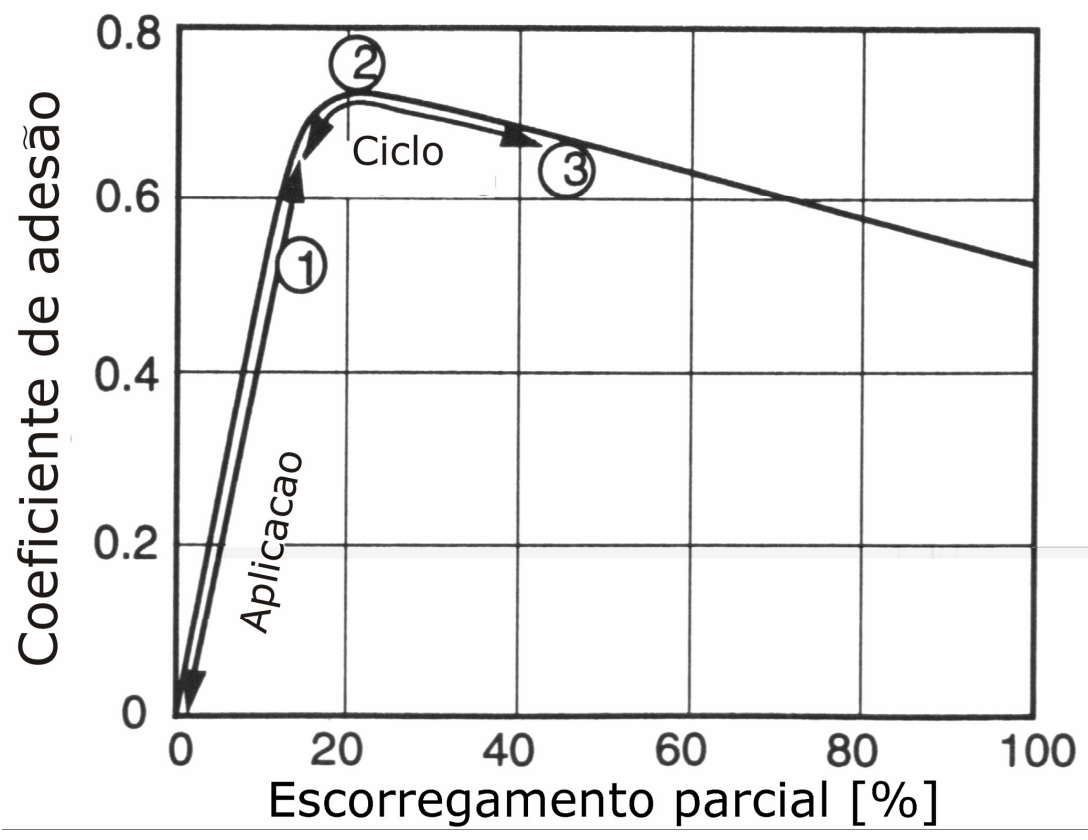

FIGURA 2.20 - ABS mantém o veículo próximo ao pico de aderência; GILLESPIE (1992).

Segundo Limpert (1992) os requisitos para o ABS são:

1. Manter a capacidade de esterçamento durante a atuação do ABS.

2. Manter a dirigibilidade e a estabilidade que geralmente é mais importante que minimizar a distância de parada. 
3. Agir o mínimo possível sobre as rodas que esterçam, especialmente em pistas com coeficientes de adesão diferentes (como mostrado na Figura 2.21 .

4. O ABS deve utilizar a aderência disponível de forma ótima.

5. Deve se adaptar rapidamente a mudanças de aderência disponível

6. Deve minimizar o movimento de guinada (yaw) quando em pistas com coeficientes de adesão diferentes (como mostrado na Figura 2.21).

7. Deve reconhecer aquaplanagem e manter a estabilidade direcional.

8. Deve frear de forma estável com o veículo fazendo curva.

9. O sistema normal de freios deve atuar de forma estável (sem perda de estabilidade direcional) em caso de defeito no ABS.

10. O ABS deve agir de maneira apropriada em todas as rodas.

11. Defeito no ABS deve ser deve ser comunicado ao condutor.

12. A habilidade requerida para manutenção e conserto deve estar de acordo com as praticadas pela industria.

13. ABS não é um substituto para a má distribuição de forças de frenagem.

14. Proprietários de caminhões puxando reboques devem ser alertados do fato de que freios hidráulicos acionados eletricamente podem afetar 0 desempenho do ABS. Assim alteram-se os requisitos do fluido de freio.

Os requisitos acima só são plenamente alcançados com a instalação do ABS em todas as rodas.

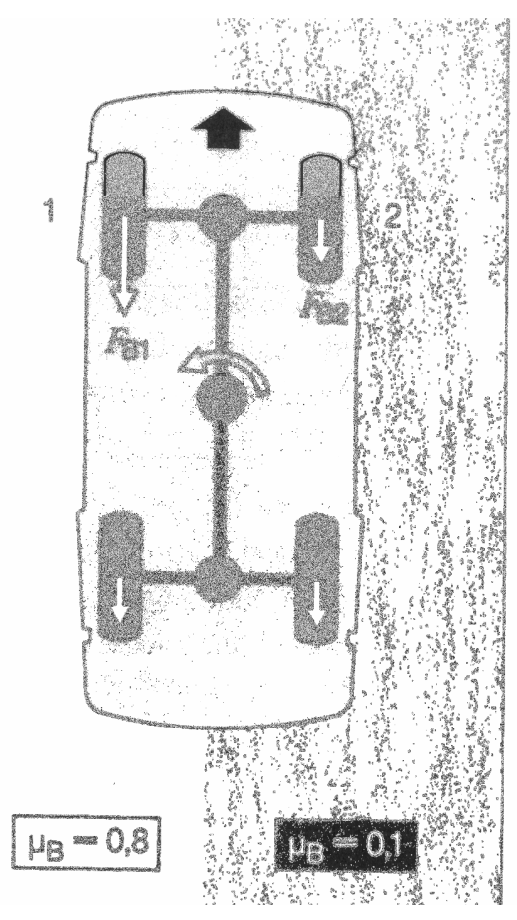

FIGURA 2.21-Momento de yaw devido a coeficientes de adesão diferentes; Limpert (1992)

Tendo em vista o funcionamento básico do ABS, Limpert(1992) mostra as seguintes estratégias de controle: 
- Single Wheel Control: O sensor de velocidade da roda controla os ajustes feitos na linha de pressão do freio para cada roda (independente das demais). É o método que resulta na força de frenagem máxima na roda. Em condições como a mostrada na Figura 2.21, a diferença das forças de frenagem causa um momento de yaw. Geralmente é usado no eixo dianteiro dos veículos automotores.

- Select-Low Control: A roda com menor aderência controla os freios de ambas as rodas do eixo. Como a aderência máxima em uma das rodas não é utilizada, faz com que o torque de frenagem seja menor que o ideal (e por conseqüência maior distância de parada). A vantagem dessa abordagem é um potencial maior para forças laterais e a ausência de momentos de yaw. Geralmente é usado nos eixos traseiros dos veículos.

- Select-High Control: A roda com maior aderência controla os freios de ambas as rodas do eixo. Isso Resulta numa maior força de frenagem mas, em contra partida, o desbalanço de forças da direita e da esquerda gera um momento de yaw e trava uma das rodas do eixo.Usado por alguns fabricantes no eixo dianteiro.

Spironelli (1999) mostra uma alternativa de controle de ABS que é baseado no controle do escorregamento da roda e não na aceleração angular.

Canale (1991) mostra a diferença da desaceleração de um veículo de quatro rodas onde cada roda é controlada independentemente (4 canais), com as rodas controladas duas a duas (2 canais) e sem ABS (Figura 2.22). 


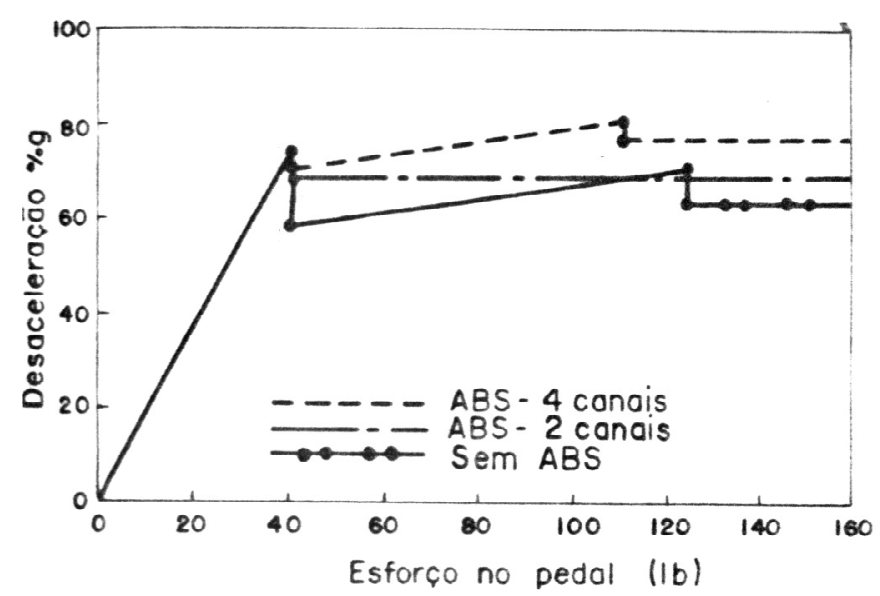

FIGURA 2.22 - Comparação da desaceleração com algumas estratégias de controle do ABS, Canale (1991).

Oppenheimer (1988) faz uma comparação da desaceleração de um veículo com o tipo de pavimento com e sem o uso do ABS em carros de passeio. Essa comparação é mostrada na Figura 2.23.

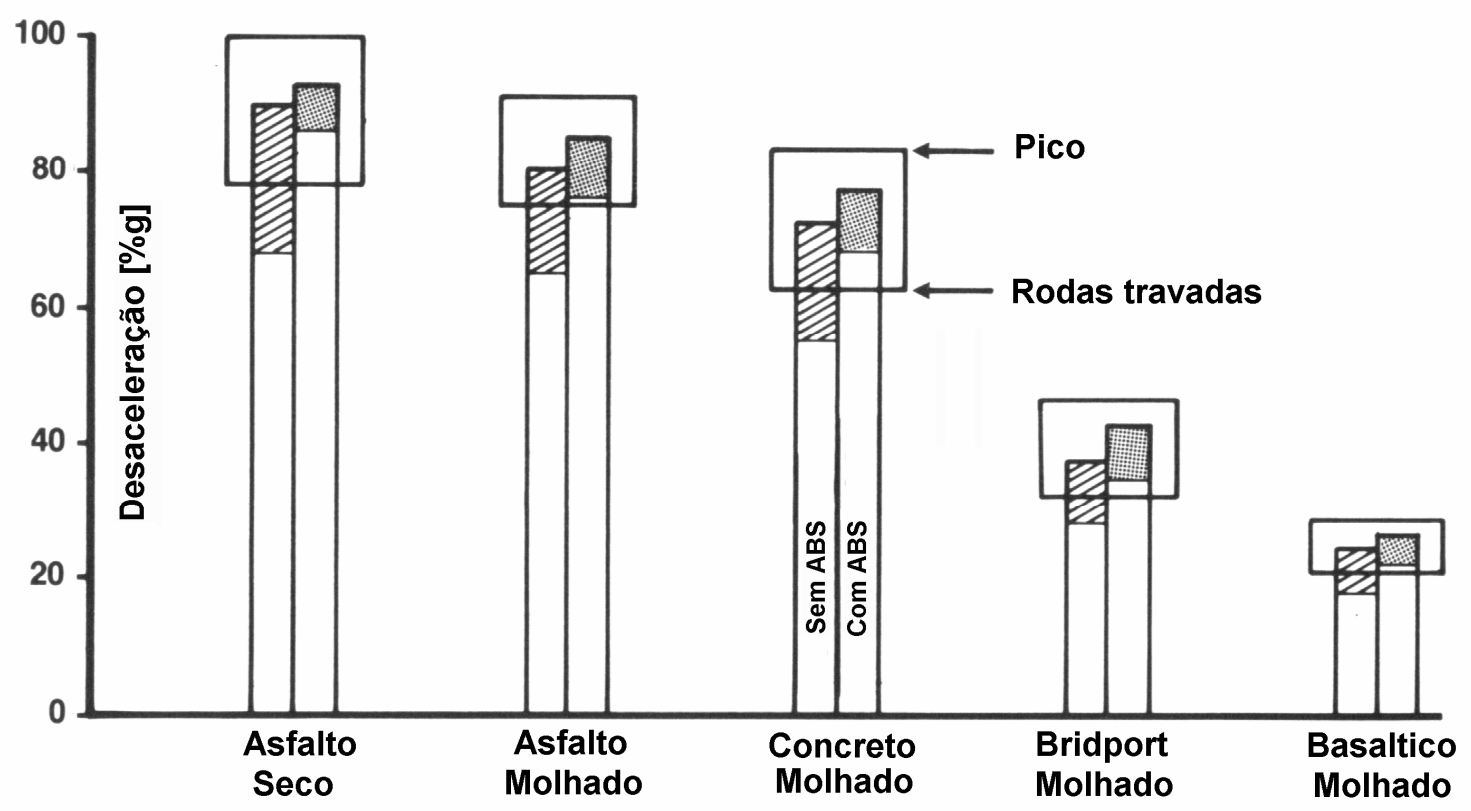

FIGURA 2.23 - Comparação da desaceleração com o tipo de pavimento, Oppenheimer (1988).

O ABS é um equipamento de segurança. Isso pode ser observado na Figura 2.24 que compara a eficiência da frenagem com a ocorrência de 
travamento das rodas. Esse travamento das rodas pode ser "traduzido" como probabilidade de acidente, uma vez que o travamento implica em perda de estabilidade. Como o ABS consegue aumentar a eficiência do sistema de freios, a probabilidade de acidentes diminui bastante. No entanto Limpert (1992) chama atenção do fato do ABS estar relacionado com alguns acidentes na Alemanha. Tais acidentes ocorriam pelo fato dos motoristas superestimarem a capacidade do sistema, dirigindo mais rápido e com menor distância em relação ao veículo da frente, principalmente em pistas escorregadias. Para completar, Evans e Gerrish (1996) realizaram um estudo com veículos de passeio que mostra que a probabilidade de um veículo se envolver em um acidente colidindo com o veículo que vai a sua frente diminui em $32 \pm 8 \%$ com o uso de ABS. Em contrapartida, a probabilidade de um veículo com ABS se envolver em um acidente em que é atingido na traseira por outro veículo que o segue aumenta em $30 \% \pm 14$. Fato que mostra que para se ter um ganho substancial de segurança toda a frota deveria ser equipada com algum dispositivo de antitravamento das rodas.

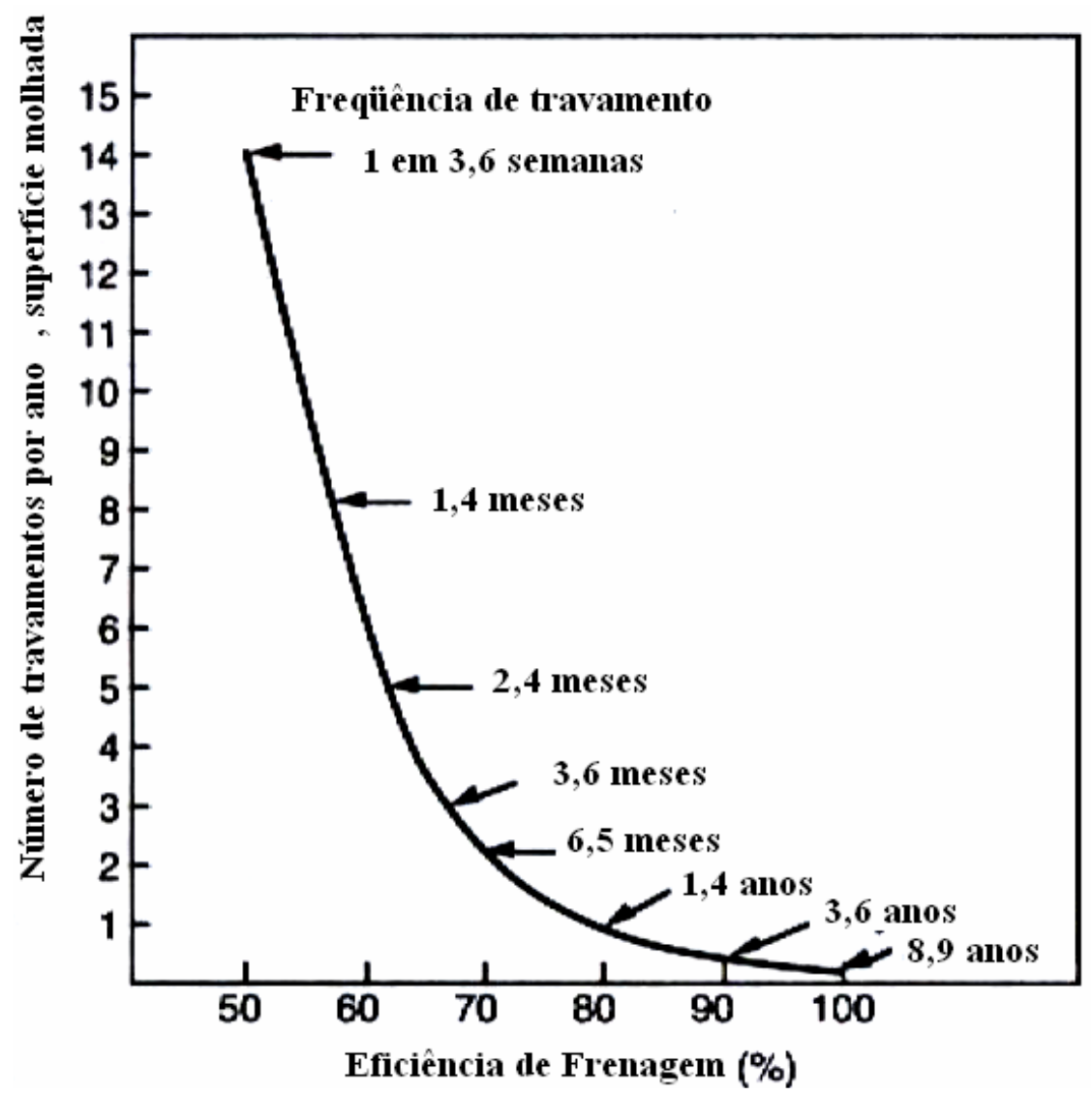

FIGURA 2.24 - Comparação da eficiência da frenagem com a probabilidade de travamento, Gillespie (1992). 
Por ser um equipamento caro o ABS não é muito comum no bi-trem ou mesmo em outros veículos comerciais brasileiros. No entanto o seu uso foi considerado neste estudo devido a sua eficácia aumentando a eficiência da frenagem como será mostrado no capítulo 3. Esse equipamento também começa a ser obrigatório em alguns países (tabela 1.1 do capítulo 1) e o Brasil deve seguir essa tendência mundial.

\subsection{Efeitos da temperatura na frenagem}

A frenagem é, principalmente, uma conversão de energia cinética e potencial em energia térmica através do atrito e é um fator importante no desempenho da frenagem. lombriller (2003) afirma que o superaquecimento dos freios pode trazer sérias conseqüências, reduzindo a segurança e aponta os seguintes problemas associados ao superaquecimento:

- Fade: é a perda de atrito entre o disco e a pastilha (ou lona e tambor) provocada pelo excessivo calor gerado durante a frenagem

- Distorções cônicas: são responsáveis pela redução do contato entre as partes atritantes que pode gerar instabilidade durante a frenagem

- Mudança no coeficiente de fricção: quando o limite térmico dos materiais que se atritam é ultrapassado, o desgaste aumenta e o comportamento é alterado, reduzindo o coeficiente de fricção e por conseqüência a eficiência da frenagem.

- Variação do fator de freio: de todas as variáveis que influenciam no fator de freio, a temperatura é a mais significativa, reduzindo 0 fator de freio que por sua vez reduz as forças de frenagem e torna o sistema menos eficiente. Uma variação do fator de freio é mostrada na Figura 2.25.

- Pontos de aquecimento no disco: altas temperaturas locais provocam pontos de aquecimento, ocasionando mudança no comportamento do metal. Esses pontos são mais duros que 0 resto da superfície devido às transformações metalúrgicas. 
- Trincas no disco: além dos pontos de aquecimento podem surgir manchas de aquecimento devido a grande taxa de trabalho aplicado no disco.

- Desgaste: quando altas temperaturas são atingidas durante a frenagem a forma do contato pastilha/disco ou lona/tambor é alterada causando desgaste não uniforme. Isso reduz a vida útil dos componentes e o freio ficará mais sensível e irregular.

Os pontos e manchas de aquecimento comentados acima são responsáveis por trincas nos discos em virtude do escoamento plástico do material da superfície, induzindo tensões após o resfriamento.

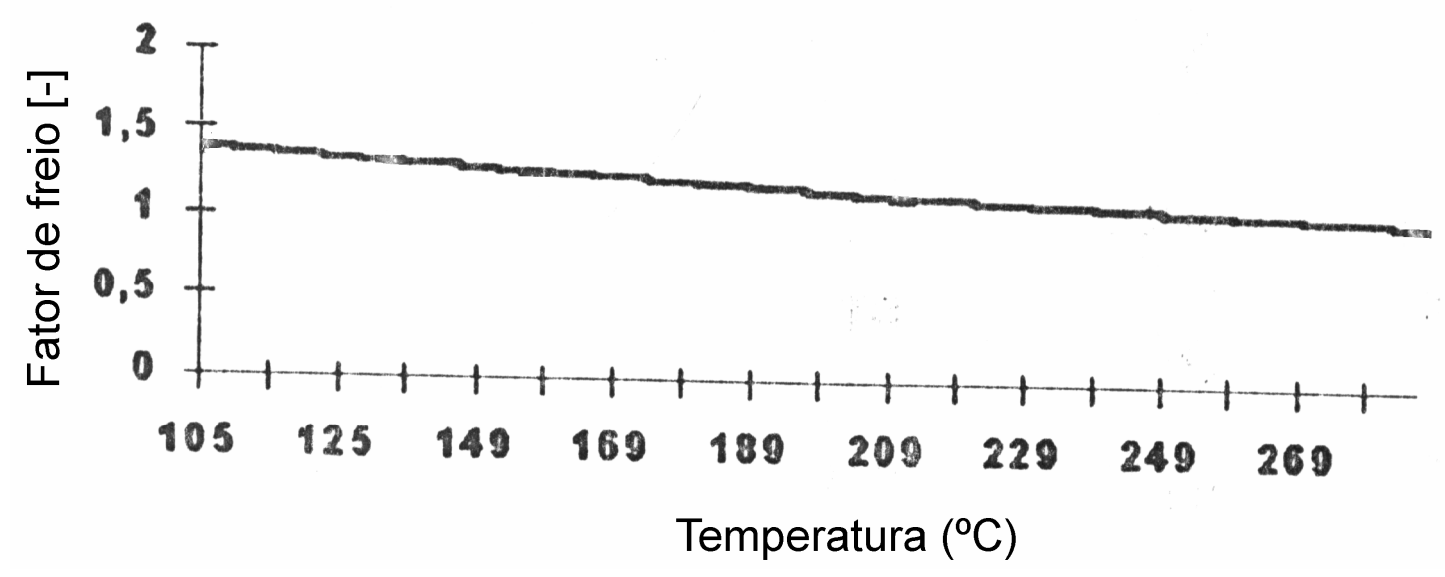

FIGURA 2.25 - Temperatura x Fator de Freio; Canale (1999).

O sistema de freio possui, principalmente, as seguintes funções:

1. Frenagem de emergência

2. Várias paradas repetidas (perímetro urbano)

3. Controle de velocidade em descida de serra

lombriller (1997) destaca a frenagem de emergência como o fator que determina as propriedades térmicas de todo o sistema. Isso ocorre porque uma quantidade de energia muito grande é liberada para o tambor (ou disco) e em um curto intervalo de tempo, fazendo com que praticamente não haja dissipação de calor para o ambiente. 


\subsection{Forças de resistência ao movimento}

Canale (1989) define as seguintes forças de resistência envolvidas no movimento de um veículo automotivo:

- Resistência ao rolamento

- Resistência devida à inclinação da pista

- Resistência do ar

- Resistência das forças de Inércia

- Resistência da transmissão

Algumas dessas forças de resistência têm grande influencia na frenagem. A resistência ao rolamento e a inércia são muito importantes no estudo da frenagem, principalmente no bi-trem, devido à sua grande capacidade de carga. Outras, como a resistência do ar, são pouco significativas devido à baixa velocidade média do movimento. Obviamente, a inclinação da pista surge apenas em aclives e declives. Um resumo dessas forças de resistência ao movimento é mostrado a seguir.

\subsubsection{Resistência ao Rolamento}

É uma das principais forças de resistência ao movimento do veículo. Ao contrário das demais forças de resistência que "aparecem" apenas em certas circunstâncias, a resistência ao rolamento esta presente no momento em que a roda começa a girar. A maior parte da energia gerada pela força de resistência ao rolamento vai para o pneu em forma de calor. Essa perda de energia é "traduzida" como uma força que age no pneu contrária ao movimento do veículo. Uma conseqüência da elevação acentuada da temperatura devido a essa energia é a redução da resistência a abrasão e à fadiga da borracha da banda de rodagem, diminuindo a vida útil do pneu. Gillespie (1992) indica os seguintes fatores como os principais responsáveis pela resistência ao rolamento.

- Energia perdida pela deformação do pneumático

- Escorregamento parcial no contato 
- Escorregamento do pneu

- Deformação da pista

- Arrasto aerodinâmico dentro e fora do pneu

- Perda de energia em impactos

Canale (1989) mostra a seguinte equação para o cálculo da resistência ao rolamento (de acordo com a Figura 2.26):

$$
R_{r}=R_{r f}+R_{r r}=f \cdot W \cdot \cos \theta
$$

Sendo:

$$
\begin{aligned}
& R_{r}=\text { força de resistência ao rolamento } \\
& R_{r f}=\text { força de resistência ao rolamento do eixo }
\end{aligned}
$$
dianteiro

$R_{\mathrm{rf}}=$ força de resistência ao rolamento do eixo traseiro

$\mathrm{f}=$ coeficiente de resistencia ao movimento

$\mathrm{W}=$ peso do veículo

$\theta=$ inclinação da pista

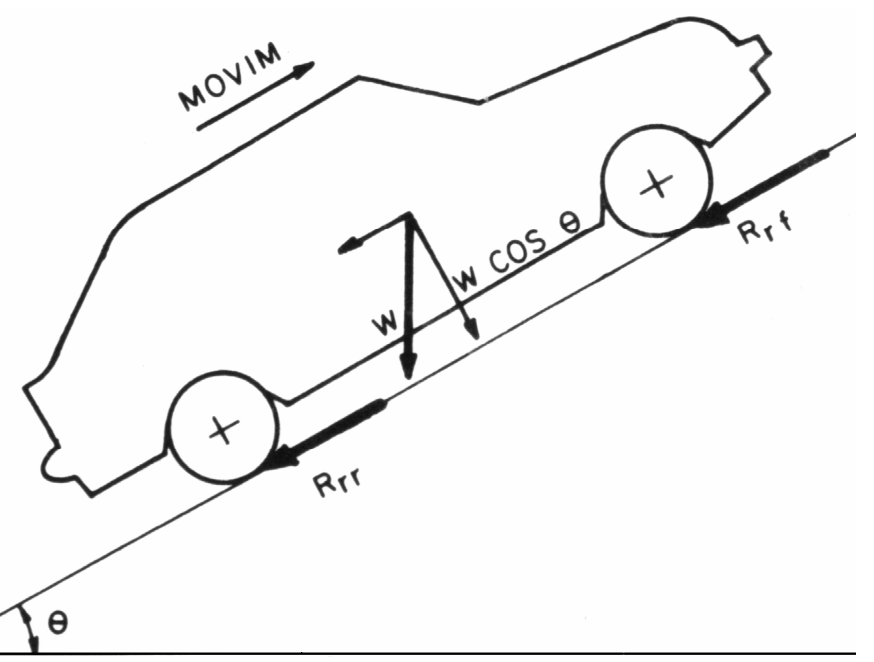

FIGURA 2.26 - Forças de resistência ao rolamento; Canale (1989).

O fator "f" é chamado de coeficiente de resistência ao rolamento. Os fatores que influenciam em "f" são:

- Temperatura do pneu: o fator "f" diminui com o aumento da temperatura 
- Pressão interna do pneu: depende do tipo de pavimento. Em superfícies macias, como areia, o aumento da pressão implica em aumento do coeficiente "f". Em superfícies duras, como concreto, o aumento da pressão resulta em diminuição de "f".

- Velocidade: o coeficiente " $\mathrm{f}$ " é aumenta significativamente com o aumento da velocidade

- Material : tanto o material da banda de rodagem quanto da lateral do pneu influenciam no coeficiente de resistência ao rolamento.

- Diâmetro do pneu: "f" diminui com o aumento do diâmetro. Principalmente em solos moles

- Força longitudinal: quanto maior a força (de tração ou frenagem) maior o coeficiente " $\mathrm{f}$ "

- Carga radial: "f" é diretamente proporcional à carga radial.

\subsubsection{Resistência devida à inclinação da pista}

A inclinação da pista pode influenciar tanto negativa (em descida de serra) como positivamente (em subida) na frenagem. $A$ força $R_{g}$ que age no direção do movimento é calculada da seguinte maneira:

$$
R_{g}=W \cdot \operatorname{sen} \theta
$$

Sendo:

$$
\begin{aligned}
& R_{g}=\text { resistência devido à inclinação } \\
& W=\text { peso do veículo } \\
& \theta=\text { inclinação da pista }
\end{aligned}
$$

\subsubsection{Resistência do ar}

As forças aerodinâmicas interagem com o veículo causando não só arrasto (força de resistência) como também força de sustentação ou compressão ("down force"), momentos de "yaw", "pitch"e "roll".

Como o fluxo de ar sobre um corpo é muito complexo surgiu a necessidade do desenvolvimento de modelos semi-empíricos para representar 
o fenômeno. Gillespie (1992) mostra a seguinte equação para o calculo da força de arrasto:

$$
\begin{aligned}
D_{A}=\frac{\rho \cdot V^{2} \cdot C_{D} \cdot A}{2} & \\
\text { Sendo: } \quad \mathrm{D}_{\mathrm{A}}=\text { força de arrasto aerodinâmico } & {[\mathrm{N}] } \\
\rho & =\text { densidade do fluido (ar) } \\
\mathrm{V} & =\text { velocidade relativa veicula/fluido } \\
\mathrm{C}_{\mathrm{D}} & =\text { coeficiente de arrasto aerodinâmico } \\
\mathrm{A} & =\text { área frontal do veículo }
\end{aligned}
$$

O coeficiente de arrasto aerodinâmico, $C_{D}$, depende da forma do corpo que está exposto ao fluxo de ar. A Figura 2.27 mostra algumas formas e seus respectivos valores de $C_{D}$.
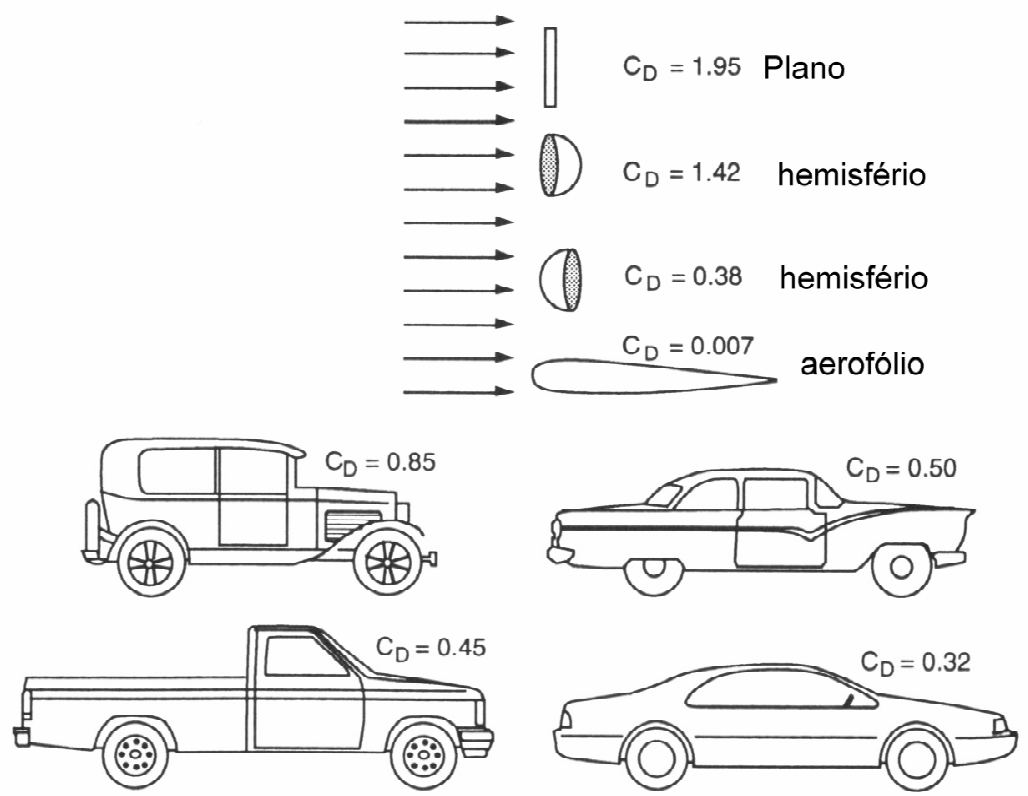

FIGURA 2.27 - Arrasto aerodinâmico; Gillespie (1992)

\subsubsection{Resistência das forças de inércia}

O movimento de translação de um veículo também implica no movimento de rotação do sistema de geração e transmissão de torque. Como para aplicar uma aceleração (ou desaceleração) a um veículo é necessário 
também acelerar (ou desacelerar) a massa em rotação do "drivetrain". Canale (1989) define um fator $\gamma_{b}$ que multiplicado pela massa do veículo inclui na mesma os efeitos das massas rotativas.

$$
\gamma_{b}=1+\frac{1}{m} \cdot \frac{\sum I \cdot \xi^{2}}{r^{2}}
$$

$$
\text { Sendo: } \quad \begin{array}{ll}
\gamma_{b} & =\text { coeficiente das inércias rolantes } \\
& m=\text { massa do veículo } \\
& \mathrm{I}=\text { momento de inércia da massa rolante } \\
& r=\text { raio da massa rolante } \\
& \xi=\text { relação de transmissão até a roda }
\end{array}
$$

\subsubsection{Resistência da transmissão}

A resistência da transmissão representa a parcela da potência perdida no processo de transmissão do torque do motor para as rodas.Geralmente é dada como uma eficiência " $\eta$ " do sistema que é medida experimentalmente ou estimada matematicamente.

\subsection{Dinâmica da frenagem}

De acordo com Gillespie (1992) a dinâmica da frenagem pode ser simplificada concentrando toda a massa do veículo no centro de gravidade. Dessa forma a equação para o cálculo da frenagem é obtida da segunda lei de Newton. Gillespie (1992) mostra a seguinte equação de frenagem para um veículo de dois eixos:

$$
\begin{aligned}
M \cdot a_{x}=-\frac{W}{g} D_{x}= & -F_{x f}-F_{x r}-D_{A}-W \cdot \operatorname{sen} \theta \\
\text { Sendo: } \quad \mathrm{M} & =\text { massa do veículo } \\
\mathrm{a}_{\mathrm{x}} & =\text { aceleração na direção " } \mathrm{x} \text { " } \\
\mathrm{W} & =\text { peso do veículo } \\
\mathrm{g} & =\text { aceleração da gravidade }
\end{aligned}
$$




$$
\begin{array}{lr}
D_{x}=\text { aceleração na direção } x & {\left[\mathrm{~m} / \mathrm{s}^{2}\right]} \\
F_{x f}=\text { forças no eixo dianteiro na direção } x & {[\mathrm{~N}]} \\
F_{x r}=\text { forcas no eixo traseiro na direção } x & {[N]} \\
D_{A}=\text { arrasto aerodinâmico } & {[N]} \\
\theta=\text { inclinação da pista } & {\left[{ }^{\circ}\right]}
\end{array}
$$

Limpert (1992) faz uma análise da distância de parada. Essa análise é mostrada na Figura 2.28 e explicada a seguir.

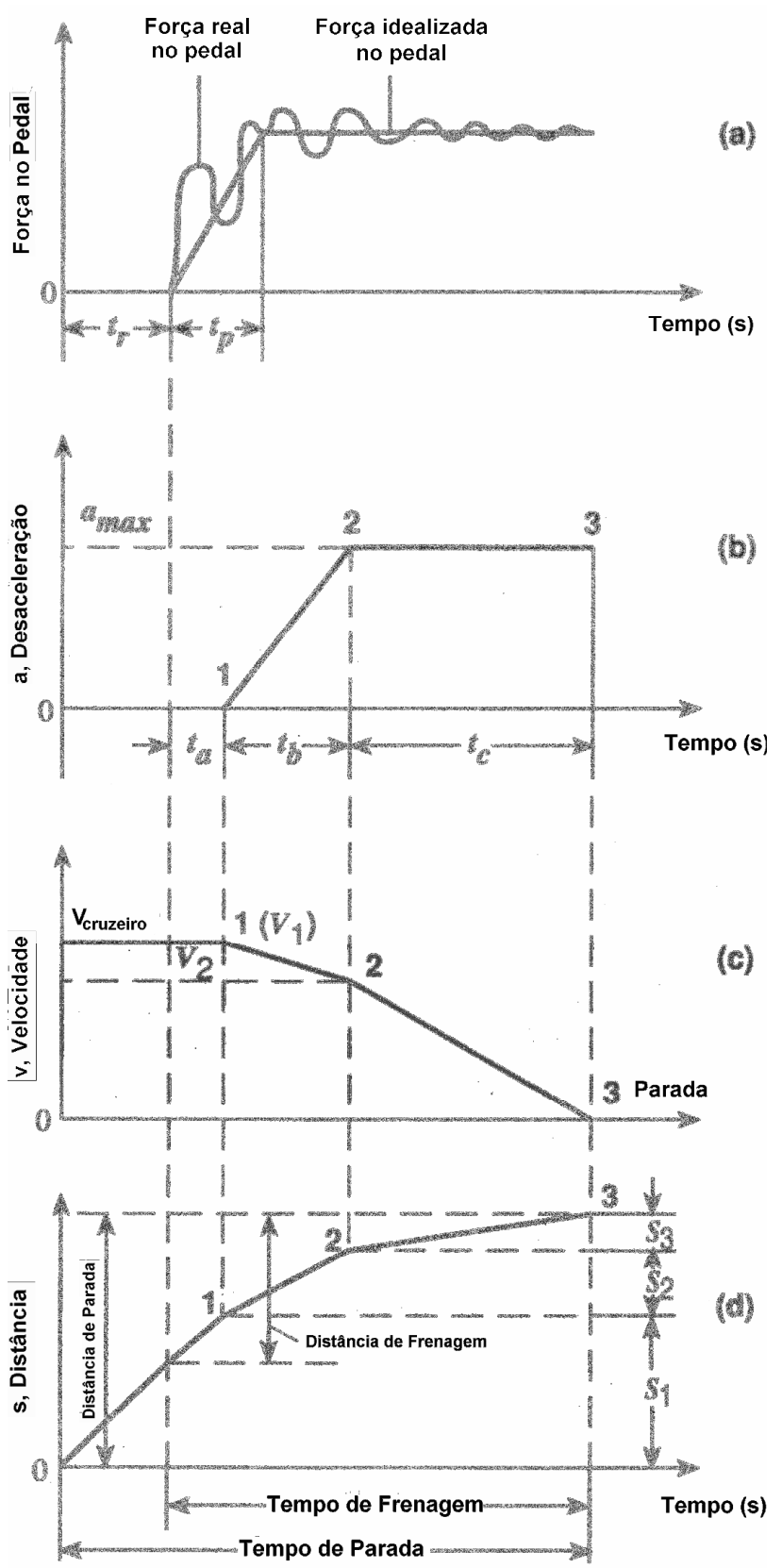

FIGURA 2.28 - Análise da distância de parada; Limpert(1992). 
A força idealizada no pedal é mostrada na Figura 2.28(a). No tempo zero o motorista reconhece a situação de perigo. Após o tempo de reação, $t_{r}, 0$ motorista começa a aplicar força no pedal de freio. Assim que o tempo de reação do sistema de freios, $t_{a}$, passa, as lonas entram em contato com $o$ tambor e o veiculo começa a desacelerar. Claro que o crescimento linear da força de frenagem linear é apenas uma aproximação. Em situações críticas, motoristas menos habilidosos tendem a reduzir a força que aplicam no pedal depois de 0,1 ou 0,2 segundo após o início da frenagem numa tentativa de regular o processo de frenagem. E quando obstáculo se aproxima, o motorista pressiona mais o pedal e a força aumenta novamente. Motoristas habilidosos geralmente aplicam forças mais próximas da idealização.

De acordo com a força idealizada, o gráfico de desaceleração é mostrado na Figura 2.28(b). A desaceleração começa a aumentar linearmente a partir do ponto 1, quando o torque de frenagem começa a se desenvolver, até atingir o ponto 2 (ou porque a força no pedal é constante ou porque todas as rodas travaram ).

A variação da velocidade no tempo é mostrada na Figura 2.28 (c). Antes de qualquer desaceleração ser aplicada, a velocidade se mantém constante (velocidade de cruzeiro). Mas isso só ocorre se as forças que retardam o veículo, tais como freio motor, retardadores, arrasto aerodinâmico ou a gravidade em um aclive, puderem ser desconsideradas. Segundo Limpert (1992) o erro por usar uma desaceleração linear ao invés de um bi-linear é de 0,5 a $1 \%$. A região entre os pontos 1 e 2 é curva, devido à variação da aceleração. A região entre os pontos 2 e 3 é linear pois é quando a aceleração está no seu ponto máximo. O veículo pára no ponto 3 .

A distância total de parada é a soma das distâncias individuais $\left(\mathrm{S}_{1}, \mathrm{~S}_{2}, \mathrm{~S}_{3}\right)$ associadas com cada intervalo de tempo, ou seja, do começo da reação até o inicio da desaceleração (associado a $S_{1}$ ), o tempo de aumento da desaceleração (associado a $S_{2}$ ) e o tempo de desaceleração constante até que o veículo pare (associado a $S_{3}$ ). Limpert (1992) demonstra que a distância de parada total é dada por: 


$$
S_{T}=S_{1}+S_{2}+S_{3}=V_{1} \cdot\left(t_{r}+t_{a}+t_{b} / 2\right)+\frac{V_{1}^{2}}{2 \cdot a_{\max }}-\frac{a_{\max } \cdot t_{b}^{2}}{24}
$$

Sendo: $\quad S_{1}=$ Distância percorrida durante momento o tempo de reação do motorista e do sistema de freios

$\mathrm{S}_{2}=$ Distância percorrida durante 0 aumento da desaceleração

$\mathrm{S}_{3}=$ Distancia percorrida durante a desaceleração máxima

$t_{r}=$ Tempo de reação do motorista

$t_{a}=$ Tempo de reação do sistema de freios

$t_{b}=$ Tempo para a pressão no circuito de freio atingir $90 \%$ da pressão máxima

$\mathrm{V}_{1}=$ Velocidade inicial do veículo

$\mathrm{a}_{\max }=$ desaceleração máxima desenvolvida pelo veículo

\subsubsection{Tempo de reação do motorista $\left(t_{r}\right)$}

O tempo de reação do motorista exerce grande influencia na distância de parada de um veículo. Limpert (1992) divide a reação do motorista em quatro partes:

- Percepção

- Julgamento

- Início da reação

- Execução da reação

Em geral, um objeto ou uma situação de perigo aparece primeiro na visão periférica do motorista.A reação humana começa apenas quando os olhos do motorista focam o objeto (a aparição do objeto na visão periférica do motorista não é o início do tempo de reação). Os motoristas utilizam atenção 
distribuída enquanto dirigem para examinar toda a cena. A ação de controle só é tomada quando a visão muda para concentrada e o perigo é focado.

Antes de focar, os olhos precisam se mover. O tempo necessário para que um objeto que esta na visão periférica do motorista seja focado varia de 0,32 a 0,55 segundo.

A reação do motorista continua e o próximo passo é quando o motorista foca o objeto e começa a tirar o pé do acelerador. Esse tempo esta entre 0,22 e 0,58 segundo.

O tempo para o motorista tirar o pé do acelerador e pisar no freio é de 0,15 a 0,21 segundo.

Todos os tempos acima foram retirados de Limpert (1992).

Alguns fatores que contribuem para a alteração do tempo de reação do motorista foram apresentados por Brossi (2002). Esses fatores são ergonomia, visibilidade, condições físicas e psicológicas do motorista. Outra variável importante é o consumo de bebidas alcoólicas por parte do motorista. Estimase que o álcool acrescenta de 0,5 a 2 segundos no tempo de reação do motorista. Mesmo em pequenas doses.

\subsubsection{Tempo de resposta do sistema de freios $\left(t_{a}+t_{b}\right)$}

Brossi (2002) define o tempo de reação do motorista como o tempo decorrido do instante em que o pedal de freio é acionado até o instante da plena atuação do sistema de freio.

Segundo Limpert (1992), freios a ar possuem um tempo significativamente longo de resposta e elevadas perdas de pressão. Esse tempo pode ser reduzido com o adequado projeto do sistema.

A Figura 2.29 apresenta uma curva típica do tempo de resposta do sistema de freios. Limpert (1992) define os tempos $t_{1}, t_{2}$ e $t_{2}$ (além de oferecer equações de como calculá-los) da seguinte maneira:

$O$ tempo $t_{1}$ representa a velocidade com a qual a onda de pressão "viaja" pela linha do sistema de freios. Indica o tempo decorrido para um sinal de pressão "viajar" da válvula de aplicação até o cilindro. 
O tempo $t_{2}$ é o necessário para que as folgas entre as lonas e o tambor sejam vencidas. É proporcional ao volume que o cilindro deve deslocar para pressionar as lonas contra os tambores.

Já o tempo $t_{3}$ consiste no tempo necessário para que a pressão na linha do sistema de freios atinja o valor máximo especificado e atue plenamente (normalmente $90 \%$ da pressão de reservatório).

Dessa forma o tempo de aplicação do sistema de freios é a soma desses três tempos.

$$
t_{\text {total }}=t_{1}+t_{2}+t_{3}
$$

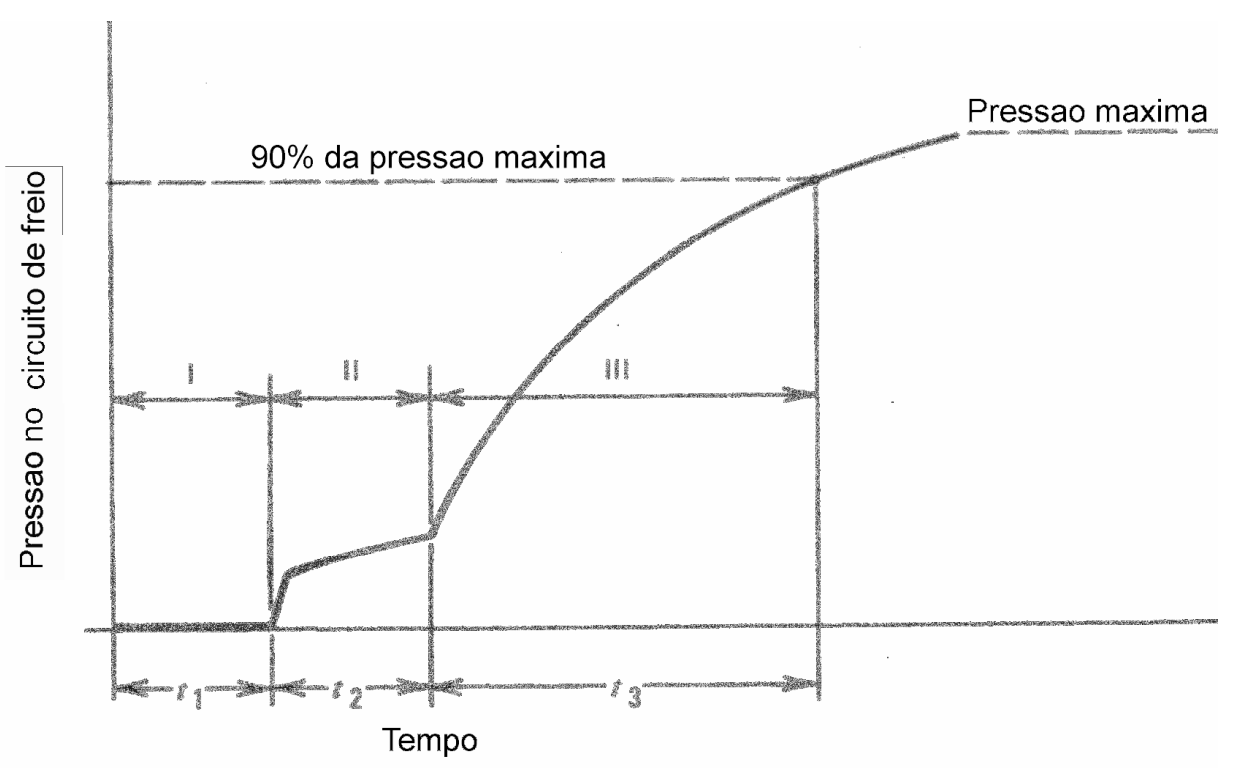

FIGURA 2.29 - Aumento da pressão em freios pneumáticos; Limpert (1992).

Estudos indicam que o aumento da pressão e a diminuição do curso do cilindro de freio reduzem o tempo necessário para vencer as folgas entre a lona e o tambor. O tempo necessário para a acomodação do torque de frenagem diminui com o aumento da pressão no sistema de freios, com o aumento da pressão do reservatório, e a diminuição do comprimento da tubulação e do curso do cilindro de freio. Como o tempo de acúmulo de pressão no circuito de freio é fortemente influenciado pelo comprimento da tubulação, os reservatórios de ar comprimido são colocados próximos aos seus respectivos cilindros de freio. 
O tempo de resposta para freios hidráulicos varia de 0,03 a 0,06 segundo, segundo Limpert (1992).

A formulação apresentada acima para o cálculo do espaço e tempo de parada foram utilizadas neste trabalho para estimar esses fatores na frenagem de emergência de um bi-trem.

\subsection{A suspensão em "tandem"}

A suspensão em "tandem" é a mais comum nos veículos de carga brasileiros, inclusive no bi-trem. As razões de serem tão comuns são explicadas a seguir.

Suspensão em "tandem" são combinações de dois eixos. Fitch (1994) enumera as seguintes vantagens dos "tandem":

1. Maiores cargas dentro da lei

2. Maior tração (quando os eixos são tracionados)

3. Maior "flotation"

4. Melhor frenagem

5. Melhor distribuição de carga

6. Redução dos choques na rodovia

A Figura 2.30 mostra o impacto sobre o pavimento de um veículo de seis rodas $\left(2 \mathrm{lb} / \mathrm{in}^{2}\right)$ e de quatro rodas $\left(6,5 \mathrm{lb} / \mathrm{in}^{2}\right)$ de eixos simples.

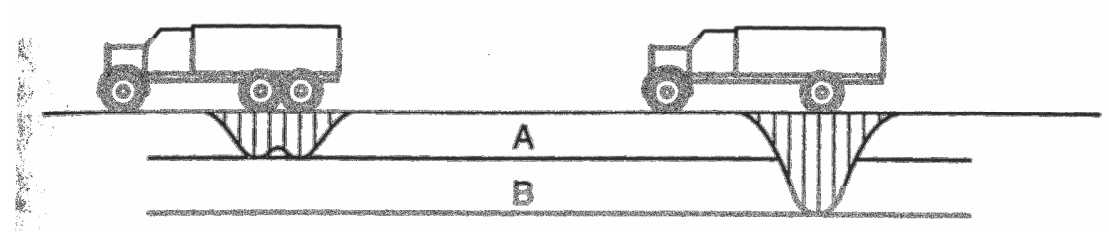

FIGURA 2.30 - Distribuição da pressão no solo para veículos com 6 e 4 rodas; Fitch (1994).

Limpert (1992) apresenta o seguinte esquema para suspenção em "tandem" com molas helicoidais (Figura 2.31). O equacionamento da mesma é mostrado em seqüência. 


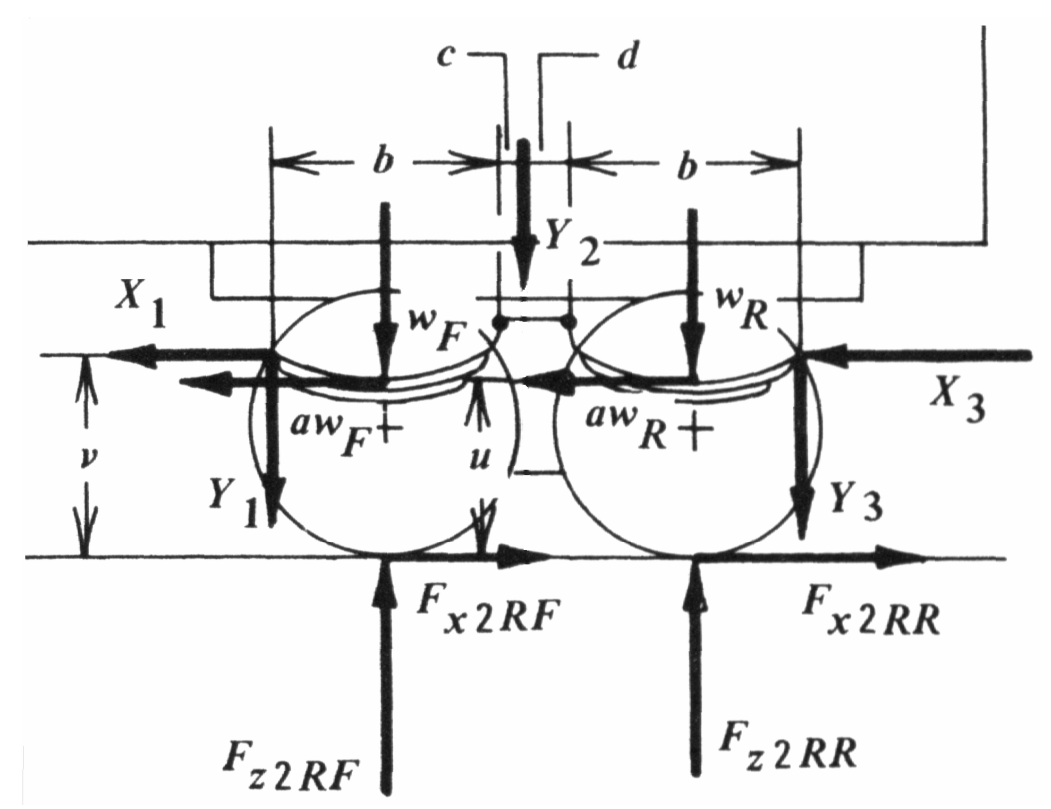

FIGURA 2.31 - Forças agindo numa suspensão em "tandem”; Limpert (1992).

Para o eixo dianteiro temos:

$$
\begin{aligned}
& X_{1}=F_{x 2 R F}+w_{F} a=0 \\
& F_{z 2 R F}=Y_{1}-\frac{Y_{2} \cdot d}{c+d}-w_{F}=0 \\
& X_{1} v+\left[Y_{1}-\frac{Y_{2} d}{c+d}\right] b / 2+a w_{F} u=0
\end{aligned}
$$

Sendo : $\quad X_{1}=$ Força na direção $x$ aplicada no ponto "1"

$\mathrm{Y}_{1}$ - Força na direção y aplicada no ponto "1"

$\mathrm{Y}_{2}$ - Força na direção y aplicada no ponto "2"

b = Dimensão da suspensão

c = Dimensão da suspensão

$\mathrm{d}$ = Dimensão da suspensão

$\mathrm{u}=$ Dimensão da suspensão

v = Dimensão da suspensão

$\mathrm{a}=$ aceleração do veículo

$\mathrm{W}_{\mathrm{F}}=$ Peso da massa não suspensa do eixo dianteiro do "tandem" 
Nesta também foi calculado o momento em torno do ponto 1.

Para o eixo traseiro:

$$
\begin{aligned}
& X_{3}-F_{x 2 R R}+a w_{R}=0 \\
& F_{z 2 R R}-Y_{3}-\frac{Y_{2} \cdot c}{c+d}-w_{R}=0 \\
& X_{3} v+\left[\frac{Y_{2} c}{c+d}-Y_{3}\right] b / 2+a w_{R} u=0 \\
& \text { Sendo: } \quad X_{3}=\text { Força na direção } x \text { aplicada no ponto "3" } \\
& \mathrm{Y}_{2}=\text { Força na direção y aplicada no ponto "2" } \\
& \mathrm{Y}_{3}=\text { Força na direção y aplicada no ponto "3" } \\
& \text { b = Dimensão da suspensão } \\
& \text { C = Dimensão da suspensão } \\
& \mathrm{d} \text { = Dimensão da suspensão } \\
& \mathrm{u}=\text { Dimensão da suspensão } \\
& \mathrm{v}=\text { Dimensão da suspensão } \\
& \text { a = aceleração do veículo }
\end{aligned}
$$

E também o momento em torno do ponto 3

Limpert (1992) resolveu as equações de frenagem para uma conFiguração cavalo (2 eixos)/ semi-reboque (eixo em tandem). O resultado é mostrado na Figura 2.32. Como se pode notar, a carga dinâmica do eixo frontal do "tandem" diminui com o aumento da desaceleração. 




FIGURA 2.32 - Carga dinâmica de eixo "tandem" em função da desaceleração; Limpert(1992)

Com base na teoria resumida exibida ao longo deste capítulo, um modelo matemático foi desenvolvido para o estudo da frenagem em regime permanente do bi-trem. A metodologia desenvolvida é apresentada no capítulo a seguir e os resultados obtidos com a planilha decorrente do modelo matemático são apresentados no capítulo 4. 


\section{METODOLOGIA}

Neste capítulo a metodologia desenvolvida para o estudo da frenagem em regime permanente de um bi-trem é apresentada. A metodologia foi aplicada em um veículo exemplo cujas características são mostradas no capítulo 4. O veículo exemplo possui freio a tambor em todos os eixos e suspensão em "tandem" metálica no eixo traseiro do cavalo mecânico e nos eixos dos semi-reboques. O sistema de freios adotado é o freio a ar acionado por came "s" e apresenta também uma alavanca ajustadora de folga automática. A utilização do ABS é das válvulas sensíveis a carga também são consideradas no modelo.

Para simular computacionalmente o comportamento de um corpo é preciso desenvolver um modelo matemático que represente o mesmo. Como geralmente é muito difícil representar matematicamente um sistema tal qual este é na realidade, algumas hipóteses que simplificam o problema e que não alteram significativamente o resultado final são adotadas.

Como o bi-trem é muito parecido com o veículo estudado por Brossi (2002), o ônibus biarticulado, a maioria das hipóteses adotadas em seu trabalho também será utilizada aqui (salvo onde indicado o contrário).

Como a parte transitória do movimento de um veículo em frenagem de emergência é muito pequena, os cálculos para a simulação serão realizados apenas na frenagem em regime permanente.

De acordo com Gillespie (1992), durante a frenagem, o veículo inteiro é desacelerado, e ele pode ser representado como um ponto material com toda a sua massa (inclusive a não suspensa) concentrada no centro de gravidade.

O tempo de resposta do sistema de freios (incluindo aqui o tempo de reação dos componentes do sistema de freio) foi considerado para o cálculo da 
distância de parada. Mas diferentemente do que foi feito por Brossi (2002), o tempo de resposta do motorista também foi considerado.

O veículo encontra-se em movimento retilíneo durante a frenagem (frenagens em trajetórias curvilíneas não serão simuladas). Além disso, o movimento é no plano (pista plana) que é a condição na qual o veículo é testado para frenagens de emergência.

A força de arrasto aerodinâmica não foi considerada, pois, segundo Limpert (1992), a sua contribuição é desprezível em frenagens de emergência.

A força de resistência devido às inércias rotativas não foi considerada (o fator $\gamma_{b}$ foi considerado igual a 1 ) pois a inércia do veículo é muito grande comparada às das massas rotativas. De qualquer forma, $\gamma_{b}$ é uma das entradas da planilha de cálculo desenvolvida e poderá ser considerada em outros estudos.

A força proveniente do freio motor não é considerada, pois a sua participação em frenagem de emergência é pequena. As simulações são feitas considerando o veículo desengatado.

Como as forças normais ao solo nos eixos são muito elevadas, a força de resistência ao rolamento foi considerada. Ela é proporcional às forças normais ao solo, conforme dito na secção 2.6.1.

As deformações dinâmicas que ocorrem no pneumático não são consideradas. Dessa forma o raio dinâmico do pneu é constante durante todo o processo de frenagem.

As forças de inércia são consideradas, juntamente como o peso, e são concentradas no CG do veículo. O contato do pneu com o pavimento também é considerado pontual e nesse ponto atuam as forças de frenagem e de resistência ao rolamento. As forças aplicadas na quinta roda do cavalo mecânico e do semi-reboque são consideradas pontuais também.

Segundo Gillespie (1992) o aumento da carga vertical no pneumático diminuí o coeficiente de adesão (tanto o de pico como o coeficiente de escorregamento) como mostrado na Figura 3.1. Geralmente esses coeficientes reduzem em 0,01 para um aumento de 10\% da carga vertical. Esse efeito, como fez Brossi (2002), não será considerado. O coeficiente de adesão máximo será considerado constante durante a frenagem. 


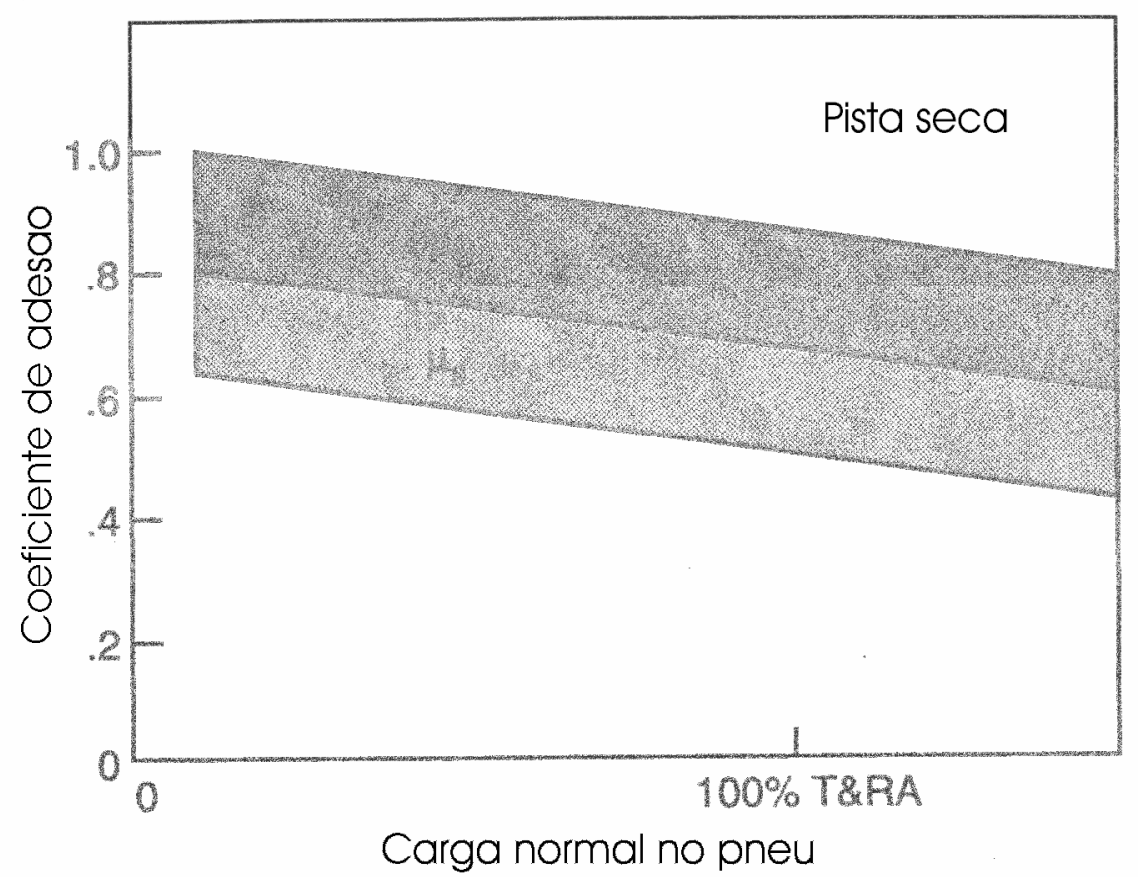

FIGURA 3.1 - Variação do coeficiente de adesão com a carga normal; Gillespie (1992).

A transição do coeficiente de adesão de pico para o coeficiente de adesão de escorregamento é considerada descontinua.

Como foi mostrado na Figura 2.20 o ABS mantém o coeficiente de adesão utilizado pelo pneumático variando em torno do pico de aderência fazendo com que o veículo freie com um coeficiente de adesão médio. Neste trabalho considera-se que o ABS mantém as rodas exatamente no pico de aderência.

A norma de freios exige que o eixo dianteiro do cavalo seja acionado por último para diminuir o risco de perda de estabilidade. Neste trabalho esse fato não é considerado e todos os eixos freiam ao mesmo tempo.

\subsection{Modelo do sistema de freios}

O modelo do sistema de geração de forças de frenagem é semelhante ao utilizado por Brossi (2002). O desenvolvimento das equações é mostrado a seguir, de acordo com a Figura 3.2. 


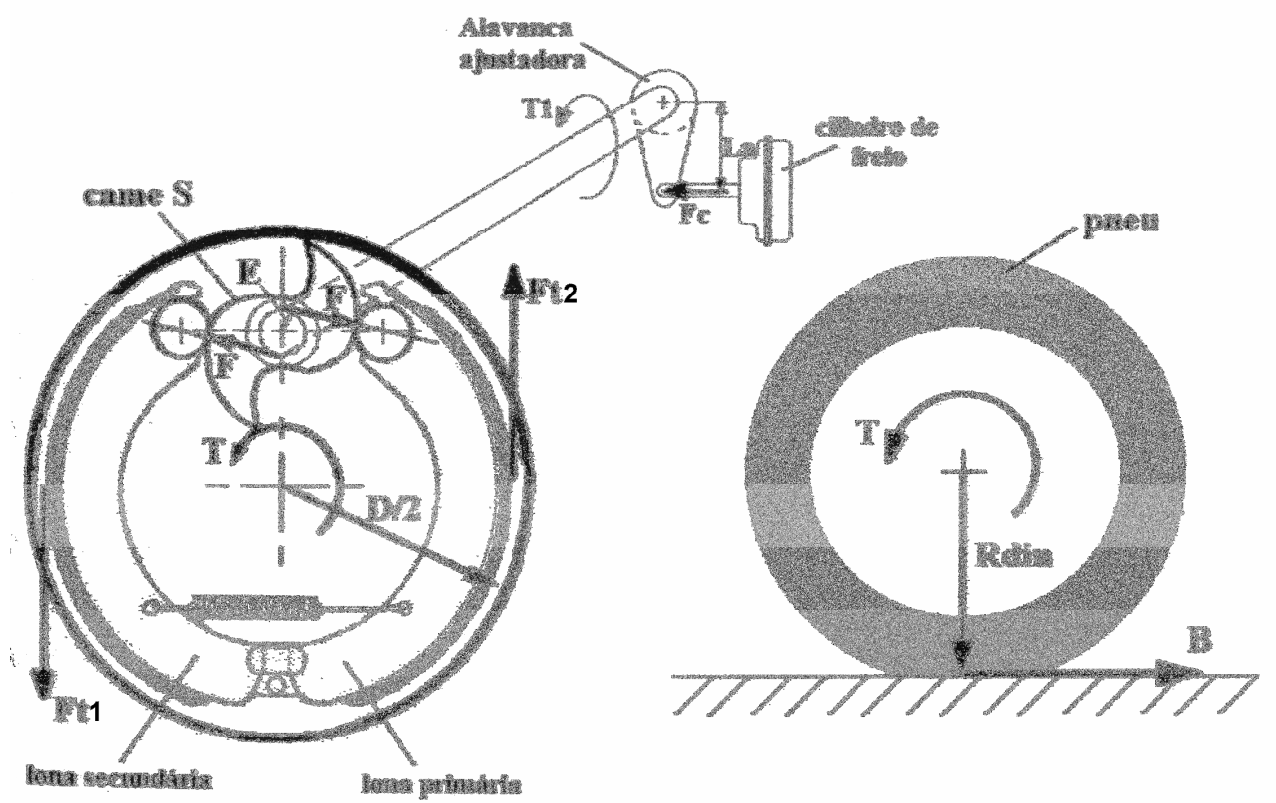

a)

b)

FIGURA 3.2 - Esquema da geração das forças de frenagem; Brossi (2002).

As forças de frenagem são geradas da seguinte maneira: o cilindro de freio empurra a alavanca ajustadora, provocando um torque $T_{1}$.

$$
T_{1}=F_{c} L_{a}=A \cdot P \cdot L_{a}
$$

Sendo:

$\mathrm{T}_{1}$ - torque aplicado no came " $\mathrm{s}$ "

[N.m]

$\mathrm{L}_{\mathrm{a}}$ - comprimento da alavanca ajustadora [m, mm ou in]

A - Área do cilindro de freio $\left[\mathrm{m}^{2}, \mathrm{~mm}^{2}\right.$, ou in $\left.{ }^{2}\right]$

$P$ - pressão que chega ao cilindro de freio $\left[\mathrm{N} / \mathrm{m}^{2}\right.$ ou bar]

$\mathrm{O}$ torque $T_{1}$ é aplicado às lonas através do came $\mathrm{s}$ (por meio da força $\mathrm{F}$ e do raio $E)$, ou seja:

$$
T_{1}=F \cdot E+F \cdot E
$$

Sendo:

$$
\begin{aligned}
& \mathrm{E}-\quad \text { raio do came "s" } \\
& \mathrm{F}-\quad \text { força que o came "s" exerce na lona }
\end{aligned}
$$

Substituindo (3.2) em (3.1)

$$
F_{c} L_{a}=2 F \cdot E \rightarrow F=\frac{A \cdot P \cdot L_{a}}{2 E}
$$


De acordo com Gillespie (1992), o fator de freio de um freio a tambor em que tanto a lona primária quanto a secundária são pivotadas é dado pela soma do fator de freio de cada lona assim:

$$
K=\frac{F_{t 1}}{F}+\frac{F_{t 2}}{F} \Rightarrow F=\frac{F_{t 1}+F_{t 2}}{K}
$$

Sendo:

$$
\begin{aligned}
& K-\text { fator de freio } \\
& F_{t 1}-\text { força que a lona primária faz no tambor } \\
& F_{t 2}-\text { força que a lona secundária faz no tambor }
\end{aligned}
$$

E substituindo (3.4) em (3.3)

$$
F_{t 1}+F_{t 2}=\frac{K \cdot A \cdot P \cdot L_{a}}{2 E}
$$

Então o torque produzido pelo tambor na roda vem da seguinte equação:

$$
T=F_{t} \frac{D}{2}+F_{t} \frac{D}{2} \Rightarrow T=\left(F_{t 1}+F_{t 2}\right) \frac{D}{2}
$$

Sendo:

$$
\begin{aligned}
& \text { T - torque de frenagem gerado pelo tambor } \\
& \text { D - diâmetro do tambor }
\end{aligned}
$$

Substituindo a equação (3.5) em (3.6) segue que

$$
T=\frac{K \cdot A \cdot P \cdot L_{a} \cdot D}{4 E}
$$

A equação (3.7) mostra o torque que o tambor aplica na roda (Figura 3.2 b). Esse torque também é calculado da seguinte maneira:

$$
T=B \cdot R_{\text {din }}
$$

Sendo:

$$
\begin{aligned}
& B \text { - força de frenagem } \\
& R_{\text {din }}-\text { raio dinâmico do pneu }
\end{aligned}
$$


Finalmente a força de frenagem, "B", é obtida substituindo (3.7) em (3.8) e multiplicando por 2 (para obter a força de frenagem no eixo que possui dois tambores) e pela eficiência do sistema de freios $(\eta)$.

$$
B=\frac{P \cdot A \cdot K \cdot D \cdot L_{a} \cdot \eta}{2 E \cdot R_{\operatorname{din}}}
$$

De acordo com Gillespie (1992), a equação para o desempenho da frenagem de um veículo pode ser obtida da segunda lei de Newton. A equação para a frenagem (a mesma equação 2.13) é mostrada a seguir.

$$
M \cdot a_{x}=-\frac{W}{g} D_{x}=-F_{x f}-F_{x r}-D_{A}-W \cdot \operatorname{sen} \theta
$$

Sendo:

$$
\begin{aligned}
& M-\text { massa do veículo } \\
& a_{x}-\text { aceleração na direção " } x " \\
& W-\text { peso do veículo } \\
& D_{x}-\text { aceleração na direção "x" } \\
& D_{A}-\text { força de arrasto aerodinâmico } \\
& \theta-\quad \text { inclinação da pista } \\
& F_{x f}-\quad \text { Força aplicada no eixo frontal na direção } x \\
& F_{x r}-\quad \text { Força aplicada no eixo traseiro na direção } x
\end{aligned}
$$

Como a resistência do ar não é considerada e a frenagem ocorre no plano (sem inclinações) os dois últimos termos da equação são iguais a zero. Como a resistência das massas rolante é considerada, a massa "M" é multiplicada por um fator $\gamma_{\mathrm{b}}$. Dessa forma a equação acima é reescrita como:

$$
\gamma_{b} M \cdot a_{x}=-F_{x}-R_{x}
$$

Sendo:

$\gamma_{b}-$ fator que considera a inércia dos elementos em rotação do veículo ligados à roda

$$
\begin{aligned}
& F_{x f}-\text { Força aplicada no eixo frontal na direção } x \\
& F_{x r}-\text { Força aplicada no eixo traseiro na direção } x
\end{aligned}
$$


Sendo $F_{x}$ a soma da forças na direção " $x$ " do eixo dianteiro e $F_{x r} a$ soma da forças na direção "x" do eixo traseiro. Assim, a desaceleração "b" é calculado como:

$$
b=\frac{B_{1}+B_{21}+B_{22}+B_{31}+B_{32}+B_{41}+B_{42}+R_{R}}{\gamma_{b}\left(W_{1}+W_{2}+W_{3}\right)}
$$

Sendo:

$$
\begin{aligned}
& b-\text { desaceleração da combinação }\left[\mathrm{m} / \mathrm{s}^{2}\right] \\
& \mathrm{B}_{1}-\text { força de frenagem no eixo dianteiro do cavalo }[\mathrm{N}] \\
& \mathrm{B}_{21}-\text { força de frenagem no eixo dianteiro do "tandem" do }
\end{aligned}
$$
cavalo

$B_{22}$ - força de frenagem no eixo traseiro do "tandem" do cavalo

$\mathrm{B}_{31}$ - força de frenagem no eixo dianteiro do "tandem" do primeiro semi-reboque

$\mathrm{B}_{32}$ - força de frenagem no eixo traseiro do "tandem" do primeiro semi-reboque

$\mathrm{B}_{41}$ - força de frenagem no eixo dianteiro do "tandem" do segundo semi-reboque

$B_{42}$ - força de frenagem no eixo traseiro do "tandem" do segundo semi-reboque

$$
\begin{aligned}
& W_{1} \text { - peso do cavalo mecânico } \\
& W_{2} \text { - peso do primeiro semi-reboque } \\
& W_{3} \text { - peso do segundo semi-reboque } \\
& \mathrm{R}_{\mathrm{r}}-\text { Força de resistência ao rolamento }
\end{aligned}
$$

A Figura 3.3 mostra um esquema das forças atuando no bi-trem.

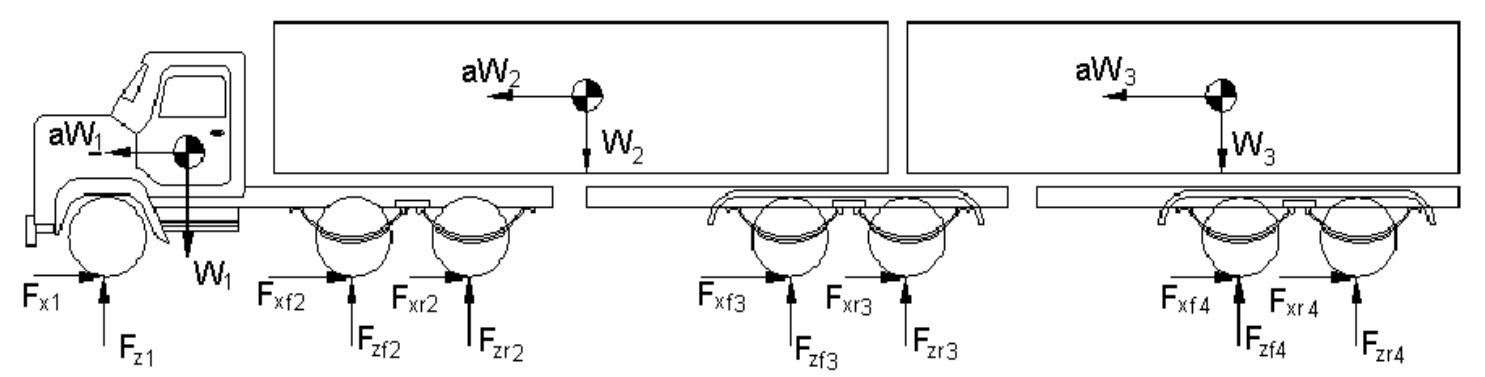

FIGURA 3.3 - Esquema simplificado das forças atuando no bi-trem 
Canale (1989) desenvolve um método para a obtenção das forças normais às rodas durante a frenagem em regime permanente. Brossi (2002) estende esse modelo para o ônibus bi-articulado. O método usado neste trabalho é o mesmo usado em Polito et al (2004a) e Polito et al (2004b). O bitrem é separado em partes, de forma semelhante à feita por Brossi (2002) para o estudo do ônibus bi-articulado. $O$ bi-trem foi então divido da seguinte forma para facilitar o estudo:

- $2^{\circ}$ Semi-reboque.

- $1^{\circ}$ Semi-reboque.

- Cavalo mecânico.

O desenvolvimento das equações (que foram obtidas com o auxilio das equações da suspensão "tandem" mostradas no capítulo anterior) são apresentadas a seguir.

\subsection{1. $2^{\circ}$ Semi-Reboque}

Um esquema das forças que atuam no segundo semi-reboque da combinação é apresentado na Figura 3.4.

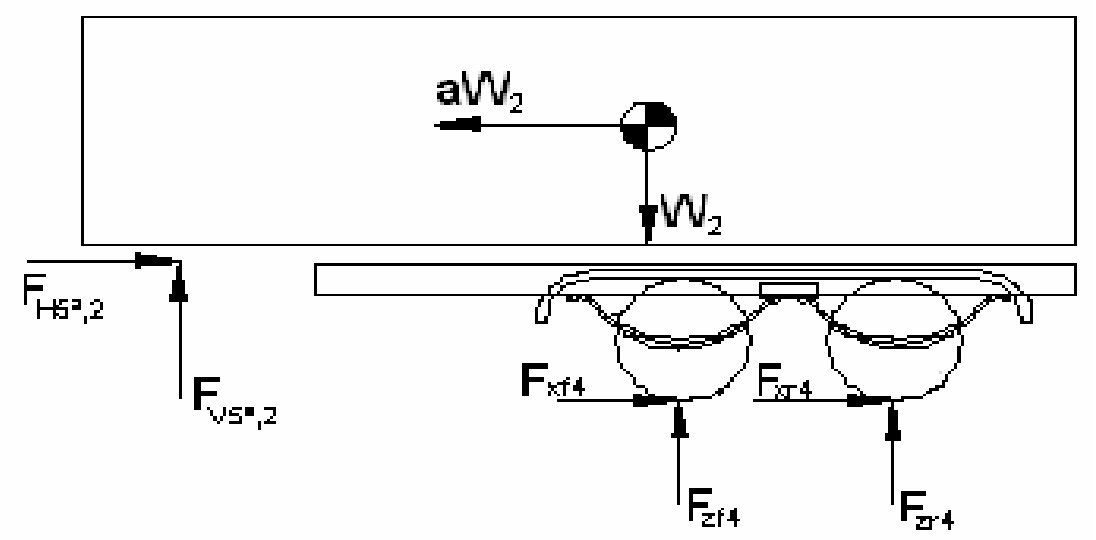

FIGURA 3.4 - Esquema das forças atuando no segundo semi-reboque

As equações são desenvolvidas a partir do cálculo do somatório de momentos (torques) em relação à quinta roda combinadas com as equações apresentadas no capítulo 2 para a suspensão em"tandem". Dessa forma obtemos: 
$\mathrm{Y} 2_{3}=\mathrm{Y} 2_{3}\left(\mathrm{~F}_{\mathrm{xf} 4}, \mathrm{~F}_{\mathrm{xr} 4}, \mathrm{~W}_{2}\right.$, geometria.......)

Ou seja, $Y 2_{3}$ (ver $Y_{2}$ na seção 2.8) é função das forças de frenagem em cada roda, do peso do semi-reboque, da geometria da suspensão e semireboque, entre outras variáveis.

$\mathrm{F}_{\mathrm{zf} 4}=\mathrm{F}_{\mathrm{zf} 4}\left(\mathrm{Y} 2_{3}, \mathrm{wf}\right.$, geometria,...)

$\mathrm{F}_{\mathrm{zr} 4}=\mathrm{F}_{\mathrm{zr} 4}\left(\mathrm{Y}_{2}, \mathrm{wr}\right.$, geometria,$\left.\ldots\right)$

\subsection{2. $1^{\circ}$ Semi-Reboque}

Agora, passa-se a estudar o $1^{\circ}$ semi-reboque da combinação. Um esquema das forças que atuam no semi-reboque é mostrado na Figura 3.5.

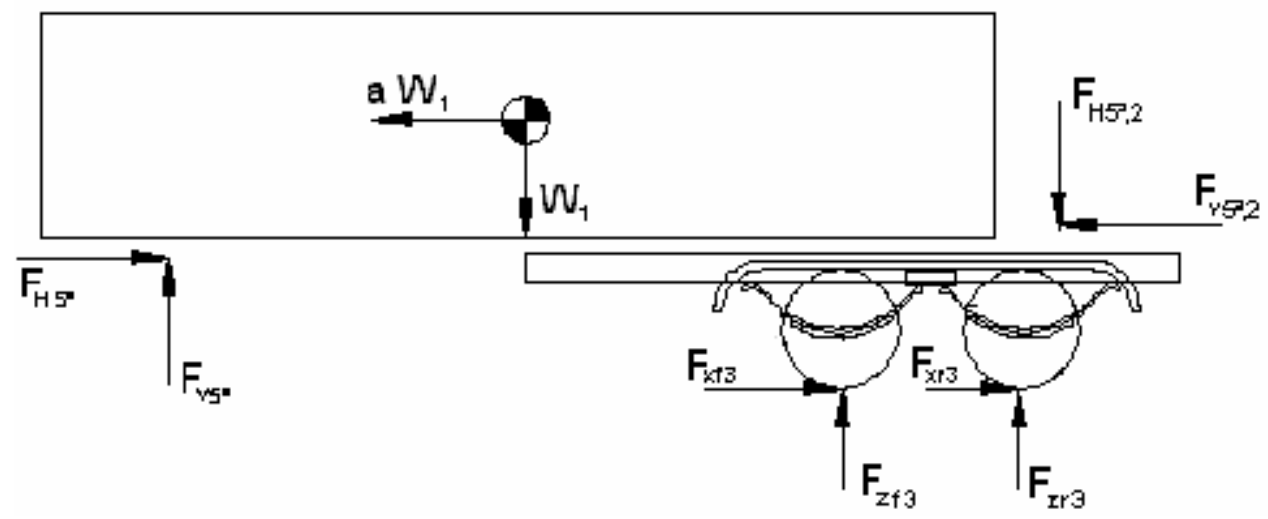

FIGURA 3.5 - Esquema das forças atuando no primeiro semi-reboque

As equações foram obtidas da mesma maneira utilizada no segundo semi-reboque, ou seja, por somatório de momento em relação à quinta roda juntamente com as equações da suspensão. Tem-se então (ver $Y_{2}$ na seção 2.8):

$\mathrm{Y} 2_{2}=\mathrm{Y} 2_{2}\left(\mathrm{~F}_{\mathrm{xf} 3}, \mathrm{~F}_{\mathrm{xr} 3}, \mathrm{~W}_{1}\right.$, geometria.......)

$\mathrm{F}_{\mathrm{zf} 3}=\mathrm{F}_{\mathrm{zf} 3}\left(\mathrm{Y} 2_{3}, \mathrm{wf}_{3}\right.$, geometria,$\left.\ldots\right)$

$\mathrm{F}_{\mathrm{zr} 3}=\mathrm{F}_{\mathrm{zr} 3}\left(\mathrm{Y} 2_{3}, \mathrm{wr}_{3}\right.$, geometria,$\left.\ldots\right)$

\subsubsection{Cavalo mecânico}

Para concluir o equacionamento da dinâmica da frenagem resta equacionar o cavalo mecânico. Um esquema é apresentado na Figura 3.6 




FIGURA 3.6 - Esquema das forças atuando no cavalo mecânico

Desta vez o ponto de referência para o cálculo do somatório de momentos é o ponto de contado da roda dianteira do cavalo mecânico com o solo. As equações encontradas, análogas às anteriores, são apresentadas a seguir (ver $Y_{2}$ na seção 2.8).

$Y 2_{1}=Y 2_{1}\left(F_{x+2}, F_{x r 2}, W_{1}\right.$, geometria.......)

$F_{\mathrm{zf2}}=\mathrm{F}_{\mathrm{zf2}}\left(\mathrm{Y} 2_{1}, \mathrm{wf}_{2}\right.$, geometria,$\left.\ldots\right)$

$F_{\mathrm{zr} 2}=F_{\mathrm{zr} 2}\left(Y 2_{1}, \mathrm{wr}_{2}\right.$, geometria,$\left.\ldots\right)$

\subsubsection{Cálculos específicos.}

Tendo em mãos as equações desenvolvidas nos tópicos anteriores, alguns cálculos específicos podem ser feitos. O primeiro cálculo realizado é o do coeficiente de adesão utilizado por cada roda. Como foi visto no capítulo anterior o coeficiente de adesão é a razão entre a força longitudinal (força de frenagem no caso) e a força normal desde que esse valor não ultrapasse 0 coeficiente de adesão máximo. Se isso ocorrer, o coeficiente utilizado é o de escorregamento. Ou seja:

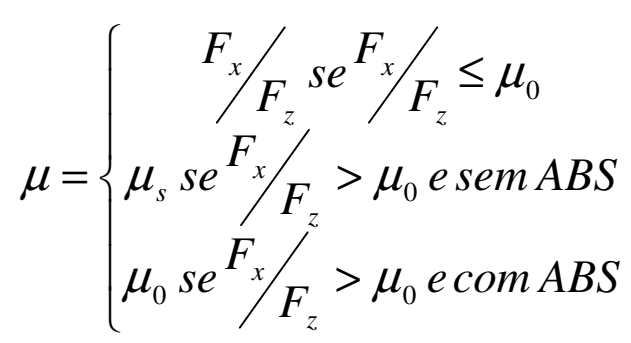

Em seguida a eficiência dos freios é calculada, de acordo com Gillepie, como sendo: 


$$
\eta=\frac{\sum F_{x, i}}{\mu_{0} \cdot \sum F_{z, i}}
$$

Também são calculados a distância percorrida até que o veículo para totalmente (utilizando a equação 2.14) e o tempo necessário para a frenagem utilizando a equação fornecida por Limper (1992) e mostrada a seguir.

$$
\begin{aligned}
& t_{t}=t_{r}+t_{a}+t_{b} / 2+V_{1} / a_{\max } \\
& \text { Sendo: } \quad t_{t}=\text { Tempo total de parada } \\
& t_{r}=\text { Tempo de reação do motorista } \\
& \mathrm{t}_{\mathrm{a}}=\text { Tempo de reação do sistema de freios } \\
& t_{b}=\text { Tempo para a pressão no circuito de freio atingir } \\
& \text { 90\% da pressão máxima } \\
& \mathrm{V}_{1}=\text { Velocidade inicial do veículo } \\
& a_{\max }=\text { desaceleração máxima desenvolvida pelo } \\
& \text { veículo } \\
& {\left[\mathrm{m} / \mathrm{s}^{2}\right]}
\end{aligned}
$$

]

]


Sendo:

$$
\begin{array}{lr}
T_{f}-\text { temperatura final do tambor } & {\left[{ }^{0}\right]} \\
T_{\text {amb }}-\text { temperatura final do tambor } & {\left[{ }^{\circ}\right]} \\
Q- & \text { energia térmica dissipada } \\
m-\quad \text { massa de troca de calor } & {[\mathrm{J}]} \\
\bar{c}-\quad \text { calor específico médio do tambor } & {[\mathrm{Jg} / \mathrm{kg} . \mathrm{K}]}
\end{array}
$$

Isso se não houver travamento das rodas. Caso contrário, toda energia é transferida para os pneus e a temperatura do tambor não muda. Ou seja, $\mathrm{T}_{\mathrm{F}}=$ $\mathrm{T}_{\mathrm{amb}}$.

Para concluir calculam-se os limites de desempenho exigidos pelo anexo 10 da norma ECE 13 que são comparados com o desempenho do veículo estudado.

\subsection{Programa computacional}

Programas computacionais são cada vez mais utilizados para 0 desenvolvimento de projetos, pois diminuem os custos, o tempo de desenvolvimento, ajudam a aprimorar a qualidade do produto entre outros fatores. Assim uma planilha de cálculos foi desenvolvida a partir do modelo matemático elaborado para auxiliar o projetista do sistema de freios de um bitrem.

A planilha de cálculos foi elaborada no programa Excel do pacote Office da Microsoft. Essa escolha vem do fato desse programa ser amplamente difundido na industria, de fácil acesso e utilização, não requerer alto poder de processamento e seu custo ser relativamente baixo.

A planilha exige alguns dados de entrada que devem ser preenchidos pelo usuário. Esses dados são as características geométricas do veículo (tal como distância entre eixos do cavalo mecânico e semi-reboques, altura do centro de gravidade e altura da quinta roda), características do sistema de freios (diâmetro do tambor, comprimento da alavanca ajustadora, fator de freio, entre outros), as condições da frenagem (coeficientes de adesão máximo $\left(\mu_{0}\right)$ e 
de escorregamento $\left(\mu_{\mathrm{s}}\right)$, velocidade inicial e etc), condições ambientais e do motorista (tempo de resposta do motorista, temperatura do ambiente...).

De posse dos dados de entrada a planilha usa a pressão no sistema de freios como variável de controle. A pressão varia de 0 (zero) à pressão máxima em intervalos de milésimos da pressão máxima, ou seja, fazendo 1001 iterações. Para cada iteração todos os cálculos descritos anteriormente são feitos como mostrado no fluxograma abaixo.

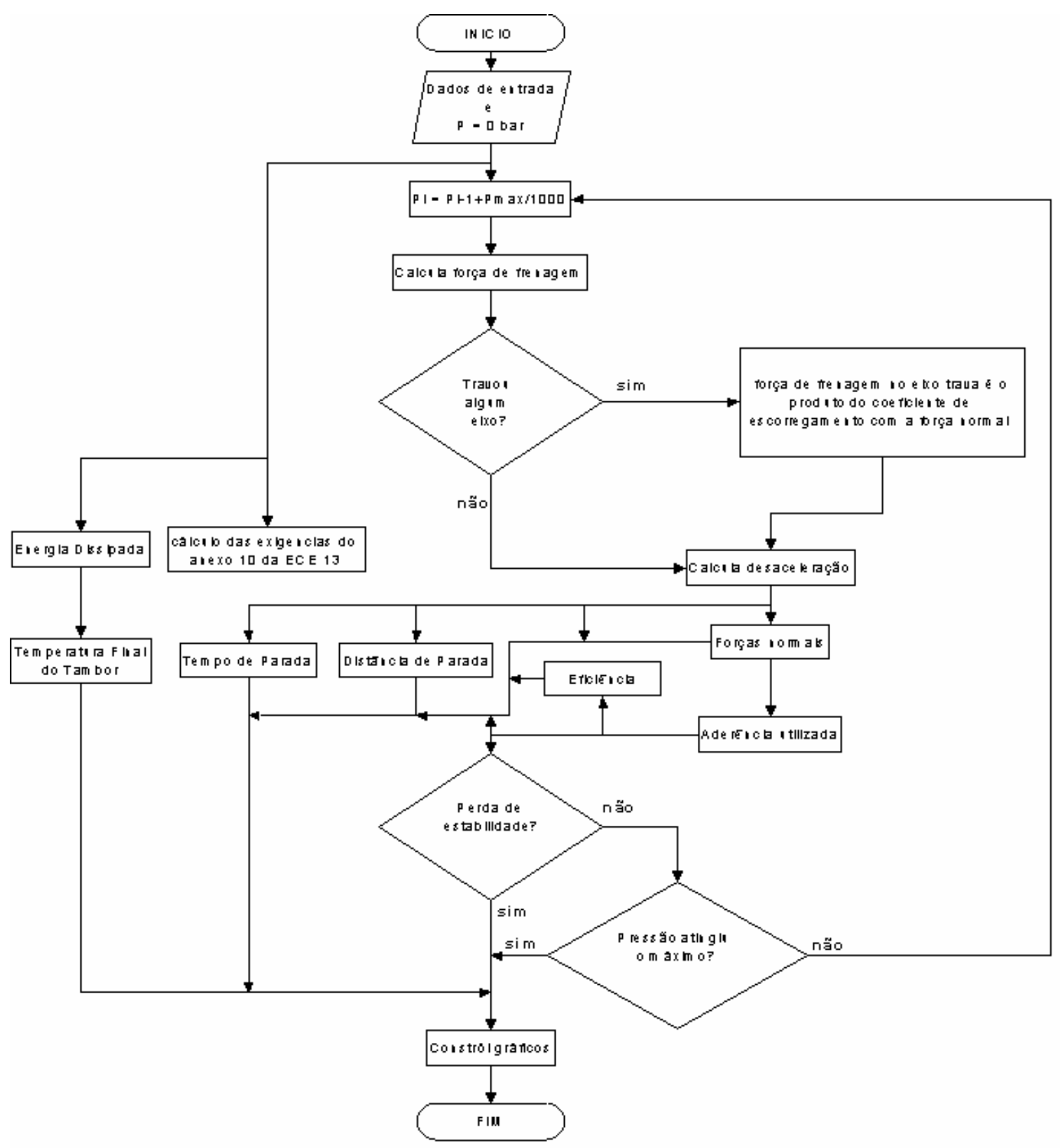

FIGURA 3.7 - Fluxograma do programa computacional 
Com a pressão no circuito de freio, calcula-se a força de frenagem teórica que o eixo geraria (de acordo com a equação 3.9). Em seguida verificase se houve travamento do eixo, conferindo-se se a força teórica calculada anteriormente é maior que o produto da força normal no eixo com o coeficiente de adesão máximo $\left(\mu_{0}\right)$. Como nesse ponto a força normal ainda não foi achada, utiliza-se a força normal calculada na iteração anterior, pois como o incremento é muito pequeno, a diferença não será significativa. Dessa forma, se não houver travamento do eixo a força é igual à força calculada no passo anterior. Se houver travamento a força de frenagem é o produto da força normal pelo coeficiente de escorregamento $\left(\mu_{\mathrm{S}}\right)$.

Com os valores das forças de frenagem em todos os eixos somadas à força de resistência ao rolamento, temos a força resultante que atua no sentido de reduzir a velocidade do veículo. Assim calcula-se a desaceleração do mesmo com a equação 3.12 .

Com a desaceleração obtida são calculados a distância e o tempo de parada (considerando os vários tempos de atraso) e as forças normais de acordo com as equações mostradas ao longo deste trabalho. Com as forças normais, calcula-se a aderência utilizada de cada eixo e então a eficiência do sistema de freios. Paralelamente, faz-se os cálculos das exigências das normas e da dissipação de energia da frenagem (equação 3.25) e finalmente a temperatura final do tambor (equação 3.26). Nesse ponto, verifica-se se houve perda de estabilidade. Caso ocorra perda de estabilidade o cálculo é interrompido. Se não mais uma iteração é realizada até que haja perda de estabilidade ou a pressão atinja o máximo. Para concluir os gráficos correspondentes às variáveis de interesse são construídos.

Os resultados obtidos com a planilha são apresentados no capítulo seguinte. 


\section{RESULTADOS OBTIDOS}

Neste capítulo serão apresentados os resultados obtidos na simulação da frenagem de um bi-trem genérico. Os resultados obtidos são apresentados em forma de gráficos. Como foi dito anteriormente, a idéia principal do trabalho é elaborar uma ferramenta que facilite o desenvolvimento do sistema de freio de um bi-trem e que preveja o seu desempenho. Para demonstrar a utilidade da planilha de cálculos desenvolvida serão apresentadas algumas sugestões de alteração do sistema de freios original para melhorar o desempenho do mesmo ou enquadra-lo dentro das exigências do anexo 10 da ECE 13.

A seguir as características geométricas do veículo serão apresentadas, bem como as condições da frenagem e as características do sistema de freios. Vale lembrar que o veículo utilizado aqui não é um veículo real, apesar dos valores serem condizentes com o que se encontra disponível no mercado.

\subsection{Características do veículo}

O trabalho desenvolvido realiza cálculos para bi-trens de 7 eixos com suspensão em tandem do tipo feixe de molas helicoidais ("leaf beam") nos eixos traseiros do cavalo mecânico e dos semi-reboques com peso total bruto máximo de 57 toneladas.

As características do cavalo mecânico são mostradas na tabela a seguir (Tabela 4.1). Na seqüência apresentam-se as tabelas referentes aos semireboques (Tabelas 4.2 e 4.3). 
Tabela 4.1 - Características do cavalo mecânico

\begin{tabular}{|c|c|c|}
\hline \multicolumn{3}{|c|}{ CAVALO MECÂNICO } \\
\hline \multicolumn{2}{|l|}{ Peso total } & $88290[N]$ \\
\hline \multicolumn{2}{|l|}{ Distância entre eixos } & $3,5[\mathrm{~m}]$ \\
\hline \multicolumn{2}{|l|}{ Distância do CG em relação ao eixo dianteiro } & $1,965[\mathrm{~m}]$ \\
\hline \multicolumn{2}{|l|}{ Altura do CG em relação ao solo } & $1,382[\mathrm{~m}]$ \\
\hline \multicolumn{2}{|l|}{$\begin{array}{l}\text { Distância da quinta roda em relação ao eixo } \\
\text { dianteiro }\end{array}$} & $3,927[\mathrm{~m}]$ \\
\hline \multicolumn{2}{|l|}{ Altura da quinta roda } & $1,382[\mathrm{~m}]$ \\
\hline \multicolumn{3}{|c|}{ Tabela 4.2 - Características do $1^{\circ}$ semi-reboque. } \\
\hline \multicolumn{3}{|l|}{ 1은-REBOQUE } \\
\hline & VAZIO & CARREGADO \\
\hline Peso total & $65.000[\mathrm{~N}]$ & $238.383[\mathrm{~N}]$ \\
\hline Distância entre eixos & \multicolumn{2}{|r|}{$5,9[\mathrm{~m}]$} \\
\hline Distância do CG em relação ao eixo dianteiro & $3,0[\mathrm{~m}]$ & $2,5[\mathrm{~m}]$ \\
\hline Altura do CG em relação ao solo & $1,32[\mathrm{~m}]$ & $1,995[\mathrm{~m}]$ \\
\hline $\begin{array}{l}\text { Distância da quinta roda em relação ao eixo } \\
\text { dianteiro }\end{array}$ & \multicolumn{2}{|c|}{$7,150[\mathrm{~m}]$} \\
\hline Altura da quinta roda & \multicolumn{2}{|r|}{$1,27[\mathrm{~m}]$} \\
\hline
\end{tabular}

Tabela 4.3 - Características do $1^{\circ} \stackrel{\text { semi-reboque. }}{ }$ '

\begin{tabular}{l|c|c|}
\hline \multicolumn{3}{|c|}{ 20 SEMI-REBOQUE } \\
\hline & VAZIO & CARREGADO \\
\hline Peso total & $65.000[\mathrm{~N}]$ & $232.797[\mathrm{~N}]$ \\
\hline Distância entre eixos & \multicolumn{2}{c}{$3,676[\mathrm{~m}]$} \\
\hline Distância do CG em relação ao eixo dianteiro & 2,95 & $2,95[\mathrm{~m}]$ \\
\hline Altura do CG em relação ao solo & $1,32[\mathrm{~m}]$ & $1,995[\mathrm{~m}]$ \\
\hline
\end{tabular}

O sistema de freio instalado no veículo exemplo é a tambor acionado por meio de um came em forma de "s". A Tabela 4.4 mostra as características do sistema de freios deste veículo exemplo (tanto o eixo dianteiro do cavalo mecânico quanto cada eixo do "tandem" apresentam o sistema de freios mostrado abaixo). 
Tabela 4.4 - Características do sistema de freio de cada eixo

\begin{tabular}{lr}
\hline \multicolumn{2}{|c|}{ SISTEMA DE FREIOS } \\
\hline Área cilindro & $24.0\left[\mathrm{in}^{21}\right.$ \\
\hline Fator de freio & $1,12[-]$ \\
\hline Diâmetro Tambor & $410,0[\mathrm{~mm}]$ \\
\hline Raio came S & $12,7[\mathrm{~mm}]$ \\
\hline Raio Dinâmico Pneu & $571,5[\mathrm{~mm}]$ \\
\hline Comprimento alavanca. Ajustadora & $139,7[\mathrm{~mm}]$ \\
\hline Largura da lona & $203,2[\mathrm{~mm}]$ \\
\hline Espessura do Tambor & $19,0[\mathrm{~mm}]$ \\
\hline Calor específico do Tambor & $544\left[\mathrm{~J} /\left(\mathrm{kg}{ }^{\star} \mathrm{K}\right)\right]$ \\
\hline Densidade do material do tambor & $7150\left[\mathrm{~kg} / \mathrm{m}^{3}\right]$ \\
\hline Rendimento & $65 \%$ \\
\hline
\end{tabular}

A Tabela 4.5 mostra as características geométricas de cada uma das suspensões em "tandem". Para maiores detalhes de cada variável observar a Figura 2.31.

Tabela 4.5 - Características da suspensão em "tandem".

\begin{tabular}{cr}
\hline \multicolumn{2}{|c|}{ SUSPENSÃO “TANDEM” } \\
\hline Massa não suspensa do eixo dianteiro & $477[\mathrm{~kg}]$ \\
\hline Massa não suspensa do eixo traseiro & $477[\mathrm{~kg}]$ \\
\hline $\mathrm{b}_{\mathrm{f}}$ & $0,989[\mathrm{~m}]$ \\
\hline $\mathrm{u}_{\mathrm{f}}$ & $0,49[\mathrm{~m}]$ \\
\hline $\mathrm{v}_{\mathrm{f}}$ & $0,755[\mathrm{~m}]$ \\
\hline $\mathrm{b}_{\mathrm{r}}$ & $0,989[\mathrm{~m}]$ \\
\hline $\mathrm{u}_{\mathrm{r}}$ & $0,49[\mathrm{~m}]$ \\
\hline $\mathrm{v}_{\mathrm{r}}$ & $0,755[\mathrm{~m}]$ \\
\hline $\mathrm{c}$ & $0,2[\mathrm{~m}]$ \\
\hline $\mathrm{d}$ & $0,2[\mathrm{~m}]$
\end{tabular}

O sub-índice "f" refere-se ao eixo dianteiro e o sub-índice "r" ao traseiro.

Para completar a Tabela 4.6 mostra as condições em que a frenagem ocorre. 
Tabela 4.6 - Condições em que a frenagem ocorre

\begin{tabular}{lr}
\hline \multicolumn{2}{|c|}{ CONDIÇÕES DA FRENAGEM } \\
\hline Aceleração da gravidade & $9,81\left[\mathrm{~m} / \mathrm{s}^{2}\right]$ \\
\hline Coeficiente de adesão máximo (pista molhada/pista seca) & $0,3 / 0,8[-]$ \\
\hline Coeficiente de adesão de escorregamento & $0,2 / 0,7[-]$ \\
(pista molhada/pista seca) & $72[\mathrm{~km} / \mathrm{h}]$ \\
\hline Velocidade inicial & $0,4[\mathrm{~s}]$ \\
\hline Tempo de resposta do motorista & $0,2[\mathrm{~s}]$ \\
\hline Tempo de resposta do sistema de freios & $0,3[\mathrm{~s}]$ \\
\hline Tempo para a pressão atingir 90\% da pressão máxima & $0[\mathrm{bar}]$ \\
\hline Pressão inicial & $8[\mathrm{bar}]$ \\
\hline Pressão final & $0,4[\mathrm{bar}]$ \\
\hline Pressão de controle das válvulas reguladoras (e pressão que os & $8[\mathrm{bar}]$ \\
\hline freios começam a atuar) & $1,2[\mathrm{bar}]$ \\
\hline Pressão máxima de saída das válvulas com o veículo carregado & $1[-]$ \\
\hline Pressão máxima de saída das válvulas com o veículo vazio & $25\left[{ }^{\circ} \mathrm{C}\right]$ \\
\hline Fator das inércias rolantes ( $\gamma_{\mathrm{b}}$ ) & $0,0012[-]$ \\
\hline Coeficiente de resistência ao rolamento & \\
\hline Temperatura ambiente & \\
\hline
\end{tabular}

\subsection{Resultados}

Uma vez que os dados foram apresentados, o próximo passo é realizar as simulações. Os gráficos mostrados nas Figuras ao longo deste capítulo são os resultados obtidos. Esses gráficos serão mostrados dois a dois contendo 0 resultado da simulação sem o uso do $A B S$ e em seguida o gráfico com o uso deste equipamento. $\mathrm{O}$ ABS é usado em todas as rodas, controladas de forma independente. A simulação será feita, primeiro com o veículo carregado e com coeficiente de adesão baixo (pista molhada), de acordo com os valores da tabela 4.6. Em seqüência será feita a simulação com o veículo vazio também em pista de baixa aderência e, para completar, serão feitas simulações em 
pistas de alta aderência. Uma análise será feita depois de cada grupo de dois gráficos na forma de pequenos comentários.

As nomenclaturas das legendas dos gráficos têm a seguinte correlação:

Eixo1 = Eixo dianteiro do cavalo mecânico

Eixo2F = Eixo dianteiro do "tandem" do cavalo mecânico

Eixo2T = Eixo traseiro do "tandem" do cavalo mecânico

Eixo3F = Eixo dianteiro do "tandem" do 1ㅇsemi-reboque

Eixo3T = Eixo traseiro do "tandem" do 1ㅇ semi-reboque

Eixo4F = Eixo dianteiro do "tandem" do 2ํㅗㅇ-reboque

Eixo4T = Eixo traseiro do "tandem" do $2^{\circ}$ semi-reboque

\subsubsection{Veículo carregado e coeficiente de adesão baixo}

Como um aspecto muito importante para o bom funcionamento do sistema de freio é a seqüência de travamento das rodas, os primeiros gráficos a serem mostrados referem-se à aderência utilizada em cada um dos eixos obtidos sem o uso do ABS e com o uso do mesmo respectivamente. A Figura 4.1 mostra a aderência utilizada em cada eixo com o aumento da pressão.

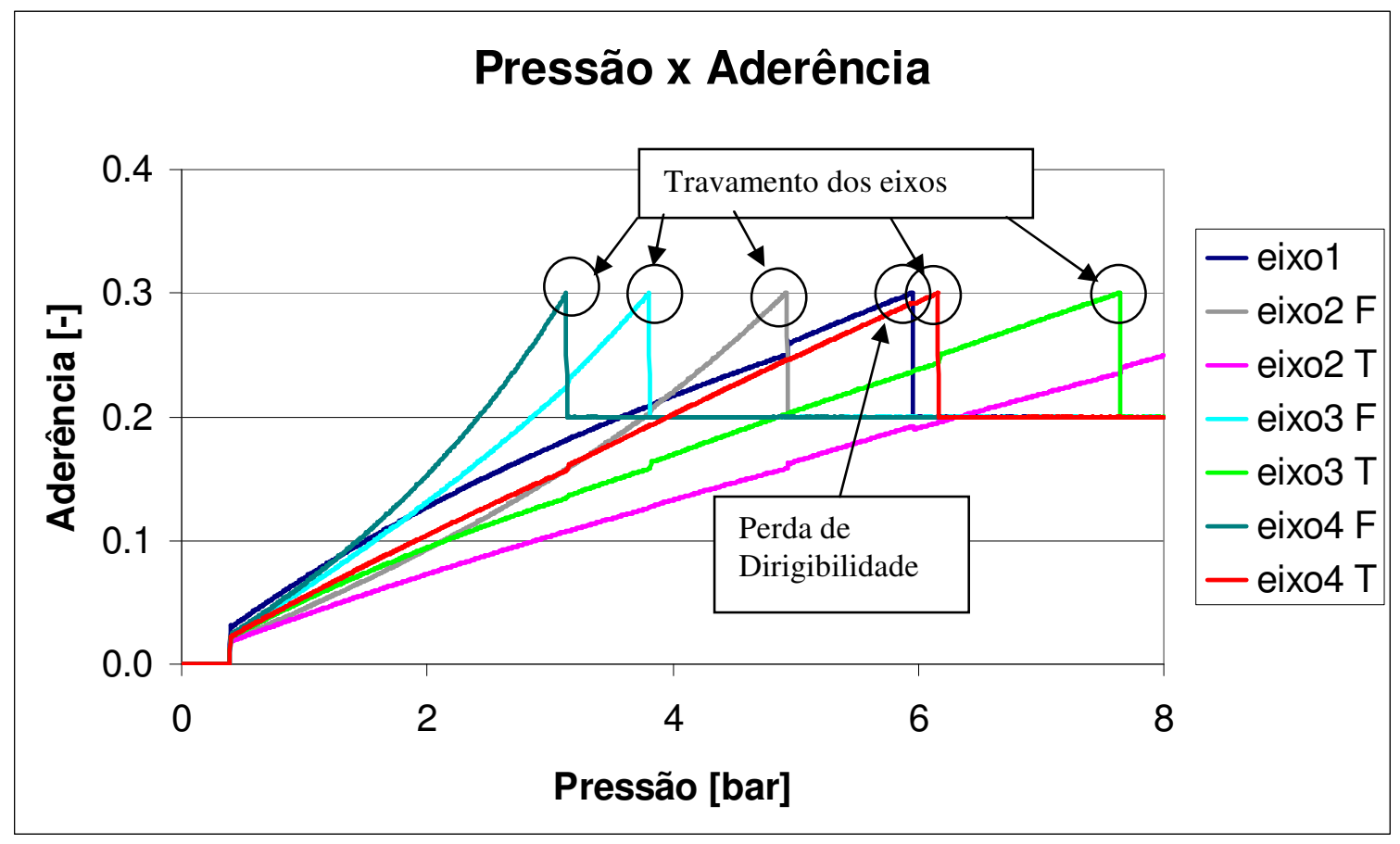

FIGURA 4.1 - Pressão x Aderência utilizada; veículo carregado; sem ABS 


\section{Pressão x Aderência}

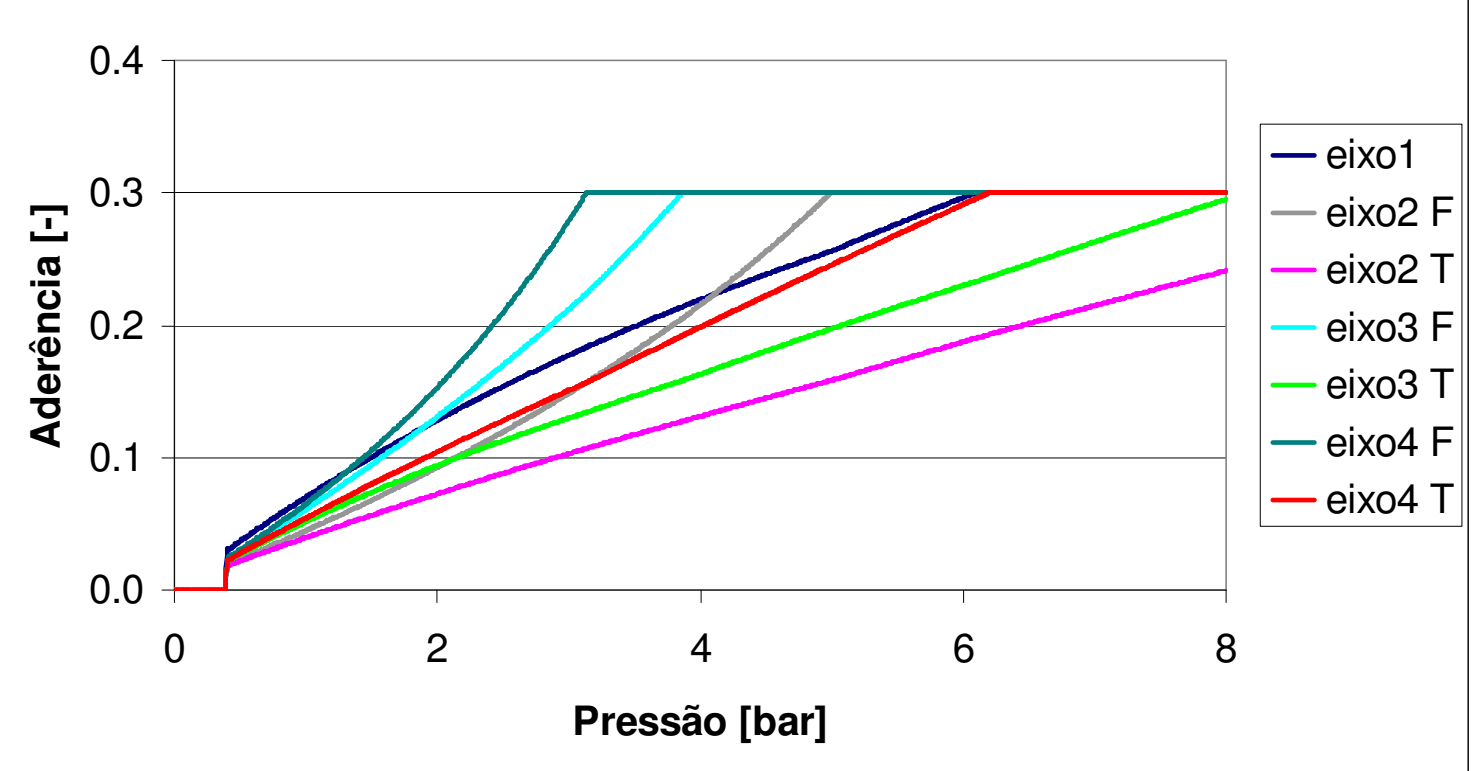

FIGURA 4.2 - Pressão x Aderência utilizada; veículo carregado; com ABS

A perda de dirigibilidade do veículo ocorre quando o eixo dianteiro do cavalo mecânico e a perda de estabilidade ocorre quando dois eixos de um determinado "tandem" travam. Quando isso ocorre os eixos em questão não mais capazes de gerar forças laterais. Nas condições apresentadas a perda de dirigibilidade ocorre quando a pressão atinge um valor em torno de 6 bar (basta verificar na Figura 4.1) quando o eixo dianteiro do cavalo mecânico trava. Isso pode fazer com que o veículo saia pela tangente, caso esteja em uma curva, pois o eixo que esterca perde a capacidade de gerar força lateral. Quando se utiliza ABS a perda de estabilidade não ocorre, pois os eixos não chegam a travar. Isso fica claro comparando os gráficos 4.1 e 4.2 acima. Quando um determinado eixo atinge o valor máximo de aderência, esse valor é mantido pelo ABS por mais que o motorista pressione o pedal de freio (notar que não há "picos" na Figura 4.2). Já sem ABS se o motorista pressionar mais o pedal de freio depois que o valor máximo é atingido, rapidamente a aderência tende ao coeficiente de aderência de escorregamento (os "picos" em destaque) na Figura 4.1.

Outro aspecto a notar é que os freios estão mal dimensionados neste caso estudado. O ideal seria que todos os eixos travassem mais ou menos 
com o mesmo valor de pressão (próximo da pressão máxima) para melhorar a eficiência. $O$ que se vê, no entanto, é que alguns eixos travam muito cedo (o primeiro eixo que trava (eixo $4 \mathrm{~F}$ ) o faz com pouco menos de 3 bar). Ainda, apesar de alguns eixos travarem próximos à pressão máxima, isso não quer dizer necessariamente que, nesses eixos, os freios estão bem dimensionados, pois isso ocorre com pistas de baixa aderência. Em pistas de alta aderência esses eixos serão subtilizados como será mostrado mais adiante.

As Figuras a seguir (Figuras 4.3 e 4.4) mostram os gráficos das forças de reação do solo sobre as rodas. A primeira coisa que se percebe é o comportamento da suspensão em "tandem" mostrado na Figura 2.32, em que o eixo traseiro do "tandem" é carregado enquanto o eixo dianteiro é descarregado.

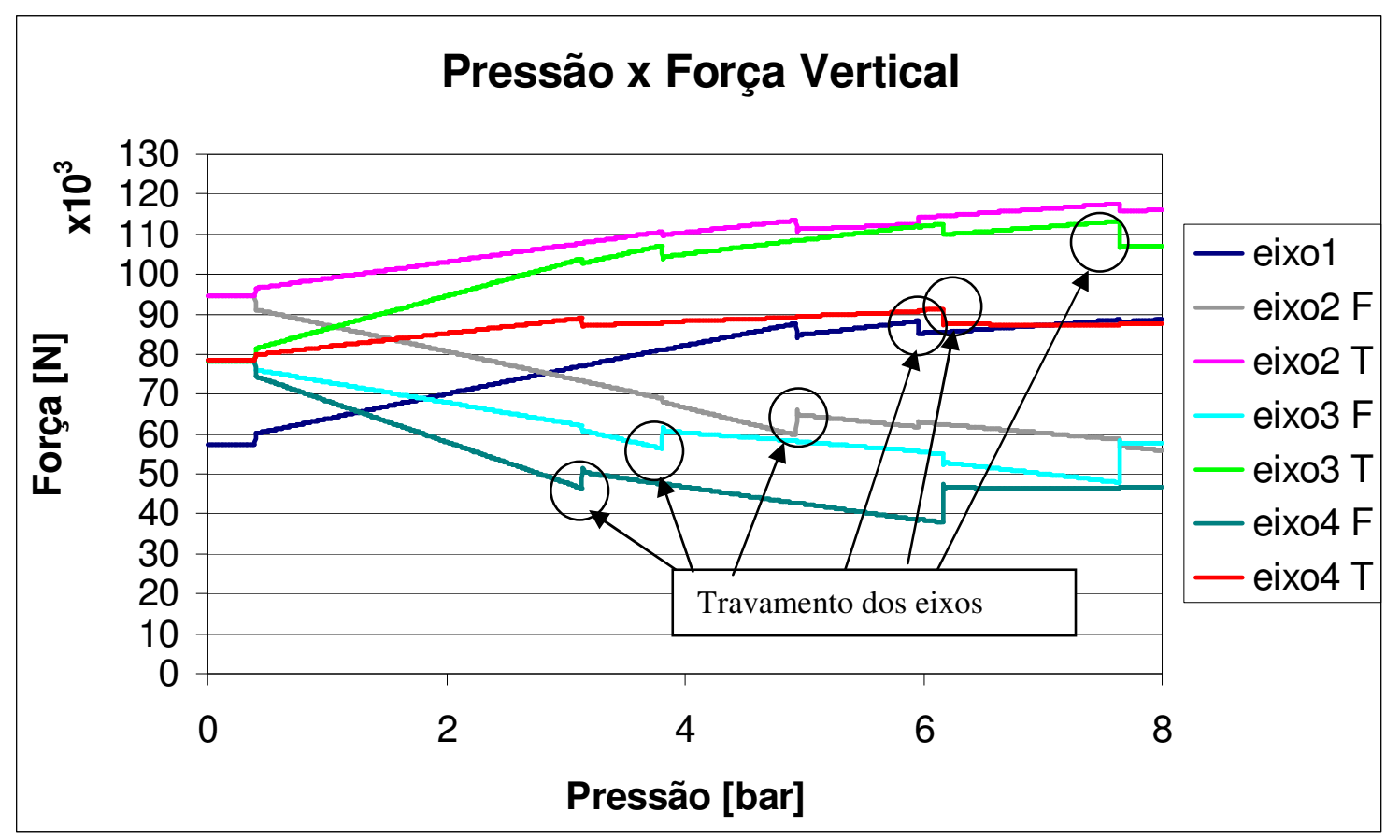

FIGURA 4.3 - Pressão x forças normais ao solo; veículo carregado sem ABS 


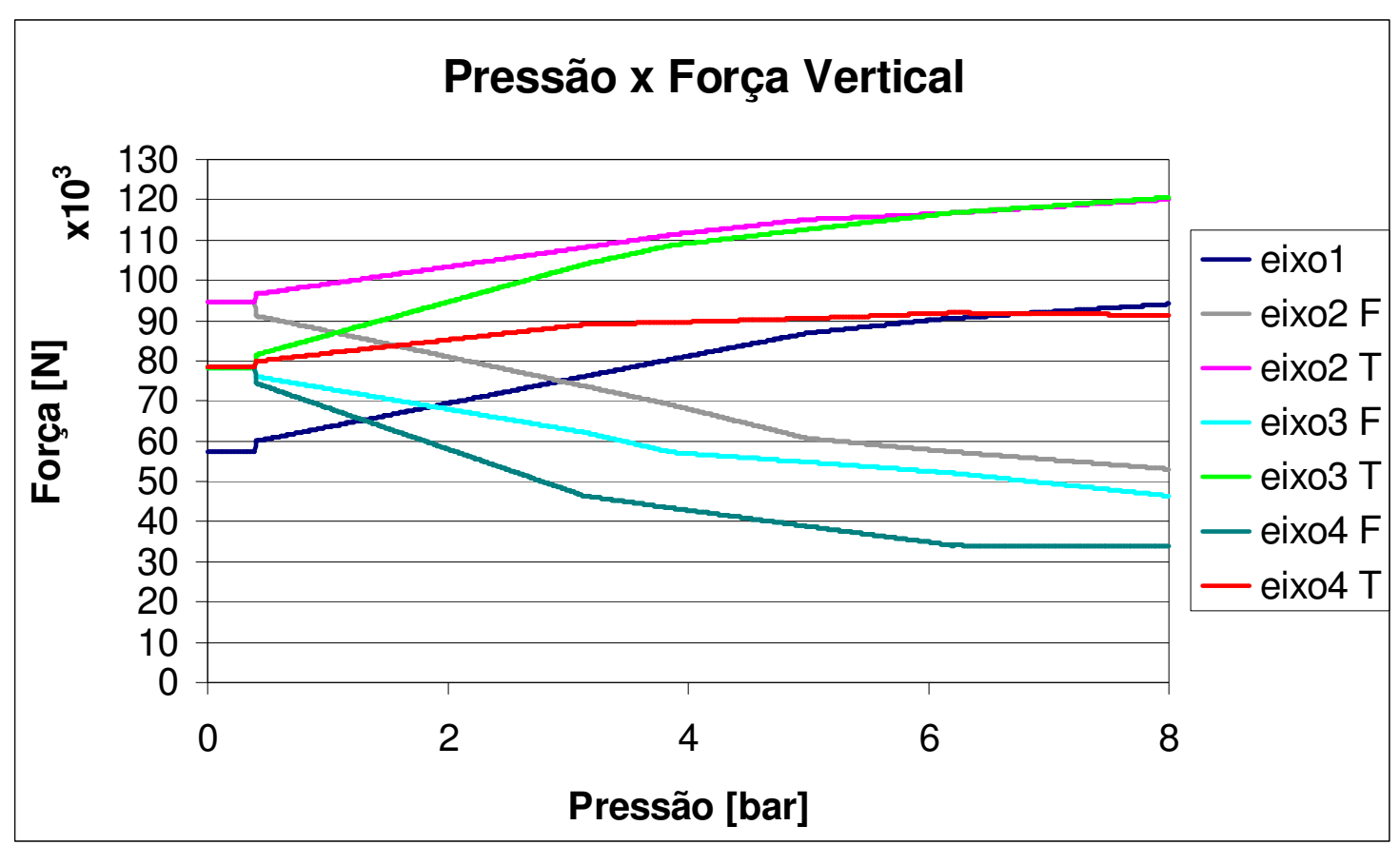

FIGURA 4.4 - Pressão x forças normais ao solo; veículo carregado com ABS

Analisando-se os gráficos 4.3 e 4.4, percebe-se uma descontinuidade nas curvas correspondentes ao veículo que não utiliza $A B S$. Tais descontinuidades são causadas pelo travamento dos eixos que acarreta em um decremento da desaceleração (como pode ser visto na Figura 4.5). Percebe-se também que quando um dos eixos do "tandem" trava, esse travamento é sentido pelo outro eixo, ou seja, se um deles recebe uma carga adicional devido ao travamento, o outro perde carga. Já com o uso de ABS, as curvas ficam bem mais suaves, pois não há nenhuma variação brusca de desaceleração. Os gráficos acima são úteis no auxílio no dimensionamento da suspensão. Como podemos ver, a carga nos eixos pode ultrapassar os $120.000 \mathrm{~N}$ em um único eixo.

Como quando se fala em frenagem a primeira coisa em que se pensa é em desaceleração, os primeiros gráficos, Figuras 4.5 e 4.6, mostraram a desaceleração máxima obtida sem o uso do ABS e com o uso do mesmo respectivamente. 


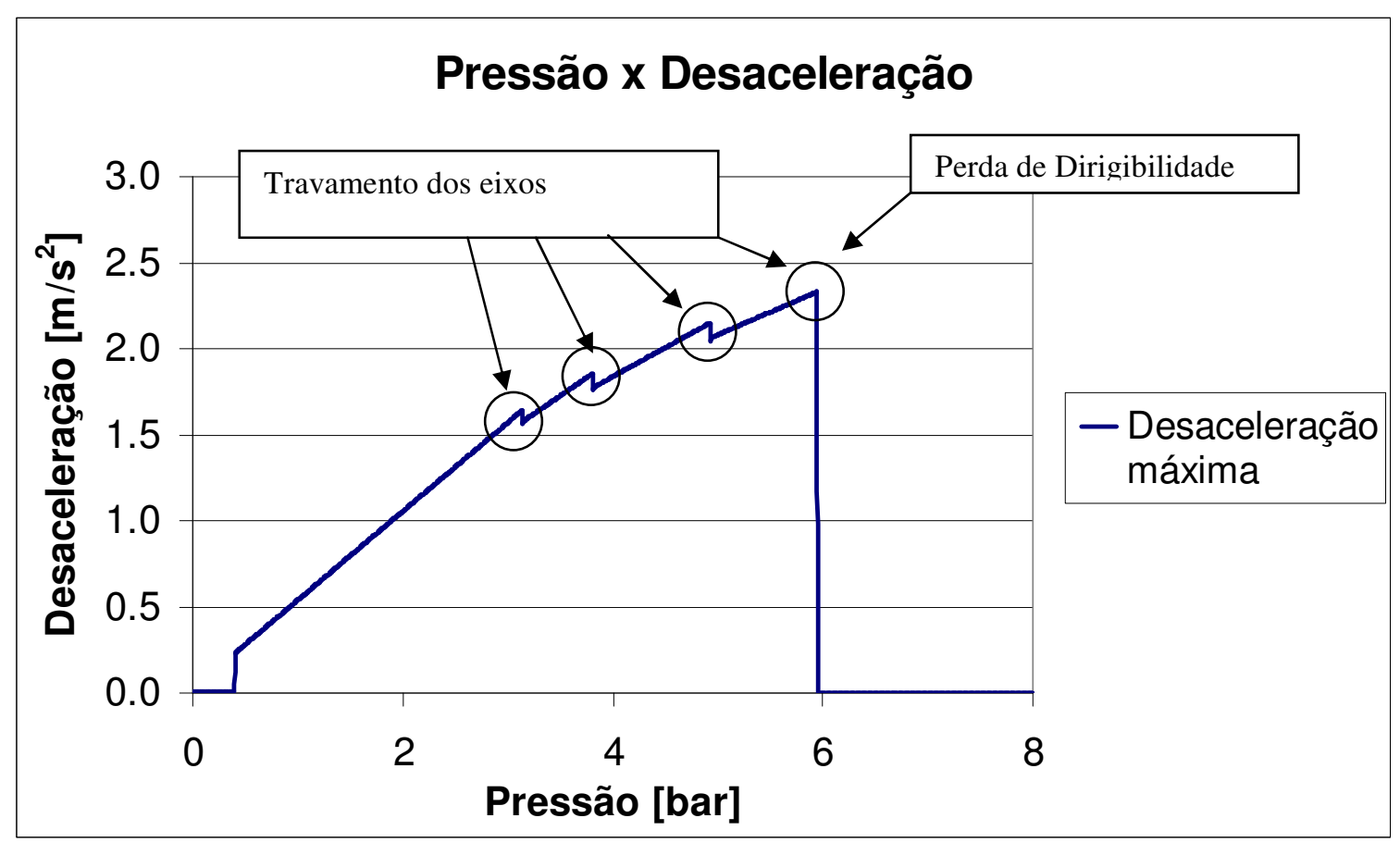

FIGURA 4.5 - Pressão x desaceleração máxima; veículo carregado sem ABS

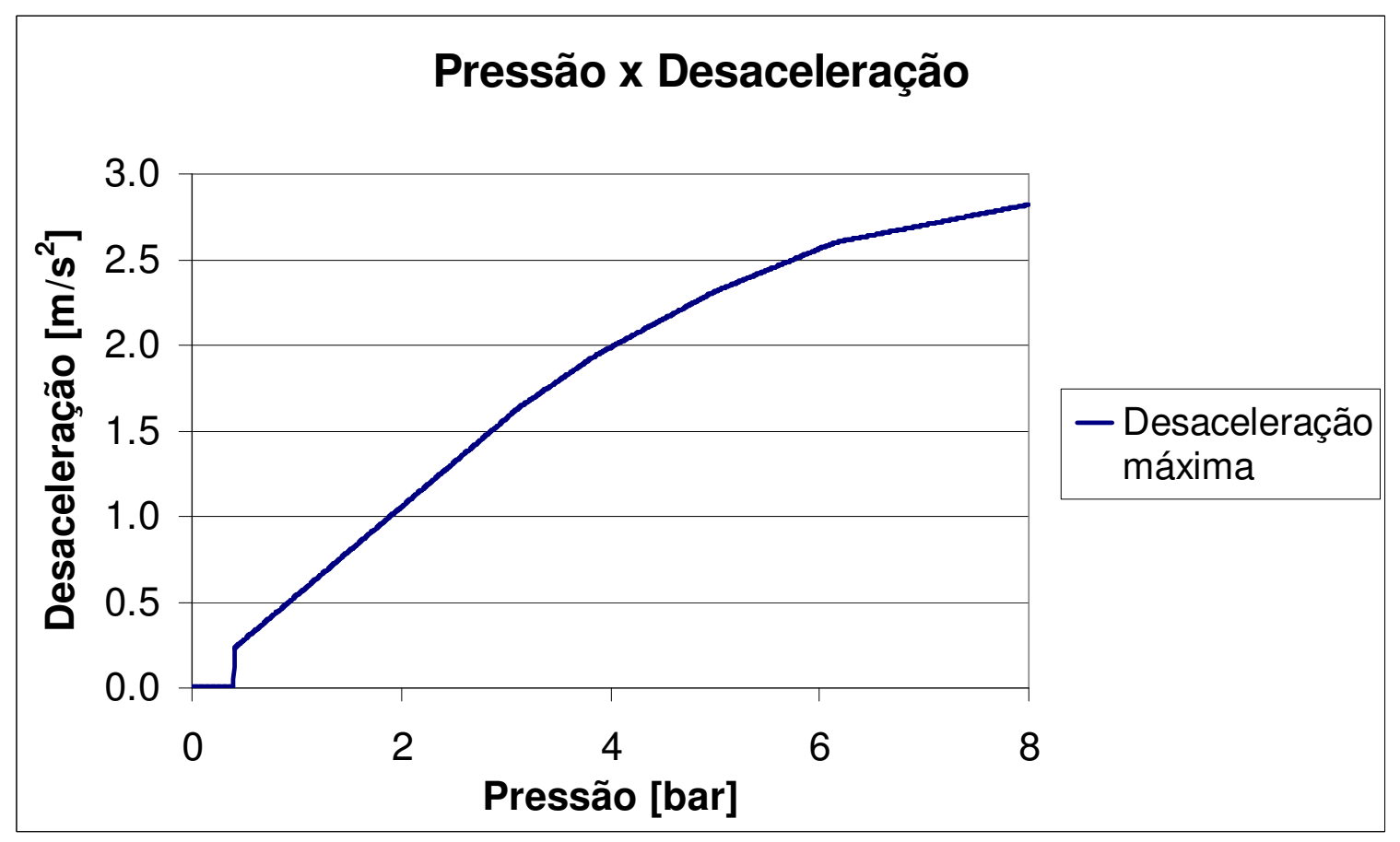

FIGURA 4.6 - Pressão x desaceleração máxima; veículo carregado com ABS

A primeira coisa que se percebe nos gráficos acima, e que já era esperado, é que a desaceleração máxima com o uso do ABS é maior do que a na frenagem sem ABS. O ganho com o uso de ABS, nessas condições em 
que a simulação foi realizada, é de aproximadamente $0,5 \mathrm{~m} / \mathrm{s}^{2}$, o que representa algo em torno de $20 \%$ em relação à desaceleração sem o uso do ABS.

Ainda, analisando-se o gráfico 4.5, notamos que o veículo perde estabilidade com pressão próxima de 6 bar, como já foi visto nos gráficos anteriormente. Deve-se observar também que a desaceleração "cai" a zero nesse ponto apenas para ilustrar o fato de que as desacelerações a partir desse ponto não são relevantes (apenas são importantes os valores antes da perda de estabilidade). Num caso real a desaceleração não cairia para zero nesse ponto.

O ABS é, antes de tudo, um equipamento para garantir a dirigibilidade , estabilidade e assim a segurança de operação de um determinado veículo. Mas como podemos ver ele também representa um ganho na capacidade de frear o veículo como se pode constatar nas Figuras 4.5 e 4.6. Isso ocorre porque o ABS aumenta a eficiência do sistema de freios, de acordo com as Figuras abaixo (4.7 e 4.8).

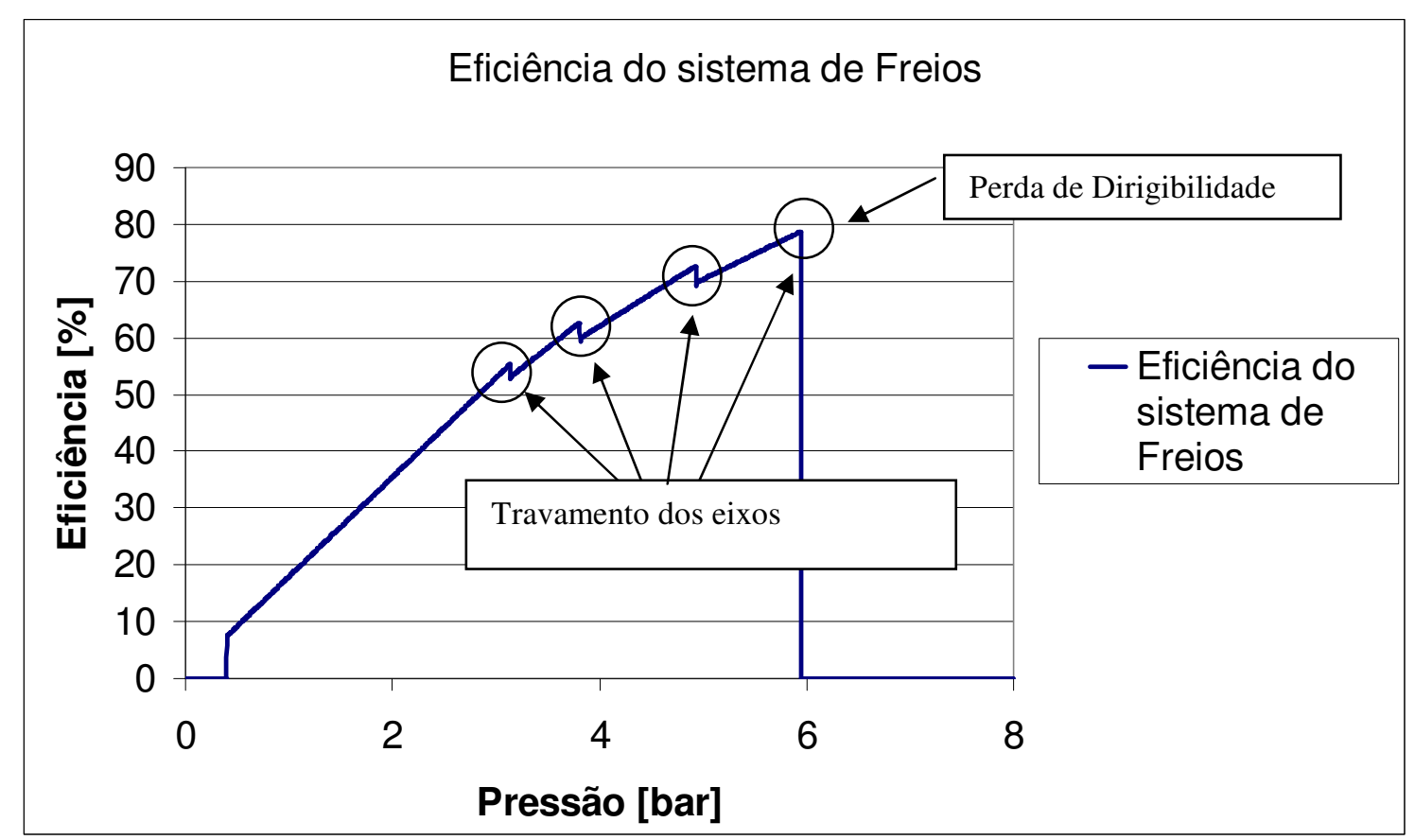

FIGURA 4.7 - Pressão x eficiência do sistema de freios; veículo carregado sem ABS. 


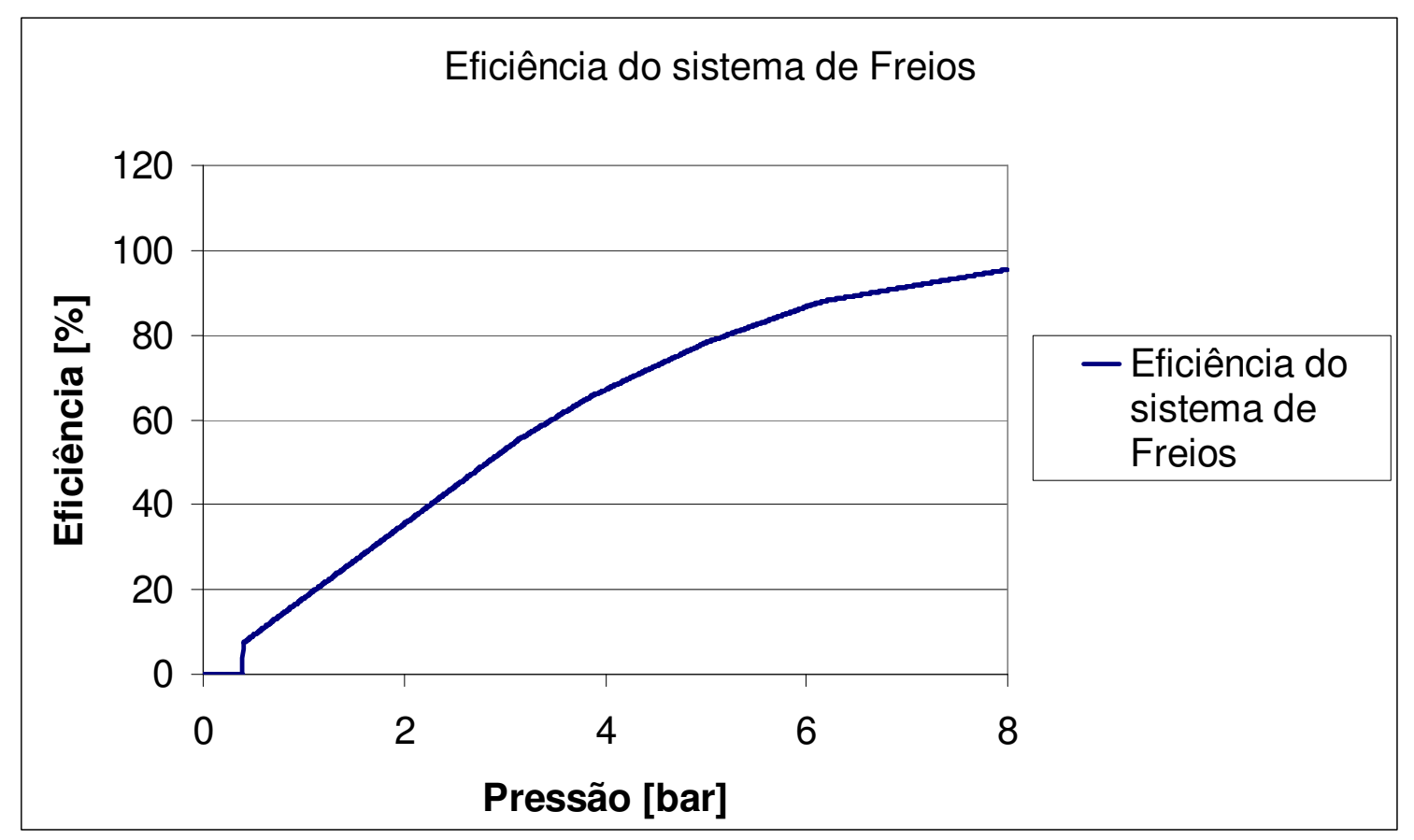

FIGURA 4.8 - Pressão x eficiência do sistema de freios; veículo carregado com ABS.

Observando-se os gráficos das Figuras 4.7 e 4.8 constata-se que 0 veículo com ABS tem eficiência próxima de 100\% (na verdade como se trata de uma condição ideal, em que o ABS mantém as rodas no pico da curva de aderência, poderia chegar a 100\%). Já com o veículo sem ABS, a eficiência é de $80 \%$. No entanto se observarmos o gráfico da Figura 2.24, a probabilidade de acidente é mais de seis vezes menor. De forma similar à Figura 4.5, a Figura 4.7 apresenta uma queda brusca da eficiência (até o valor zero) quando ocorre a perda de estabilidade. O motivo é o mesmo nos dois gráficos. $\mathrm{Na}$ seqüência serão mostrados os gráficos do espaço necessário para frenagem e também do tempo necessário para parar totalmente o veículo (Figuras 4.9 a 4.12). Como o espaço e o tempo de parada estão relacionados, os quatro gráficos serão comentados simultaneamente. 


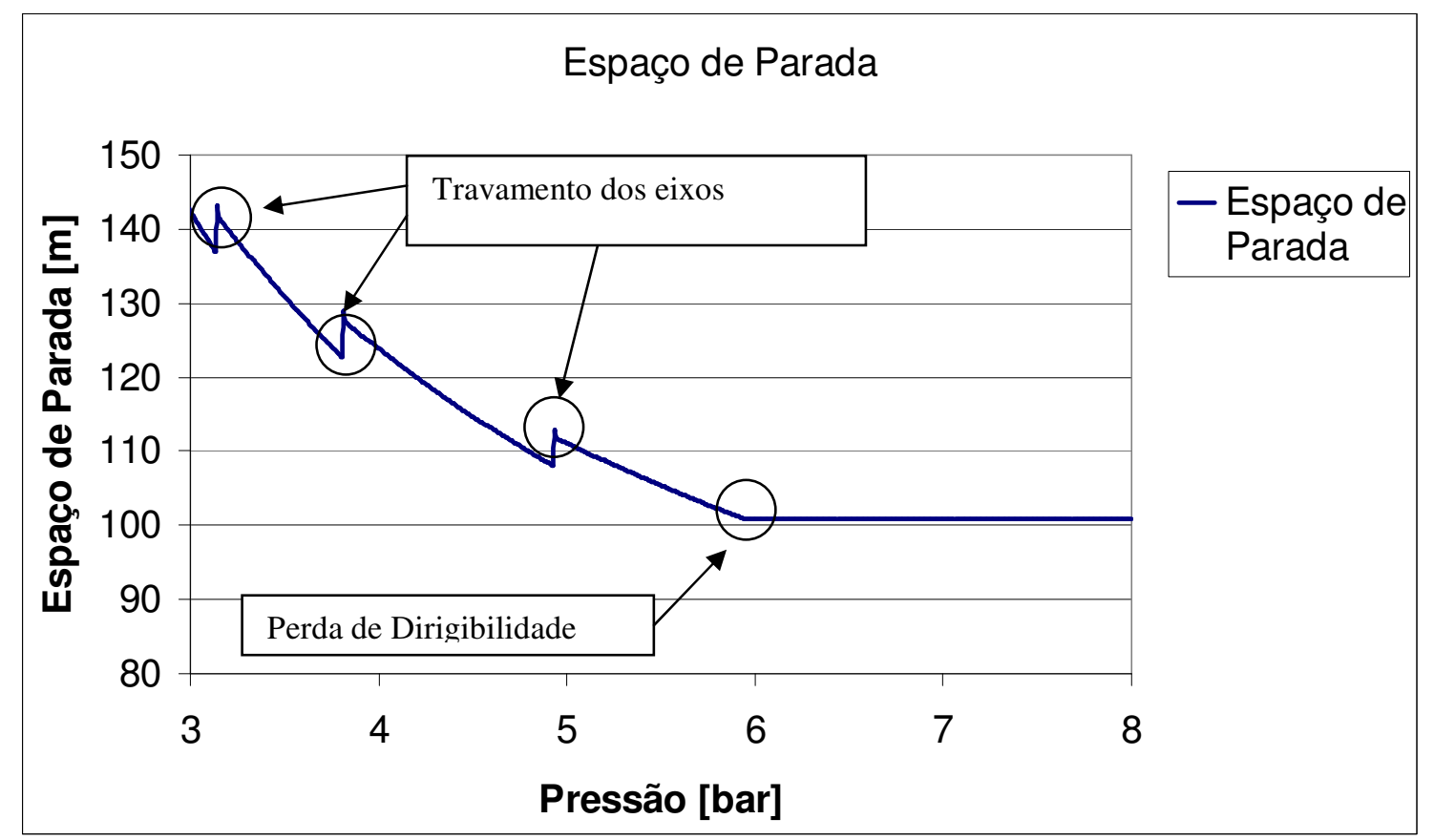

FIGURA 4.9 - Pressão x espaço de parada; veículo carregado sem ABS.

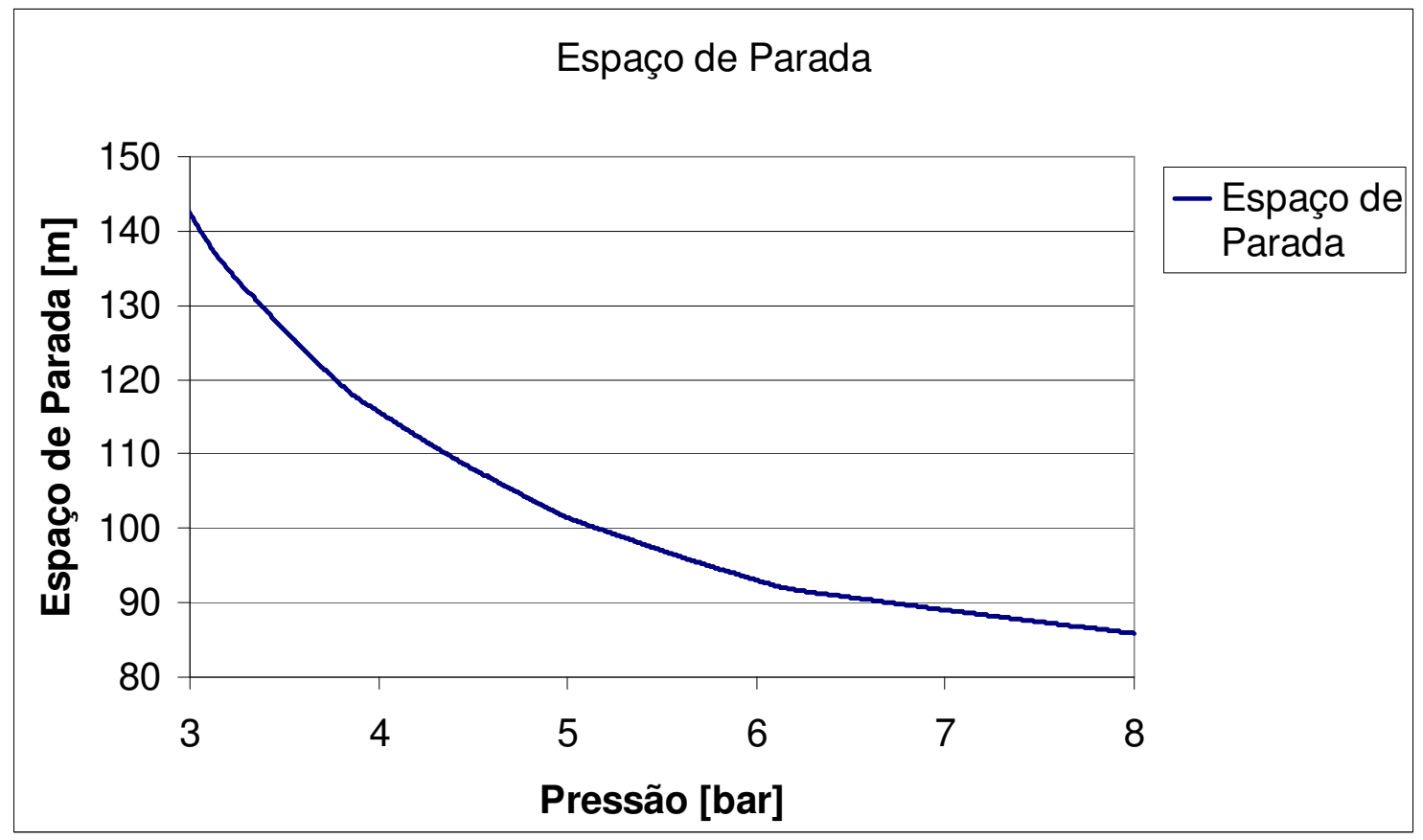

FIGURA 4.10 - Pressão x espaço de parada; veículo carregado com ABS. 


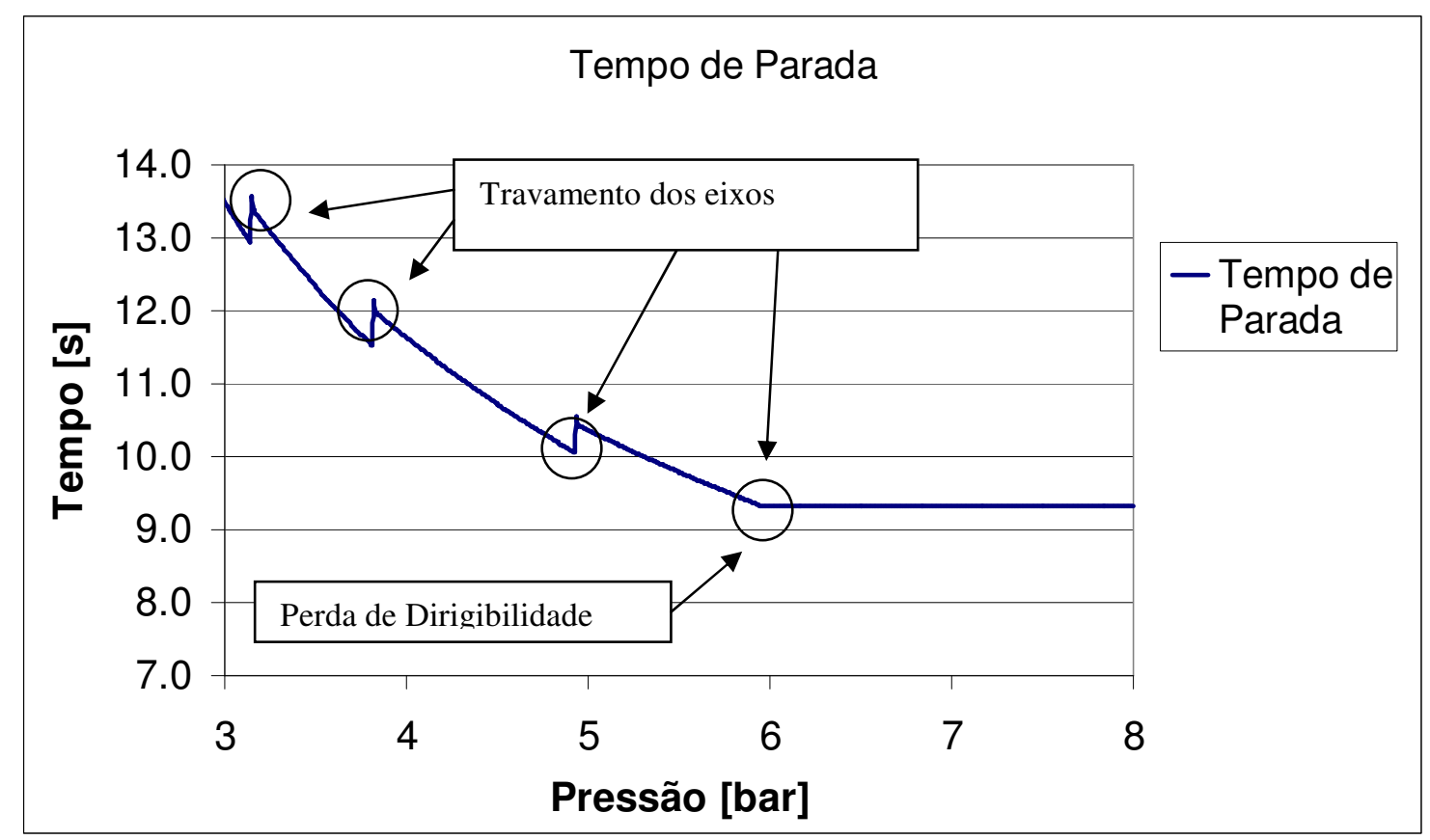

FIGURA 4.11 - Pressão x tempo de parada; veículo carregado sem ABS.

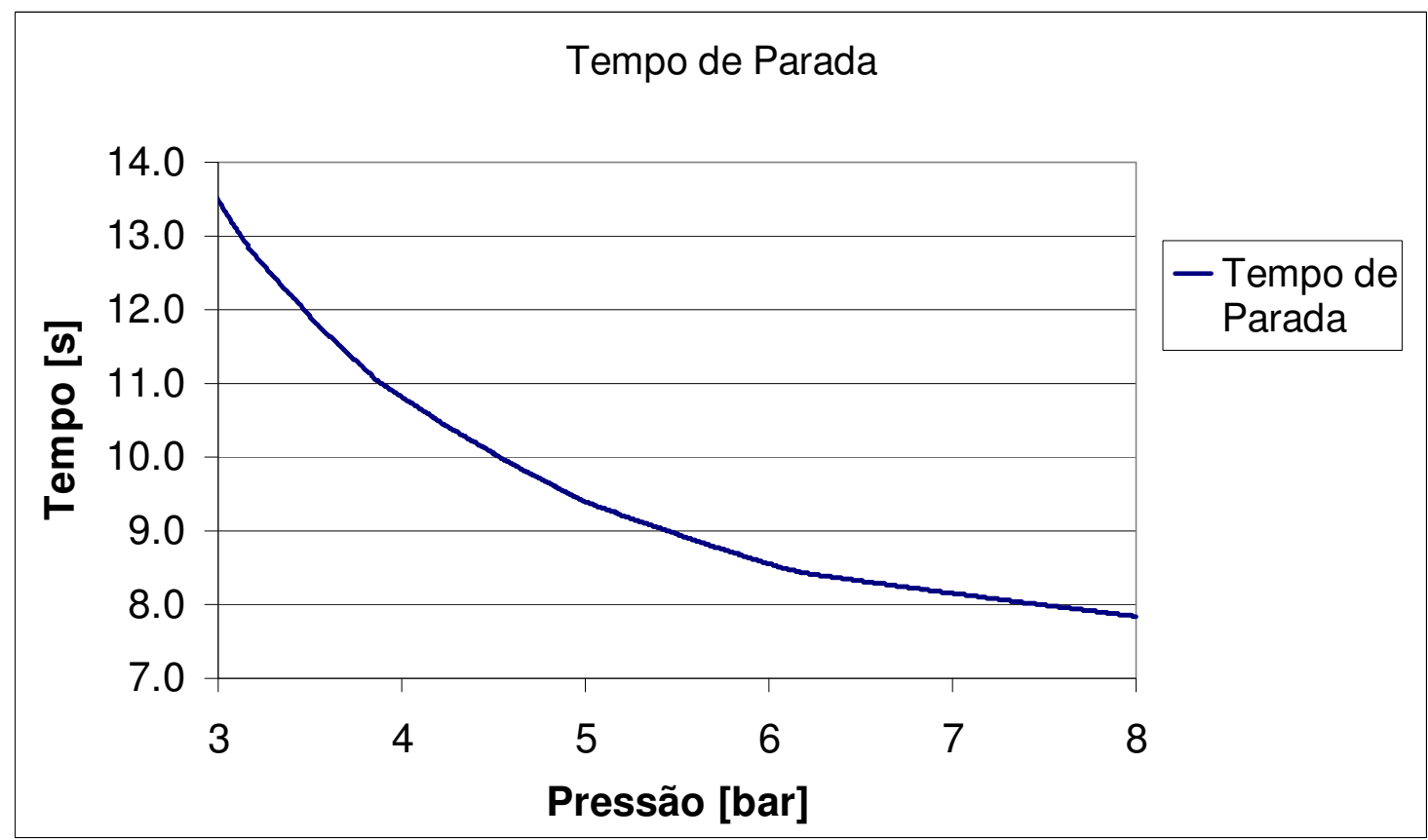

FIGURA 4.12 - Pressão x tempo de parada; veículo carregado com ABS.

A primeira coisa que se observa é que os gráficos de espaço de parada e tempo de parada se "sobrepõem". O que não é surpresa, pois ambos estão relacionados. Nota-se também que o espaço e o tempo de parada diminuem em mais de $10 \%$ quando se utiliza o ABS devido às vantagens proporcionadas 
pelo $A B S$ que já foram comentadas anteriormente. Nota-se também alguns picos nos gráficos para o veículo sem $A B S$ que ocorrem devido ao travamento dos eixos (e por conseqüência a diminuição de desaceleração, ver Figura 4.5). Nesses mesmos gráficos há uma região plana logo que o veículo perde a estabilidade. Num caso real esses valores não ficam constantes. Esse comportamento foi adotado neste trabalho apenas para reforçar que os valores além deste ponto não são relevantes (como já foi feito nos gráficos anteriores). A seguir, os gráficos da temperatura do tambor do sistema de freios após a frenagem são mostrados.

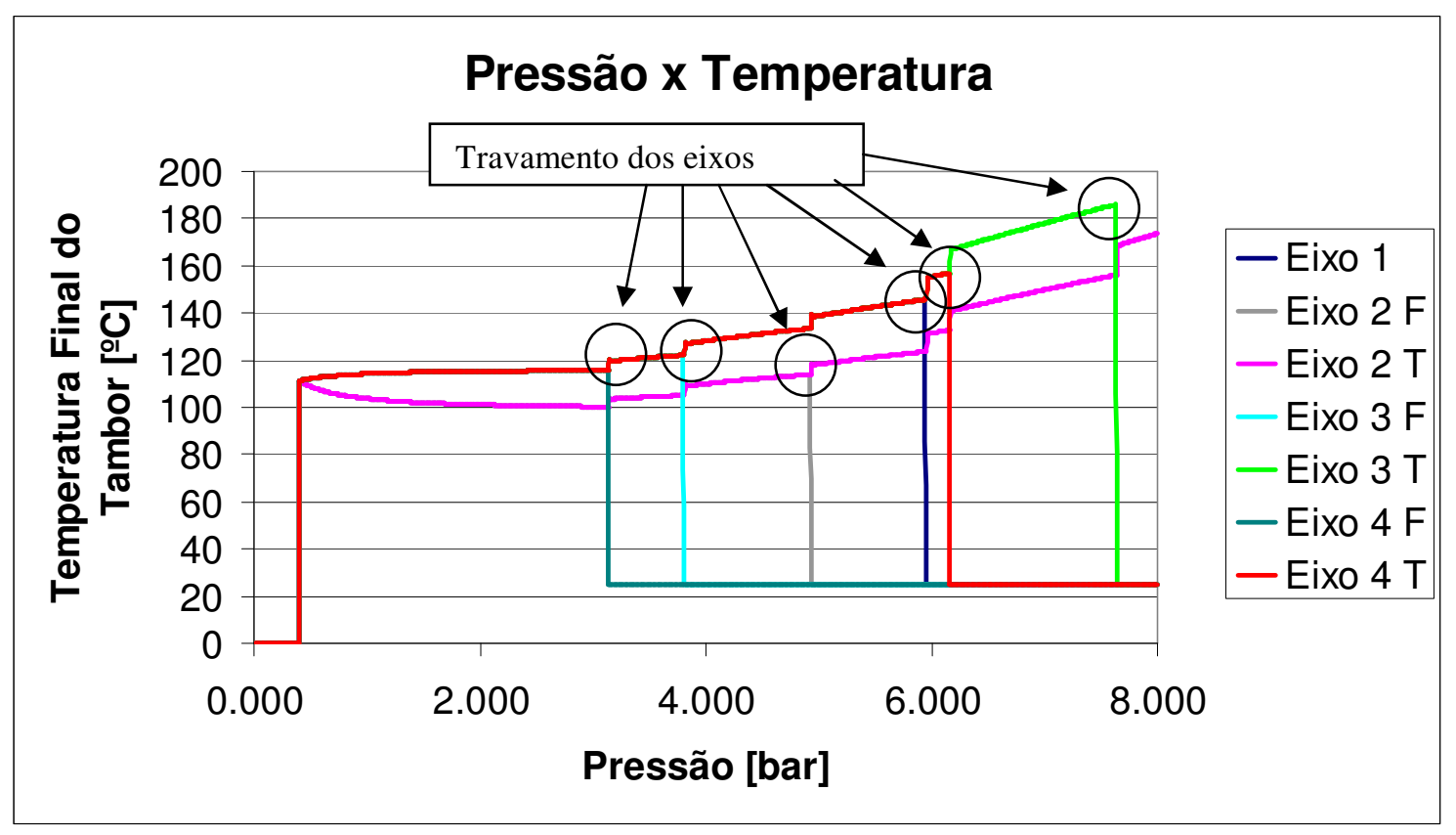

FIGURA 4.13 - Pressão x temperatura final do tambor; veículo carregado sem ABS. 




FIGURA 4.14 - Pressão x temperatura final do tambor; veículo carregado com ABS.

Na Figura 4.13 pode-se observar que quando ocorre o travamento do eixo, a temperatura do tambor passa a ser igual à temperatura do ambiente. Isso ocorre porque, ao travar, a energia já não é mais transferida, em forma de calor, para o tambor e sim para o pneu. O que não é desejado, pois altas temperaturas podem deteriorar o pneumático. Comparando a Figura $4.13 \mathrm{com}$ a 4.14 percebe-se que a temperatura final do tambor no veículo que utiliza ABS é menor. Isso ocorre porque os eixos que não travam no veículo sem ABS são responsáveis por uma parte maior da força de frenagem (ver Figuras $4.15 \mathrm{e}$ 4.16) e, por conseqüência têm que absorver mais energia. O ABS também tende a equilibrar as temperaturas nos freios, evitando picos devido à má distribuição das forças de frenagem. 


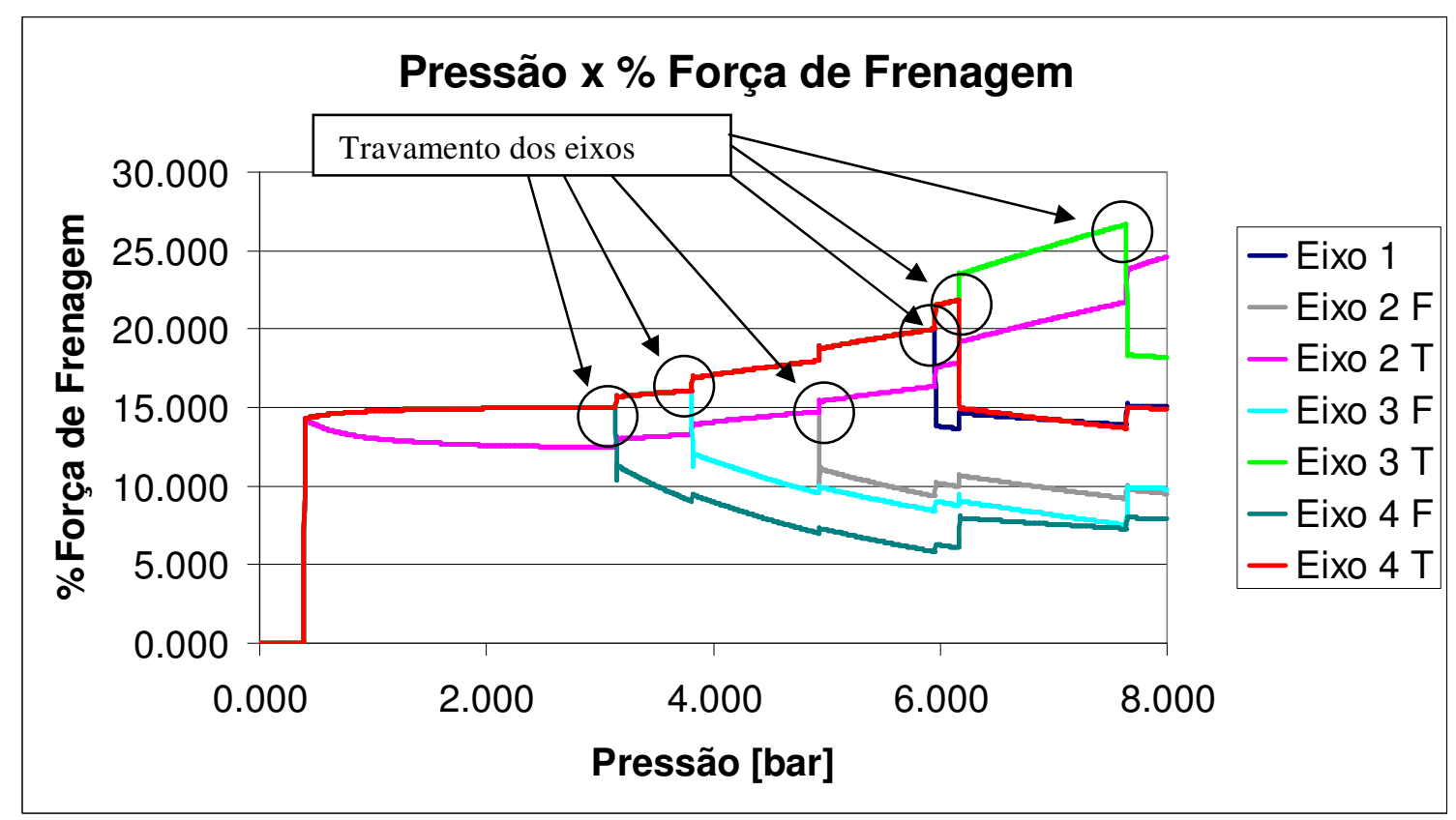

FIGURA 4.15 - Pressão x \% força de frenagem; veículo carregado sem ABS.



FIGURA 4.16 - Pressão x \% força de frenagem; veículo carregado com ABS.

As Figuras 4.15 e 4.16 mostram a porcentagem da força de frenagem de cada eixo em função da pressão. Podemos notar que na Figura 4.15 há uma queda brusca da porcentagem de força de frenagem em alguns eixos. São nesses pontos que ocorrem o travamento dos eixos correspondentes. A queda na "participação" da frenagem ocorre porque, de repente, a aderência utilizada 
cai rapidamente. Já na Figura 4.16, do veículo com ABS, essa queda é bem mais suave e ocorre devido à diminuição da força normal no eixo (ver Figura 4.4). A seguir, nas Figuras 4.17 e 4.18, serão apresentados os gráficos da força de frenagem em cada eixo.

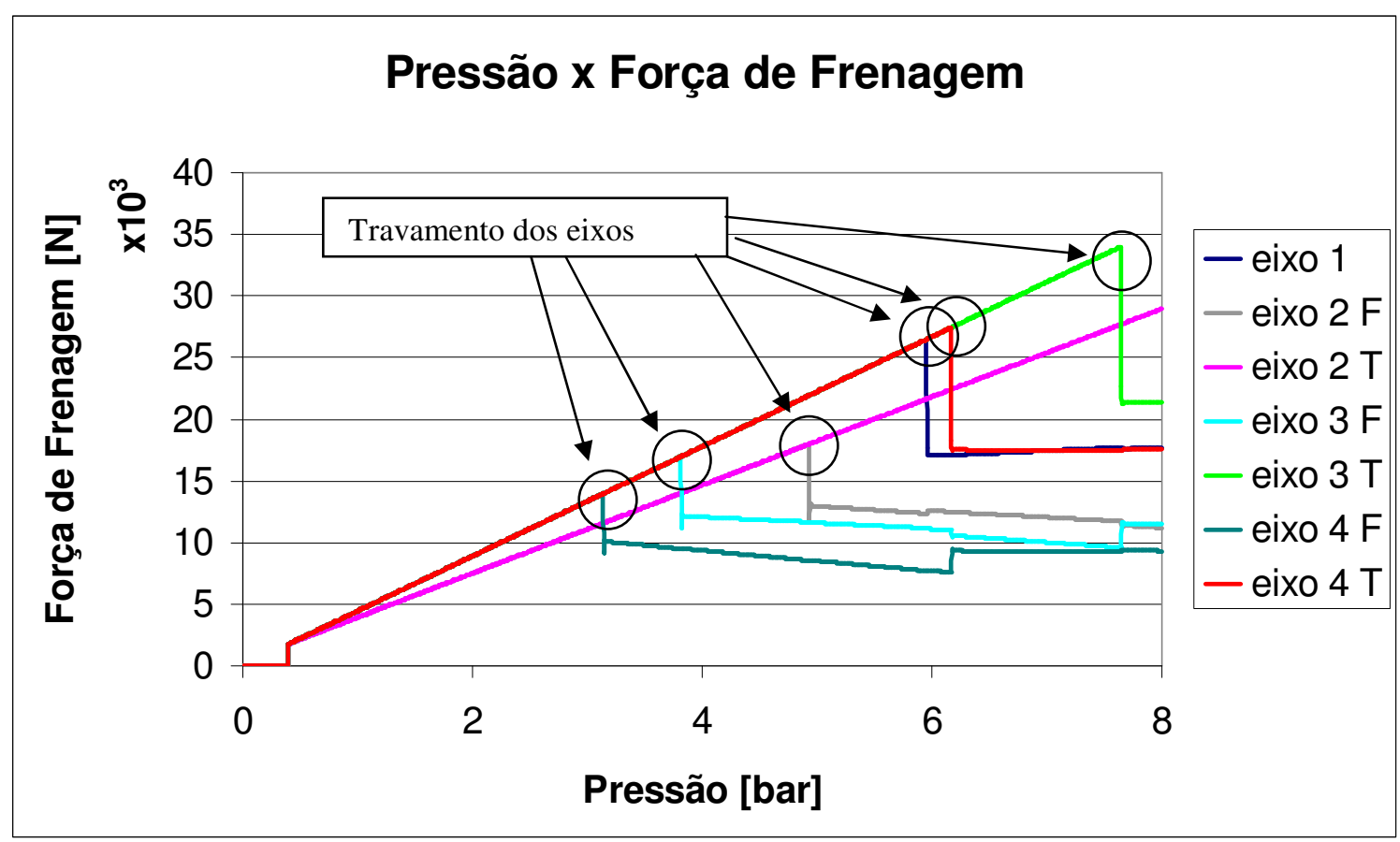

FIGURA 4.17 - Pressão $x$ força de frenagem; veículo carregado sem ABS.

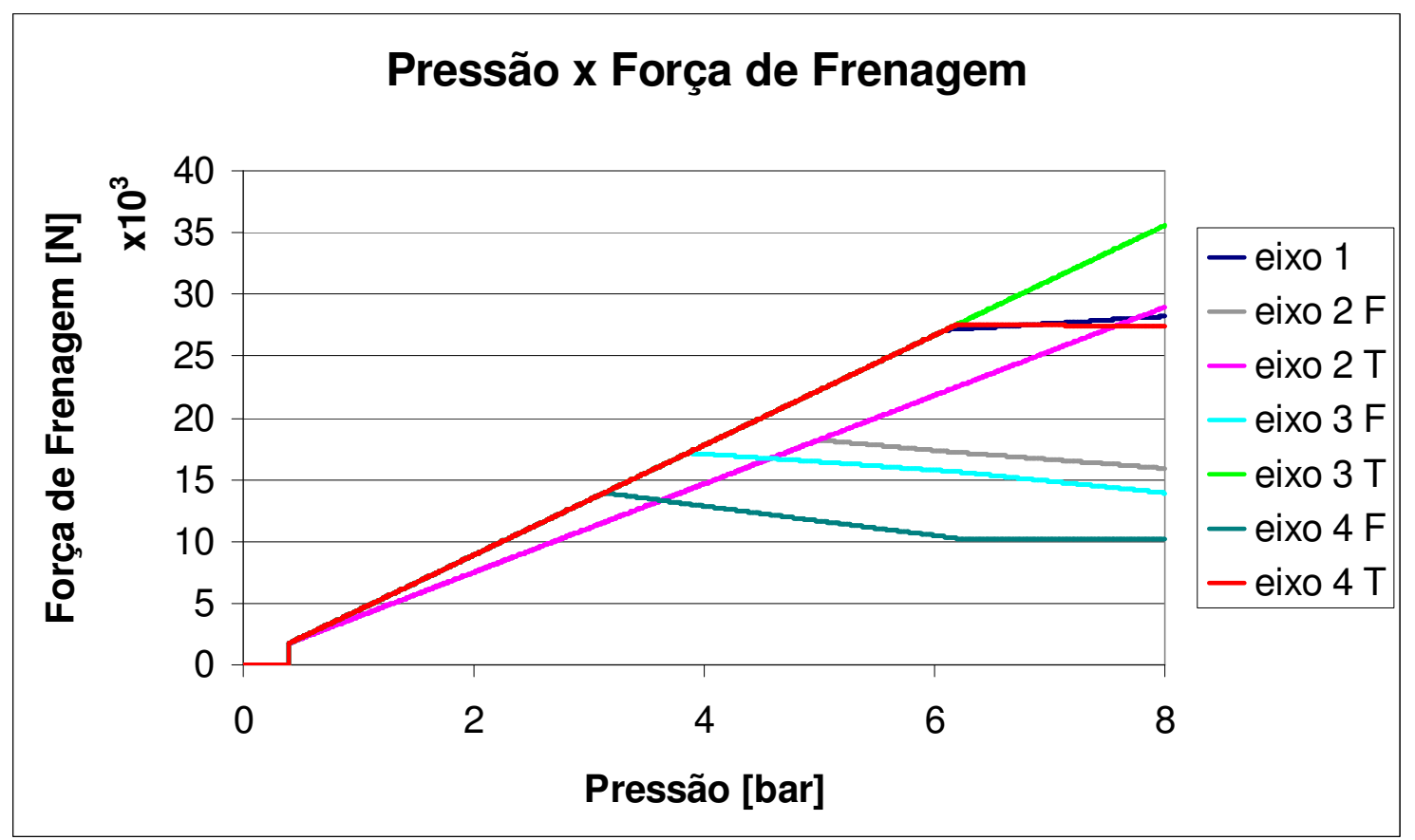

FIGURA 4.18 - Pressão $x$ força de frenagem; veículo carregado com ABS. 
Observando a Figura 4.17 pode-se entender melhor o comportamento mostrado no gráfico 4.15. Pode-se ver o momento em que os eixos travam, e por conseqüência a queda da força de frenagem (resultado da transição do coeficiente de aderência máximo para o coeficiente de aderência de escorregamento). Na Figura 4.18 nota-se que quando os eixos atingem o coeficiente de aderência máximo, a queda da força de frenagem é bem suave (devido à diminuição da força normal).

\subsubsection{Veículo vazio e coeficiente de adesão baixo}

Os gráficos do veículo vazio serão apresentados a seguir. Deve-se lembrar que os semi-reboques e o eixo "tandem" do cavalo mecânico são equipados com uma válvula sensível à carga, ou seja, a pressão de 8 bar mostrada no gráfico não é a pressão que chega no cilindro de freio. A pressão correta seria 1,2 bar como se vê na Figura 4.19 que é a curva da válvula (Os dois semi-reboques usam a mesma válvula).

Não serão apresentados todos os gráficos obtidos com a planilha de cálculos para o veículo vazio. Apenas os mais pertinentes para a comparação.

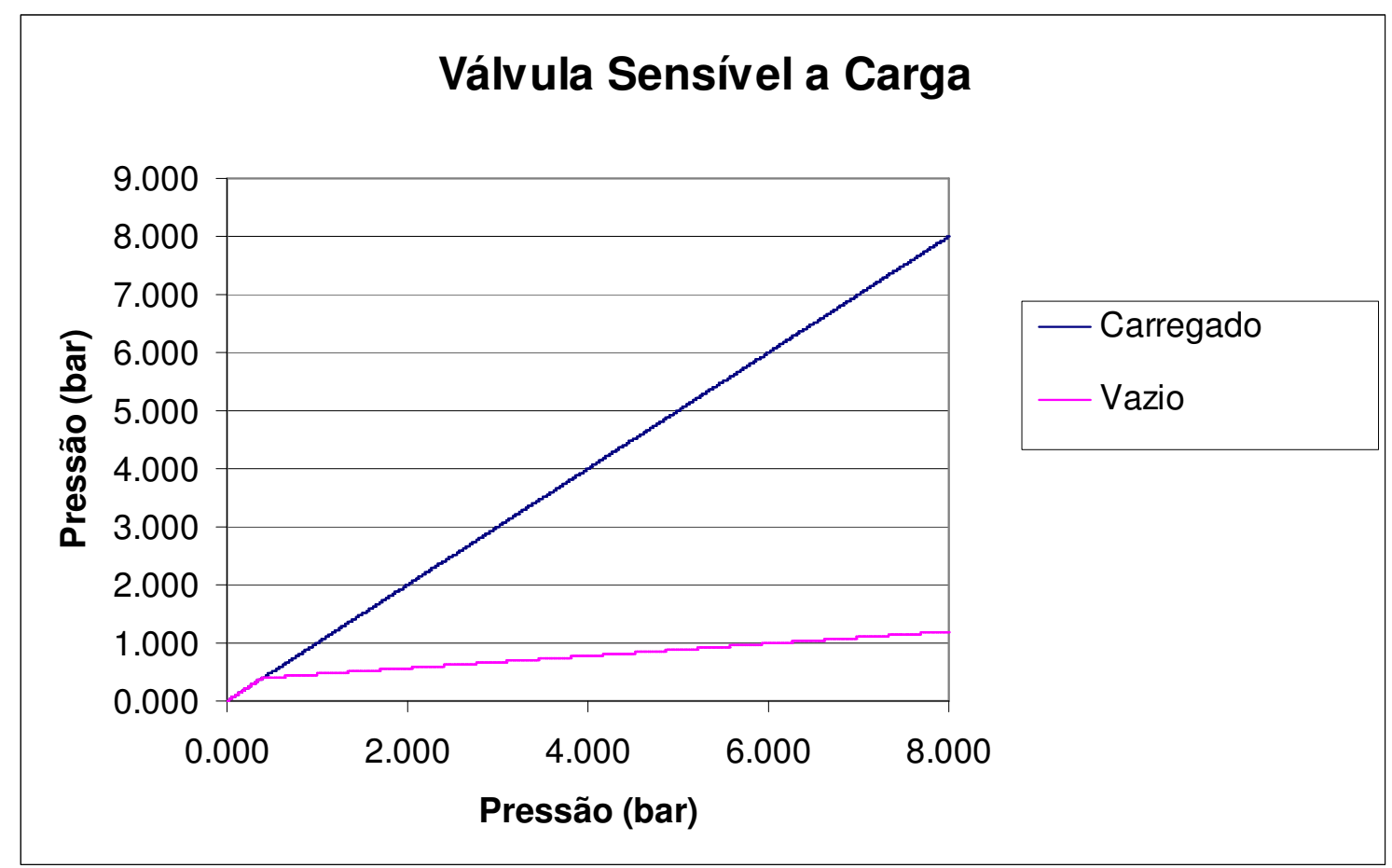

FIGURA 4.19 - Pressão de Entrada x Pressão de Saída; curva da válvula 
Os primeiros gráficos a serem mostrados são os da seqüência de travamento dos eixos (aderência utilizada) sem (Figura 4.20) e com ABS (Figura 4.21).

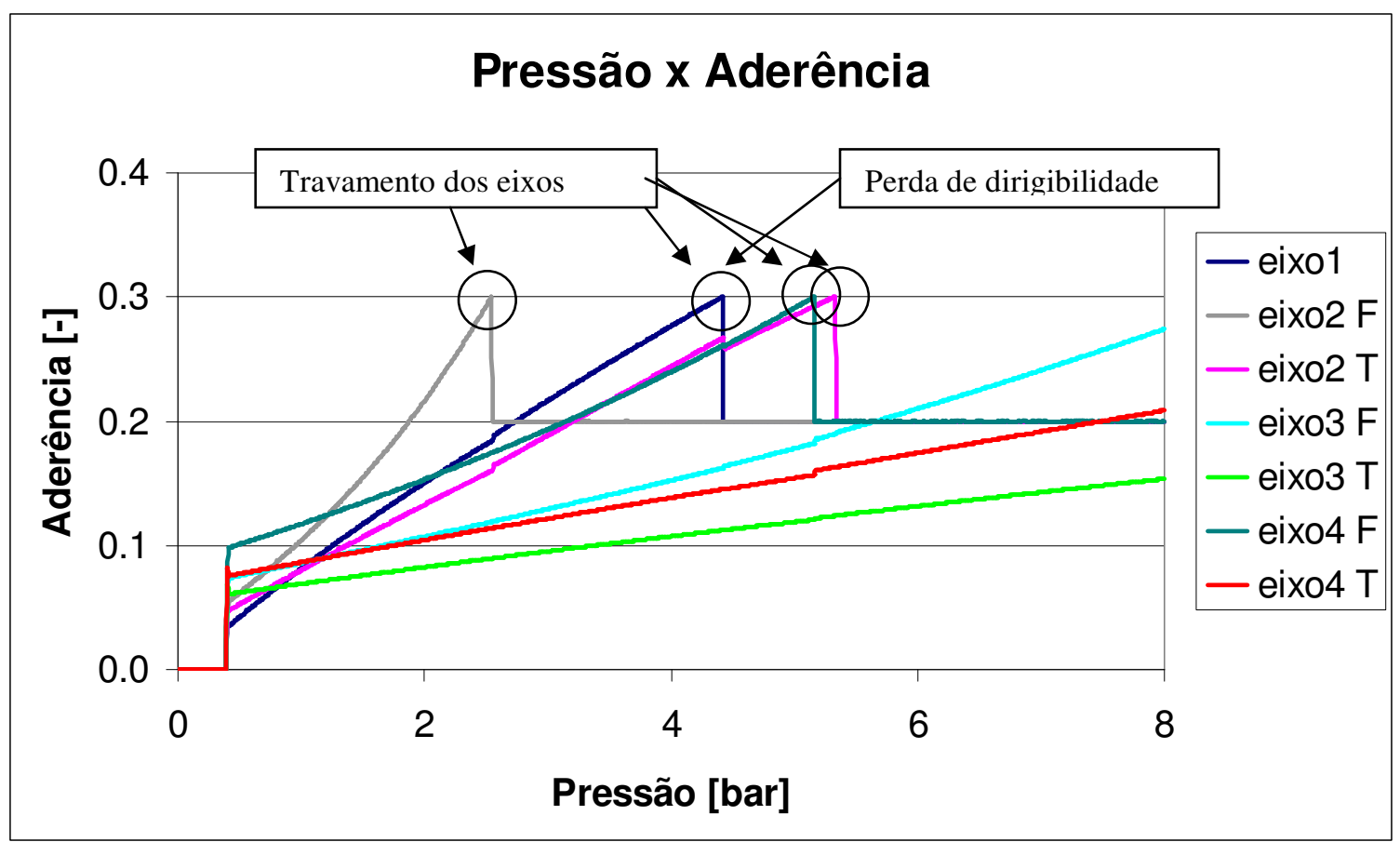

FIGURA 4.20 - Pressão x Aderência utilizada; veículo descarregado; sem ABS

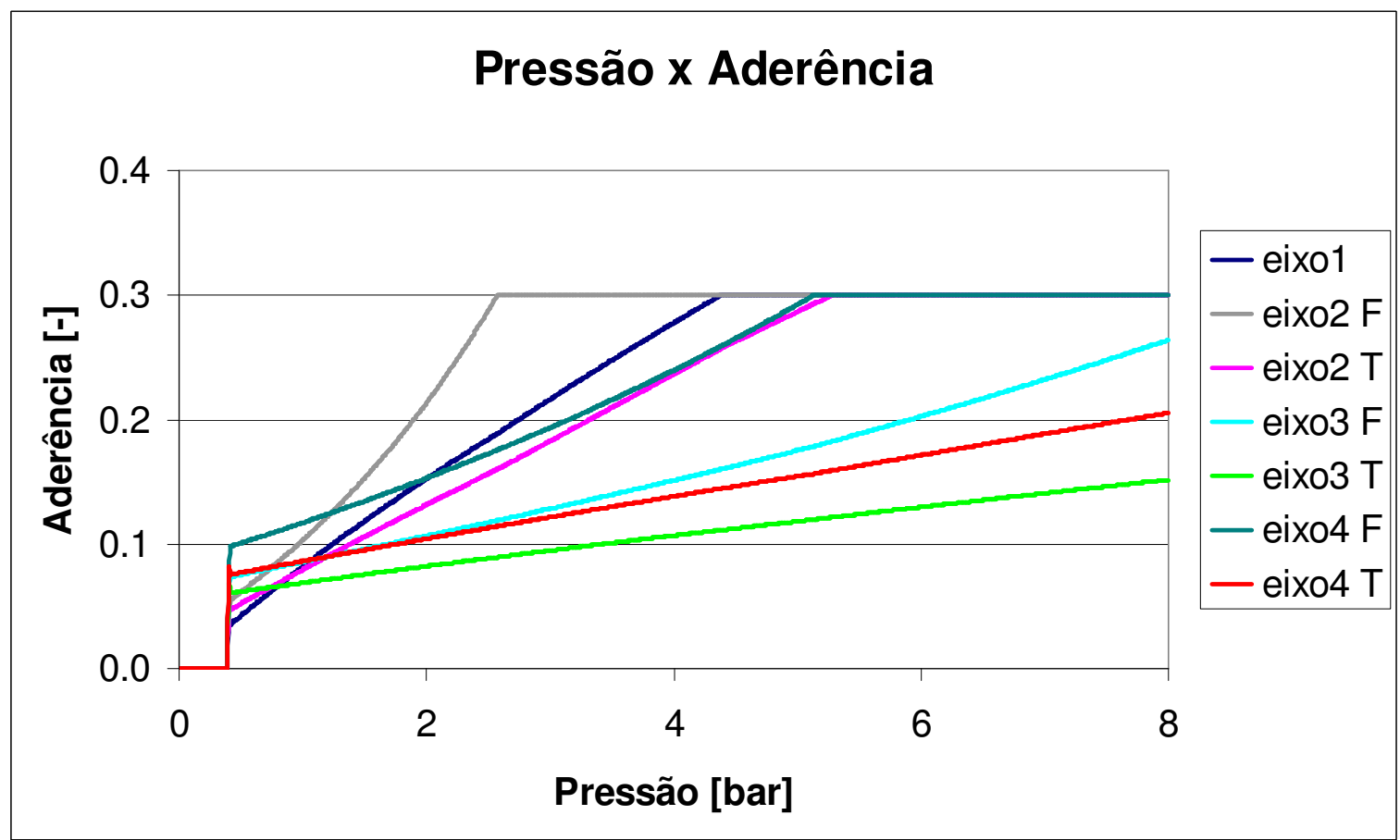

FIGURA 4.21 - Pressão x Aderência utilizada; veículo descarregado; com ABS 
Nestes dois gráficos pode-se ver a grande vantagem proporcionada com o ABS. Essa vantagem se torna evidente em condições adversas à frenagem (com baixa força normal nas rodas e baixa aderência). Percebe-se que, mesmo com o uso da válvula sensível à carga, o veículo perde dirigibilidade muito rápido, com aproximadamente 4 bar de pressão, ou seja, metade do curso do pedal de freio devido ao travamento do eixo dianteiro do cavalo mecânico. Já com o ABS é possível usar o curso todo do pedal de freio sem comprometer a estabilidade. Isso fica claro nos gráficos da eficiência de frenagem (Figuras 4.22 e 4.23$)$.

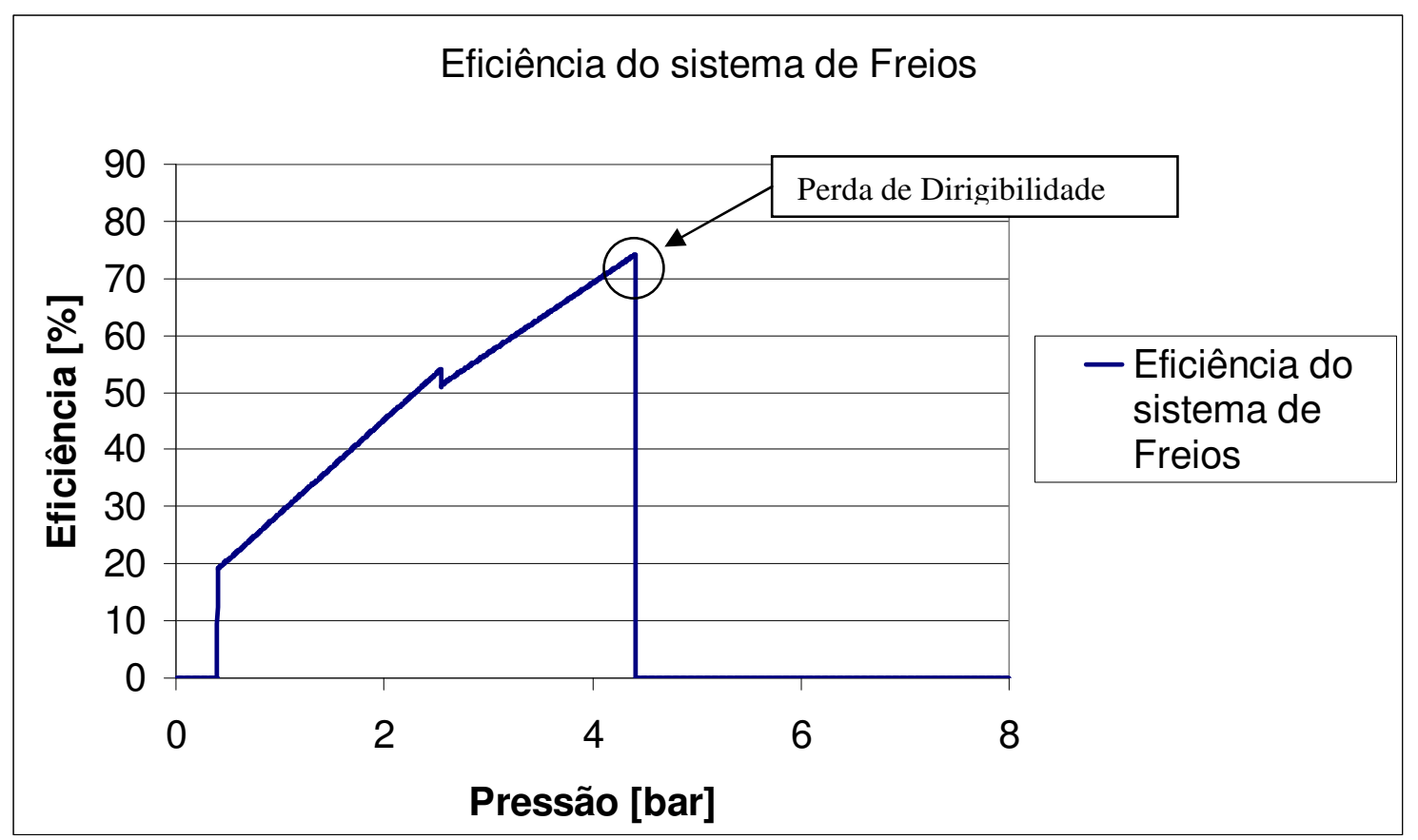

FIGURA 4.22 - Pressão x eficiência do sistema de freios; veículo descarregado sem ABS. 


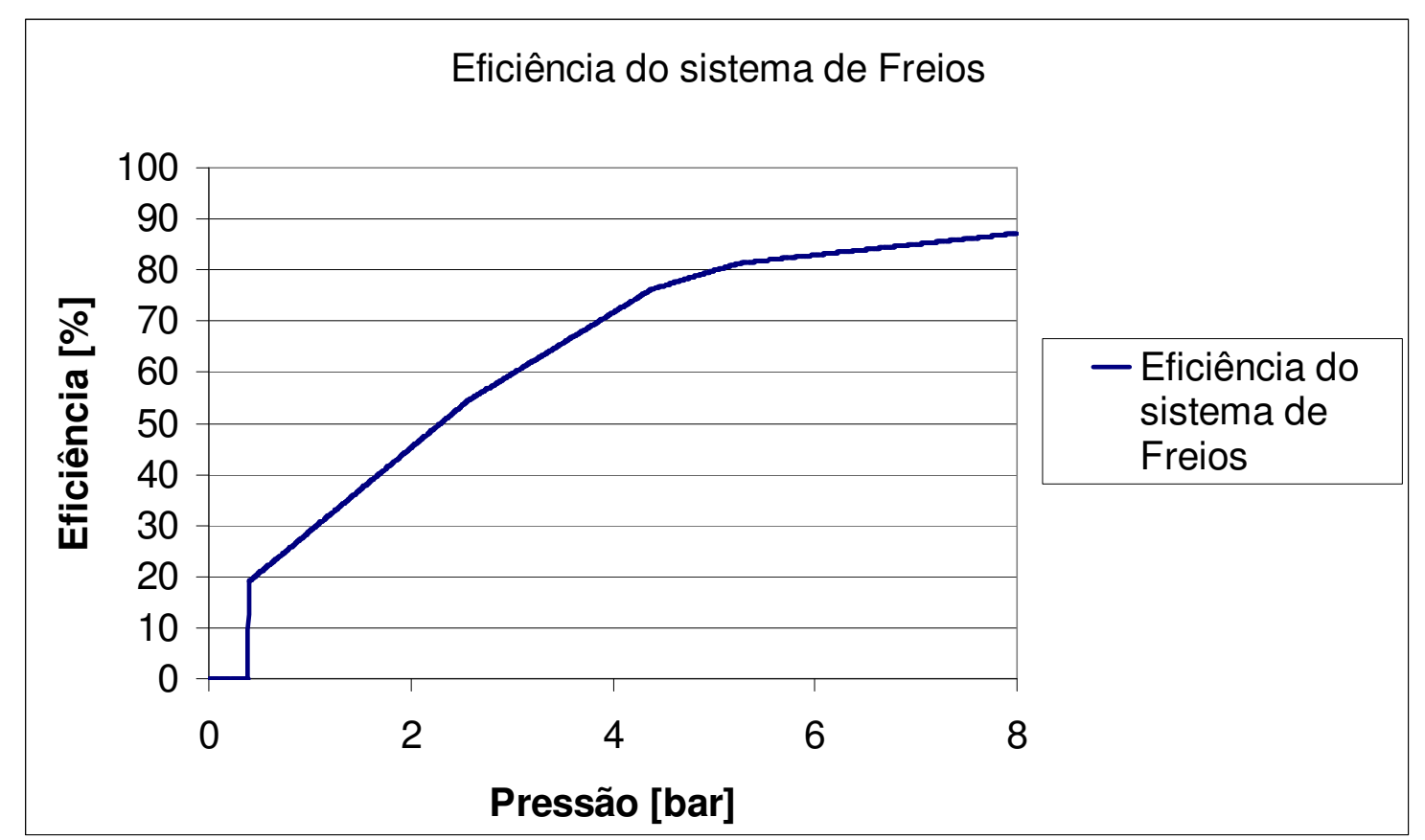

FIGURA 4.23 - Pressão x eficiência do sistema de freios; veículo descarregado com ABS

Pode-se notar que a eficiência da frenagem com o veículo descarregado é menor comparado com o mesmo veículo carregado (tanto no veículo equipado com $A B S$ quanto no sem $A B S$ ). Isso ocorre, primeiro porque com menos força normal sobre as rodas, menor será a força de frenagem. Segundo, devido às válvulas reguladoras de pressão, a força de frenagem se reduz ainda mais. Terceiro, no caso em que não se utiliza ABS, a perda de estabilidade acontece muito rápido, o que leva a perda de eficiência. As Figuras 4.26 e 4.27 mostram como seria a eficiência caso não se utilizasse as válvulas.

Para completar são mostrados a seguir, nas Figuras 4.24 e 4.25 , os gráficos de desaceleração sem e com ABS respectivamente. 


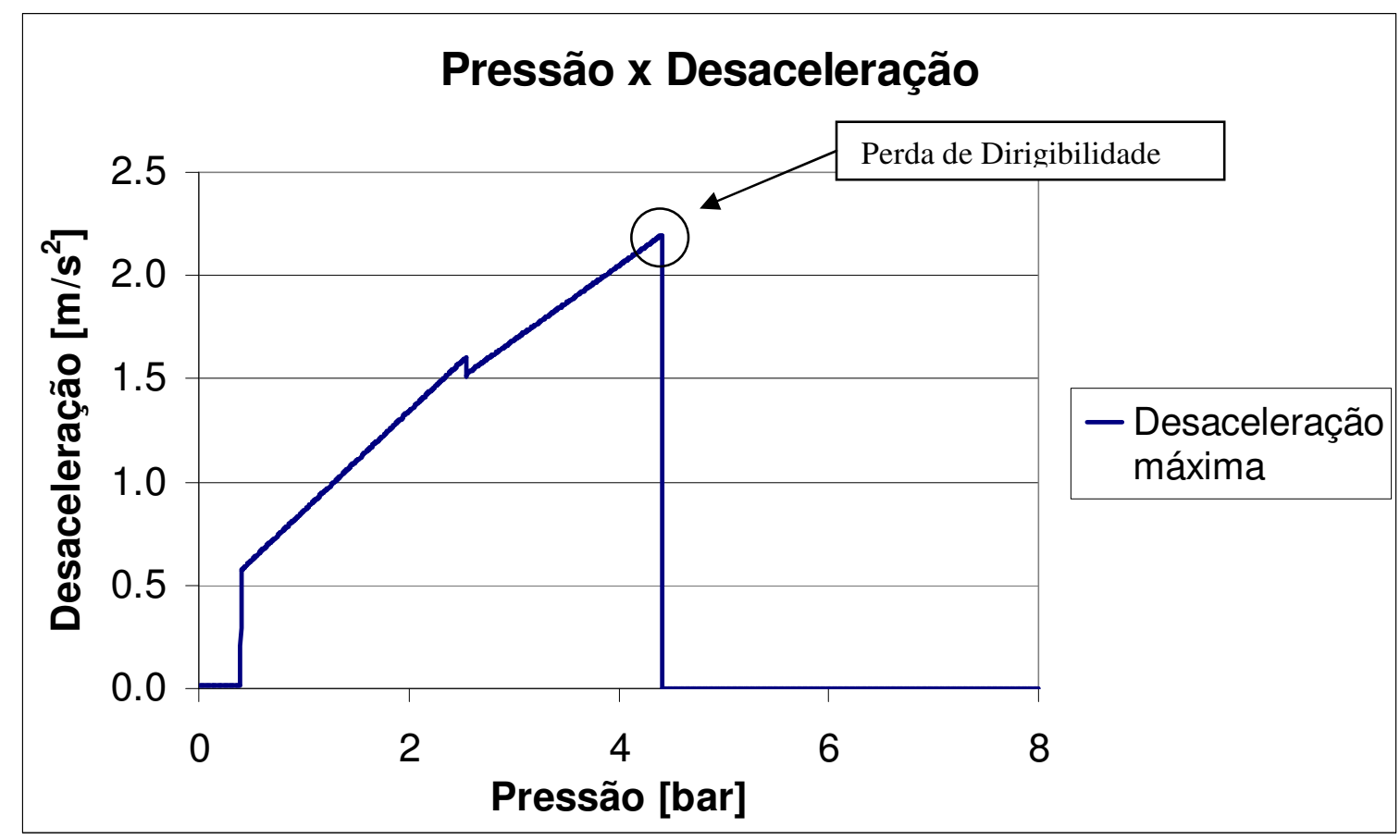

FIGURA 4.24 - Pressão x desaceleração máxima; veículo descarregado sem $\mathrm{ABS}$

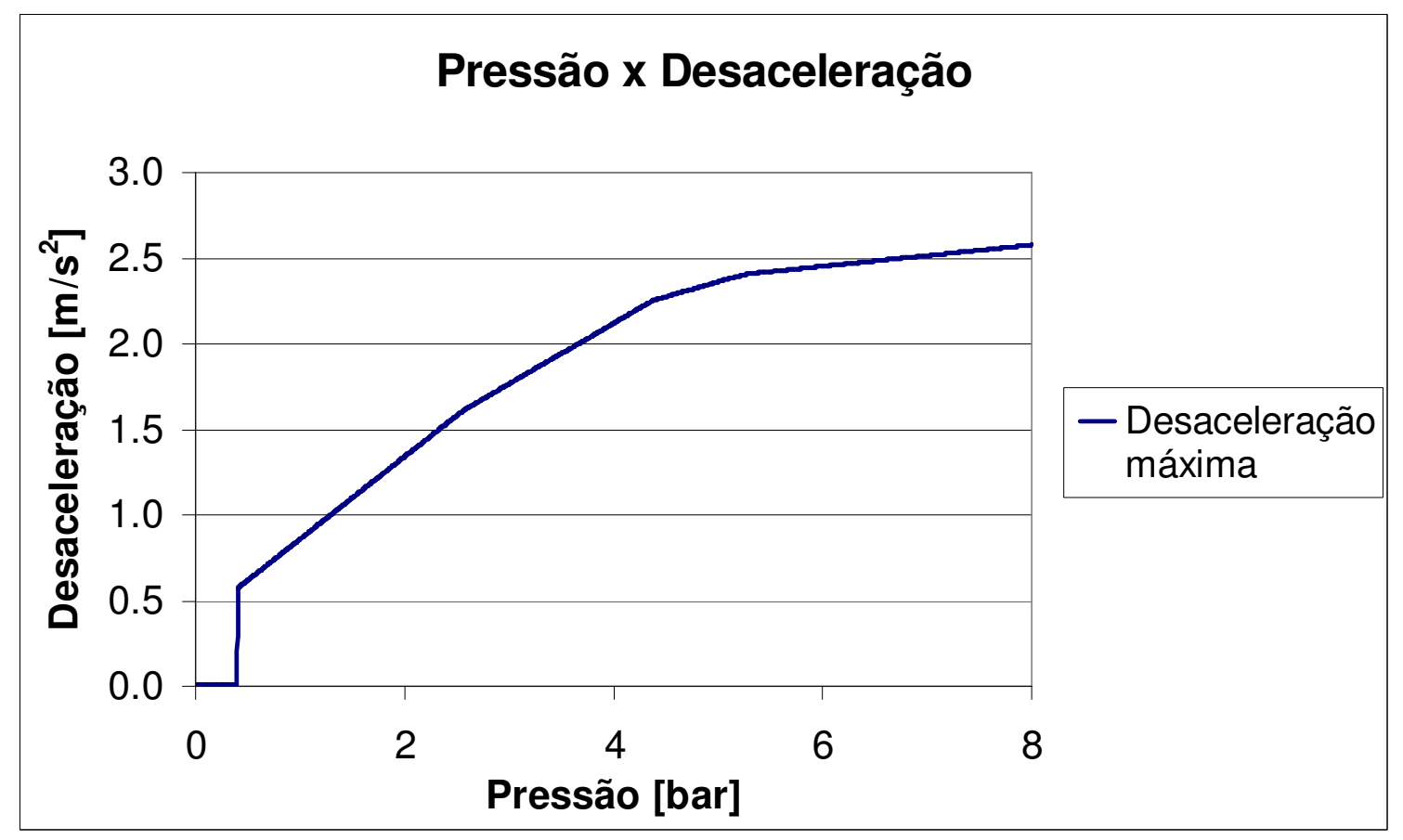

FIGURA 4.25 - Pressão x desaceleração máxima; veículo descarregado com ABS

Como já era esperado, a desaceleração do veículo que utiliza ABS é maior do que a desaceleração do veículo sem ABS. Isso ocorre devido ao 
travamento do eixo dianteiro do cavalo mecânico fazendo com que, sem ABS, o veículo perca dirigibilidade. Caso não se utilizasse as válvulas sensíveis à carga, a diferença seria ainda maior, como mostrado nas Figuras a seguir.

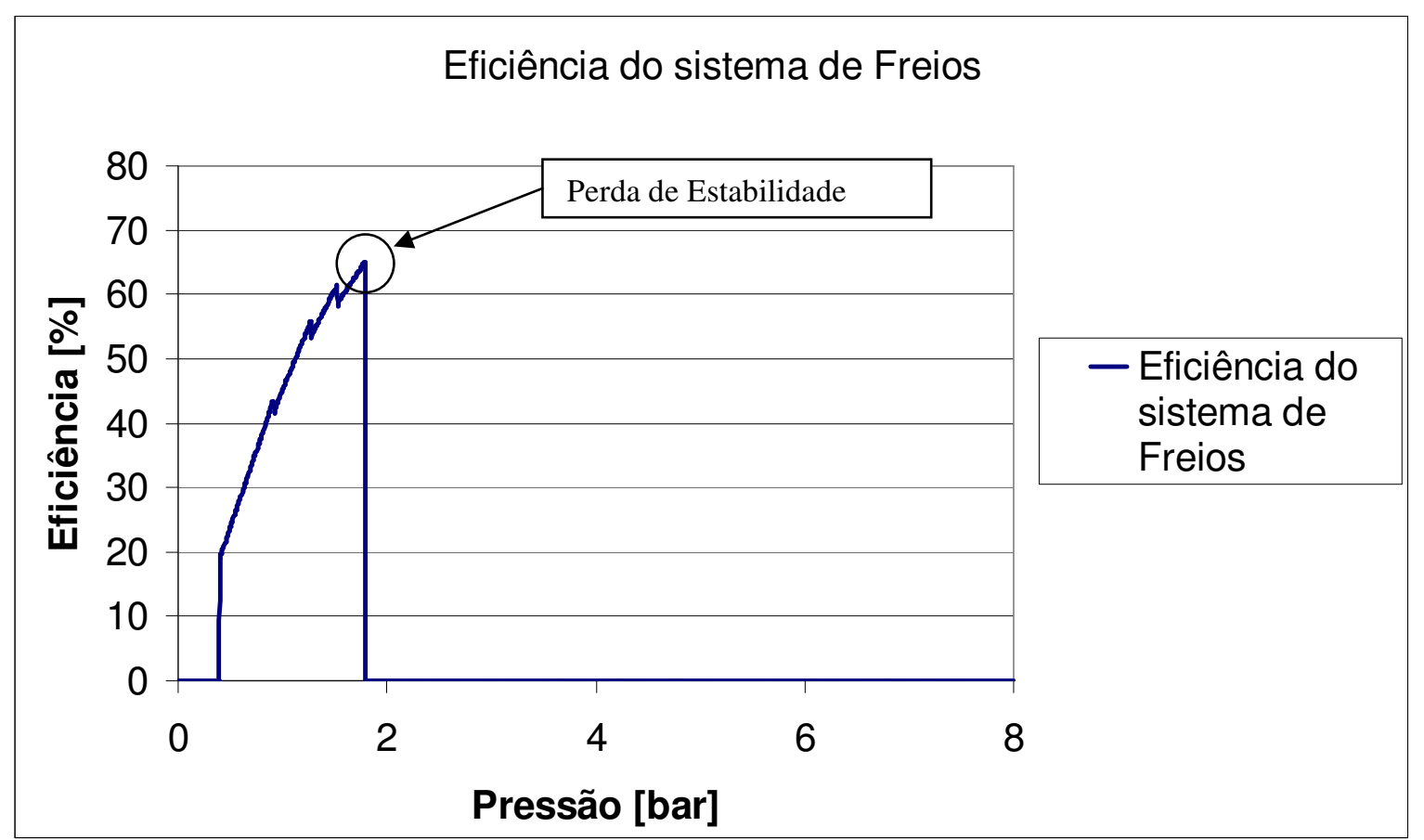

FIGURA 4.26 - Pressão x eficiência do sistema de freios; veículo descarregado sem ABS e sem válvula reguladora

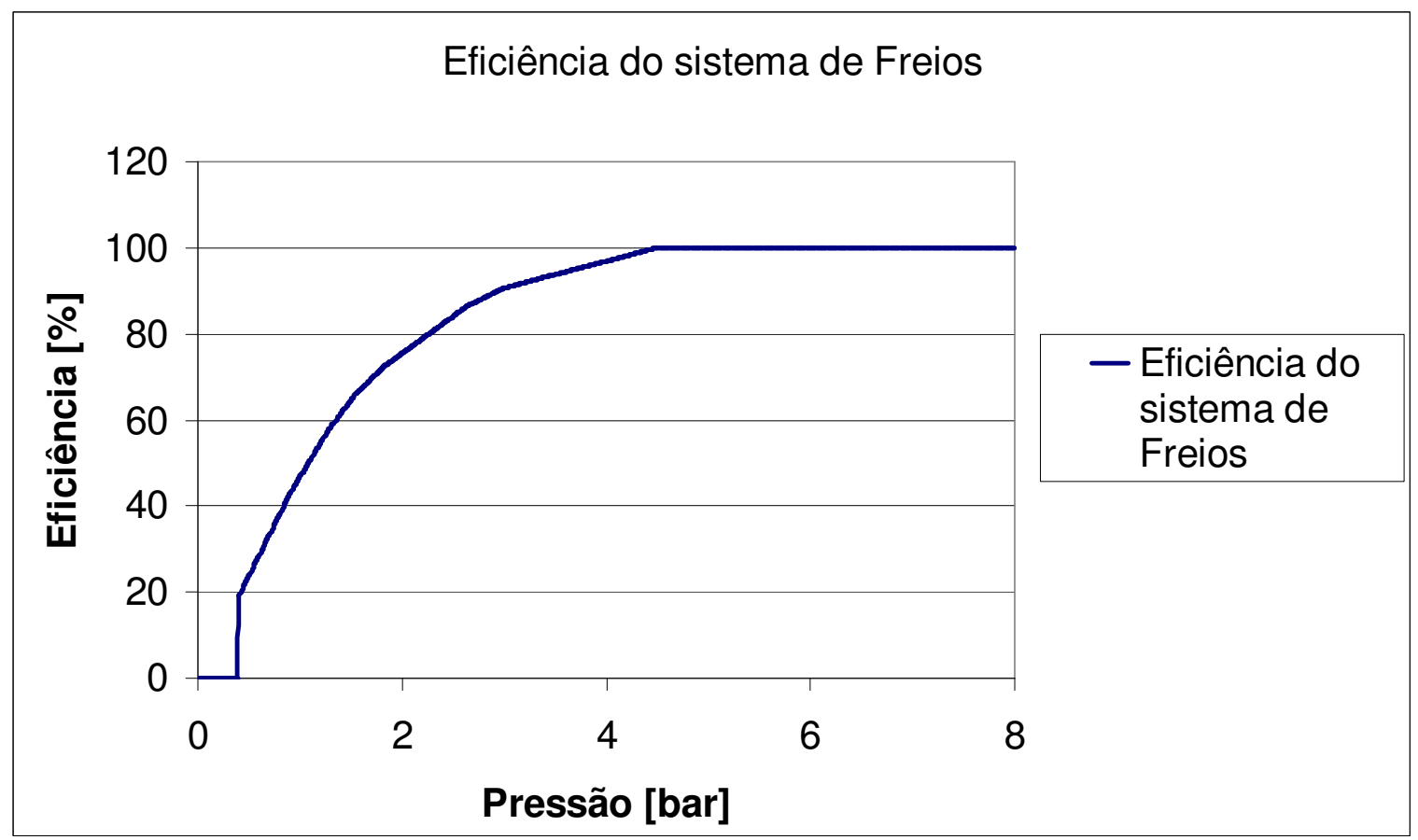

FIGURA 4.27 - Pressão x eficiência do sistema de freios; veículo descarregado com ABS e sem válvula reguladora. 
Quando não se utilizam as válvulas, o veículo que está equipado com ABS atinge $100 \%$ de eficiência (lembrando que se trata de um caso ideal), o que é obvio se pensar que o ABS é um equipamento desenvolvido para se obter segurança em pistas com baixa aderência e pouca força normal. Vale lembrar que esse resultado também poderia ser obtido com a utilização das válvulas, desde que essas estivessem bem reguladas. A eficiência aumentou um pouco também quando não se utiliza $A B S$. No entanto isso também se deve ao fato de as válvulas não estarem bem reguladas.

\subsubsection{Veículo carregado e coeficiente de adesão alto}

O próximo passo é apresentar os resultados obtidos com o veículo carregado e em pista de alta aderência. A ordem a ser seguida na apresentação dos resultados é a mesma utilizada para a simulação em baixa aderência, ou seja, as Figuras 4.28 e 4.29 mostram a seqüência de travamento dos eixos sem e com ABS respectivamente.

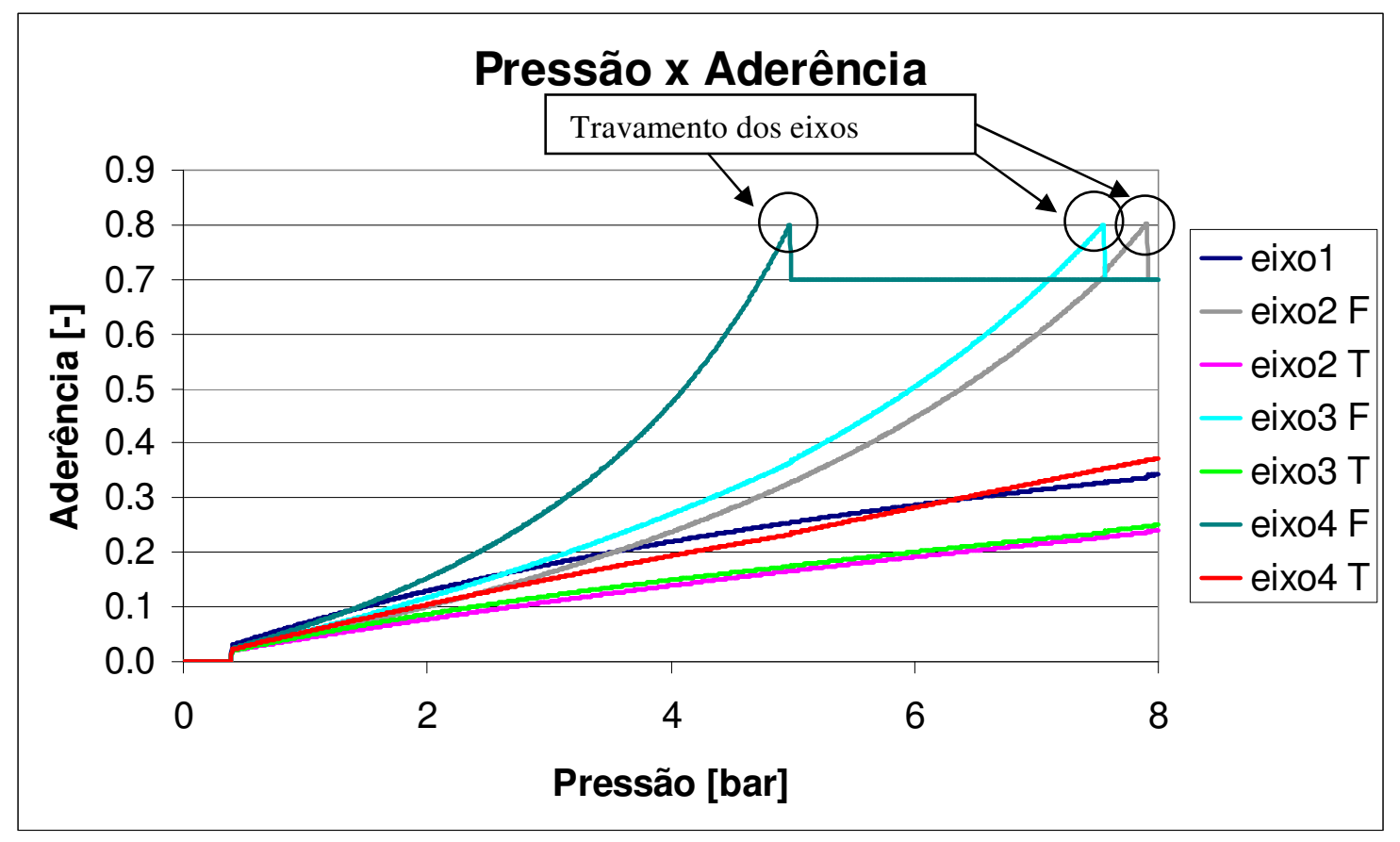

FIGURA 4.28 - Pressão x Aderência utilizada; veículo carregado; sem ABS 


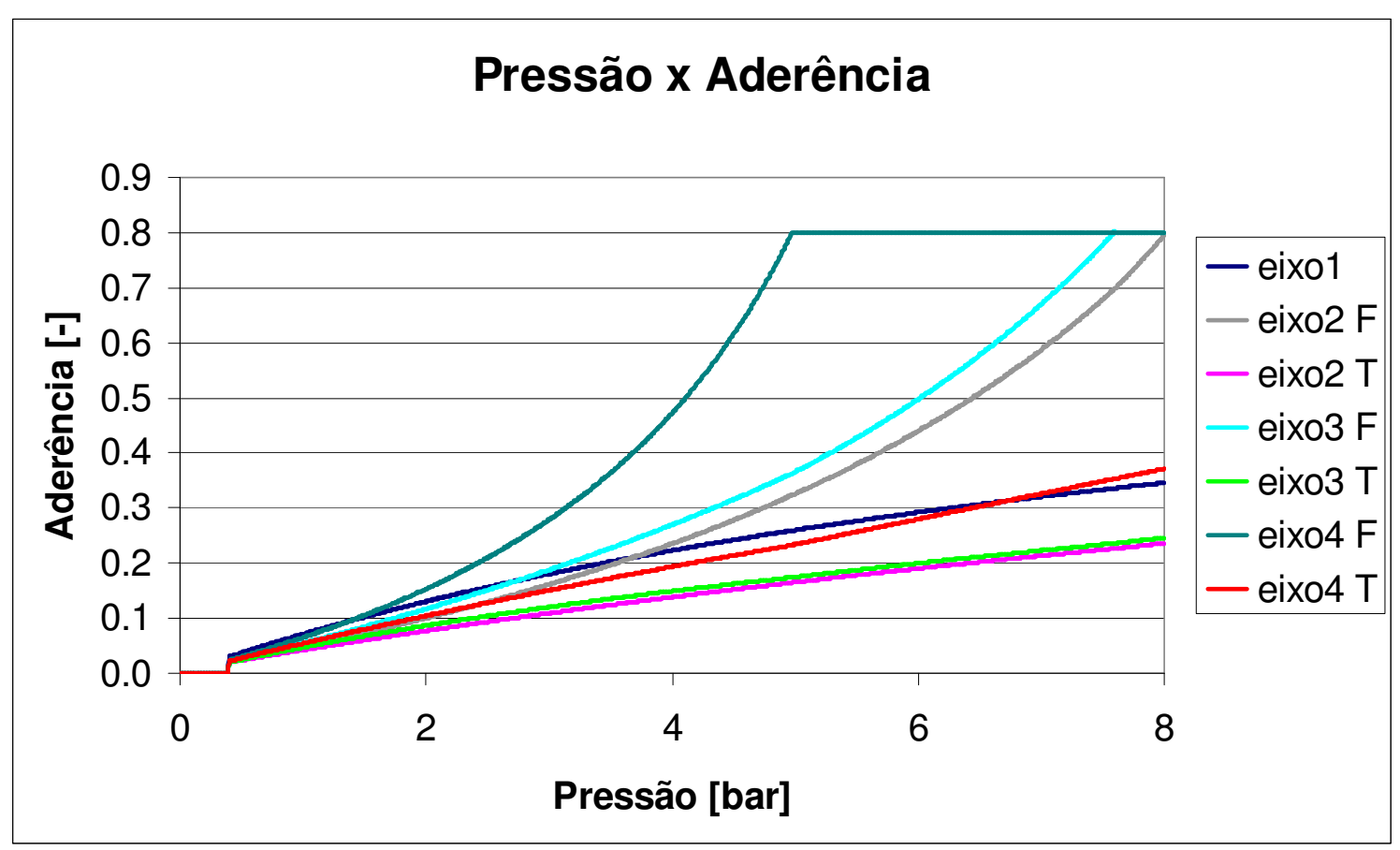

FIGURA 4.29 - Pressão x Aderência utilizada; veículo carregado; com ABS.

Analisando-se os gráficos acima, percebe-se que o freio deste veículo esta sub-dimensionado (basta ver os gráficos de eficiência mais adiante). Muitos eixos ficam bem longe do coeficiente de aderência máximo, o que quer dizer que as forças de frenagem nesses eixos são bem menores que a máxima possível. Aparentemente os freios desse veículo foram otimizados para pistas de baixa aderência, diminuindo o desempenho do mesmo em pistas de alta aderência. Percebe-se também que, aqui, não há perda de estabilidade. As Figuras 4.30 e 4.31 mostram as forças de reação do pavimento (forças verticais nos eixos). 


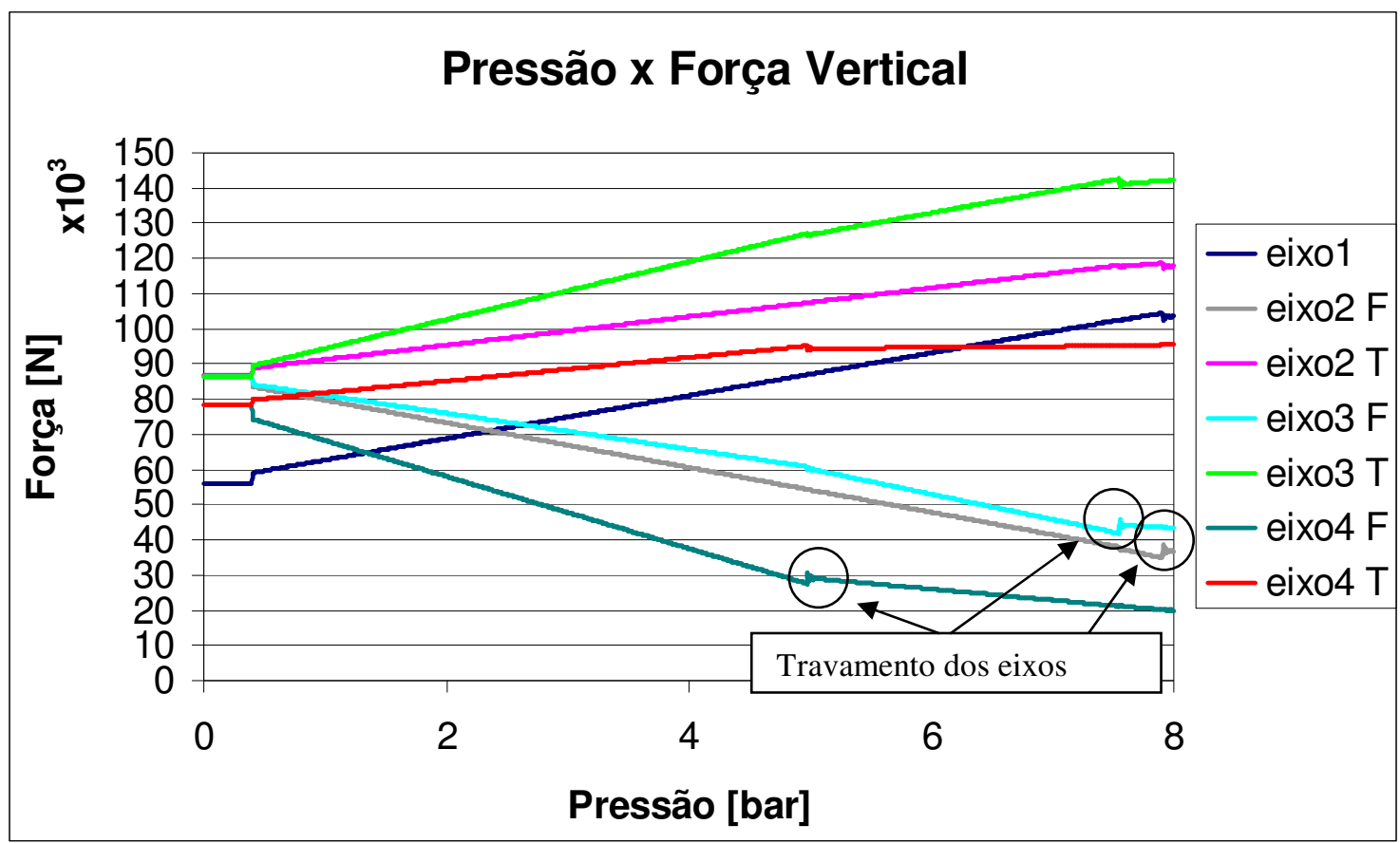

FIGURA 4.30 - Pressão x forças normais ao solo; veículo carregado sem ABS

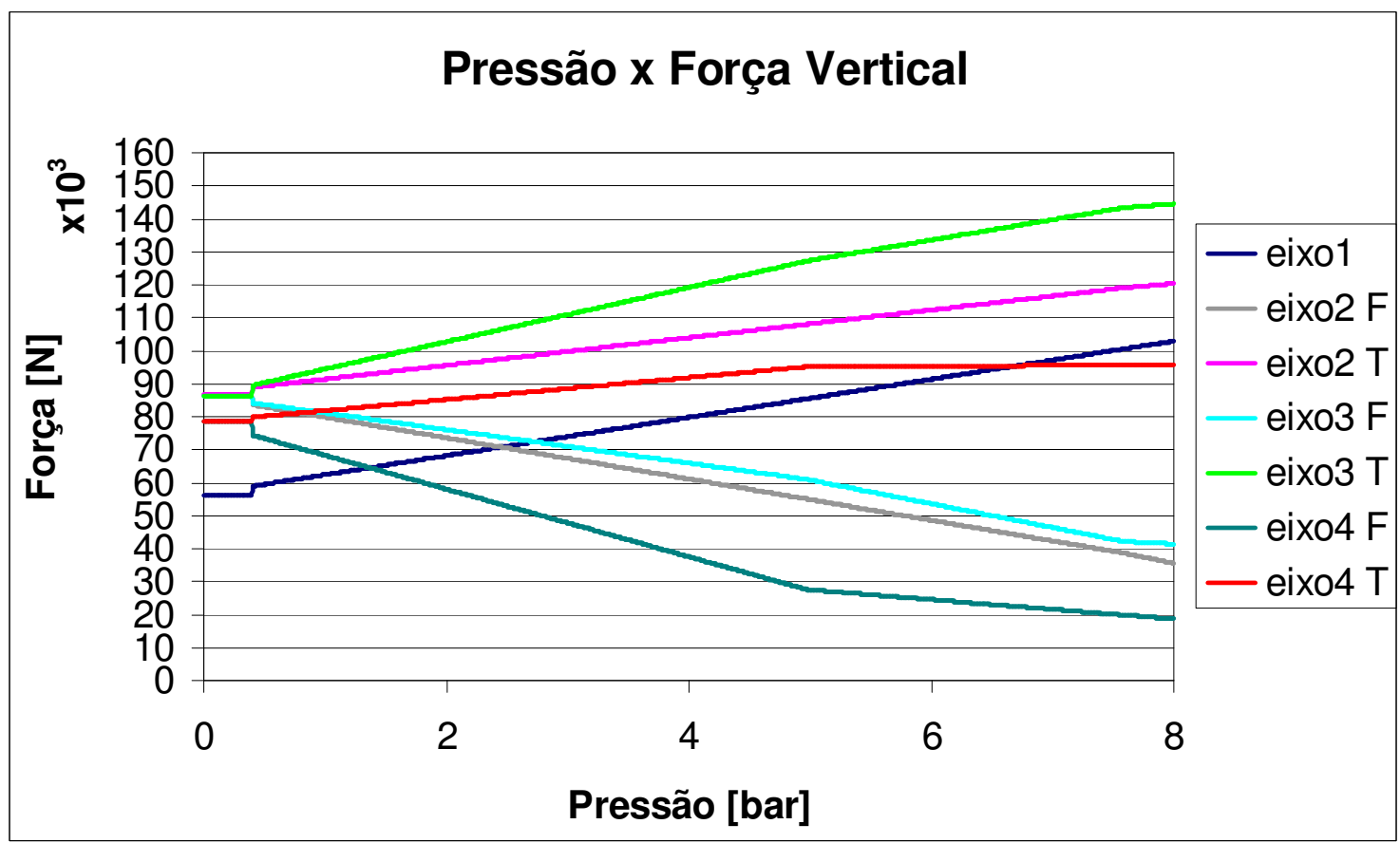

FIGURA 4.31 - Pressão $x$ forças normais ao solo; veículo carregado com ABS

Nas Figuras acima (Figuras 4.30 e 4.31) percebe-se que os eixos que mais têm aumento da força normal são o eixo dianteiro do cavalo mecânico e o eixo traseiro do "tandem" do primeiro semi-reboque (do mesmo modo que em 
pistas de baixa aderência). Em ambos, o ganho é de aproximadamente 40.000 $\mathrm{N}$ com as cargas nos eixos podendo ultrapassar os $130.000 \mathrm{~N}$.

As Figuras seguintes (4.32 e 4.33) apresentam a desaceleração conseguida pelo veículo

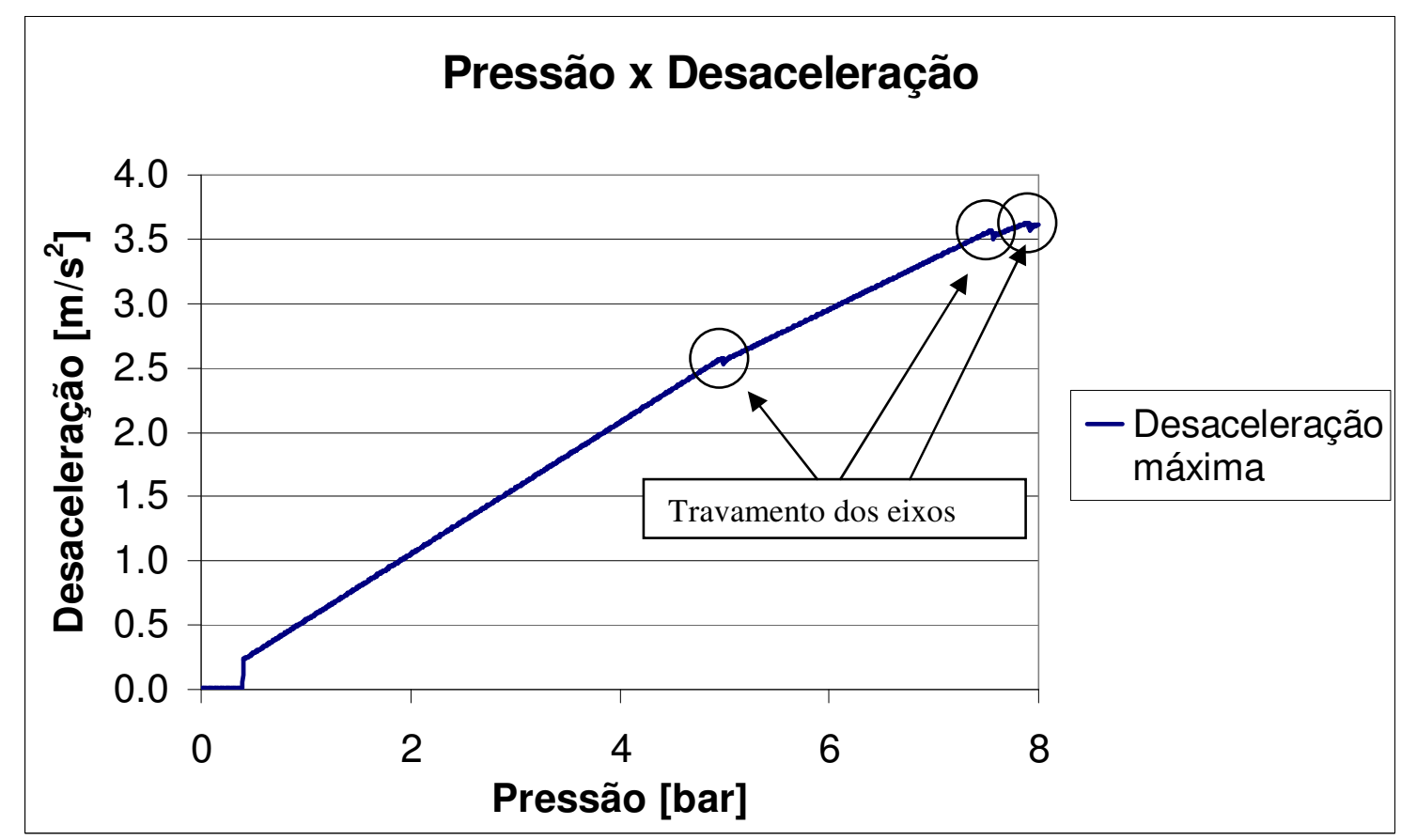

FIGURA 4.32 - Pressão x desaceleração máxima; veículo carregado sem ABS

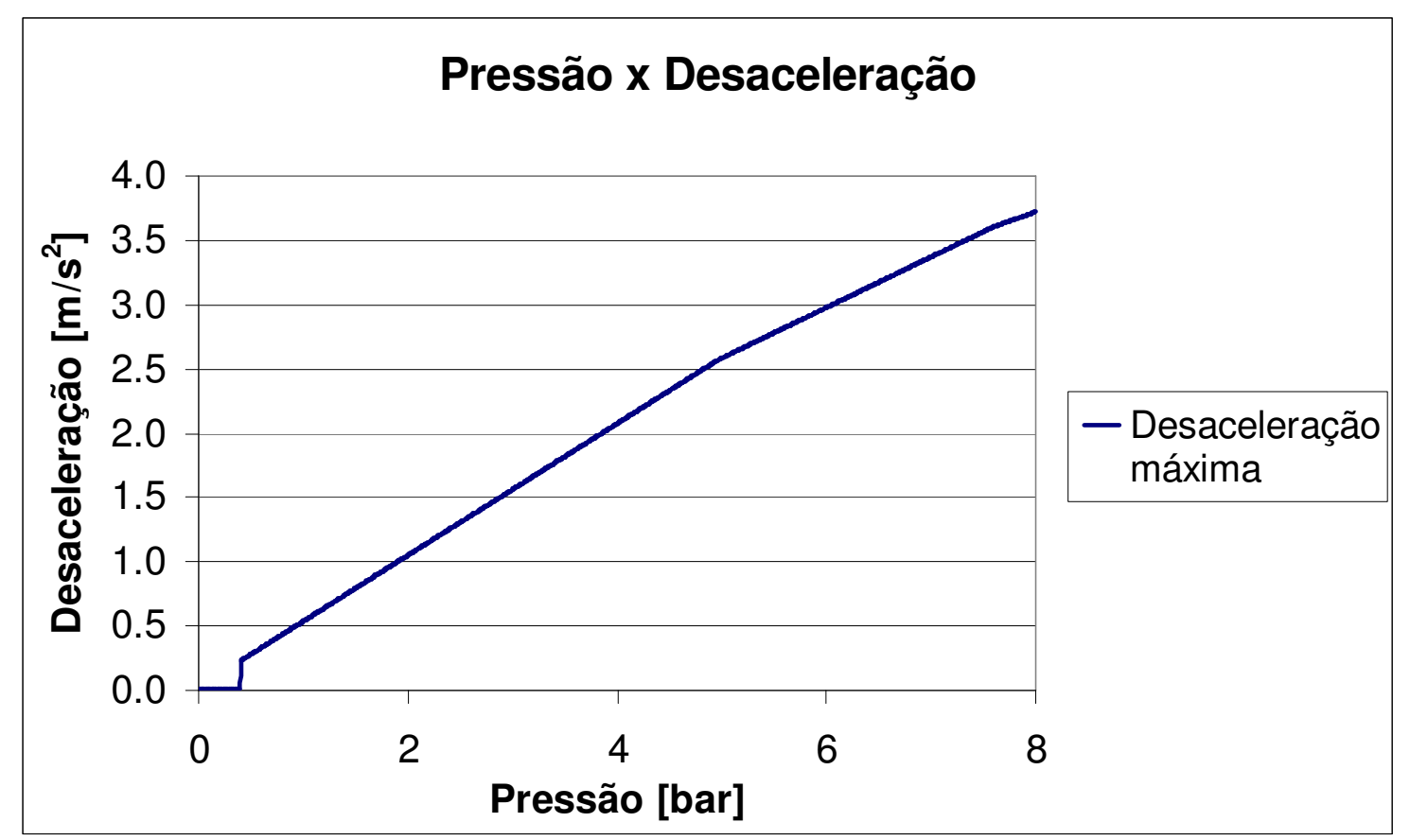

FIGURA 4.33 - Pressão x desaceleração máxima; veículo carregado e com ABS 
Como já era esperado, a desaceleração em pista seca (de alta aderência) é maior que em pistas de baixa aderência. Mas como já foi visto, o sistema de freios está sub-dimensionado o que significa que a desaceleração poderia ser ainda maior. Se o sistema de freios tivesse $100 \%$ e eficiência a desaceleração máxima seria de $\mu_{0} \mathrm{~g}$, ou seja, algo em torno de $7,8 \mathrm{~m} / \mathrm{s}^{2}$, praticamente o dobro da que foi conseguida. Isso fica bem claro nas Figuras a seguir (4.34 e 4.35) que mostram a eficiência do sistema.

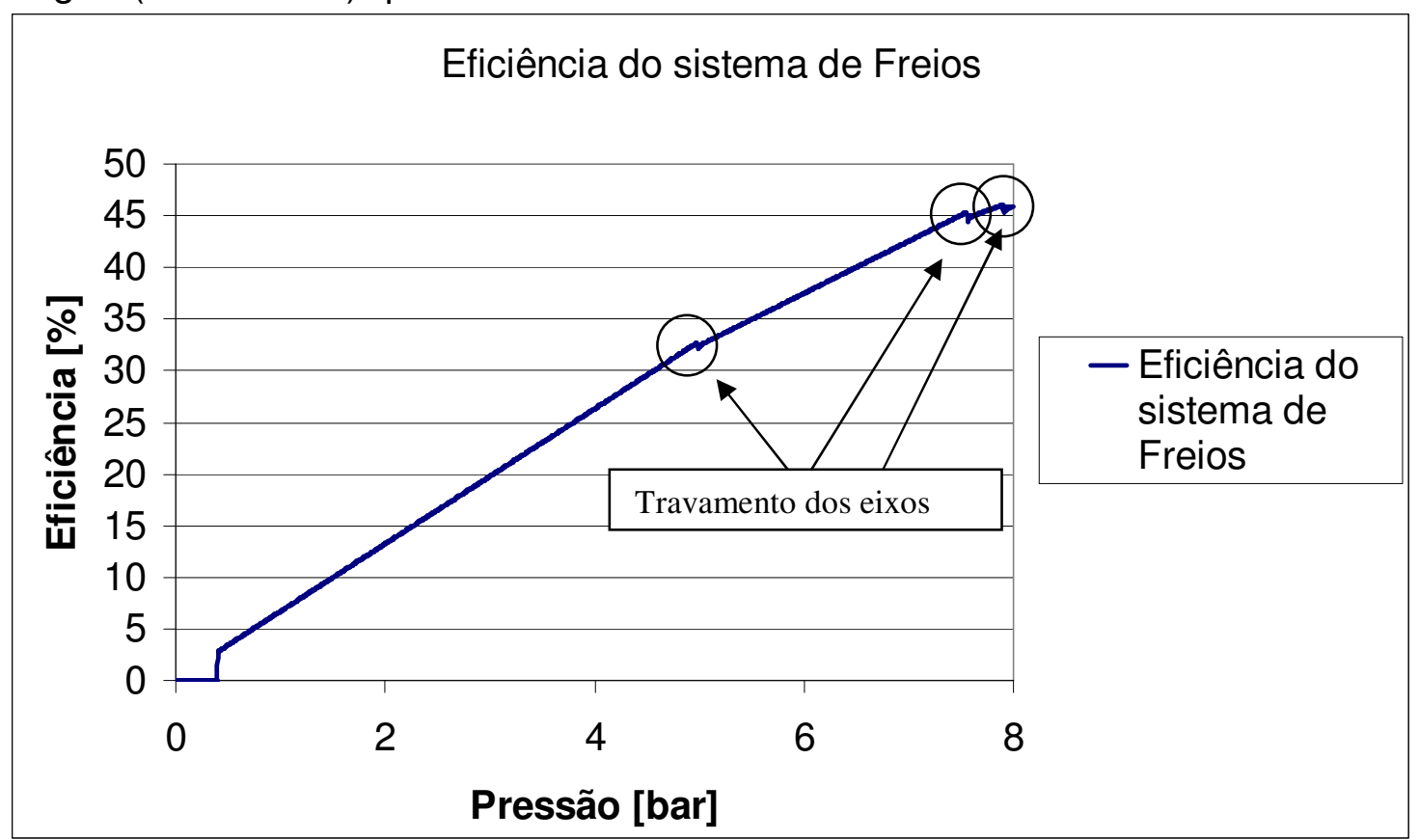

FIGURA 4.34 - Pressão x eficiência; veículo carregado sem ABS

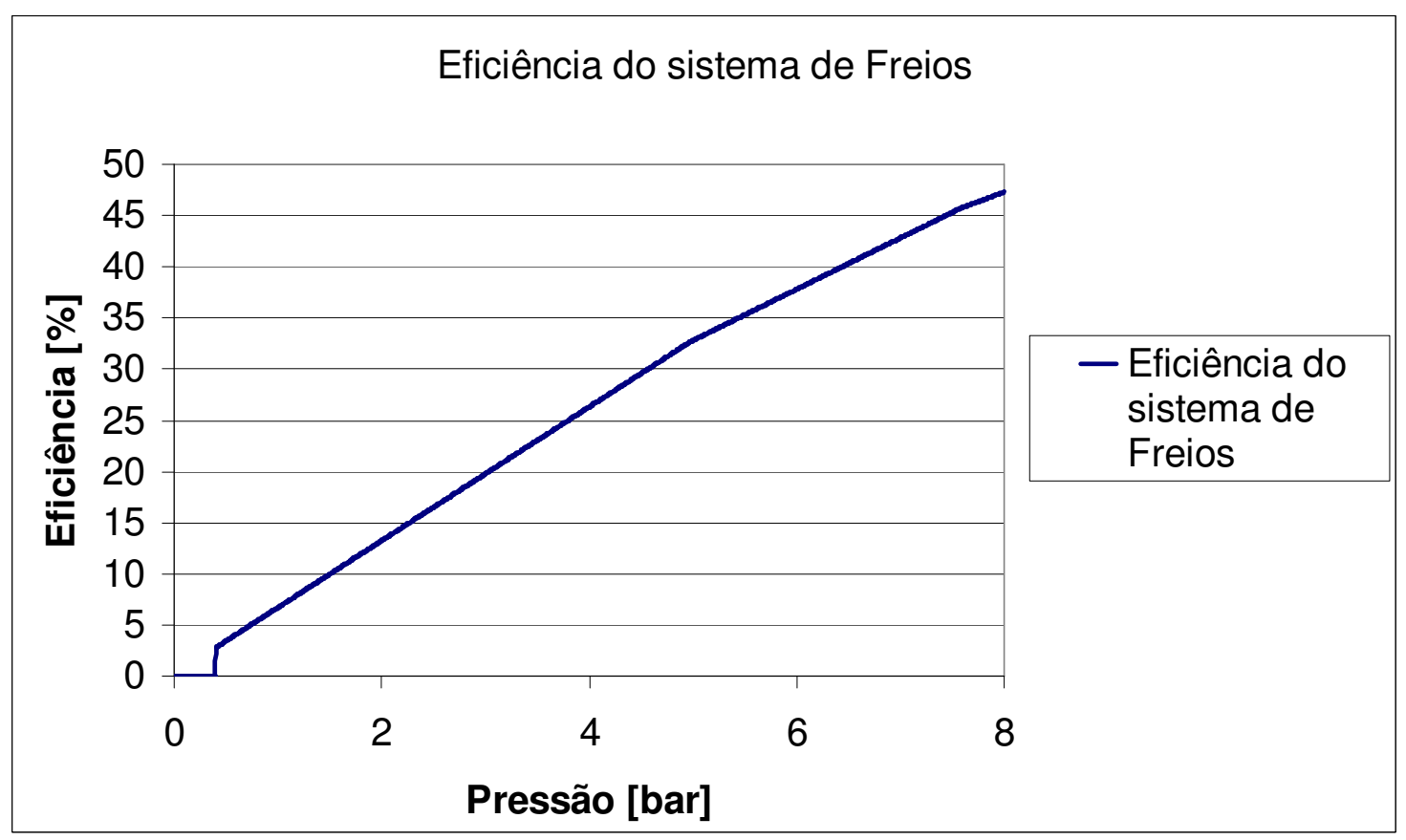

FIGURA 4.35 - Pressão x eficiência; veículo carregado com ABS 
Como o sistema de freios não usa toda a aderência disponível (Figura 4.28 e 4.29), a eficiência é baixa (menos de 50\%), ou seja, o sistema poderia frear duas vezes melhor como já foi dito. No entanto, com esse sistema de freios, não há perda de estabilidade. Ainda, por não usar toda a aderência disponível, praticamente não há diferença no desempenho com a utilização ou não de ABS. As Figuras de 4.36 a 4.39 reforçam essa afirmação.

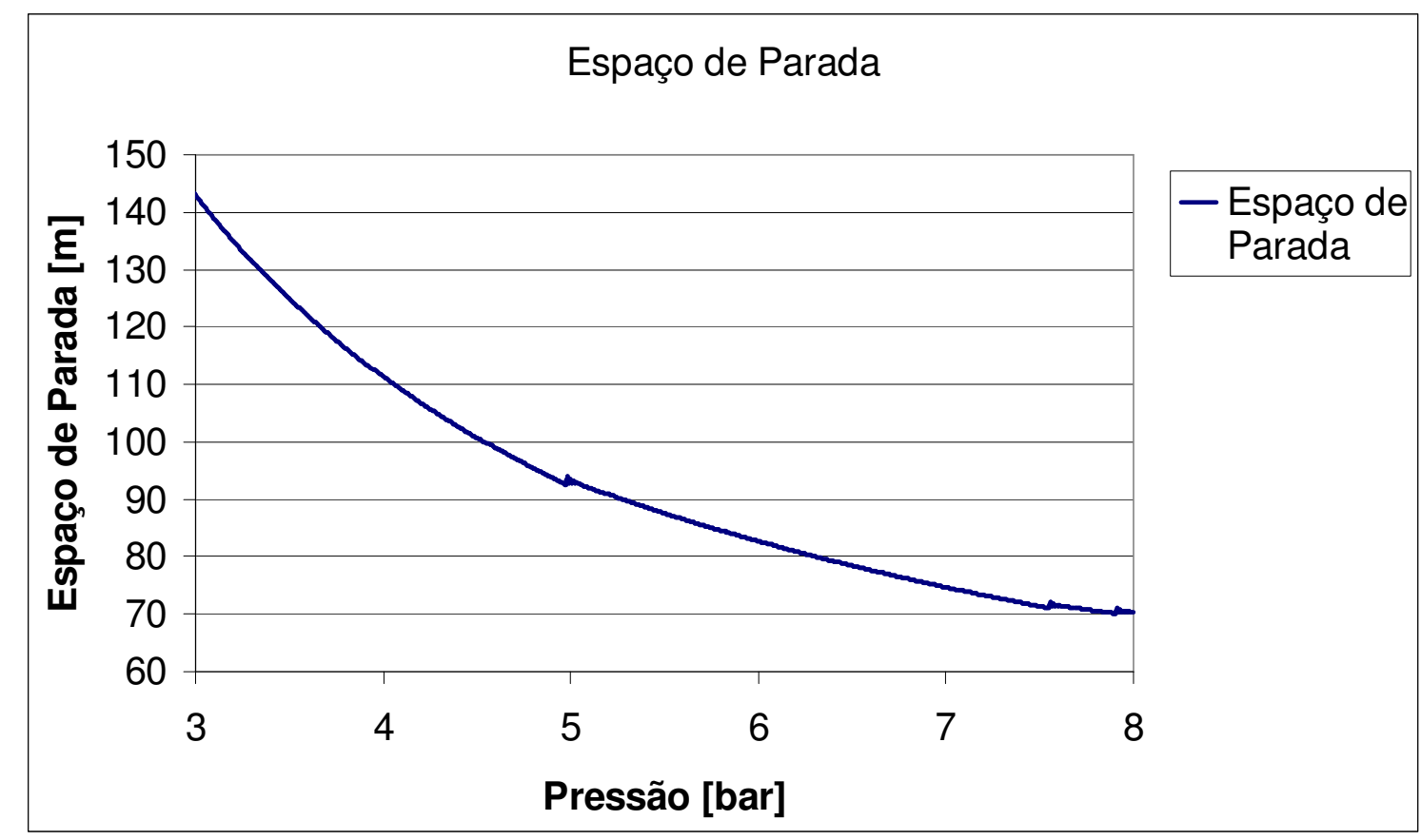

FIGURA 4.36 - Pressão x espaço de parada; veículo carregado sem ABS

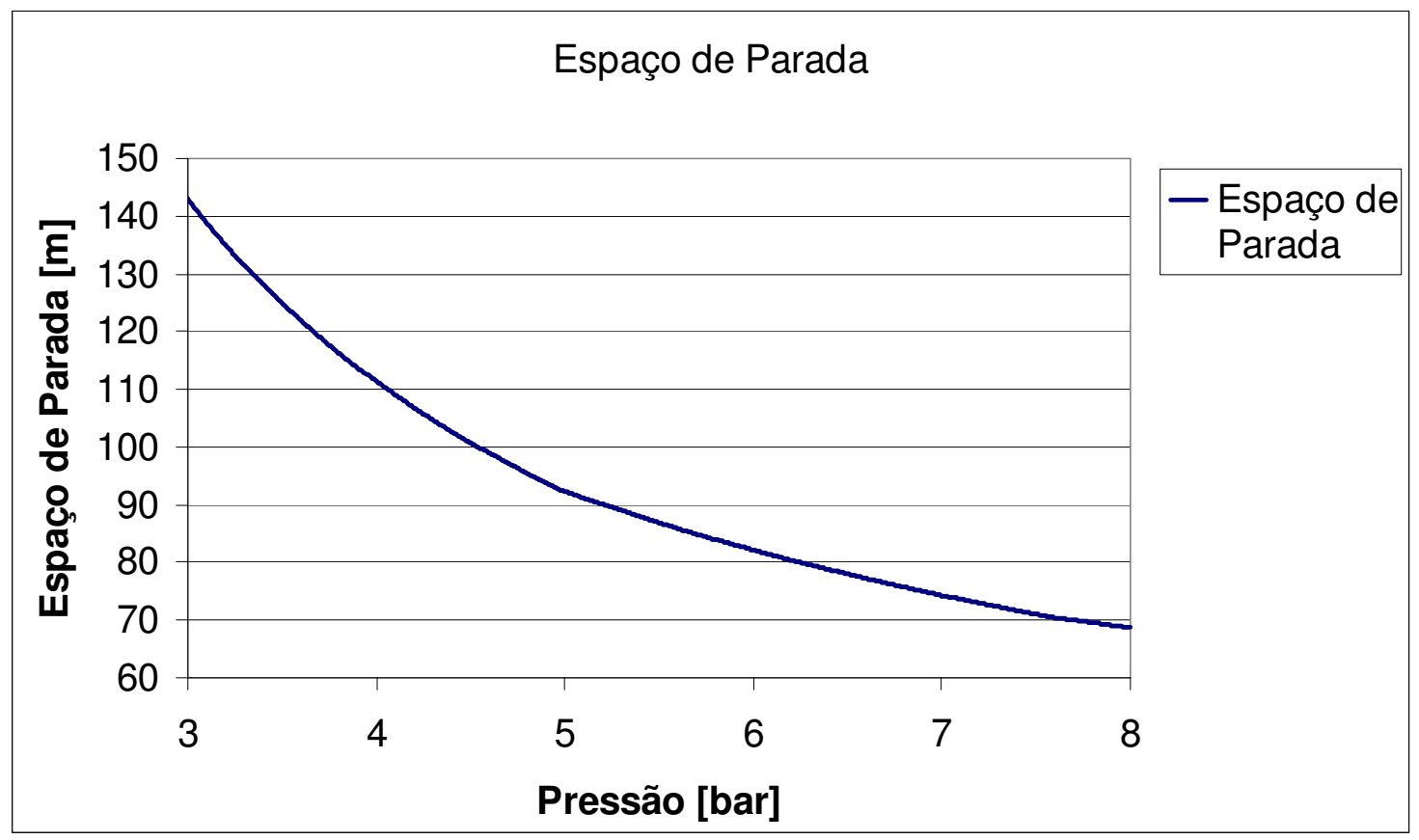

FIGURA 4.37 - Pressão x espaço de parada; veículo carregado com ABS 


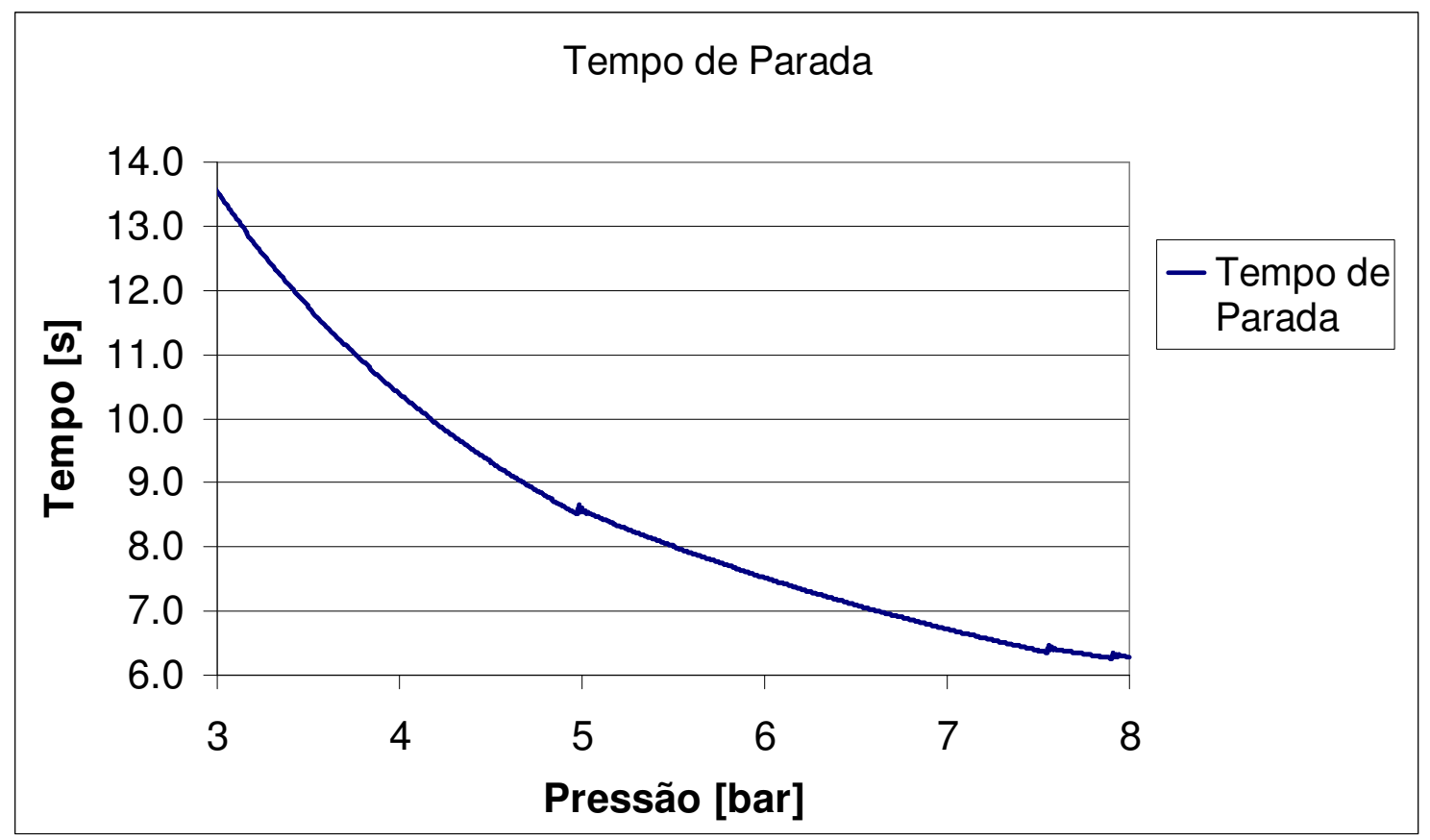

FIGURA 4.38 - Pressão x tempo de parada; veículo carregado sem ABS.

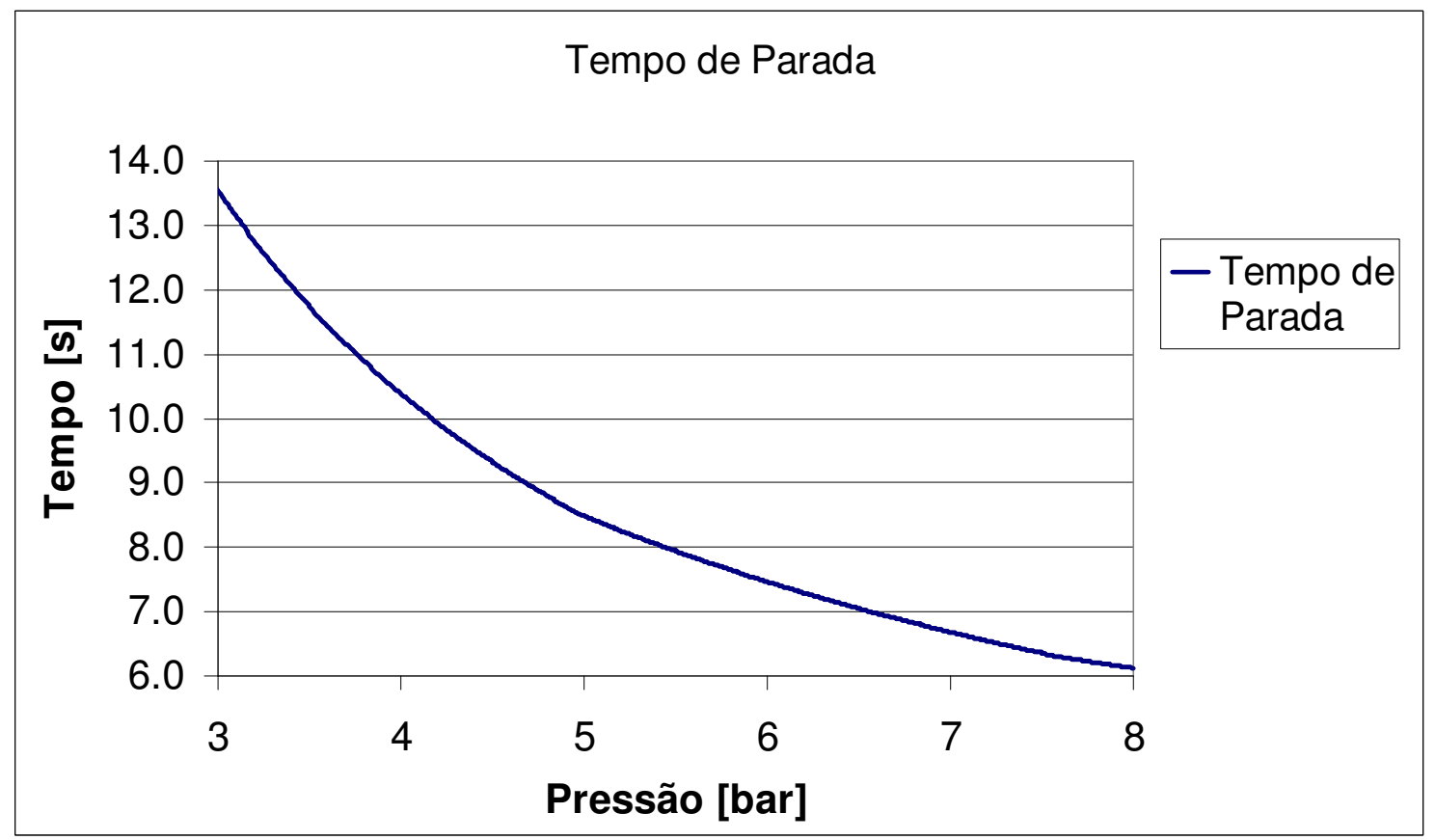

FIGURA 4.39 - Pressão x tempo de parada; veículo carregado com ABS. 
Os gráficos de espaço de parada e tempo de parada da Figura 4.36 á 4.39 comprovam que o ABS não exerce forte influência no desempenho na frenagem. Mas vale lembrar que o ABS é um equipamento de segurança desenvolvido para melhorar a eficiência do sistema de freios em baixa aderência e com o veículo descarregado. Como já foi visto anteriormente, ele cumpre o seu papel neste sistema. A seguir, apresenta-se a variação da temperatura dos tambores de freio sem ABS (Figura 4.40) e com ABS (Figura 4.41).

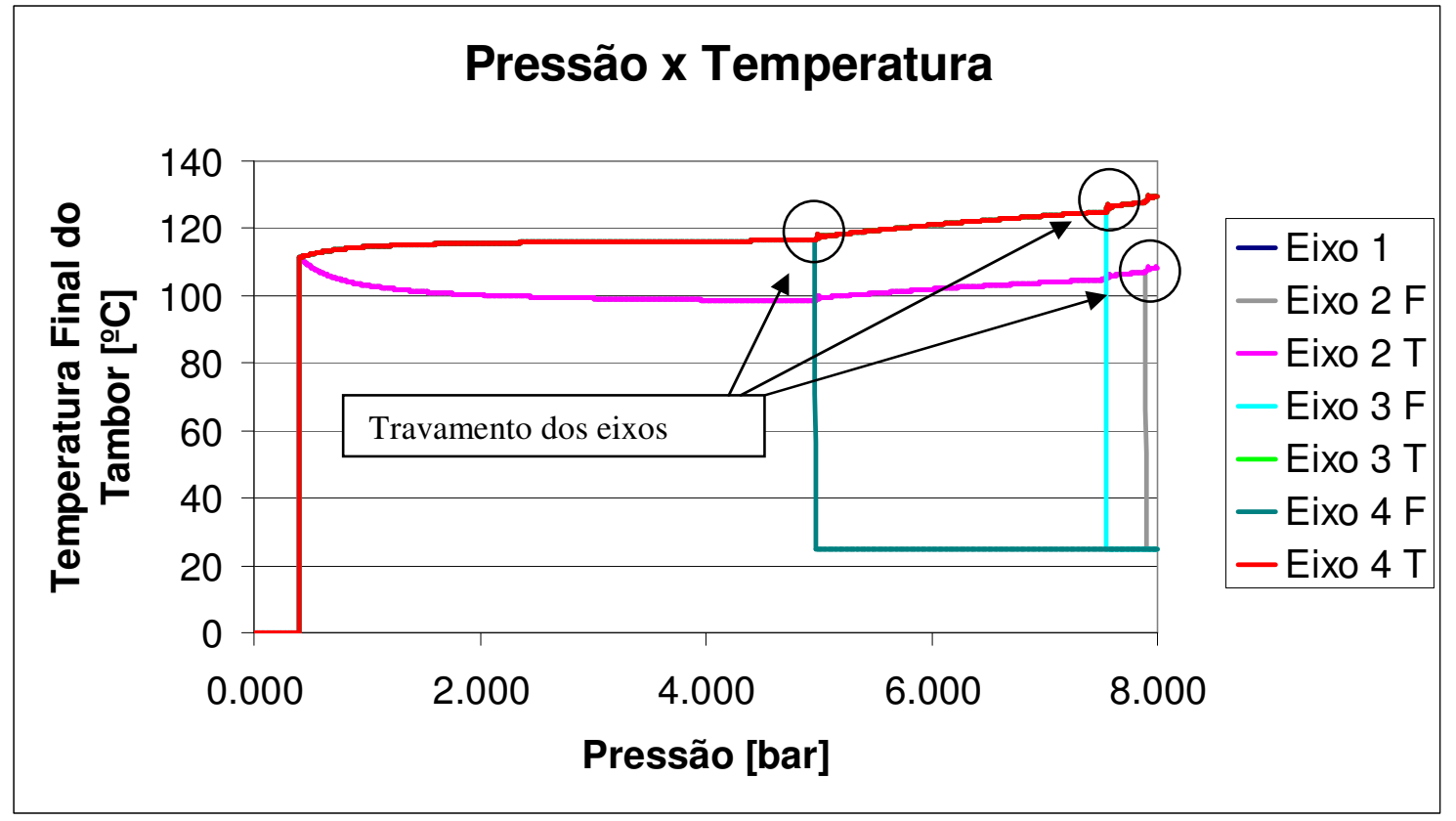

FIGURA 4.40 - Pressão x temperatura final do tambor; veículo carregado sem ABS. 


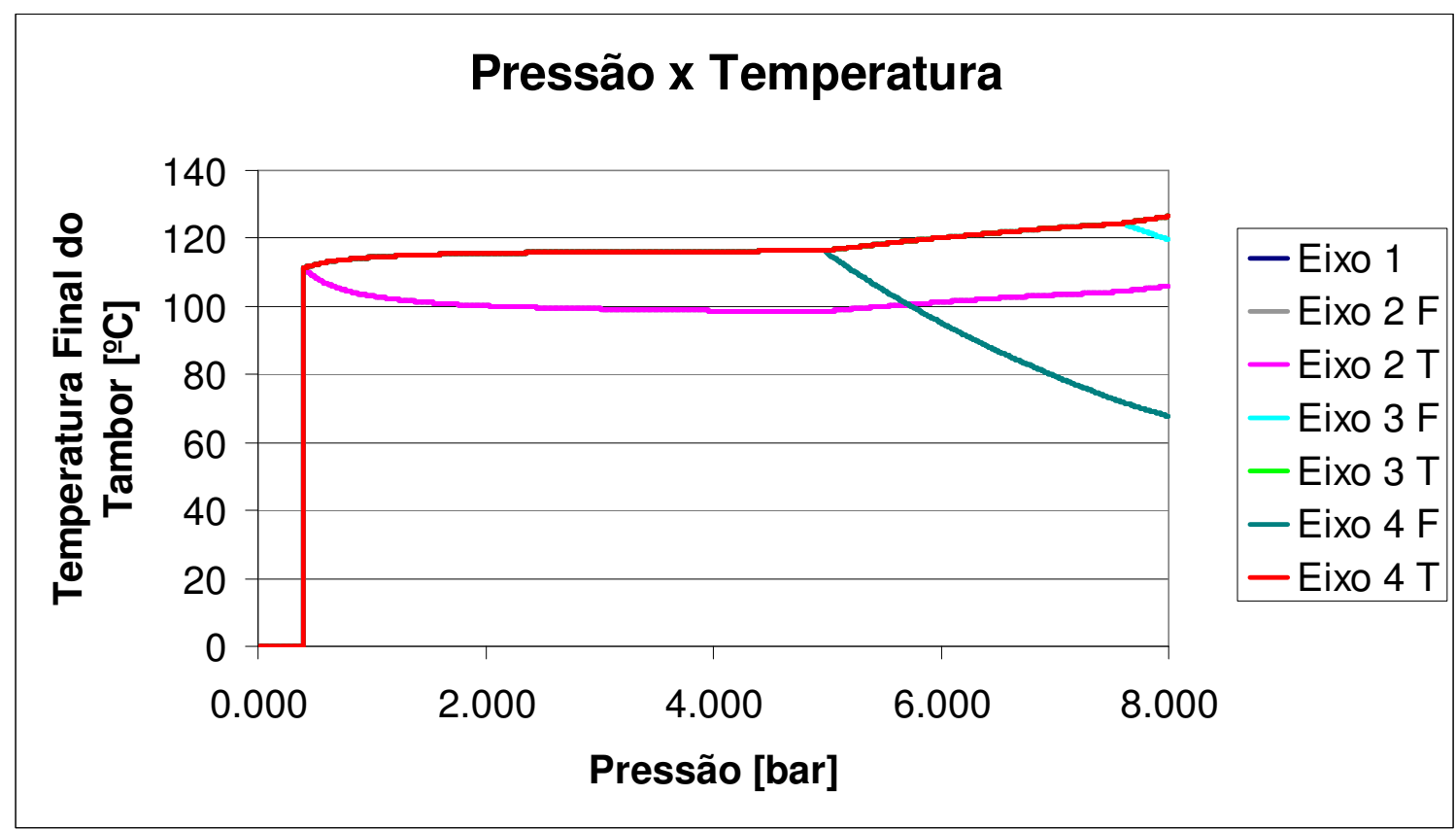

FIGURA 4.41 - Pressão x temperatura final do tambor; veículo carregado com ABS.

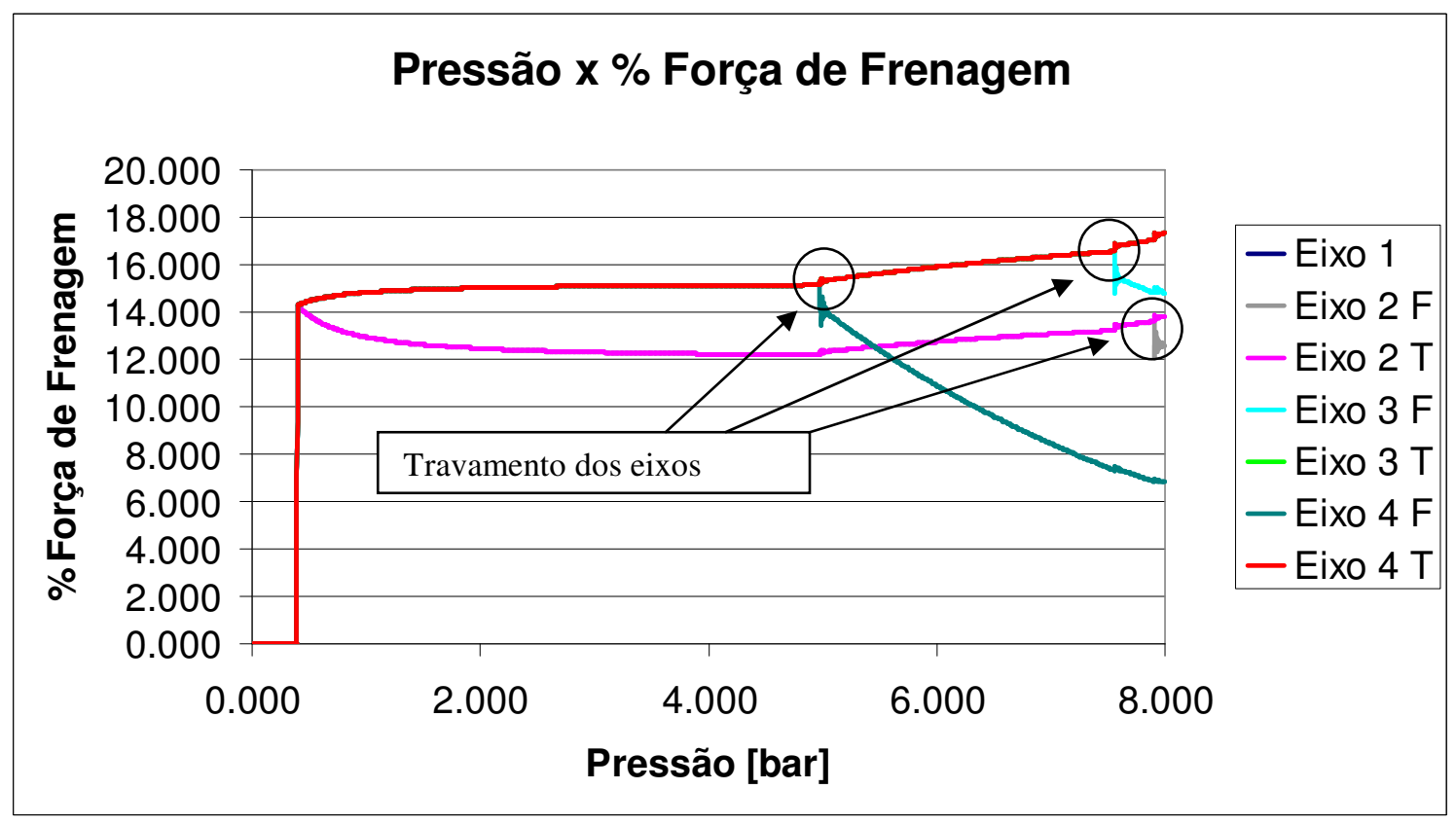

FIGURA 4.42 - Pressão x \% força de frenagem; veículo carregado sem ABS. 


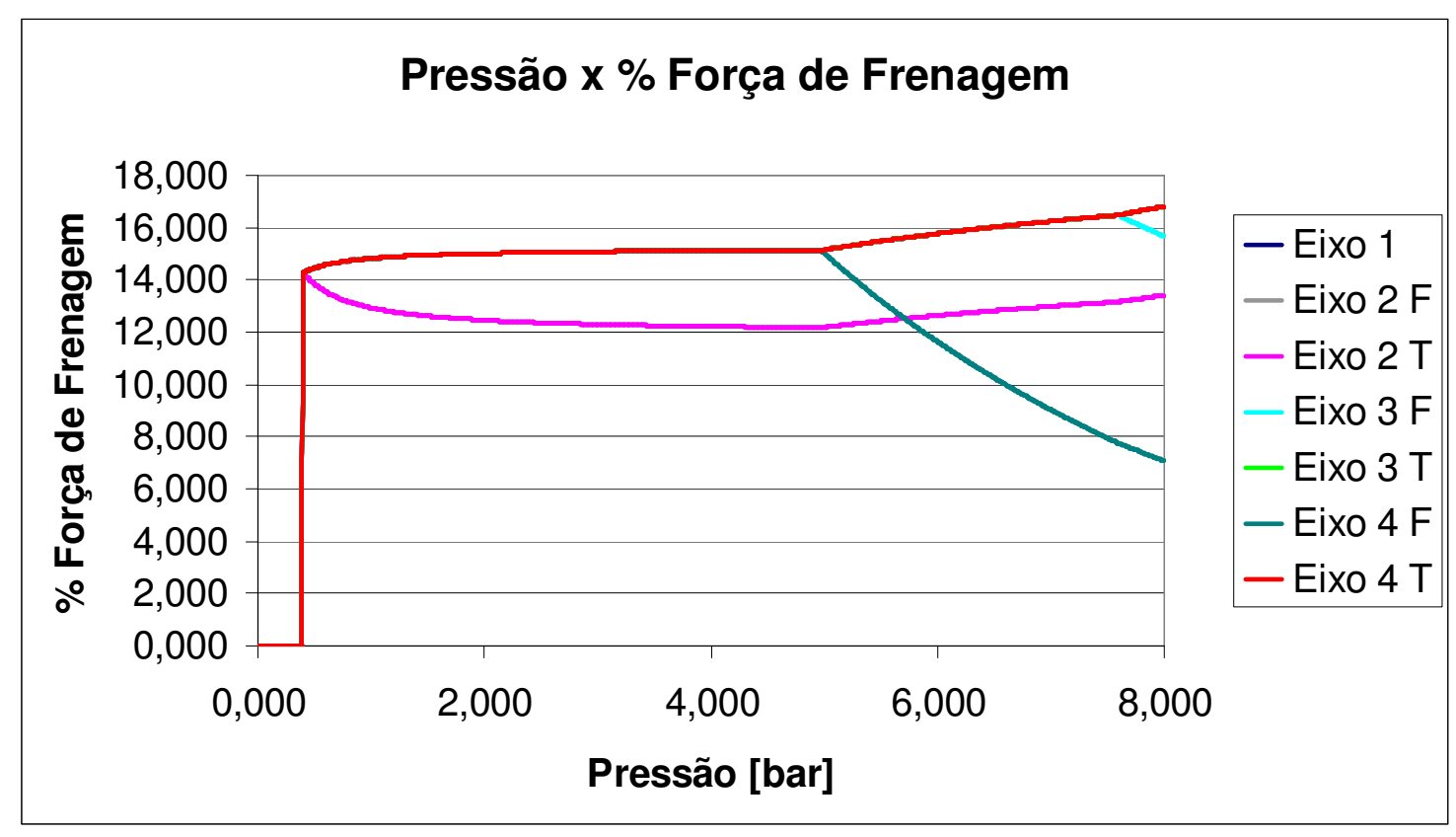

FIGURA 4.43 - Pressão x \% força de frenagem; veículo carregado com ABS.

Como não há nenhum eixo responsável por uma parcela grande da frenagem (Figuras 4.42 e 4.43) a temperatura final dos tambores acaba sendo menor do que em pistas em baixa aderência e como muitos eixos não travam, várias curvas acabam se sobrepondo.

Como já foi mencionado, muitos eixos contribuem na mesma proporção, o que explica a menor temperatura final dos tambores. Pela mesma razão as curvas de vários eixos acabam se sobrepondo. Isso acontece porque o sistema de freios é igual para todos os eixos. E por não ocorrer travamento faz também com que vários eixos desenvolvam a mesma força de frenagem (de acordo com as Figuras 4.44 e 4.45). 




FIGURA 4.44 - Pressão x força de frenagem; veículo carregado sem ABS.



FIGURA 4.45 - Pressão x força de frenagem; veículo carregado com ABS.

\subsubsection{Distribuição ideal e análise do anexo 10 da ECE R13}

Com a planilha desenvolvida para realizar os cálculos do veículo com ABS é possível obter a distribuição ideal das forças de frenagem. A força de frenagem deve ser distribuída de acordo com a força normal em cada eixo. A 
Figura 4.46 mostra a distribuição ideal da força de frenagem em função da desaceleração imposta.

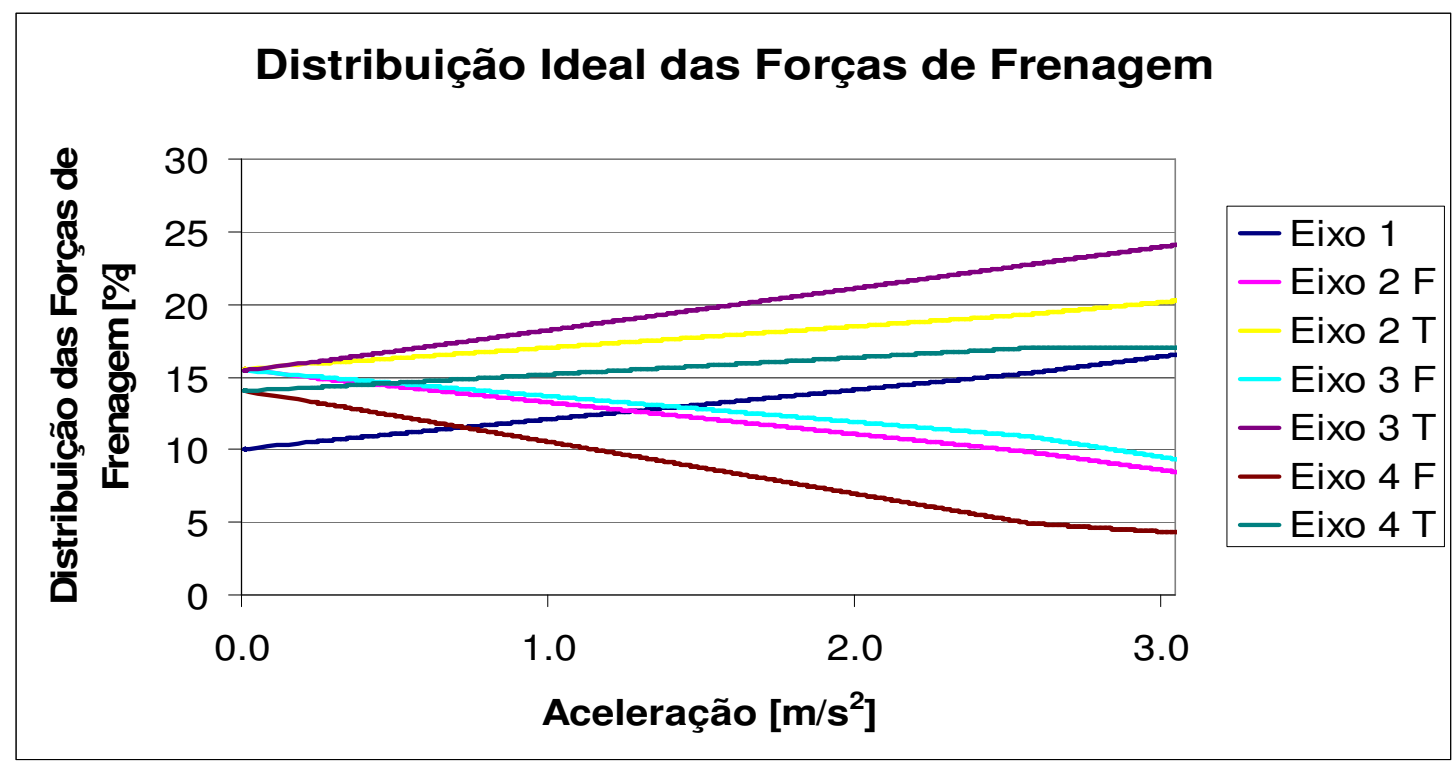

FIGURA 4.46 - distribuição ideal das forças de frenagem

Com essas planilhas também é possível verificar se o desempenho do veículo esta de acordo com o exigido pelo anexo 10 da ECE R-13, tanto para o cavalo mecânico quanto para os semi-reboques. Essa norma exige que a relação da força de frenagem com o peso estático ( $\mathrm{Tm} / \mathrm{Pm}$ no cavalo mecânico e $\operatorname{Tr} / \operatorname{Pr}$ nos semi-reboques) em cada eixo fique dentro de uma certa fronteira. Além dessa exigência, também foi feito a relação da força de frenagem com o peso dinâmico. O resultado é mostrado a seguir.

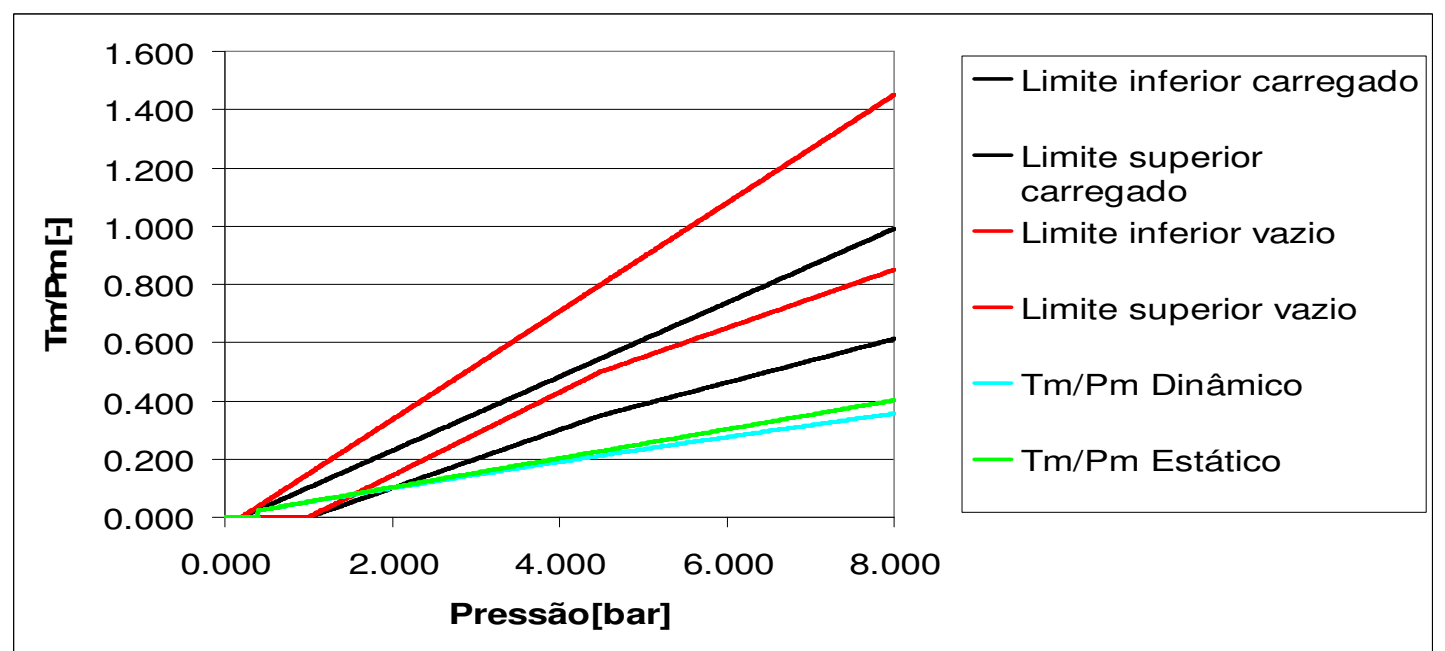

FIGURA 4.47 - Diagrama 3 (para cavalo mecânico) do anexo 10 da ECE R13 Veículo carregado e sem ABS. 




FIGURA 4.48 - Diagrama 3 (para cavalo mecânico) do anexo 10 da ECE R13 Veículo carregado e com ABS

Como se nota nas Figuras 4.47 e 4.48, o cavalo mecânico não atende os requisitos do anexo 10 da ECE R-13. Esses resultados serão comentados após a apresentação dos resultados obtidos para os semi-reboques.

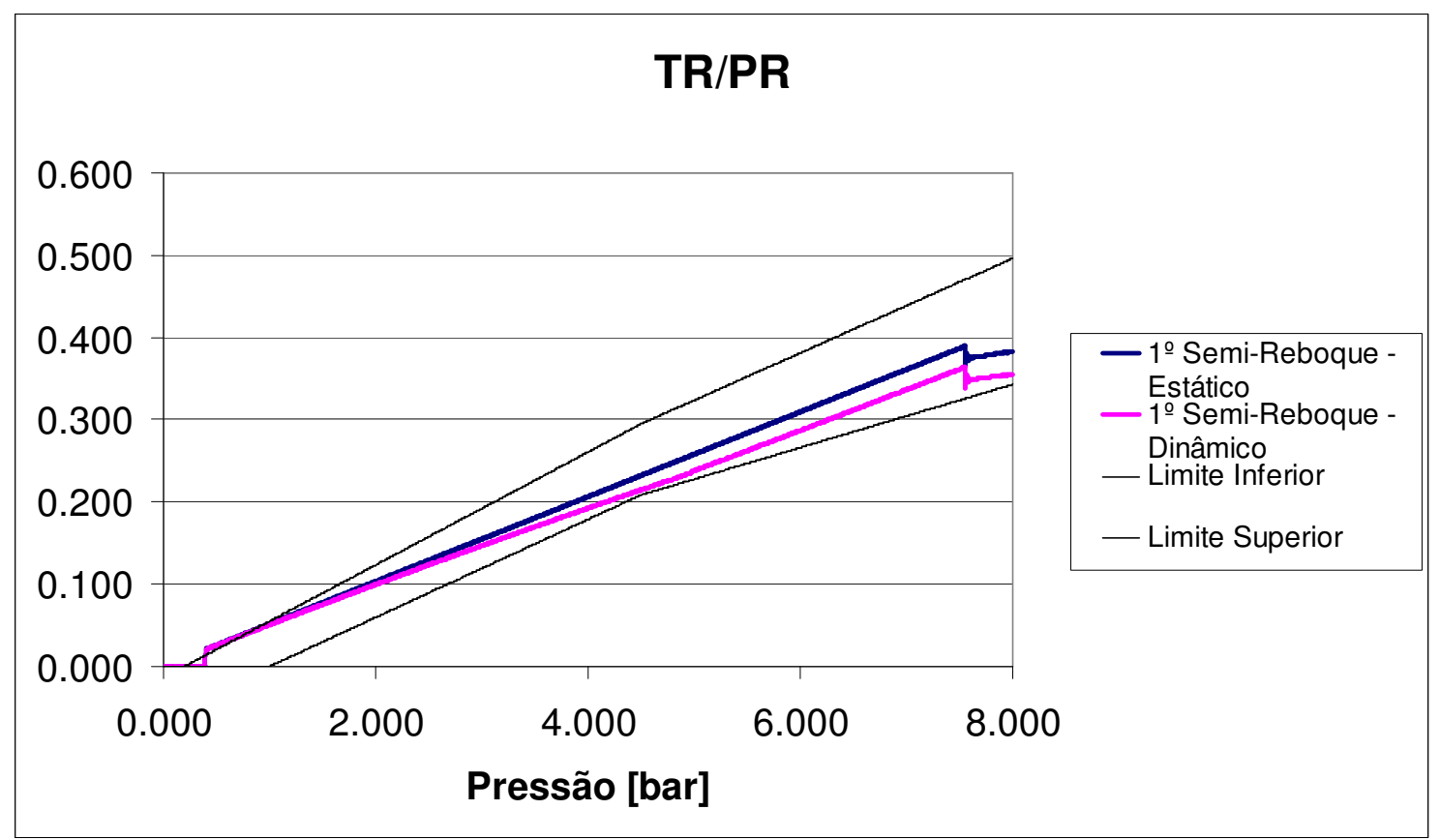

FIGURA 4.49 - Diagrama 4 do anexo 10 da ECE R13; 1ํ Semi-reboque Veículo carregado e sem ABS 


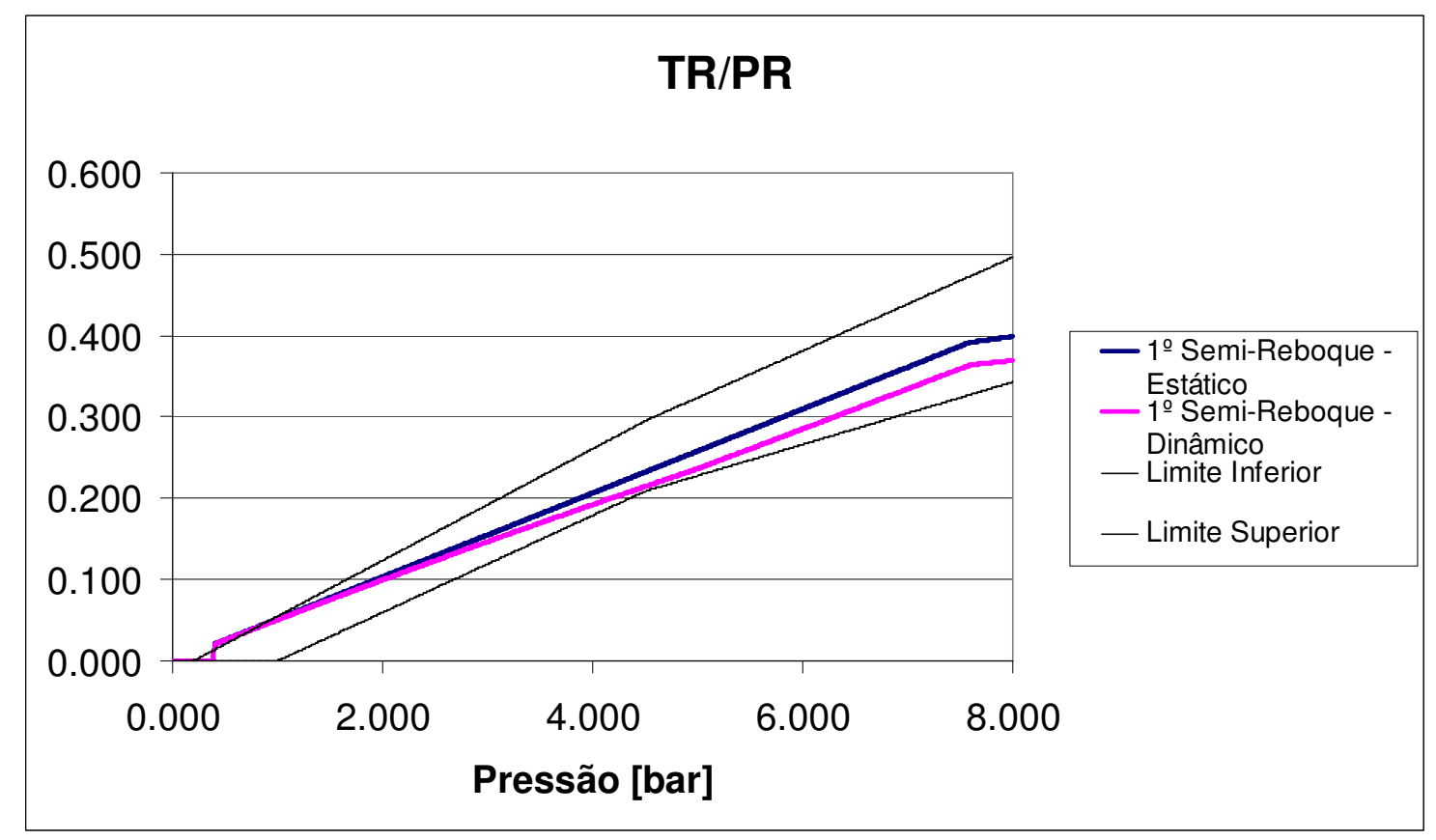

FIGURA 4.50 - Diagrama 4 do anexo 10 da ECE R13; $1^{\circ}$ Semi-reboque Veículo carregado e com ABS



FIGURA 4.51 - Diagrama 4 do anexo 10 da ECE R13; 2 Semi-reboque Veículo carregado e sem ABS 


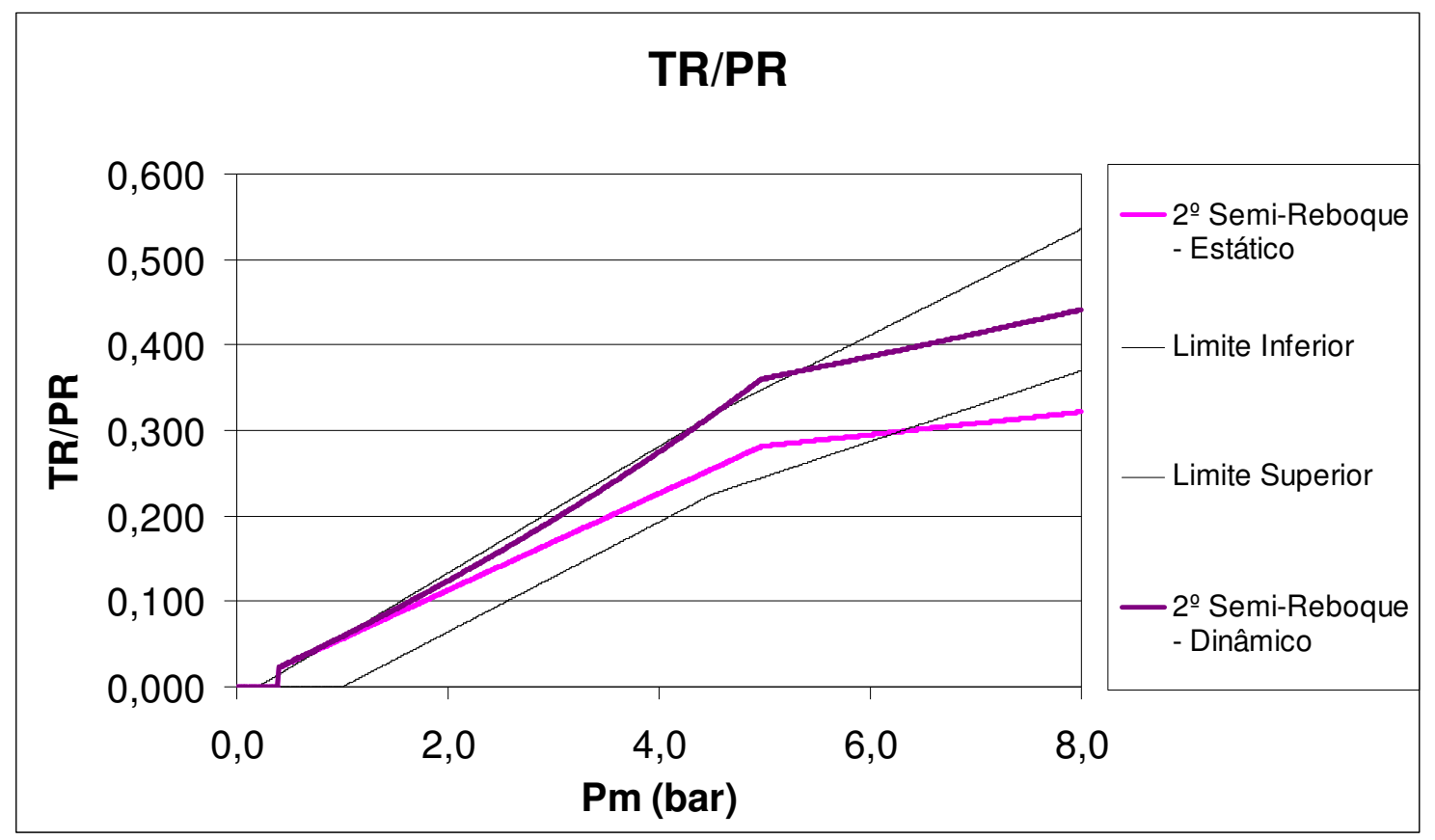

FIGURA 4.52 - Diagrama 4 do anexo 10 da ECE R13; 2ํSemi-reboque Veículo carregado e com ABS

Os semi-reboques da composição, do mesmo modo que o cavalo mecânico, também não são aprovados de acordo com o diagrama 4 do anexo 10 da ECE R13. Mas apesar de não atenderem os requisitos da norma, eles ficam muito próximos disso, de forma que em uma avaliação um pouco menos rigorosa os semi-reboques seriam aprovados. No entanto, essa norma foi desenvolvida pensando em uma composição simples de cavalo mecânico e um semi-reboque. Ou seja, uma legislação exclusiva para o bi-trem se faz necessária como será explicado no capítulo de conclusões. Uma demonstração dessa afirmação pode ser vista a seguir.

\subsubsection{Análise da dinâmica da frenagem com dados alterados}

Algumas modificações do sistema de freios foram sugeridas por este autor. Essas alterações foram feitas levando-se em conta apenas o desempenho da frenagem. Nenhuma análise de custos foi feita para garantir a viabilidade econômica da decisão tomada. 
Como os eixos dianteiros dos "tandem" perdem força normal, as alterações foram feitas no sentido de diminuir as forças de frenagem neles. Por conseqüência a força normal no eixo traseiro do "tandem" aumenta e assim as forças de frenagens nesses eixos devem ser maiores.

A primeira alteração, que é "sentida" por todos os eixos é o aumento da pressão máxima de 8 para 10 bar. As modificações feitas no sistema de freios são mostradas nas tabelas a seguir. A coluna "Antes da alteração" refere-se a como o sistema era antes das alterações serem realizadas. As demais colunas mostram o sistema sugerido.

Tabela 4.7 - Alterações sugeridas no sistema de freios do cavalo mecânico

\begin{tabular}{|c|c|c|c|c|}
\hline \multicolumn{5}{|c|}{ CAVALO MECÂNICO } \\
\hline & $\begin{array}{l}\text { Antes da } \\
\text { alteração }\end{array}$ & $\begin{array}{c}\text { Eixo dianteiro } \\
\text { do cavalo }\end{array}$ & $\begin{array}{l}\text { Eixo dianteiro do } \\
\text { "tandem" do cavalo }\end{array}$ & $\begin{array}{l}\text { Eixo traseiro do } \\
\text { "tandem" do cavalo }\end{array}$ \\
\hline Área cilindro & $24.0\left[\mathrm{in}^{2]}\right.$ & $30.0\left[\mathrm{in}^{2}\right]$ & $15.0\left[\mathrm{in}^{2}\right]$ & $30.0\left[\mathrm{in}^{2}\right]$ \\
\hline Fator de freio & $1,12[-]$ & $1,5[-]$ & $1,12[-]$ & $1,5[-]$ \\
\hline Diâmetro Tambor & $410,0[\mathrm{~mm}]$ & $600,0[\mathrm{~mm}]$ & $200,0[\mathrm{~mm}]$ & $\underline{650,0[\mathrm{~mm}]}$ \\
\hline Raio came $S$ & $12,7[\mathrm{~mm}]$ & $12,7[\mathrm{~mm}]$ & $12,7[\mathrm{~mm}]$ & $12,7[\mathrm{~mm}]$ \\
\hline Raio Dinâmico Pneu & $571,5[\mathrm{~mm}]$ & $571,5[\mathrm{~mm}]$ & $571,5[\mathrm{~mm}]$ & $571,5[\mathrm{~mm}]$ \\
\hline $\begin{array}{c}\text { Comprimento } \\
\text { alavanca ajustadora }\end{array}$ & $139,7[\mathrm{~mm}]$ & 150 [mm] & $120[\mathrm{~mm}]$ & $150[\mathrm{~mm}]$ \\
\hline Largura da lona & $203,2[\mathrm{~mm}]$ & $203,2[\mathrm{~mm}]$ & $203,2[\mathrm{~mm}]$ & $203,2[\mathrm{~mm}]$ \\
\hline $\begin{array}{c}\text { Espessura do } \\
\text { Tambor }\end{array}$ & $19,0[\mathrm{~mm}]$ & $19,0[\mathrm{~mm}]$ & $19,0[\mathrm{~mm}]$ & $19,0[\mathrm{~mm}]$ \\
\hline $\begin{array}{c}\text { Calor específico do } \\
\text { Tambor }\end{array}$ & $\begin{array}{c}544 \\
{\left[\mathrm{~J} /\left(\mathrm{kg}^{*} \mathrm{~K}\right)\right]}\end{array}$ & $544\left[\mathrm{~J} /\left(\mathrm{kg}^{\star} \mathrm{K}\right)\right]$ & $544\left[\mathrm{~J} /\left(\mathrm{kg}^{*} \mathrm{~K}\right)\right]$ & $544\left[\mathrm{~J} /\left(\mathrm{kg}^{*} \mathrm{~K}\right)\right]$ \\
\hline $\begin{array}{l}\text { Densidade do } \\
\text { material do tambor }\end{array}$ & $7150\left[\mathrm{~kg} / \mathrm{m}^{3}\right]$ & $7150\left[\mathrm{~kg} / \mathrm{m}^{3}\right]$ & $7150\left[\mathrm{~kg} / \mathrm{m}^{3}\right]$ & $7150\left[\mathrm{~kg} / \mathrm{m}^{3}\right]$ \\
\hline Rendimento & $65 \%$ & $65 \%$ & $65 \%$ & $65 \%$ \\
\hline
\end{tabular}


Tabela 4.8 - Alterações sugeridas no sistema de freios do $1^{\circ}$ semi-reboque

\begin{tabular}{|c|c|c|c|}
\hline \multicolumn{4}{|c|}{ 1\% SEMI-REBOQUE } \\
\hline & $\begin{array}{l}\text { Antes da } \\
\text { alteração }\end{array}$ & $\begin{array}{l}\text { Eixo dianteiro do } \\
\text { "tandem" do cavalo }\end{array}$ & $\begin{array}{l}\text { Eixo traseiro do } \\
\text { "tandem" do cavalo }\end{array}$ \\
\hline Área cilindro & $24.0\left[\mathrm{in}^{2]}\right.$ & $15.0\left[\mathrm{in}^{2}\right]$ & $30.0\left[\mathrm{in}^{2}\right]$ \\
\hline Fator de freio & $1,12[-]$ & $81,12[-]$ & $1,5[-]$ \\
\hline Diâmetro Tambor & $410,0[\mathrm{~mm}]$ & $200,0[\mathrm{~mm}]$ & $650,0[\mathrm{~mm}]$ \\
\hline Raio came $S$ & $12,7[\mathrm{~mm}]$ & $12,7[\mathrm{~mm}]$ & $12,7[\mathrm{~mm}]$ \\
\hline Raio Dinâmico Pneu & $571,5[\mathrm{~mm}]$ & $571,5[\mathrm{~mm}]$ & $571,5[\mathrm{~mm}]$ \\
\hline $\begin{array}{c}\text { Comprimento alavanca } \\
\text { ajustadora }\end{array}$ & $139,7[\mathrm{~mm}]$ & $120[\mathrm{~mm}]$ & $150[\mathrm{~mm}]$ \\
\hline Largura da lona & $203,2[\mathrm{~mm}]$ & $203,2[\mathrm{~mm}]$ & $203,2[\mathrm{~mm}]$ \\
\hline Espessura do Tambor & $19,0[\mathrm{~mm}]$ & $19,0[\mathrm{~mm}]$ & $19,0[\mathrm{~mm}]$ \\
\hline $\begin{array}{c}\text { Calor específico do } \\
\text { Tambor }\end{array}$ & $544\left[\mathrm{~J} /\left(\mathrm{kg}^{*} \mathrm{~K}\right)\right]$ & $544\left[\mathrm{~J} /\left(\mathrm{kg}^{*} \mathrm{~K}\right)\right]$ & $544\left[\mathrm{~J} /\left(\mathrm{kg}^{*} \mathrm{~K}\right)\right]$ \\
\hline $\begin{array}{c}\text { Densidade do material do } \\
\text { tambor }\end{array}$ & $7150\left[\mathrm{~kg} / \mathrm{m}^{3}\right]$ & $7150\left[\mathrm{~kg} / \mathrm{m}^{3}\right]$ & $7150\left[\mathrm{~kg} / \mathrm{m}^{3}\right]$ \\
\hline Rendimento & $65 \%$ & $65 \%$ & $65 \%$ \\
\hline
\end{tabular}

Tabela 4.9 - Alterações sugeridas no sistema de freios do $1^{\circ}$ semi-reboque

\begin{tabular}{|c|c|c|c}
\hline \multicolumn{4}{|c|}{$\mathbf{2}^{\mathbf{0}}$ SEMI-REBOQUE } \\
\hline & $\begin{array}{c}\text { Antes da } \\
\text { alteração }\end{array}$ & $\begin{array}{c}\text { Eixo dianteiro do } \\
\text { "tandem" do cavalo }\end{array}$ & $\begin{array}{c}\text { Eixo traseiro do } \\
\text { "tandem" do cavalo }\end{array}$ \\
\hline Área cilindro & $24.0\left[\mathrm{in}^{2]}\right.$ & $\underline{\mathbf{1 5 . 0}\left[\mathbf{i n}^{2}\right]}$ & $\underline{\mathbf{3 0 . 0}\left[\mathbf{i n}^{2}\right]}$ \\
\hline Fator de freio & $1,12[-]$ & $\mathbf{1 , 5}[-]$ \\
\hline Diâmetro Tambor & $410,0[\mathrm{~mm}]$ & $\underline{\mathbf{2 0 0 , 0}[\mathrm{mm}]}$ & $\underline{\mathbf{6 0 0 , 0}[\mathrm{mm}]}$ \\
\hline Raio came S & $12,7[\mathrm{~mm}]$ & $12,7[\mathrm{~mm}]$ & $12,7[\mathrm{~mm}]$ \\
\hline Raio Dinâmico Pneu & $571,5[\mathrm{~mm}]$ & $571,5[\mathrm{~mm}]$ & $571,5[\mathrm{~mm}]$ \\
\hline $\begin{array}{c}\text { Comprimento alavanca } \\
\text { ajustadora }\end{array}$ & $139,7[\mathrm{~mm}]$ & $\mathbf{1 2 0}[\mathrm{mm}]$ & $\underline{\mathbf{1 5 0}[\mathrm{mm}]}$ \\
\hline Largura da lona & $203,2[\mathrm{~mm}]$ & $203,2[\mathrm{~mm}]$ & $203,2[\mathrm{~mm}]$ \\
\hline Espessura do Tambor & $19,0[\mathrm{~mm}]$ & $19,0[\mathrm{~mm}]$ & $19,0[\mathrm{~mm}]$ \\
\hline $\begin{array}{c}\text { Calor específico do } \\
\text { Tambor }\end{array}$ & $544\left[\mathrm{~J} /\left(\mathrm{kg}{ }^{*} \mathrm{~K}\right)\right]$ & $544\left[\mathrm{~J} /\left(\mathrm{kg}{ }^{*} \mathrm{~K}\right)\right]$ & $544\left[\mathrm{~J} /\left(\mathrm{kg}{ }^{*} \mathrm{~K}\right)\right]$ \\
\hline $\begin{array}{c}\text { Densidade do material do } \\
\text { tambor }\end{array}$ & $7150\left[\mathrm{~kg} / \mathrm{m}^{3}\right]$ & $7150\left[\mathrm{~kg} / \mathrm{m}^{3}\right]$ & $7150\left[\mathrm{~kg} / \mathrm{m}^{3}\right]$ \\
\hline Rendimento & $65 \%$ & $65 \%$ & $65 \%$ \\
\hline
\end{tabular}

O desempenho da combinação é mostrado em forma de gráficos a seguir. Apenas os gráficos mais relevantes serão apresentados. As simulações foram feitas apenas no veículo sem ABS para garantir que o ganho de desempenho seja referente apenas às modificações realizadas. 


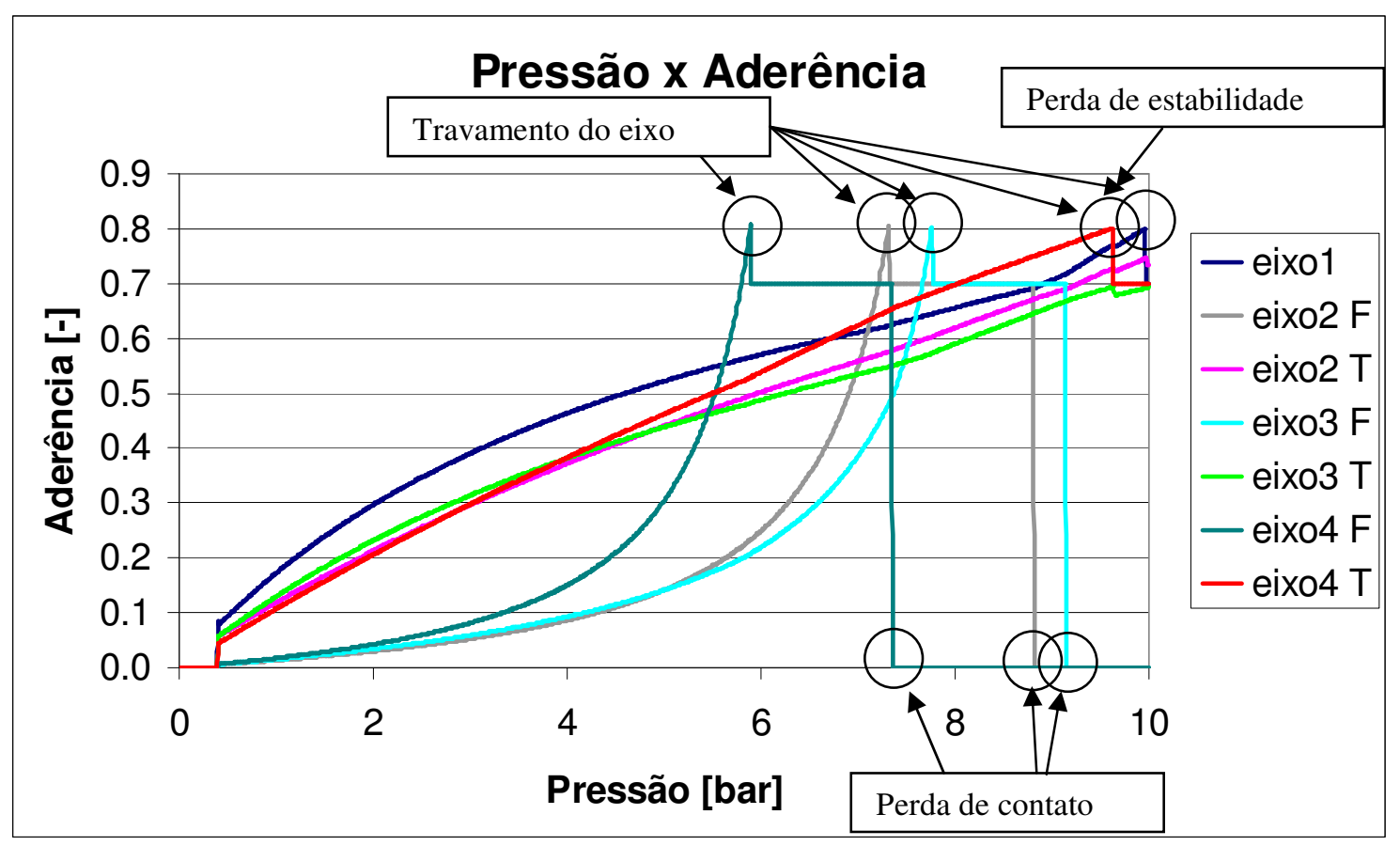

FIGURA 4.53 - Pressão x Aderência utilizada; veículo carregado; sem ABS ; sistema de freios alterado

A Figura 4.53 mostra a seqüência de travamento dos eixos. Com o sistema de freios modificado, nenhum eixo é subtilizado, com todos os eixos atingindo o limite de aderência ou se aproximando a ele. Os eixos ainda atingem o valor máximo em valores próximos e o veículo, nessas condições de carregamento, perde estabilidade em pistas secas apenas com 10 bar de pressão, quando o eixo dianteiro do cavalo mecânico trava. Os eixos dianteiros de todos os "tandem" perdem a força normal muito rápido e acabam por perder contato com o pavimento. Isso não chega a ser um problema pois os eixos traseiros "ganham" essa força normal aumentando a sua capacidade de frenagem e mantendo a dirigibilidade do veículo.

A Figura 4.54 mostra a desaceleração máxima conseguida com o novo sistema de freios. Comparando com a Figura 4.32 percebe-se a desaceleração praticamente dobrou com a adoção do novo sistema de freios. 


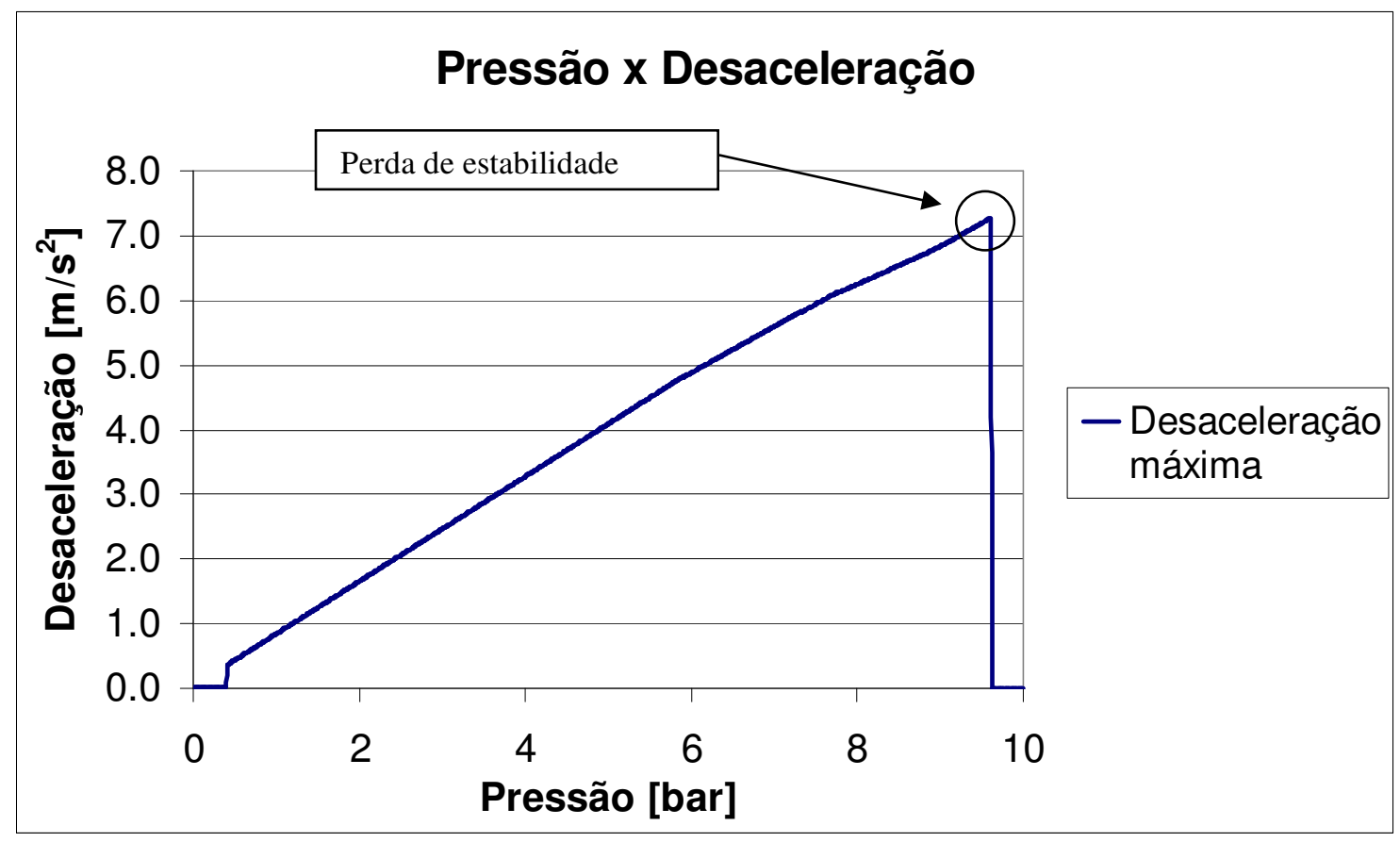

FIGURA 4.54 - Pressão x desaceleração máxima; veículo carregado sem ABS; sistema de freios alterado

As Figuras 4.55, 4.56 e 4.57 comparam a capacidade de frenagem deste veículo com o exigido pelo anexo 10 da ECE R13.

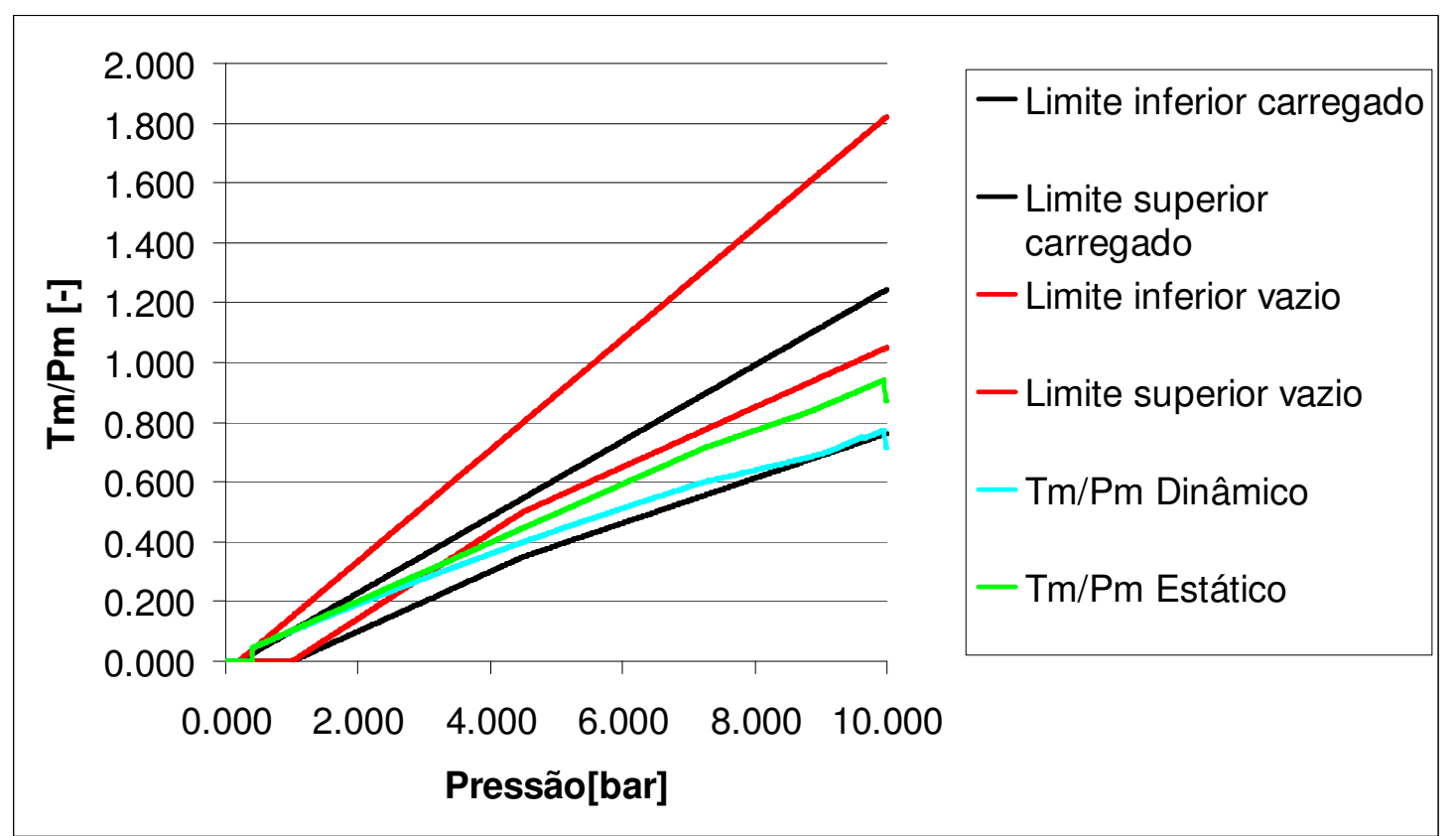

FIGURA 4.55 - Diagrama 3 (para cavalo mecânico) do anexo 10 da ECE R13 - Veículo carregado e sem ABS ; sistema de freios alterado 


\section{TR/PR}

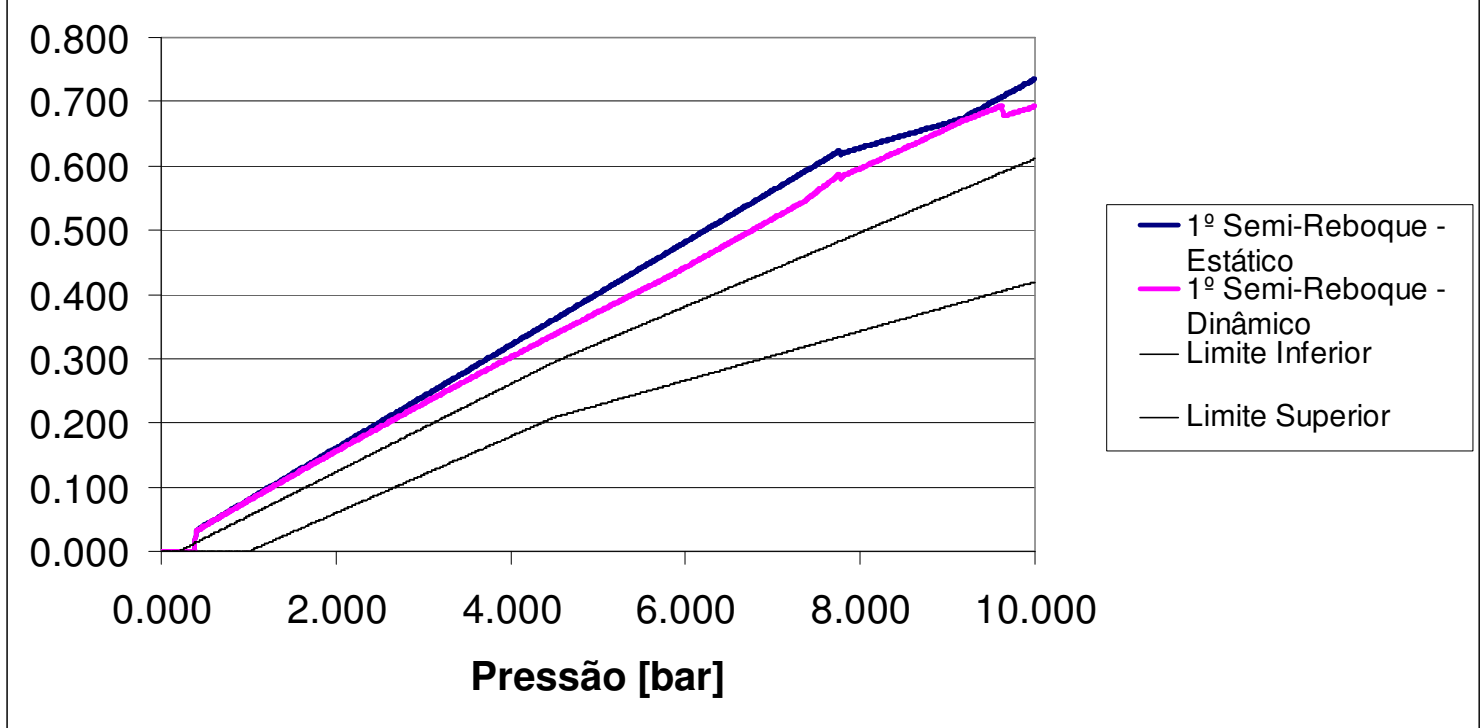

FIGURA 4.56 - Diagrama 4 do anexo 10 da ECE R13; 1ํ Semi-reboque Veículo carregado e sem ABS; sistema de freios alterado

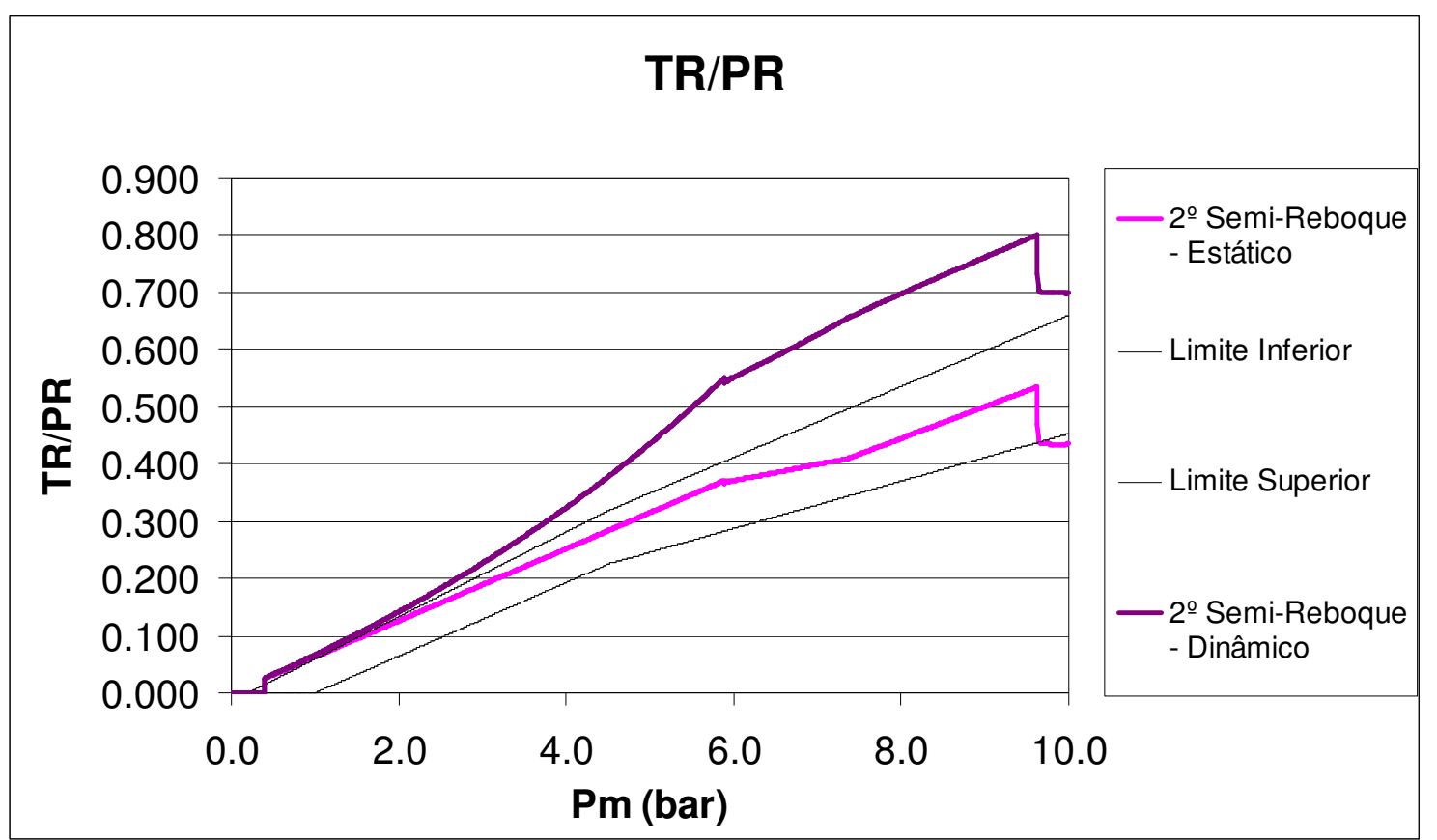

FIGURA 4.57 - Diagrama 4 do anexo 10 da ECE R13; $2^{\circ}$ Semi-reboque Veículo carregado e sem ABS; sistema de freios alterado

Analisando-se os gráficos 4.55 a 4.57 podemos concluir que tanto o cavalo mecânico quanto o segundo semi-reboque estão dentro do exigido pelo 
anexo 10 da ECE R13. Mas como já foi comentado anteriormente, uma legislação que preveja o bi-trem é necessária. Essa nova legislação se justifica pela Figura 4.55. Por meio dela, mais precisamente pela curva chamada de "dinâmico" (ver os gráficos 4.55 a 4.57), pode-se concluir que o sistema de freios do primeiro semi-reboque é muito bom apesar de estar "fora de norma". Essa curva "dinâmico" é na verdade a aderência utilizada. E constata-se que a aderência utilizada pelo primeiro semi-reboque é de aproximadamente 0,7 de 0,8 disponível. Ou seja, a relação mostrada na Figura 4.55 poderia ser ainda maior, mais longe da fronteira exigida pela norma. Resumindo se for utilizado 0 anexo 10 da ECE R13 para o projeto do sistema de freios, toda aderência disponível não vai ser utilizada, diminuindo, assim, a eficiência do sistema de freios. A explicação desse fenômeno será apresentada no próximo capítulo. 


\section{CONCLUSÃO}

Uma visão geral sobre a ferramenta elaborada nos permite concluir que a mesma é muito útil no desenvolvimento de sistema de freios para bi-trens, pois poderá diminuir o custo e o tempo de projeto uma vez que reduz o número de teste de pista visto que o veículo já estará próximo da condição ótima. Os testes seriam apenas para se fazer o ajuste fino do sistema. A planilha de cálculo desenvolvida para este trabalho proporciona uma melhor compreensão do processo de frenagem de um bi-trem. Com ela também é possível analisar o desempenho e a estabilidade do processo de frenagem em qualquer condição operacional (ou seja, com qualquer nível de aderência na pista e qualquer carregamento do veículo).

A planilha de cálculo desenvolvida permite obter as forças de frenagem e a sua distribuição, as forças normais ao pavimento nas rodas, a aderência utilizada em cada eixo, a desaceleração máxima, a eficiência de frenagem, espaço e tempo de parada, a temperatura do tambor de freio após a frenagem, a distribuição ideal das forças de frenagem e de verificar se o veículo cumpre os requisitos impostos pelo anexo 10 da ECE-R13. Ela também é de fácil acesso uma vez que foi desenvolvida em um software de uso comum na indústria brasileira e requer pouco poder de processamento.

Com esse modelo, é possível comprovar o comportamento da suspensão em "tandem" previsto por Limpert (1992), ou seja, que na frenagem o eixo dianteiro perde força normal enquanto o traseiro ganha. Esse comportamento leva ao travamento dos eixos dianteiros de cada "tandem" com uma força de frenagem relativamente baixa, como já foi comentado ao longo do texto e pode ser visto em diversos gráficos apresentados no tópico anterior. Apesar desse travamento prematuro não ser particularmente muito crucial no desempenho e na segurança da frenagem, pois o eixo traseiro ainda rola com 
uma força de frenagem maior, permitindo o controle do veículo, ele faz com que os pneus do eixo dianteiro se desgastem muito rapidamente. Isso permite concluir que algum dispositivo antitravamento instalado nesses eixos seria muito útil e muito utilizado já que esses eixos travam mesmo em condições favoráveis (pista de alta aderência e carga total).

Uma das deficiências do modelo desenvolvido é o fato do mesmo só tratar da frenagem em regime permanente. Apesar do regime transitório ser muito curto, não tendo influência significativa na frenagem, seria interessante conhecer o seu comportamento, pois durante o regime transitório podem surgir forças importantes para o desenvolvimento da suspensão, eixos e outros componentes do veículo.

Com este estudo é possível mostrar que, apesar da função principal ser manter a estabilidade e a dirigibilidade, o ABS diminui o espaço necessário para frear o veículo de uma maneira geral.

A influência da suspensão na frenagem diminui com a adoção do $A B S$, pois o eixo freia com a capacidade máxima disponível e ainda é capaz de gerar força lateral por mais que o motorista pressione o pedal de freio.

Alterando a característica de alguns componentes do sistema de freios do veículo é possível melhorar o desempenho da frenagem do bi-trem, aumentando assim a sua eficiência, diminuindo a distância necessária para pará-lo completamente e evitar o travamento prematuro de eixos. Ao Evitar o travamento prematuro dos eixos, aumenta-se a eficiência de frenagem do veículo o tornado mais seguro (de acordo com a Figura 2.24).

No final do capítulo 4 foi mostrado que um veículo que atende os requisitos do anexo 10 da ECE R13 tem eficiência menor que um veículo com as modificações propostas neste trabalho. Isso acontece porque a norma foi desenvolvida tendo-se em mente um veículo combinado simples (cavalo mecânico + semi-reboque). Nessa composição simples ocorre a transferência de peso do semi-reboque como mostrado na Figura 5.1 abaixo. Dessa forma a relação da força de frenagem pela reação estática (TR/PR) deve ser menor que a relação da força de frenagem com a reação dinâmica $(\mu)$, pois a força de reação do solo diminui com o aumento da desaceleração. 


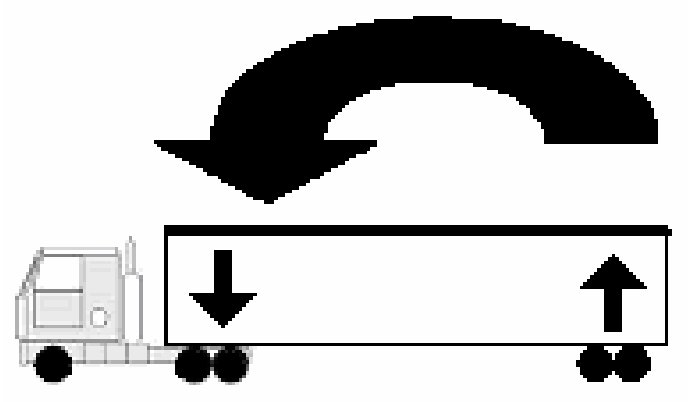

FIGURA 5.1 - Transferência de peso num cavalo mecânico + semi-reboque; a força de compressão no eixo traseiro do cavalo mecânico aumenta enquanto diminui no semi-reboque

Em um bi-trem o segundo semi-reboque experimenta o mesmo fenômeno do semi-reboque descrito acima. E o mesmo ocorre com o cavalo mecânico. Já no primeiro semi-reboque ocorre algo diferente. Ocorre a transferência de peso do $1^{\circ}$ semi-reboque para o cavalo, mas também ocorre a transferência de peso do $2^{\circ}$ semi-reboque como visto na Figura 5.2 abaixo. Ou seja, a força de reação dinâmica do solo pode aumentar, diminuir ou até mesmo ficar constante se a transferência da composição for a mesma em ambos semi-reboques. Dessa forma uma revisão do anexo 10 da ECE R13 se faz necessária, pois ela não prevê o comportamento mostrado na Figura 5.2.

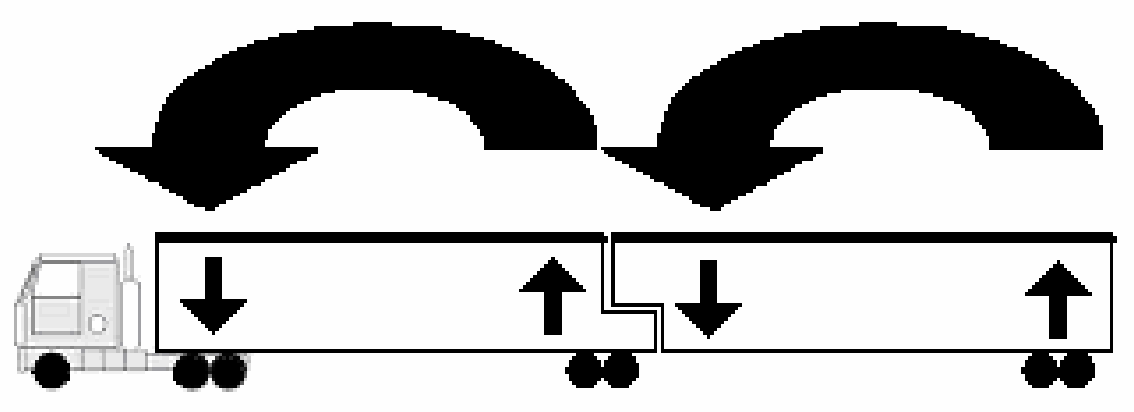

FIGURA 5.2 - Transferência de peso num bi-trem

O bi-trem é uma combinação que cada vez mais cai no gosto do frotista brasileiro. Com esse tipo veículo é possível transportar mais carga com custo operacional mais baixo e reduzir a quantidade de poluentes lançados na atmosfera com a diminuição do número de veículos tratores. 
O bi-trem ainda tem a vantagem de não necessitar de autorização especial de trânsito (AET) para rodar nas vias brasileiras (ver capítulo 1). Ainda, segundo Reis (2004) o impacto do bi-trem em pontes é pequeno e o impacto no pavimento, devido à suspensão "tandem" é menor que o de um semi-reboque comum de 3 eixos.

Como recomendações para futuros trabalhos podem-se citar a importância de realizar um estudo semelhante para outros tipos de suspensão, incluir o regime transitório da frenagem na simulação, simular outras combinações de veículos de carga que surgiram recentemente no Brasil como o rodo-trem, por exemplo, fazer um estudo do passeio do CG como feito por Canale(1991), incluir a possibilidade de freios a disco que começam a ser utilizados, principalmente no cavalo mecânico, e por último simular a frenagem com diversas estratégias de controle do ABS diferentes. 


\section{REFERÊNCIAS BIBLIOGRÁFICAS}

BRASIL (1998) Resolução no 12/98 do CONTRAN de 23 de Setembro de 1998. Estabelece os limites de peso e dimensões para veículos que transitem por vias terrestres.

BRASIL (1998) Resolução no 68/98 do CONTRAN de 23 de Setembro de 1998. Requisitos de segurança necessários à circulação de Combinações de Veículos de Carga.

BRASIL (2004) Resolução no 164/04 do CONTRAN de 15 de Setembro de 2004. Acresce parágrafo único ao art. $1^{\circ}$ da Resolução.

BROSSI A. (2002). Estudo do desempenho de Frenagem de um Ônibus Biarticulado,São Carlos,SP. 134p dissertação (mestrado). Escola de Engenharia de São Carlos, Universidade de São Paulo, São Carlos (1994)

CANALE A.C. (1989). Automobilismo: Dinâmica e Desempenho, São Paulo: Érica

CANALE A.C. (1991). Estudo do Desempenho de Autoveículos Rodoviários Considerando o Passeio do Centro de Gravidade e Restrições Impostas Pelo Binômio Pneumático x Pavimento, São Carlos, SP. 290p. Tese (Doutorado) Escola de Engenharia de São Carlos, Universidade de São Paulo, São Carlos. 1991.

CANALE A.C. (1998). Desempenho de Autoveículos Rodoviários, São Paulo. Apostila

CANALE, A. C., POLITO, R. F., WIDMER, J. A., BOTELHO, J. H., GUTIERREZ, J. C. H., KISS, V. A. (2005). Importância de um Plano de Revisão e Complementação das Normas e Regulamentações de Frenagem de Veículos Rodoviários de Carga no Brasil 7º Colloquium Internacional de Freios, 2005, Gramado.

DIXON, J.C.(1996). Tires,Suspension and Handling,E.U.A.:SAE 
Europa (2003) Anexo 10 ECE-R13 - Prescrições Uniformes Para Certificação dos Veículos das Categorias M, N e O, com Relação à Frenagem.

Evans L., GERRISH P.H. (1996) ANTILOCK BRAKES AND RISK OF FRONT AND REAR IMPACT IN TWO-VEHICLE CRASHES in: Accid. Anal. and Prev.. Vol. 28, No. 3, pp. 315-323, 1996

FERNANDES D.L.G. (1994). Estudo da Frenagem de Autoveículos Rodoviários Articulados Pesados. 153p dissertação (mestrado). Escola de Engenharia de São Carlos, Universidade de São Paulo, São Carlos (1994)

FERNANDES D.L.G. et al.(1997). Performance and Directional Stability of Combination Vehicles During the Brake Process Under Any Operation Condition. Apresentado no $30^{\circ}$ ISATA, Florença, Itália N. $97 V R 048$.

FERNANDES D.L.G. et al (1998). Mapas de Desempenho: Uma Análise Completa do Desempenho de Veículos Pesados na Frenagem. In: VII CONGRESSO E EXPOSIÇÃO INTERNACIONAIS DA MOBILIDADE,1998 São Paulo N.982915

FITCH J.W.(1994) Motor Truck Engineering Handbook, EUA, SAE ISBN: 153091-378-9

FORKENBROCK, D.J., HANLEY, P.F. (2002). Fatal crash involvement by multiple-trailer trucks. Transportation Research Part A, n.37 p. 419-433, jul.

GILLESPIE (1992). Fundamentals of Vehicle Dynamics, E.U.A.:SAE

IOMBRILLER, S. F. (1997), Estudo do Desempenho na Frenagem de Emergência de um Ô São Carlos, SP. 81p. Tese (doutorado). Escola de Engenharia de São nibus Considerando o Efeito da Temperatura no Contato Lona Tambor Carlos, Universidade de São Paulo, São Carlos (1997)

IOMBRILLER, S. F. (2003) Análise Térmica e Dinâmica do Sistema de Freio a Disco de Veículos Comerciais Pesados, São Carlos, SP. 177p. Tese (doutorado). Escola de Engenharia de São Carlos, Universidade de São Paulo, São Carlos (2003)

LIMPERT R. (1992). Brake Design and Safety, E.U.A.: SAE

MILLIKEN(1995). Race Car Vehicle Dynamics, E.U.A.:SAE

OPPENHEIMER P. (1988) Comparing Stopping Capability of Cars with and Without Antilock Brake System (ABS) .N.880324

OPPENHEIMER P. (1996). Comparing Stopping Capability of Car With and Without Antilock Brake System (ABS). ABS-TCS-VDC Where Will the Tecnologios Lead Us?, EUA, p209-232. 
Polito R.F., CANALE A.C. (2004a). Simulação da frenagem de um bi-trem em regime permanente e a influência da suspensão em "tandem" no desempenho. COLOQUIUM INTERNACIONAL DE FREIOS, 2004 Caxias do sul

Polito R.F., CANALE A.C. (2004b). Influência da Suspensão em "Tandem" no Desempenho da Frenagem de Um Bi-Trem. CONGRESSO SAE 2004, São Paulo

REIS, N.G. (1996). Viabilidade de Operação do Duplo Semi-reboque de Cinco Eixos no Brasil. 173p dissertação (mestrado). Escola de Engenharia de São Carlos, Universidade de São Paulo, São Carlos. 1996.

REIS N. G. Bitrem sem AET: Uma Medida Acertada (2004). Canal Técnico e econômico. Disponível em:

http://www.ntcelogistica.org.br/Tecnico/tecnico artigocompleto.asp?CodArti=37 Acesso em 20 jan. 2005

SCHARFF R. (1989). Complete Brake System,E.U.A.:Delmar Publisher Inc.

SPIRONELLI F.G. Estudo dos Sistemas de Freio Anti-blocante (ABS) Utilizando um Modelo de Controlador de Escorregamento SCBS (Slip Control Braking System), São Carlos, SP. 129p. Dissertação (mestrado). Escola de Engenharia de São Carlos, Universidade de São Paulo, São Carlos (1999). 